
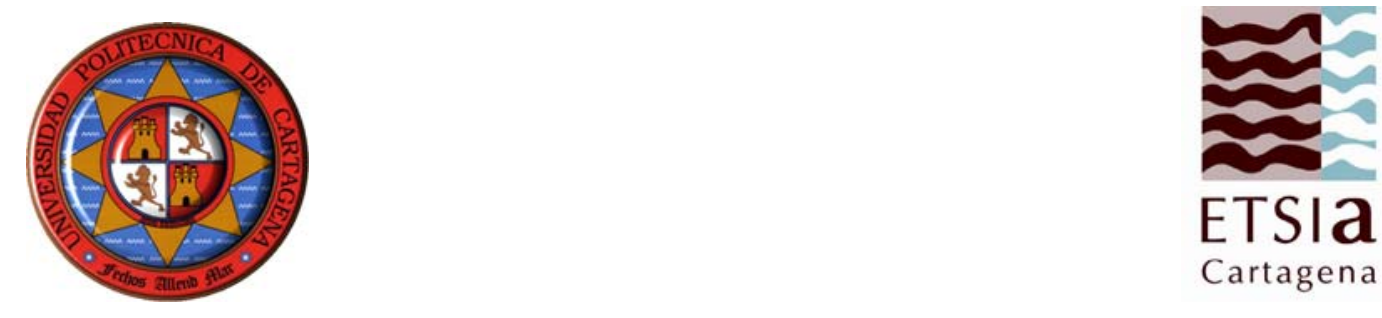

\title{
Respuesta Agronómica y Fisiológica del Almendro al Riego Deficitario. Indicadores de Estrés Hídrico
}

\author{
Pedro Antonio Nortes Tortosa \\ Ingeniero Agrónomo
}

Directores: Rafael Domingo Miguel Alejandro Pérez Pastor

Memoria presentada para optar al grado de Doctor por la Universidad Politécnica de Cartagena

Cartagena, 2008 

El ingeniero agrónomo Pedro Antonio Nortes Tortosa, ha disfrutado durante el tiempo de realización de su Tesis Doctoral, de una beca del programa de Formación de Profesorado Universitario (FPU), del Ministerio de Educación y Ciencia. La parte experimental de la presente Memoria de Tesis se ha desarrollado en el marco del proyecto "Riego Inteligente para un Manejo Sostenible en Frutales (RIMAS): Mejora de la Gestión y Productividad para Asegurar la Competitividad" (AGL2000-0387-C05-05), del Ministerio de Educación y Ciencia. 

Comisión de Doctorado

\section{AUTORIZACIÓN DE LA PRESENTACIÓN DE LA TESIS DOCTORAL POR LOS DIRECTORES}

D. Rafael Domingo Miguel y D. Alejandro Pérez Pastor, Profesores Doctores del Área de Producción Vegetal en el Departamento de Producción Vegetal.

\section{AUTOR IZAN:}

La presentación de la Tesis Doctoral titulada "Respuesta Agronómica y Fisiológica del Almendro al Riego Deficitario. Indicadores de Estrés Hídrico", realizada por D. Pedro Antonio Nortes Tortosa, bajo nuestra dirección y supervisión, en el Departamento de Producción Vegetal, y que presenta para la obtención del grado de Doctor por la Universidad Politécnica de Cartagena.

En Cartagena, a 18 de febrero de 2008

LOS DIRECTORES DE TESIS

Fdo.: Rafael Domingo Miguel

Fdo.: Alejandro Pérez Pastor 

UNIVERSIDAD POLITÉCNICA DE CARTAGENA

Comisión de Doctorado

\section{AUTORIZACIÓN DE LA PRESENTACIÓN DE LA TESIS DOCTORAL POR EL DEPARTAMENTO RESPONSABLE}

D. Sebastián Bañón Arias, Director del Departamento de Producción Vegetal.

\section{INFORMA:}

Que la Tesis Doctoral titulada "Respuesta Agronómica y Fisiológica del Almendro al Riego Deficitario. Indicadores Biológicos", ha sido realizada por D. Pedro Antonio Nortes Tortosa, bajo la dirección y supervisión de D. Rafael Domingo Miguel y D. Alejandro Pérez Pastor y que el Departamento ha dado su conformidad para que sea presentada ante la Comisión de Doctorado.

En Cartagena, a 18 de febrero de 2008

EL DIRECTOR DEL DEPARTAMENTO

Fdo.: Sebastián Bañón Arias 

A Lourdes 



\section{Agradecimientos}

Probablemente sea este uno de los apartados de mayor importancia y dificultad de este trabajo, ya que en él debieran de aparecer todas aquellas personas e instituciones que de alguna manera han ayudado en la realización del mismo, y han contribuido a mi formación tanto investigadora, como personal.

A Rafael Domingo y Alejandro Pérez, por haber dirigido la presente Tesis Doctoral, por haberme iniciado en este mundo, por haber puesto a mi disposición todos los medios tanto materiales como humanos necesarios, así como por los consejos y conocimientos traspasados y por la amistad que nos une.

A Alain Baille y Mayla, por haberme brindado la oportunidad de trabajar junto a ellos, por todos los ofrecimientos desinteresados hacia mí, por motivarme a finalizar el presente trabajo y por toda la comprensión en estos últimos meses. Merci beaucoup por todo.

Del mismo modo, quisiera agradecer de forma especial al Proyecto Europeo "Sustainable orchard irrigation for improving fruit quality and sfatety" (IRRIQUAL FP6-2004-FOOD-3B), sin cuya financiación no hubiera sido posible la finalización del presente trabajo.

A Gregorio Egea, por encima de todo amigo y gran compañero de fatigas. Gracias de todo corazón por todos tus consejos en los momentos difíciles, por todas tus aportaciones al presente trabajo y por todos los buenos momentos que hemos pasado juntos, esperemos poder seguir en esta andadura que comenzamos hace años prácticamente juntos, siempre será un placer trabajar junto a ti.

A los integrantes del proyecto coordinado del que ha salido la financiación para la realización de este trabajo, en especial a los compañeros del CEBAS, Arturo Torrecillas y Juan José Alarcón, del IRTA, Carmen Biel, Joan Bonany y Jaume Casadeseus, del IVIA, Juan Ramón Castel y Diego Intrigliolo e IRNAS, José Enrique Fernández y Félix Moreno.

Al todo el personal de la finca experimental “Tomas Ferro", en especial a Francisco Solano, José Anastasio Egea , Pedro Mateo y José Antonio García, por haber llevado de forma tan brillante todas las labores culturales de la parcela experimental y por haber colaborado en la toma de datos experimentales.

A la empresa agrícola Arroyo Marín S.L., por haber puesto de forma desinteresada la finca la Corverica a nuestra disposición. 
A los compañeros del Área de Ingeniería Agroforestal, por haberme acogido tan calurosamente desde el principio entre ellos, en especial a Bernardo, Victoriano, Joaquín, José Miguel y mis compañeros de laboratorio Belén, Maliko, José y Paco.

A los compañeros del departamento de Producción Vegetal, en especial a Elisa, Manolón, Ana María, Manolo y Lucia.

A los colegas del INRA d'Avignon, por haberme hecho disfrutar de mi estancia entre ellos, en especial a Gilles Vercambre, Michel Gènard, Françoise Lescourret, Wu BenHong, Emilio Nicolás, Thomas, Magali, Ruth, Caroline, ..., lista como casi todas interminable, por ello gracias a todos y perdonad todos aquellos que no figuren en ella.

A Wenceslao Conejero y Pedro Sánchez, por haber colaborado durante la realización de sus trabajos fin de carrera en todas las tareas de toma y elaboración de resultados experimentales.

A los grandes amigos y compañeros de la Universidad Politécnica de Cartagena, destacar en esta gran familia a los amigos de la ETSII, Roque Torres, José María Fernández Meroño y Jesús Rubio, así como a Francisco Alcón y María Dolores de Miguel, del departamento de Economía de la Empresa, gracias a todos por la ayuda prestada tanto a nivel personal como en la puesta a punto de algunos equipos.

A Oussama Mounzer y Mona Kassen, por haber estado desde que llegaron a estás tierras junto a mi, ha sido un placer conoceros y espero formar parte de vuestras vidas durante siempre.

A mis amigas Toñi y Merche, por todos los buenos momentos que hemos pasados juntos, por los grandes recuerdos que quedan de nuestros viajes, tanto por tierras francesas, que bonito el festival, como tantos lugares visitados, cenas, comidas y demás eventos, no cambiéis nunca y recordar que siempre estaré a vuestro lado.

A mi familia, por haberme apoyado siempre, por aguantar mis cambios de humor, en ocasiones frecuentes y por vuestro cariño, Mama, te sientes identificada. Mis hermanos Diego y Patxi, y mis padres Paco y Reme, mis cuñados y cuñadas y como no a las dos alegrías y juguetes de la casa Alejandro y Marco, a todos y de todo corazón gracias por ser como sois.

Y finalmente, a la persona que desde hace ya muchos años me acompaña, ella y sólo ella sabe todos los buenos momentos y los malos que hemos pasado desde el inicio de esta andadura, de hecho fue la que me animó en principio a tomar este camino, de ella es el $51 \%$ del trabajo presentado, por no decir más. Muchas gracias Lourdes, mi futura mama. 


\section{Resumen}

El objetivo global de esta memoria fue estudiar la respuesta agronómica y fisiológica de almendros jóvenes y adultos a la aplicación de distintas estrategias de riego deficitario, y evaluar la utilidad y aplicabilidad de distintos indicadores del estado hídrico del árbol en la programación del riego. Para ello se establecieron tres ensayos en dos parcelas experimentales: uno en almendros adultos cv. 'Colorada' regados con agua de elevada salinidad y que constó de tres tratamientos de riego: (i) Tсть, regado al $125 \%$ ETc durante todo el ciclo de cultivo; (ii) TRDC, regado al $100 \%$ del TстL hasta alcanzar el tamaño exterior del fruto, $70 \%$ hasta el inicio de la fase IV, $30 \%$ hasta recolección y $70 \%$ durante el resto de la estación de riego y (iii) Tsco, sin riego durante todo el año, y otros dos en almendros jóvenes cv. 'Marta', con agua de buena calidad y con un total de cinco tratamientos: (i) TстL, regado al $120 \%$ ETc durante todo el ciclo de cultivo; (ii, iii) TRD80 y TrD60, regado al $80 \mathrm{y}$ $60 \%$ de la ETc durante todo el ciclo de cultivo y (iv, v) Trdc40 y Trdc20, regados al $100 \%$ ETc durante todo el ciclo de cultivo excepto en la fase IV, donde recibieron el 40 y $20 \%$ de la ETc respectivamente.

Los principales mecanismos desarrollados por los almendros adultos bajo condiciones de estrés hídrico y salino fueron: (i) una disminución del potencial hídrico foliar, al objeto de generar un mayor gradiente de potencial hídrico entre el suelo y la hoja, y de este modo favorecer la absorción de agua, (ii) una temprana regulación estomática, desde las primeras horas del día, permitiéndole una mayor eficiencia en la absorción de $\mathrm{CO}_{2}$ respecto a las pérdidas de agua, (iii) un ajuste osmótico durante la mayor parte de la estación de crecimiento, lo que permitió mantener la turgencia celular y compensar las disminuciones de potencial hídrico foliar y (iv) una disminución del índice de área foliar (LAI), lo que supuso una contribución adicional al mantenimiento de la turgencia, ya que al disminuir el ratio brotes/raíz se redujo la tasa transpirativa para idéntica demanda evaporante.

En cuanto a los rendimientos obtenidos, los tratamientos control y de riego deficitario controlado (RDC) mostraron valores superiores a los esperados para la salinidad presente en el agua de riego. Por otro lado, el tratamiento RDC, con un ahorro de agua del $50 \%$ obtuvo una producción similar al control. Estos resultados muestran una buena adaptación de esta variedad autóctona al estrés hídrico y salino, lo que le permite utilizar más eficazmente el agua disponible.

De los parámetros evaluados en almendros jóvenes fue el crecimiento vegetativo el más sensible al déficit hídrico, y en especial el diámetro del tronco. Los tratamientos más afectados fueron aquéllos en los que el estrés hídrico fue más intenso y aplicado desde el primer año de plantación $\left(\mathrm{T}_{\mathrm{RD} 60} \mathrm{y}\right.$ 
$\mathrm{T}_{\mathrm{RDC} 40}$ ). Sin embargo, el rendimiento no se vio, prácticamente, afectado, ya que tan sólo $\mathrm{T}_{\mathrm{RD} 60} \mathrm{y}$ en su tercer año de ensayo presentó valores inferiores al control. La disminución del diámetro de tronco y consecuentemente del volumen de copa supone un menor espacio para el asentamiento de frutos y, en definitiva, una menor carga productiva. Cabría, por lo tanto, esperar una acentuación de estas diferencias a más largo plazo. Todo ello, muestra la conveniencia de realizar una programación del riego con criterios de crecimiento y desarrollo en los primeros años de la plantación al objeto de alcanzar el estado adulto lo más rápidamente posible.

De los diferentes indicadores evaluados del estado hídrico del árbol fue la máxima contracción diaria del tronco (MCD) la que presentó la mayor correlación con el potencial hídrico foliar al alba $\left(\Psi_{2}\right)$ y de tallo a mediodía $\left(\Psi_{t}\right)$, parámetros utilizados tradicionalmente de referencia en este tipo de estudios. Lo mismo sucedió en las correlaciones con la evapotranspiración de referencia (ETo) y el déficit de presión de vapor (DPV). Esto unido al hecho de detectar rápidamente cambios de humedad en el suelo, de su posible automatización y del seguimiento en tiempo real del estado hídrico del árbol le convierte en una herramienta muy útil para el manejo y automatización del riego. Dentro de esta línea, es de destacar la estrecha relación observada a nivel estacional y mensual entre la máxima contracción diaria (MCD) y el déficit de presión de vapor (DPV), lo que ha permitido establecer líneas de referencia de posible aplicación a la programación automática del riego en el cultivo del almendro. 


\section{Abstract}

The main objective of this Doctoral Thesis was to evaluate the agronomic and physiologic responses of both young and adult almond trees to distinct deficit irrigation strategies, as well as to assess the applicability and utility of several plant water status indicators for irrigation scheduling. To this aim, three experiments were planned on two different experimental plots:

a) one of them carried out on adult 'Colorada' almond trees irrigated with highly saline water, where three irrigation treatments were established: (i) $\mathrm{T}_{\mathrm{CTL}}$, irrigated at $125 \% \mathrm{ET}_{\mathrm{C}}$ throughout all growing season; (ii) $\mathrm{T}_{\mathrm{RDC}}$, receiving $100 \% \mathrm{~T}_{\mathrm{CTL}}$ until the fruit reached its definitive external size, then $70 \% \mathrm{~T}_{\text {СТL }}$ until the beginning of stage IV, $30 \%$ during stage IV and $70 \% \mathrm{~T}_{\text {CTL }}$ in postharvest; and (iii) $\mathrm{T}_{\mathrm{SCO}}$, rainfed treatment.

b) two of them carried out on young 'Marta' almond trees, where five irrigation treatments were defined (i, ii, iii) $\mathrm{T}_{\mathrm{CTL}}, \mathrm{T}_{\mathrm{RD} 80}$ and $\mathrm{T}_{\mathrm{RD} 60}$, irrigated at 120, 80 and $60 \% \mathrm{ET}_{\mathrm{C}}$ all growing season and (iv, v) $\mathrm{T}_{\mathrm{RDC} 40}$ and $\mathrm{T}_{\mathrm{RDC} 20}$, irrigated at $100 \% \mathrm{ET}_{\mathrm{C}}$ during all year except during stage IV, when 40 and $20 \%$ ETc was supplied, respectively.

The most significant mechanisms of adult almond trees under both water and salt stresses (Experiment 1) were: (i) a decrease in predawn leaf water potential, which allows the plant to preserve a water potential gradient between soil and leaves in order to maintain root water uptake; (ii) an early stomatal regulation, evidenced since the first hours of the day, that maximizes $\mathrm{CO}_{2}$ assimilation efficiency with respect to water losses; (iii) osmotic adjustment which took place during most of the growing season, and allowed the plant to maintain cell turgor and thus compensating leaf water potential decline; and (iv) leaf area index (LAI) decrease, which supposed an additional contribution to maintain cell turgor, since it reduces shoot/root ratio and therefore the transpiration rate for a similar evaporative demand.

With respect to the productive response, both control and regulated deficit irrigation (RDI) treatments showed higher values than expected taking into account the salinity level of irrigation water. On the other hand, RDI treatment, which saved $50 \%$ of the irrigation water volume, presented similar yield to control treatment. These results evidence a good degree of adaptation of this autochthon variety to both water and salt stresses, leading to a more efficient use of soil available water.

From the results of Experiments 2 and 3, vegetative growth indicators were the most sensitive to water stress, in particular trunk diameter. Trees growing under the most severe water stress conditions $\left(\mathrm{T}_{\mathrm{RD} 60}\right.$ and $\left.\mathrm{T}_{\mathrm{RDC} 40}\right)$ were 
the most affected in terms of tree growth, particularly those trees that suffered water restriction since the beginning of the plantation. The analysis of the productive response showed no significant changes between water restricted and control treatments, except for $\mathrm{T}_{\mathrm{RD} 60}$ which presented lower yield values than control treatment in the third year of study. The general tree growth decrease observed in water-restricted young almond trees when compared to fully irrigated trees lead to smaller tree crowns, and is likely to reduce the number of fruit positions and thus crop load once the trees reach the productive period. Consequently, it results highly convenient to establish irrigation scheduling criteria aimed to allow young trees to reach the productive period as fast as possible.

Among all the tree water status indicators considered in this study, maximum daily shrinkage (MDS) presented the best correlation with predawn leaf water potential $\left(\Psi_{a}\right)$ and midday stem water potential $\left(\Psi_{t}\right)$, indicators traditionally considered as reference in this kind of studies. A similar result was found when analyzing the correlations with crop reference evapotranspiration (ETo) and vapour pressure deficit (VPD). In addition, we obtained a close relationship between MDS and VPD on both seasonal and monthly basis, which allowed establishing reference baselines that might be used for irrigation scheduling. These results, joined to the reliability of this indicator to detect soil moisture changes as well as the possibility of continuously monitoring tree water status, makes MDS a pertinent and useful plant state variable to be used in almond irrigation scheduling, provided reference baselines are available. 


\section{Índice}

1. Justificación y objetivos .......................................................... 1

2. Antecedentes.............................................................................

2.1. El cultivo del almendro ..................................................................... 9

2.2. Estrategias de riego para optimizar el uso del agua............................10

2.3. Programación del riego ………………………………………………..... 13

2.3.1. Cálculo de las necesidades hídricas del cultivo.....................14

2.3.1.1. Métodos climáticos.............................................................14

2.3.1.2. Métodos basados en el estado hídrico del suelo..............18

2.3.1.3. Métodos basados en el estado hídrico de la planta .........25

3. Métodos y técnicas utilizadas.................................................. 31

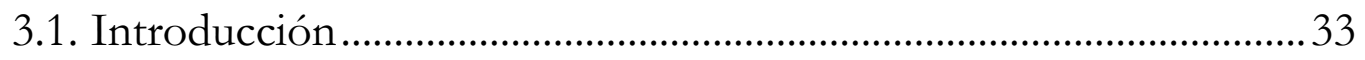

3.2. Medida de las variables climáticas ............................................................. 33

3.3. Medida del estado hídrico del suelo....................................................... 39

3.4. Medida del estado hídrico de la planta ...................................................40

4. Respuesta agronómica y fisiológica de almendros jóvenes al riego deficitario .............................................. 47

4.1. Introducción ........................................................................................... 49

4.2. Material y métodos .................................................................................... 49

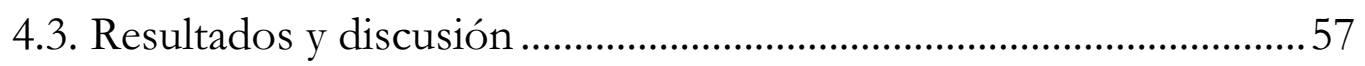

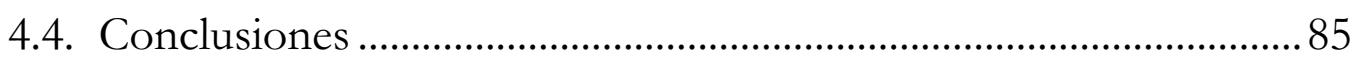

5. Relaciones hídricas y producción de almendros regados con agua salina............................................................... 87

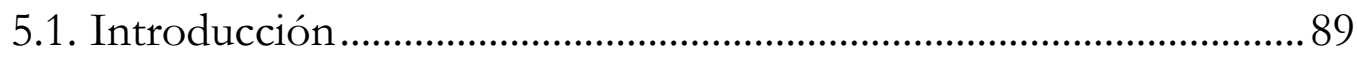




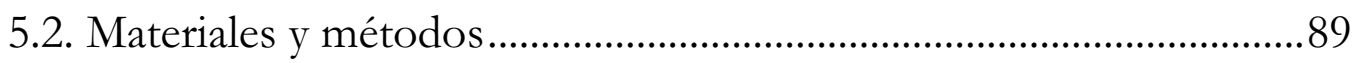

5.3. Resultados y discusión .......................................................................95

5.3.1. Relaciones hídricas ...............................................................95

5.3.2. Contenido mineral en hoja ....................................................115

5.3.3. Crecimiento vegetativo..........................................................122

5.3.4. Producción y componentes ..................................................128

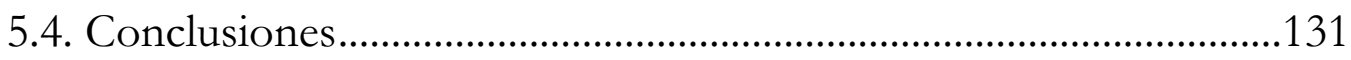

\section{Estudio de la sensibilidad de indicadores biológicos en la} caracterización del estado hídrico del árbol .....................135

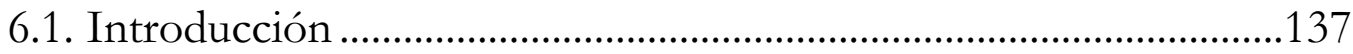

6.2. Materiales y métodos.............................................................................138

6.3. Almendros jóvenes no productivos ....................................................141

6.3.1. Tratamientos de riego ............................................................141

6.3.2. Resultado y discusión ............................................................141

6.3.3. Conclusiones ..........................................................................147

6.4. Almendros jóvenes al inicio de su entrada en producción..............148

6.4.1. Tratamientos de riego.............................................................148

6.4.2. Resultados y discusión.............................................................148

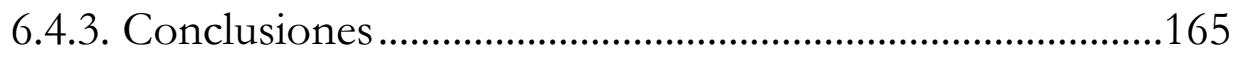

7. Bibliografía ...............................................................167 


\section{Índice de figuras}

Figura 2.1. Disposición de tubos de acceso para realización de balance hídrico (izquierda) y componentes del balance hídrico y de energía en riego localizado (adaptado de Fereres et al., 1981b) (derecha)..........18

Figura 3.1. Estación climática automática de la ESEA 'Tomás Ferro' y disposición de los distintos sensores.

Figura 3.2. Sensor de humedad relativa, modelo HUMICAP 180...................34

Figura 3.3. Sensor de radiación global......................................................................

Figura 3.4. Sensor de radiación neta........................................................................

Figura 3.5. Pluviómetro con sensor FSS500 colocado a 1.5 m del suelo. ......37

Figura 3.6. Sensor de velocidad y dirección de viento.......................................... 37

Figura 3.7. Sistema de gestión de datos................................................................... 38

Figura 3.8. Batería de tensiómetros y sensor Watermark con medidor

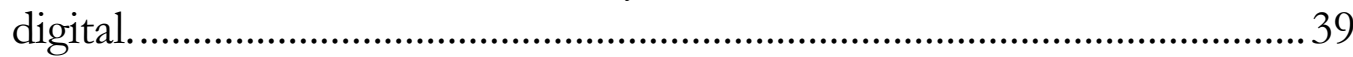

Figura 3.9. a) Equipo TDR y sondas instaladas en suelo, b) sensores FDR sobre guía y c) sensores FDR instalados en campo. .................................40

Figura 3.10. Cámara de presión. ................................................................................. 41

Figura 3.11. a) Elección de las hojas, b) colocación de plástico negro y c) envoltura con papel de aluminio................................................................... 42

Figura 3.12. Osmómetro ROEBLING mod. 13DR. ..............................................4 43

Figura 3.13. Porómetro LICOR LI-1600 ...............................................................4 43

Figura 3.14. Sensor LVDT y portasensor en tronco.............................................4

Figura 3.15. Representación gráfica de la máxima contracción diaria (MCD) y tasa de crecimiento diaria de tronco (TCD) a partir de la variación del diámetro de tronco (VDT) en almendros............................45

Figura 3.16. Equipos MicroIsis en parcela experimental....................................4 45

Figura 4.1. Plano de localización de la parcela experimental .............................50 
Figura 4.2. Vista general de la parcela experimental de almendros (ETSIA-UPCT)

Figura 4.3. Vista aérea de la Estación Experimental Agroalimentaria (ESEA) 'Tomás Ferro'

Figura 4.4. Tasas de evapotranspiración de referencia, precipitación y riego mensual aplicado al tratamiento control durante el período 2001-2004.

Figura 4.5. Porcentaje de la ETc aplicado en cada tratamiento de riego y período fenológico del cultivo.

Figura 4.6. Detalle del método de la recogida de raíces. 'Trinchera' ...............54

Figura 4.7. Detalle del punto de medida del tronco .............................................55

Figura 4.8. Recogida de hojas al final de la estación.............................................56

Figura 4.9. Relación peso fresco $v$ seso seco de los restos de poda, para los cinco tratamientos de riego $\mathrm{T}_{\mathrm{CTL}}(\bullet), \mathrm{T}_{\mathrm{RD} 80}(\boldsymbol{\Delta}), \mathrm{T}_{\mathrm{RD} 60}(\Delta)$,

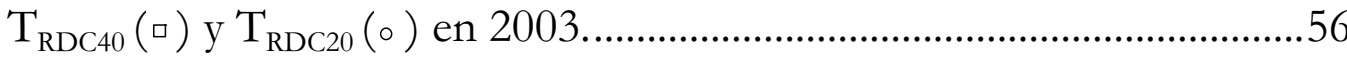

Figura 4.10. Secado al aire de la cosecha individualmente. 57

Figura 4.11. Evolución del potencial matricial $\left(\Psi_{\mathrm{m}}\right)$ en los 5 tratamientos de riego: $\mathrm{T}_{\mathrm{CTL}}(\stackrel{\bullet}{-}), \mathrm{T}_{\mathrm{RD} 80}\left({ }^{--}\right), \mathrm{T}_{\mathrm{RD} 60}\left({ }^{-\Delta-}\right), \mathrm{T}_{\mathrm{RDC} 40}(\cdots \cdots \cdots) \mathrm{y}$ $\mathrm{T}_{\mathrm{RDC} 20}(-)$, durante el 2002, a 30, 60 y $90 \mathrm{~cm}$ de profundidad. $*^{1}$ $\mathrm{y} *^{2}$ indican el cambio de riego en los tratamientos $\mathrm{T}_{\mathrm{RDC} 40}$ y $\mathrm{T}_{\mathrm{RDC} 20}$ al $40 \%$ y $20 \%$ de la $\mathrm{ET}_{\mathrm{c}}$ respectivamente; * indica la restitución del riego al $100 \%$

Figura 4.12. Evolución del contenido de humedad volumétrica relativa al valor máximo obtenido tras una lluvia de $80 \mathrm{~mm}$, en 4 tratamientos de riego y para 6 profundidades diferentes. Julio de 2002.

Figura 4.13. Evolución estacional de potencial hídrico al alba $\left(\Psi_{a}\right)$, potencial de presión $\left(\Psi_{\mathrm{p}}\right)$ y potencial osmótico saturado $\left(\Psi_{\mathrm{OS}}\right)$ de los tratamientos de riego ensayados: $\mathrm{T}_{\mathrm{CTL}}(-\bullet), \mathrm{T}_{\mathrm{RD} 80}\left({ }^{-}-\right), \mathrm{T}_{\mathrm{RD} 60}$ $\left({ }^{-\Delta-}\right), \mathrm{T}_{\mathrm{RDC} 40}(\cdots \circ \cdots)$ y $\mathrm{T}_{\mathrm{RDC} 20}(--)$ durante 2002 (a) y 2003 (b). Cada punto corresponde a la media de 3 repeticiones \pm ES. La línea de puntos delimita el período de aplicación del RDC. Las barras indican los valores del déficit de presión de vapor máximo diario (DPV) 
Figura 4.14. Evolución diaria de la radiación fotosintéticamente activa $\left(\mathrm{RFA}-{ }^{-}\right)$, potencial hídrico de tallo $\left(\Psi_{\mathrm{t}}\right)$ y conductancia foliar $\left(\mathrm{g}_{\mathrm{f}}\right)$ en los distintos tratamientos de riego: $\mathrm{T}_{\mathrm{CTL}}\left({ }^{\bullet}\right), \mathrm{T}_{\mathrm{RD} 80}\left({ }^{-}-\right)$, $\mathrm{T}_{\mathrm{RD} 60}\left({ }^{-\Delta-}\right), \mathrm{T}_{\mathrm{RDC} 40}(\cdots . \cdots)$ y $\mathrm{T}_{\mathrm{RDC} 20}(-\cdots)$. (a) septiembre de $2002 \mathrm{y}$ (b) agosto de 2003. Cada punto corresponde a la media de tres repeticiones $\pm \mathrm{ES}$.

Figura 4.15. a) Relación entre el potencial hídrico foliar antes del alba $\left(\Psi_{2}\right)$ y la humedad volumétrica en el perfil de suelo $0-90 \mathrm{~cm}\left(\theta_{\mathrm{v}}\right)\left(\Psi_{\mathrm{a}}\right.$ $\left.=-27.01 \theta_{\mathrm{v}}^{-1.022} ;\left(\mathrm{R}^{2}=0.77\right) \mathrm{P}<0.05\right)$. b) Relación entre el potencial de tallo a mediodía $\left(\Psi_{t}\right)$ y la humedad volumétrica en el perfil de suelo $0-90 \mathrm{~cm}\left(\theta_{\mathrm{v}}\right)\left(\Psi_{\mathrm{t}}=-49.76 \theta_{\mathrm{v}}^{-0.977} ;\left(\mathrm{R}^{2}=0.74\right) \mathrm{P}<0.001\right)$. Para los tratamientos de riego, $\mathrm{T}_{\mathrm{CTL}}(\bullet), \mathrm{T}_{\mathrm{RD} 80}(\boldsymbol{\bullet}) \mathrm{y}_{\mathrm{RDC} 20}(\boldsymbol{\bullet})$.

Figura 4.16. Distribución de la densidad de longitud de raíces (DLR, $\mathrm{cm}$ de raíz $\mathrm{cm}^{-3}$ de suelo) en el tratamiento control, para la profundidad y distancia perpendicular a la línea portagoteros de 0 a $110 \mathrm{~cm}$. Las figuras a y b corresponden a raíces menores de $1 \mathrm{~mm}$ de diámetro y c y d, a mayores de $1 \mathrm{~mm}$, en 2002 y 2003, respectivamente.

Figura 4.17. Distribución de la densidad de peso seco del total de raíces (mg de raíz $\mathrm{cm}^{-3}$ de suelo) en el tratamiento control, para la profundidad y distancia perpendicular a la línea portagoteros de $0 \mathrm{a}$ $110 \mathrm{~cm}$, en 2002 (a) y 2003 (b).

Figura 4.18. Dinámica de crecimiento en longitud de los brotes del tratamiento control. Cada punto corresponde a la media de 3 repeticiones $\pm \mathrm{ES}$.

Figura 4.19. Dinámica de crecimiento en longitud de los brotes en los 5 tratamientos de riego: $\mathrm{T}_{\mathrm{CTL}}\left({ }^{-}\right), \mathrm{T}_{\mathrm{RD} 80}\left({ }^{-}-\right), \mathrm{T}_{\mathrm{RD} 60}\left({ }^{-\Delta-}\right), \mathrm{T}_{\mathrm{RDC} 40}$ $(\cdots \cdots \cdots)$ y $\mathrm{T}_{\mathrm{RDC} 20}(-\cdots)$. Cada punto corresponde a la media de 3 repeticiones $\pm \mathrm{ES}$. La línea vertical de puntos indica el período de aplicación del déficit en los tratamientos $\mathrm{T}_{\mathrm{RDC} 40} \mathrm{y} \mathrm{T}_{\mathrm{RDC} 20}$.

Figura 4.20. Evolución del diámetro de tronco en los 5 tratamientos de riego durante el periodo experimental. $\mathrm{T}_{\mathrm{CTL}}(-), \mathrm{T}_{\mathrm{RD} 80}(--)$, $\mathrm{T}_{\mathrm{RD} 60}(-), \mathrm{T}_{\mathrm{RDC} 40}(--)$ y $\mathrm{T}_{\mathrm{RDC} 20}(--)$. Las líneas verticales de puntos indican los períodos de aplicación del déficit en los

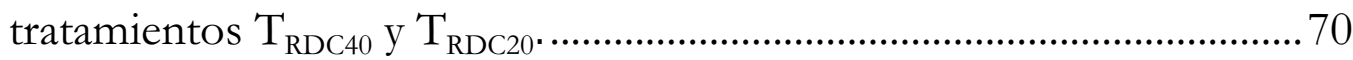

Figura 4.21. Relaciones entre el incremento de diámetro de tronco y la integral de estrés. $\Delta \mathrm{DT}=-0.16 \mathrm{~S}_{\Psi_{\text {tallo }}}+0.96, \mathrm{R}^{2}=0.96$, en 2002 
$(\bullet) ; \Delta \mathrm{DT}=-0.01 \mathrm{~S}_{\Psi_{\text {tallo }}}+19.8, \mathrm{R}^{2}=0.83$, en $2003(\circ) \mathrm{y} \Delta \mathrm{DT}=$ $0.246 \mathrm{~S}_{\Psi_{\text {alba }}}+31.57, \mathrm{R}^{2}=0.92$, en $2002(\bullet)$ y $\Delta \mathrm{DT}=-0.313 \mathrm{~S}_{\Psi_{\text {alba }}}+$ $17.88, \mathrm{R}^{2}=0.83$, en $2003(\circ) . \mathrm{S}_{\Psi_{\text {tallo }}}$ corresponde al periodo días $140-270$ y $S_{\Psi_{a l b a}}$ al periodo $190-270$.

Figura 4.22. Porcentaje de superficie sombreada durante el periodo experimental, en los cinco tratamientos de riego: $\mathrm{T}_{\mathrm{CTL}}(\mathbf{)}), \mathrm{T}_{\mathrm{RD} 80}$ $(\square), \mathrm{T}_{\mathrm{RD} 60}(\square), \mathrm{T}_{\mathrm{RDC} 40}(\square)$ y $\mathrm{T}_{\mathrm{RDC} 20}(\square)$. Columnas del mismo año seguidas de letras diferentes indican diferencias significativas entre tratamientos según el test de Tukey ${ }_{0.05}$

Figura 4.23. (a) Relación entre el área foliar (AF) y la dotación de agua de riego $(\mathrm{R})$ durante el periodo 2001-2003 $\left(\mathrm{AF}=6.89 \mathrm{R}-1.58 ; \mathrm{R}^{2}=\right.$ 0.91; $\mathrm{P}<0.05) . \mathrm{T}_{\mathrm{CTL}}(\bullet), \mathrm{T}_{\mathrm{RD} 80}(\boldsymbol{\Delta}), \mathrm{T}_{\mathrm{RD} 60}(\boldsymbol{\Delta}), \mathrm{T}_{\mathrm{RDC} 40}(\mathrm{O})$ y $\mathrm{T}_{\mathrm{RDC} 20}$ (-). (b) Área foliar en función de la integral de estrés $\left(S_{\Psi_{\text {tallo }}}\right)$ obtenida a partir de los valores de potencial de tallo a mediodía: AF $=18.24-0.11 \mathrm{~S}_{\Psi_{\text {tallo }}}\left(\mathrm{R}^{2}=0.54 ; \mathrm{P}<0.05\right) ; \mathrm{AF}=34.81-0.16 \mathrm{~S}_{\Psi_{\text {tallo }}}$ $\left(\mathrm{R}^{2}=0.601 ; \mathrm{P}<0.05\right)$, en $2002(\bullet)$ y $2003(\circ)$, para el período de días $140-270$.

Figura 4.24. Relación entre el porcentaje de área sombreada (SS) y el índice de área foliar (IAF) a partir de los 4 años de ensayo y para los 5 tratamientos de riego. $\mathrm{T}_{\mathrm{CTL}}(\bullet), \mathrm{T}_{\mathrm{RD} 80}(\boldsymbol{\Delta}), \mathrm{T}_{\mathrm{RD} 60}(\boldsymbol{\Delta}), \mathrm{T}_{\mathrm{RDC} 40}(\mathrm{O}) \mathrm{y}$ $\mathrm{T}_{\mathrm{RDC} 20}(\boldsymbol{\bullet}) . \mathrm{SS}=26.5 \mathrm{IAF}+5.74 ; \mathrm{R}^{2}=0.98 \mathrm{P}<0.001$.

Figura 4.25. Peso seco de poda en los 5 tratamientos de riego: $\mathrm{T}_{\mathrm{CTL}}$ $(\square), \mathrm{T}_{\mathrm{RD} 80}(\square), \mathrm{T}_{\mathrm{RD} 60}(\square), \mathrm{T}_{\mathrm{RDC} 40}(\square)$ y $\mathrm{T}_{\mathrm{RDC} 20}$ durante el periodo experimental. Cada barra corresponde a la media de tres repeticiones \pm ES. Letras diferentes dentro del mismo año indican diferencias significativas entre tratamientos según el test de Tukey 0.05

Figura 4.26. Relación entre el peso seco de poda (Ps) y el volumen de de riego anual año $(\mathrm{R})$, durante el periodo 2002-2004 (Ps $=0.002 \mathrm{R}+$ $\left.2.07 \mathrm{R}^{2}=0.87 \mathrm{P}<0.05\right)$ Cada punto corresponde a la media de 30 árboles por tratamiento en cada año, $\mathrm{T}_{\mathrm{CTL}}(\bullet), \mathrm{T}_{\mathrm{RD} 80}(\bullet), \mathrm{T}_{\mathrm{RD} 60}(\Delta)$, $\mathrm{T}_{\mathrm{RDC} 40}(\mathrm{O})$ y $\mathrm{T}_{\mathrm{RDC} 20}(\boldsymbol{\bullet})$.

Figura 4.27. Evolución de los estados fenológicos de yemas de flor (A-I), bajo condiciones de adecuado suministro hídrico en 2002 (a) y 2003 (b). Las cajas horizontales indican el inicio y final de cada fase fenológica, y la línea vertical interior de cada caja indica el momento en el que el $50 \%$ de las yemas han alcanzado dicho estado. 
Figura 4.28. Evolución de los estados fenológicos de las yemas de flor en almendro 'Marta', durante los años 2002 y 2003, en los tratamientos ensayados: $\mathrm{T}_{\mathrm{CTL}}(-\bullet), \mathrm{T}_{\mathrm{RD} 80}(-\boldsymbol{-}), \mathrm{T}_{\mathrm{RD} 60}\left({ }^{-\Delta-}\right), \mathrm{T}_{\mathrm{RDC} 40}(\cdots \cdot \cdots) \mathrm{y}$ $\mathrm{T}_{\mathrm{RDC} 20}$ (--). Cada punto corresponde a la media de tres repeticiones $\pm \mathrm{ES}$.

Figura 4.29. Evolución del crecimiento longitudinal del pericarpio durante los años $2002(\bullet-), 2003(-\circ-)$ y $2004(-\triangle)$ en el tratamiento control. Cada punto corresponde a la media de 3 repeticiones \pm ES.

Figura 4.30. Evolución del diámetro longitudinal (A), ecuatorial (B) y trasversal $(\mathrm{C})$ en $\mathrm{T}_{\mathrm{CTL}}\left({ }^{-}-\right), \mathrm{T}_{\mathrm{RD} 80}(-\boldsymbol{-}-), \mathrm{T}_{\mathrm{RD} 60}\left({ }^{-\Delta-}\right)$ y $\mathrm{T}_{\mathrm{RDC} 40}$ ( ……) durante el 2003. Cada punto corresponde a la media de 3 repeticiones $\pm \mathrm{ES}$.

Figura 4.31. Evolución del peso seco del grano durante el 2003 en los cinco tratamientos de riego: $\mathrm{T}_{\mathrm{CTL}}(-\bullet), \mathrm{T}_{\mathrm{RD} 80}\left({ }^{-\boldsymbol{-}}\right), \mathrm{T}_{\mathrm{RD} 60}\left({ }^{-\Delta-}\right)$, $\mathrm{T}_{\mathrm{RDC} 40}(\cdots \cdots \cdots)$ y $\mathrm{T}_{\mathrm{RDC} 20}(--)$. Cada punto corresponde a la media de 3 repeticiones $\pm \mathrm{ES}$.

Figura 4.32. Porcentaje respecto al total del crecimiento longitudinal $(-\bullet)$ y peso seco $\left(-\sim^{-}\right)$del fruto y longitud de brotes $(\cdots \Delta \cdots)$ en el tratamiento control. (a) 2002 y (b) 2003.

Figura 5.1. Evolución mensual de la temperatura máxima, mínima y media, evapotraspiración de referencia y lluvia durante el periodo experimental, 1999-2003.

Figura 5.2. Régimen de riego, en los distintos tratamientos, de acuerdo a las fases del ciclo anual de almendros 'Colorada'.

Figura 5.3. Vista aérea de la plantación comercial de almendros 'La Corverica'. El recuadro en negro señala la parcela experimental en la que se realizó el ensayo, de acuerdo con la distribución de tratamientos indicada.

Figura 5.4. Evolución del contenido volumétrico de agua en el suelo relativo al control $\left(\theta_{\mathrm{VTi}} / \theta_{\mathrm{VTCt}}\right)$, para las profundidades de $0-30,30-$ $60,60-90$ y $90-120 \mathrm{~cm}$. Los puntos representan el promedio de tres sondas de TDR situadas a $0.5 \mathrm{~m}(\mathrm{~A}, \mathrm{~B}, \mathrm{C}, \mathrm{D})$ y $1 \mathrm{~m}(\mathrm{E}, \mathrm{F}, \mathrm{G}, \mathrm{H})$ del emisor $\left(\mathrm{T}_{\mathrm{CTL}}(-), \mathrm{T}_{\mathrm{RDC}}(\cdots \Delta \cdots)\right.$ y $\left.\mathrm{T}_{\mathrm{SCO}}(-\mathrm{O} \cdot)\right)$. Los asteriscos indican el período de riego al $30 \%$ del $\mathrm{T}_{\mathrm{CTL}}$ en $\mathrm{T}_{\mathrm{RDC}}$. 2000. 
Figura 5.5. Perfiles de salinidad (CE) y concentración de cloruros [Cl] en el extracto de saturación, a finales de agosto de 2000, en la zona húmeda $(-\bullet)$ y frente húmedo (-० .) del círculo mojado por el emisor. La línea horizontal representa el ES medio del perfil.

Figura 5.6. Perfiles de salinidad $(\mathrm{CE}$ y $[\mathrm{Cl}]$ en el extracto de saturación del suelo) en la capa de 0 a $1.20 \mathrm{~m}$ de profundidad para el tratamiento $\mathrm{T}_{\mathrm{RDC}}$, antes $(\bullet-)$ y después $(-\circ \cdot)$ de $160 \mathrm{~mm}$ de lluvia. Los valores corresponden al frente húmedo del volumen humectado.

Figura 5.7. Evolución estacional del potencial hídrico foliar al alba $\left(\Psi_{a}\right)$ y a mediodía $\left(\Psi_{\mathrm{md}}\right)$ en 2000 , para los tres tratamientos de riego: $\mathrm{T}_{\mathrm{CTL}}$ $(-\bullet), \mathrm{T}_{\mathrm{RDC}}(\cdots \Delta)$ y $\mathrm{T}_{\mathrm{SCO}}\left(-\bullet^{-}\right)$. Cada punto corresponde a la media de 3 repeticiones \pm ES. $\downarrow$ indica el cambio de riego en el tratamiento $\mathrm{T}_{\mathrm{RD}}$

Figura 5.8. Evolución estacional de la conductancia foliar (g) en el año 2000 , en los 3 tratamientos de riego: $\mathrm{T}_{\mathrm{CTL}}(-\bullet), \mathrm{T}_{\mathrm{RDC}}(\cdots \Delta \cdots)$ y $\mathrm{T}_{\mathrm{SCO}}$ $(-\circ \cdot)$. Cada punto corresponde a la media de 3 repeticiones \pm ES. $\downarrow$ indica el cambio de riego en el tratamiento $\mathrm{T}_{\mathrm{RDC}}$

Figura 5.9. Evolución diaria de la radiación fotosintéticamente activa (RFA, - -), déficit de presión de vapor (DPV, $\square-)$, potencial hídrico $\left(\Psi_{\mathrm{l}}\right)$ y conductancia foliar $\left(\mathrm{g}_{\mathrm{j}}\right)$ en los tres tratamientos de riego: $\mathrm{T}_{\text {СTL }}(-\bullet), \mathrm{T}_{\mathrm{RDC}}(\cdots \Delta)$ y $\mathrm{T}_{\mathrm{SCO}}(-\circ)$, en 2001. Cada punto representa la media de tres repeticiones $\pm \mathrm{ES} . *$ indica la existencia de diferencias significativas entre $\mathrm{T}_{\mathrm{CTL}}$ y $\mathrm{T}_{\mathrm{SCO}}, \mathrm{y}$ ** entre todas las posibles comparaciones pareadas.

Figura 5.10. Evolución diaria de la radiación fotosintéticamente activa, RFA ( $\square)$, déficit de presión de vapor, DPV, ( $\checkmark)$ potencial hídrico foliar $\left(\Psi_{\mathrm{t}}\right)$, de tallo $\left(\Psi_{\mathrm{t}}\right)$ y conductancia foliar $\left(\mathrm{g}_{\mathrm{t}}\right)$, para los 3 tratamientos: $\mathrm{T}_{\mathrm{CTL}}(-\bullet), \mathrm{T}_{\mathrm{RDC}}(\cdots \Delta \cdots)$ y $\mathrm{T}_{\mathrm{SCO}}(-\circ \cdot), 19$ julio 2000. Cada punto corresponde a la media de 3 repeticiones \pm ES.

Figura 5.11. Relaciones entre el potencial hídrico foliar y el déficit de presión de vapor obtenidas en las tres evoluciones diarias de 2001, para los 3 tratamientos $\mathrm{T}_{\mathrm{CTL}}(\bullet), \mathrm{T}_{\mathrm{RDC}}(\Delta)$ y $\mathrm{T}_{\mathrm{SCO}}(\mathrm{o})$.

Figura 5.12. Conductancia foliar a mediodía $\left(\mathrm{g}_{\mathrm{l}}\right)$ en función del potencial hídrico foliar a mediodía $\left(\Psi_{\mathrm{md}}\right)$, durante julio de 2000 y 2001, en los tratamientos $\mathrm{T}_{\mathrm{CTL}}(\bullet), \mathrm{T}_{\mathrm{RDC}}(\Delta)$ y $_{\mathrm{SCO}}(\mathrm{o})$. Cada punto representa la 
media de 3 medidas. La ecuación de la línea de ajuste viene dado por: $\mathrm{g}_{\mathrm{l}}\left(\mathrm{mmol} \mathrm{m} \mathrm{s}^{-1}\right)=607.8+169.9 \Psi_{\mathrm{md}}(\mathrm{MPa}) ; \mathrm{R}^{2}=0.83^{* * *}$

Figura 5.13. Variación diurna de la relación conductancia foliar $\left(\mathrm{g}_{1}\right)$ y potencial hídrico foliar $\left(\Psi_{1}\right)$ de almendros 'Colorada', en función del tratamientos de riego: $\mathrm{T}_{\mathrm{CTL}}(-\bullet), \mathrm{T}_{\mathrm{RDC}}(\cdots \Delta)$ y $\mathrm{T}_{\mathrm{SCO}}(-\circ \cdot)$. Cada punto es la media de tres medidas por árbol en seis árboles por tratamiento. Las flechas indican el sentido horario de la evolución de los parámetros.

Figura 5.14. Evoluciones diarias del potencial hídrico foliar $(\bullet-)$ y de las componentes osmótica $(-\bullet)$ y de presión $(-\circ)$ en mayo, julio y octubre de 2001, para los tres tratamientos de riego.

Figura 5.15. Detalle de necrosis en puntas de hojas por toxicidad de cloruros y sodio

Figura 5.16. Efecto del régimen de riego sobre el contenido y evolución en hoja de cloruros, sodio y potasio a lo largo del ciclo de cultivo de 2001, para los tres tratamientos de riego: $\mathrm{T}_{\mathrm{CTL}}(\square), \mathrm{T}_{\mathrm{RDC}}(\square) \mathrm{y}$ $\mathrm{T}_{\mathrm{SCO}}(\square)$. Las barras representan ES.

Figura 5.17. Dinámica del crecimiento de brotes en longitud y tasa de crecimiento relativa en 2000 y 2001, para los tres tratamientos $T_{\text {CTL }}$ $(-\bullet), \mathrm{T}_{\mathrm{RDC}}(\cdots \Delta)$ y $\mathrm{T}_{\mathrm{SCO}}(-\circ \cdot)$. Cada punto corresponde a la media de 3 repeticiones \pm ES.

Figura 5.18. Evolución del diámetro de brotes y tasa de crecimiento relativa durante el 2001, para los tres tratamientos $\mathrm{T}_{\mathrm{CTL}}(-\bullet), \mathrm{T}_{\mathrm{RDC}}$ $(\cdots \Delta)$ y $\mathrm{T}_{\mathrm{SCO}}(-\mathrm{O} \cdot)$. Cada punto corresponde a la media de 3 repeticiones $\pm \mathrm{ES}$

Figura 5.19. Diámetro de tronco al final de las campañas 1999 y 2001, para los tratamientos $\mathrm{T}_{\mathrm{CTL}}(\square), \mathrm{T}_{\mathrm{RDC}}(\square)$ y $\mathrm{T}_{\mathrm{SCO}}(\square)$. Cada punto corresponde a la media de 3 repeticiones \pm ES.

Figura 5.20. Evolución del diámetro longitudinal y ecuatorial de los frutos y en peso seco del grano, para los tres tratamientos $\mathrm{T}_{\text {CTL }}$ $(-\bullet), \mathrm{T}_{\mathrm{RDC}}(\cdots \Delta \cdots)$ y $\mathrm{T}_{\mathrm{SCO}}(-\mathrm{O} \cdot)$, durante los años 2000 (a) у 2001 (b). Cada punto corresponde a la media de 3 repeticiones \pm ES.

Figura 6.1. Vista general y evolución de la parcela experimental de almendros (ETSIA-UPCT) durante el periodo de estudio 
Figura 6.2. Valores diarios de temperatura máxima y mínima, pluviométrica, evapotranspiración de referencia Penman Monteith, máximo déficit de presión de vapor en la parcela experimental durante 2002-2004.

Figura 6.3. Evolución del potencial hídrico foliar al alba $\left(\Psi_{2}\right)$, mediodía $\left(\Psi_{\mathrm{md}}\right)$, tallo $\left(\Psi_{\mathrm{t}}\right)$ y conductancia foliar $\left(\mathrm{g}_{\mathrm{f}}\right)$ en los tres tratamientos de riego, $\mathrm{T}_{\mathrm{CTL}}(--), \mathrm{T}_{\mathrm{RDC} 60}\left(--_{--}\right)$y $\mathrm{T}_{\mathrm{RDC} 40}(---\cdots)$. Los puntos corresponden a la media de tres repeticiones \pm ES. Los asteriscos indican el comienzo y final del periodo al $40 \%$ de la ETc en $\mathrm{T}_{\mathrm{RDC} 40} .142$

Figura 6.4. Fluctuaciones medias del diámetro de tronco durante la estación de crecimiento para los tres tratamientos de riego: $\mathrm{T}_{\text {CTL }}$ (-), $\mathrm{T}_{\mathrm{RD} 60}(-)$ y $\mathrm{T}_{\mathrm{RDC} 40}(--)$. Cada mes está caracterizado por un periodo de seis días. Las columnas numéricas representan la media mensual de crecimiento diario para los diferentes tratamientos. Los valores seguidos de letras distintas son estadísticamente diferentes según el test de Tukey ${ }_{0.05}$.

Figura 6.5. Evolución relativa de los parámetros: Potencial hídrico foliar al alba, mediodía y tallo a mediodía, $\Psi_{\text {a }}$ y $\Psi_{\text {md }}, \Psi_{\mathrm{t}}\left(\mathrm{T}_{\mathrm{n}} / \mathrm{T}_{\mathrm{CTI}}\right)$, conductancia foliar, $\mathrm{g}_{\mathrm{l}}\left(\mathrm{T}_{\mathrm{CTL}} / \mathrm{T}_{\mathrm{n}}\right)$, máxima contracción diaria, $\mathrm{MCD}$ $\left(\mathrm{Tn} / \mathrm{T}_{\mathrm{CTL}}\right)$ y crecimiento diario a partir de los máximos diámetros, TCD ( $\left.\mathrm{T}_{\mathrm{CTL}} / \mathrm{Tn}\right)$. Los asteriscos indican el inicio y final del periodo al $40 \%$ de la ETc en $\mathrm{T}_{\mathrm{RD}}$

Figura 6.6. Evolución anual del diámetro de tronco en los distintos tratamientos de riego, $\mathrm{T}_{\mathrm{CTL}}(-), \mathrm{T}_{\mathrm{RD} 60}(-)$ y $\mathrm{T}_{\mathrm{RDC} 40}(--) \ldots \ldots \ldots . . .146$

Figura 6.7.- Evolución de la máxima contracción diaria para los diferentes tratamientos de riego, $\mathrm{T}_{\mathrm{CTL}}(-), \mathrm{T}_{\mathrm{RD} 60}(-)$ y $\mathrm{T}_{\mathrm{RDC} 40}$

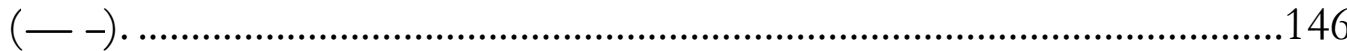

Figura 6.8.- Relaciones del potencial de tallo a mediodía $\left(\Psi_{t}\right)$ y máxima contracción diaria (MCD) y la evapotranspiración de referencia Penman Monteith (ETo) para el tratamiento control. $\Psi_{\mathrm{t}}=-0.091$ ETo $-0.35\left(\mathrm{R}^{2}=0.827, \mathrm{P}<0.05\right) ; \mathrm{MCD}_{\mathrm{TCTL}}=25.2+22.7$ ETo $\left(\mathrm{R}^{2}\right.$ $=0.479, \mathrm{P}<0.05)$.

Figura 6.9. Evolución estacional del potencial de tallo $\left(\Psi_{t}\right)$ y conductancia foliar a mediodía $\left(\mathrm{g}_{\mathrm{I}}\right)$, en los cuatro tratamientos de riego $\mathrm{T}_{\mathrm{CTL}}(-\bullet), \mathrm{T}_{\mathrm{RD} 80}(-\mathbf{-}), \mathrm{T}_{\mathrm{RD} 60}\left(-\wedge_{--}\right)$у $\mathrm{T}_{\mathrm{RDC} 20}(-\cdots)$. Cada punto corresponde a la media de 3 repeticiones \pm ES. Las 
líneas de trazo discontinuo indican el inicio y fin del periodo de riego al $20 \%$ ETc en $\mathrm{T}_{\mathrm{RDC} 20}$, y las de puntos la semana de recuperación al $120 \%$ de la ETc en todos los tratamientos.

Figura 6.10. Evolución de las variaciones de diámetro de tronco (VDT), radiación global $(\mathrm{G})$, déficit de presión de vapor (DPV) y potencial hídrico de tallo a mediodía ( $\left.\Psi_{t}\right)$ en los cuatro tratamientos de riego $\mathrm{T}_{\mathrm{CTL}}(-\bullet), \mathrm{T}_{\mathrm{RD} 80}(--), \mathrm{T}_{\mathrm{RD} 60}(-\triangle-\cdot)$ y $\mathrm{T}_{\mathrm{RDC} 20}(-\cdots)$ y en un tronco muerto ( ), durante el día 224.

Figura 6.11. Relación a lo largo de una jornada (día 224) entre el potencial hídrico de tallo y las variaciones de diámetro de tronco, para los tratamientos de riego $\mathrm{T}_{\mathrm{CTL}}(\bullet-), \mathrm{T}_{\mathrm{RD} 60}(-\wedge-\cdot)$ y $\mathrm{T}_{\mathrm{RDC} 20}\left(-\mathrm{O}^{-\cdots}\right)$. Las flechas indican el sentido horario de la relación entre ambos parámetros.

Figura 6.12. Evolución estacional del diámetro máximo (MXTD) y de la tasa de crecimiento diaria de tronco (TCD), en los tratamientos $\mathrm{T}_{\mathrm{CTL}}(-\bullet), \mathrm{T}_{\mathrm{RD} 80}(-\mathbf{-}), \mathrm{T}_{\mathrm{RD} 60}(-\triangle--)$ y $\mathrm{T}_{\mathrm{RDC} 20}(-\cdots)$. Cada punto corresponde a la media de 6 sensores LVDT \pm ES. La línea de trazo discontinuo indica el inicio y fin del periodo al $20 \%$ ETc en $\mathrm{T}_{\mathrm{RDC} 20}$, y la de puntos la semana de riego al $120 \%$ de la ETc en todos los tratamientos.

Figura 6.13. Evolución estacional de la máxima contracción diaria (MCD) y déficit de presión de vapor máximo diario (DPV) (a) y máxima contracción diaria quincenal, en $\mathrm{T}_{\mathrm{CTL}}\left(-;-\mathrm{C}_{\mathrm{RD} 80}\right.$

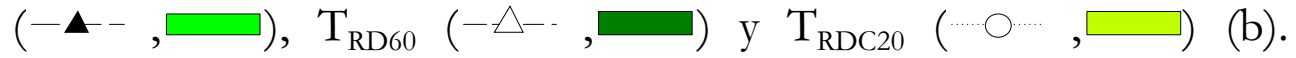
Cada punto corresponde a la media de 6 sensores LVDT \pm ES. La línea de trazo discontinuo indica el inicio y fin del periodo al $20 \%$ ETc en $\mathrm{T}_{\mathrm{RDC} 20}$, y la de puntos la semana de riego al $120 \%$ de la ETc.

Figura 6.14. Evolución anual de las variaciones de diámetro de tronco (VDT), en los cuatro tratamientos de riego. Cada curva corresponde a un sensor LVDT representativo de cada tratamiento, $\mathrm{T}_{\mathrm{CTL}}(\quad), \mathrm{T}_{\mathrm{RD} 80}(\quad), \mathrm{T}_{\mathrm{RD} 60}(\quad)$ y $\mathrm{T}_{\mathrm{RDC} 20}(\quad)$. La línea discontinua muestra el inicio y final del periodo de reducción del riego en $\mathrm{T}_{\mathrm{RDC} 20}$

Figura 6.15. Relaciones entre TCD y MCD y el potencial hídrico foliar al alba $\left(\Psi_{2}\right)$ y el de tallo a mediodía $\left(\Psi_{\text {一 }}\right)$, durante el periodo 
experimental., para los 4 tratamientos de riego: $\mathrm{T}_{\mathrm{CTL}}(\bullet), \mathrm{T}_{\mathrm{RD} 80}(\mathbf{\Delta})$, $\mathrm{T}_{\mathrm{RD} 60}(\nabla)$ y $\mathrm{T}_{\mathrm{RDC} 20}(\mathrm{O}) \ldots \ldots \ldots \ldots \ldots \ldots \ldots \ldots \ldots \ldots \ldots \ldots \ldots \ldots \ldots \ldots \ldots \ldots \ldots \ldots \ldots \ldots \ldots \ldots \ldots \ldots \ldots \ldots . . .158$

Figura 6.16. Relaciones entre MCD y el potencial de presión a mediodía:

(a) hojas cubiertas $\left(\Psi_{\mathrm{pt}}\right)$ y $(\mathrm{b})$ sin cubrir $\left(\Psi_{\mathrm{p}}\right)$, durante el periodo experimental y para los 4 tratamientos de riego $\mathrm{T}_{\mathrm{CTL}}(\bullet), \mathrm{T}_{\mathrm{RD} 80}(\boldsymbol{\bullet})$,

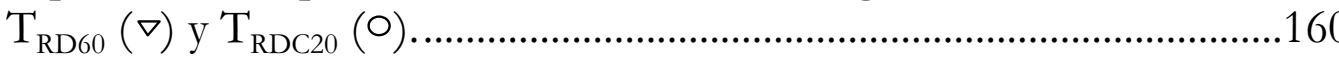

Figura 6.17. Relación entre la evapotranspiración de referencia Penman Monteith (ETo PM) y la máxima contracción diaria de tronco (MCD) durante el periodo experimental, para los 4 tratamientos de riego, $\mathrm{T}_{\mathrm{CTL}}(\bullet), \mathrm{T}_{\mathrm{RD} 80}(\bullet), \mathrm{T}_{\mathrm{RD} 60}(\nabla)$ y $\mathrm{T}_{\mathrm{RDC} 20}(\mathrm{O})$

Figura 6.18. Relación entre la máxima contracción diaria de tronco (MCD) y el potencial de tallo a mediodía $\left(\Psi_{t}\right)$ durante el periodo experimental, para los 4 tratamientos de riego, $\mathrm{T}_{\mathrm{CTL}}(\bullet), \mathrm{T}_{\mathrm{RD} 80}(\boldsymbol{\bullet})$, $\mathrm{T}_{\mathrm{RD} 60}(\nabla)$ y $\mathrm{T}_{\mathrm{RDC} 20}(\mathrm{O})$

Figura 6.19. Relaciones entre el déficit de presión de vapor máximo diario (DPV) y el potencial de tallo a mediodía $\left(\Psi_{t}\right.$ ) (a) y la máxima contracción diaria (MCD) (b) para los distintos tratamientos de riego, $\mathrm{T}_{\mathrm{CTL}}(\bullet), \mathrm{T}_{\mathrm{RD} 80}(\bullet), \mathrm{T}_{\mathrm{RD} 60}(\nabla)$ y $\mathrm{T}_{\mathrm{RDC} 20}(\mathrm{O})$.

Figura 6.20. Relaciones mensuales entre la máxima contracción diaria de tronco $(\mathrm{MCD})$ y el déficit de vapor máximo diario (DPV) para los tratamientos de riego $\mathrm{T}_{\mathrm{CTL}}(\bullet)$ y $\mathrm{T}_{\mathrm{RD} 80}(\mathbf{\bullet})$. 


\section{Índice de tablas}

Tabla 3.1. Características de los sensores utilizados. .38

Tabla 4.1. Volúmenes de agua aplicados durante el período experimental $\left(\mathrm{m}^{3} \mathrm{ha}^{-1}\right)$ y porcentaje respecto al control, para los 5 tratamientos de riego.

Tabla 4.2. Valores medios prerriego de $\Psi_{\mathrm{m}}$ en tres momentos característicos de 2002, según la estrategia de riego y para los 5 tratamientos, a 30, 60 y $90 \mathrm{~cm}$ de profundidad.

Tabla 4.3. Incremento anual de la sección transversal del tronco $\left(\Delta \mathrm{ST}^{\prime} \mathrm{T}\right)$ y pendiente media de crecimiento (m) durante el periodo abriloctubre.

Tabla 4.4. Evolución del número de hojas y área foliar (AF) del árbol en los cinco tratamientos de riego. Período $2001-2003$.

Tabla 4.5. Periodos de predominio y ${ }^{\circ} \mathrm{C}$ GDH acumulados en los distintos estados fenológicos del almendro 'Marta', bajo condiciones de adecuado suministro hídrico.

Tabla 4.6. Valores medios de los parámetros productivos para los distintos tratamientos durante el periodo experimental 2002-2004...... 82

Tabla 4.7. Valores medios del peso seco del grano en los cinco tratamientos de riego durante el período 2002-2004. Cada valor representa la media de 12 árboles por tratamiento

Tabla 4.8. Índices de eficiencia productiva y de uso del agua de riego (EUA) de almendros 'Marta' durante el período experimental.

Tabla 5.1. Agua aplicada, lluvia y valores medios de potencial matricial previos al riego, durante los tres períodos de $\mathrm{T}_{\mathrm{RDC}}$ en 2000.

Tabla 5.2. Valores de los componentes del potencial hídrico foliar en diferentes fechas y para los tres tratamientos de riego: potencial osmótico a máxima saturación $\left(\Psi_{\mathrm{os}}\right)$, potenciales osmótico y de presión actual a mediodía $\left(\Psi_{\mathrm{o} \text { md }}\right)$ y $\left(\Psi_{\mathrm{p} \mathrm{md}}\right) \cdot 2001$.

Tabla 5.3. Resultados del análisis foliar en los tratamientos: $T_{C T L}, T_{R D C} y$ 
Tabla 5.4. Concentración de cloruro en hojas y brotes del año en base a materia seca. Julio de 2000.

Tabla 5.5. Contribución de los solutos $\mathrm{Na}^{+}, \mathrm{K}^{+}$y $\mathrm{Cl}^{-}$en $\mathrm{MPa}$ al potencial osmótico foliar a saturación $\left(\Psi_{\mathrm{os}}\right)$, en tres momentos representativos del manejo del riego en RDC. 2001

Tabla 5.6. Valores medios del área foliar unitaria y total del árbol, peso específico e índice de área foliar (IAF) de los 3 tratamientos, de acuerdo al total de hojas presentes en el árbol tras la cosecha de 2000 .

Tabla 5.7. Producción total y rendimiento en grano y aparente del agua (EUA, $\mathrm{kg}$ de almendra cáscara por $\mathrm{m}^{3}$ de agua de riego más lluvia)...129

Tabla 5.8. Componentes de la producción durante el período experimental 1999-2002.

Tabla 6.1. Valores medios del ratio 'Señal/Ruido' para los diferentes índices de estrés evaluados. Junio - mediados de septiembre de 2003.

Tabla 6.2 Valores de los parámetros de las relaciones máxima contracción diaria $(\mathrm{MDC}, \mu \mathrm{m})$ y crecimiento diario de tronco (TCD, $\mu \mathrm{m}$ día $^{-1}$ ) versus potencial hídrico foliar al alba $\left(\Psi_{\text {a }}\right)$, de tallo a mediodía $\left(\Psi_{\mathrm{t}}\right)$ y de presión en hojas expuestas y cubiertas $\left(\Psi_{\mathrm{p}}, \Psi_{\mathrm{p} t}\right)$, en $\mathrm{MPa}$.

Tabla 6.3. Relaciones estacionales entre la máxima contracción diaria (MDC, $\mu \mathrm{m})$ y el potencial tallo $\left(\Psi_{\mathrm{t}}, \mathrm{MPa}\right)$, para los cuatro tratamientos de riego.

Tabla 6.4. Relaciones entre el potencial de tallo $\left(\Psi_{t}, \mathrm{MPa}\right)$ y la máxima contracción diaria $(\mathrm{MDC}, \mu \mathrm{m})$ frente al déficit de presión de vapor máximo a mediodía (DPV, $\mathrm{kPa}$ ), para los cuatro tratamientos de riego. 


\section{Lista de símbolos y acrónimos}

\begin{tabular}{|c|c|c|}
\hline $\begin{array}{l}\text { Símbolos } \\
\text { latinos }\end{array}$ & Descripción & Unidades \\
\hline $\mathrm{C}$ & Capacitancia & $\mathrm{F}$ \\
\hline $\mathrm{CE}_{\mathrm{e}}$ & $\begin{array}{l}\text { Conductividad eléctrica del extracto de } \\
\text { saturación }\end{array}$ & $\mathrm{dS} \mathrm{m}^{-1}$ \\
\hline$e_{a}$ & Tensión de vapor actual & $\mathrm{kPa}$ \\
\hline $\mathrm{e}_{\mathrm{s}}$ & Tensión de vapor saturante & $\mathrm{kPa}$ \\
\hline $\mathrm{F}$ & Frecuencia & $\mathrm{Hz}$ \\
\hline G & Densidad de flujo de calor del suelo & MJ m día $^{-1}$ \\
\hline$g_{1}$ & Conductancia foliar & $\mathrm{mmol} \mathrm{m} \mathrm{s}^{-1}$ \\
\hline $\mathrm{H}$ & Flujo de calor sensible & MJ m ${ }^{-2}$ día $^{-1}$ \\
\hline $\mathrm{k}_{\mathrm{a}}$ & Constante dieléctrica & \\
\hline $\mathrm{K}_{\mathrm{c}}$ & Coeficiente de cultivo & \\
\hline$K_{\mathrm{r}}$ & Coeficiente de riego & \\
\hline $\mathrm{L}^{1}$ & Coeficiente de autoinducción & \\
\hline $\mathrm{P}$ & Precipitación & $\mathrm{mm}$ \\
\hline $\mathrm{P}_{\mathrm{F}}$ & Peso fresco & $g$ \\
\hline $\mathrm{P}_{\mathrm{s}}$ & Peso seco & $g$ \\
\hline $\mathrm{R}$ & Riego & $\mathrm{mm}$ \\
\hline $\mathrm{R}_{\mathrm{n}}$ & Radiación neta & $\mathrm{W} \mathrm{m}^{-2}$ \\
\hline $\mathrm{T}$ & Temperatura & ${ }^{\circ} \mathrm{C}$ \\
\hline $\mathrm{u}$ & Velocidad del viento & $\mathrm{m} \mathrm{s}^{-1}$ \\
\hline $\begin{array}{l}\text { Símbolos } \\
\text { griegos }\end{array}$ & Descripción & Unidades \\
\hline$\Delta$ & $\begin{array}{l}\text { Pendiente de la curva de presión de } \\
\text { vapor }\end{array}$ & $\mathrm{kPa}{ }^{\circ} \mathrm{C}-1$ \\
\hline$\gamma$ & Constante psicrométrica & $\mathrm{kPa}{ }^{\circ} \mathrm{C}^{-1}$ \\
\hline$\Psi$ & Potencial hídrico foliar & $\mathrm{MPa}$ \\
\hline$\Psi_{\mathrm{a}}$ & Potencial hídrico foliar al alba & $\mathrm{MPa}$ \\
\hline$\Psi_{\mathrm{g}}$ & Potencial gravitacional & $\mathrm{MPa}$ \\
\hline$\Psi_{\mathrm{H}}^{\mathrm{s}}$ & Potencial hidráulico & $\mathrm{MPa}$ \\
\hline$\Psi_{\mathrm{m}}$ & Potencial mátrico & $\mathrm{MPa}$ \\
\hline$\Psi_{\mathrm{md}}$ & Potencial hídrico foliar a mediodía & $\mathrm{MPa}$ \\
\hline$\Psi_{\mathrm{o}}$ & Potencial osmótico foliar & $\mathrm{MPa}$ \\
\hline$\Psi_{\text {os }}$ & Potencial osmótico saturado & $\mathrm{MPa}$ \\
\hline$\Psi_{\mathrm{p}}$ & Potencial de presión & $\mathrm{MPa}$ \\
\hline$\Psi_{\mathrm{t}}$ & Potencial hídrico de hoja cubierta & $\mathrm{MPa}$ \\
\hline
\end{tabular}




\begin{tabular}{|c|c|c|}
\hline$\varnothing_{\mathrm{e}}$ & Diámetro ecuatorial & $\mathrm{mm}$ \\
\hline$\varnothing_{\mathrm{L}}$ & Diámetro longitudinal & $\mathrm{mm}$ \\
\hline$\varnothing_{t}$ & Diámetro transversal & $\mathrm{mm}$ \\
\hline$\theta_{g}$ & $\begin{array}{l}\text { Contenido gravimétrico de agua del } \\
\text { suelo }\end{array}$ & $\%$ \\
\hline$\theta_{\mathrm{v}}$ & $\begin{array}{l}\text { Contenido volumétrico de agua del } \\
\text { suelo }\end{array}$ & $\%$ \\
\hline $\mathrm{S}_{\Psi}$ & Integral de estrés & MPa día \\
\hline Acrónimo & Descripción & Unidades \\
\hline $\mathrm{ABA}$ & Ácido abscísico & \\
\hline $\mathrm{AF}$ & Área foliar & $\mathrm{m}^{2}$ \\
\hline CA & Crecimiento acumulado & $\mu \mathrm{m}$ \\
\hline $\mathrm{Cc}$ & Capacidad de capo & $\%$ \\
\hline CWSI & Crop water stress index & $\%$ \\
\hline DLR & Densidad de longitud radicular & $\mathrm{cm} \mathrm{cm}^{-3}$ \\
\hline DPR & Densidad de peso radicular & $\mathrm{g} \mathrm{cm}^{-3}$ \\
\hline DPV & Déficit de presión de vapor & $\mathrm{kPa}$ \\
\hline $\mathrm{ES}$ & Error estándar & \\
\hline ESEA & $\begin{array}{l}\text { Estación Experimental Agroalimentaria } \\
\text { 'Tomás Ferro' }\end{array}$ & \\
\hline ETc & Evapotranspiración del cultivo & $\mathrm{mm}$ día $^{-1}$ \\
\hline ETo & Evapotranspiración de referencia & $\mathrm{mm} \mathrm{día}{ }^{-1}$ \\
\hline EUA & Eficiencia de uso del agua & $\mathrm{kg} \mathrm{m}^{-3}$ \\
\hline FAO & Food and Agriculture Organization & \\
\hline FDR & $\begin{array}{l}\text { Reflectometría en dominio de la } \\
\text { frecuencia }\end{array}$ & \\
\hline $\mathrm{GDH}$ & Hora grado de crecimiento & \\
\hline HR & Humedad relativa & $\%$ \\
\hline IAF & Índice de área foliar & $\mathrm{m}^{2} \mathrm{~m}^{-2}$ \\
\hline LVDT & Linear variable differential transformer & \\
\hline MCD & Máxima contracción diaria & $\mu \mathrm{m}$ \\
\hline $\mathrm{MCD}_{\text {ref }}$ & Máxima contracción diaria de referencia & $\mu \mathrm{m}$ \\
\hline & Materia seca & $\mathrm{mg}$ \\
\hline PRD & $\begin{array}{l}\text { Riego por desecación parcial del } \\
\text { sistema radicular }\end{array}$ & \\
\hline $\mathrm{RD}$ & Riego deficitario & \\
\hline RDC & Riego deficitario controlado & \\
\hline RFA & Radiación fotosintéticamente activa & $\mathrm{W} \mathrm{m} \mathrm{m}^{-2}$ \\
\hline RTD & Resistance temperature detector & \\
\hline SS & Superficie sombrada & $\%$ \\
\hline TCD & Tasa de crecimiento diario & $\mu \mathrm{m}$ día $^{-1}$ \\
\hline
\end{tabular}


TDR Reflectometría en dominio del tiempo

$\mathrm{T}_{\mathrm{mh}} \quad$ Temperatura media horaria $\quad{ }^{\circ} \mathrm{C}$

$\mathrm{T}_{\mathrm{s}} \quad$ Temperatura seca ${ }^{\circ} \mathrm{C}$

UT Universal time

VDT Variación de diámetro de tronco

$\Delta \mathrm{DT}$

Incremento anual de diámetro de

$\Delta \mathrm{STT}$ tronco

$\mathrm{mm}$

Área de sección transversal de tronco $\quad \mathrm{cm}^{2}$ 



\section{Justificación y objetivos}



Las limitaciones de agua para el regadío, en las zonas del sudeste español, alcanzan dimensiones preocupantes y suponen una amenaza seria de desaparición de cultivos tradicionales y de movimiento de personas que optan por otras actividades. Esta situación ha generado un interés y preocupación creciente por el ahorro de agua, en especial en la agricultura de regadío, principal destinatario de los recursos hídricos $(\approx 80 \%)$ y donde las eficiencias medias de uso del agua aún se sitúan en valores bajos. La racionalización en el uso del agua es un objetivo prioritario y de plena actualidad para nuestra sociedad y es fuente de debate en diferentes esferas del ámbito social, político y económico.

El sector frutícola no es ajeno a esta problemática y por tanto debe hacer frente a la creciente disminución de un recurso limitado como es el agua, manteniendo e incluso incrementando la rentabilidad de sus explotaciones, mediante la reducción de costes y el aumento de la calidad de sus productos.

El almendro, con más de 640000 ha, ocupa tras el olivo y el viñedo el tercer lugar en superficie dedicada a cultivos leñosos en España (http://faostat.fao.org). Murcia es una de las regiones en la que tradicionalmente se ha cultivado y producido almendra, alcanzando en la actualidad una extensión que supera las 74000 ha, representando el $11 \%$ de la superficie total nacional y de las que se obtiene unas $30400 \mathrm{t}$ de almendra en cáscara (www.carm.es/econet). Sin embargo, su importante presencia no va asociada a la necesaria rentabilidad de las plantaciones. Su característica situación marginal, debida en parte a su inherente carácter rústico, le ha convertido en un prototipo de cultivo leñoso extensivo al que se le dedican pocos cuidados.

En la Región de Murcia, la mayor parte de las plantaciones se encuentran en secano, y la cosecha de almendra en grano, como promedio, es inferior a $150 \mathrm{~kg} \mathrm{ha}{ }^{-1}$, producción que está muy por debajo de la que se considera como necesaria para cubrir los costes que ocasiona una hectárea en una explotación de secano mínimamente atendida (Felipe, 2000). Sin embargo, la repercusión productiva que el agua tiene sobre estas plantaciones es muy importante, con un ratio medio de 1/10 favorable a las condiciones de regadío (Girona y Marsal, 1995). Esta realidad, junto con los altos precios de la almendra en las últimas campañas ha animado a muchos agricultores a la puesta en riego por goteo de sus plantaciones de almendro, en ocasiones, a costa de reducir la superficie en regadío dedicada a otros cultivos. Además, la demostrada tolerancia del almendro al déficit hídrico durante la fase de llenado del grano (fase IV), que coincide con los meses de mayor demanda evaporativa (junio-agosto) y cuando bajo nuestras condiciones de clima mediterráneo la escasez de recursos hídricos se acentúa, hacen del almendro 
un cultivo idóneo para su utilización en estrategias de riego deficitario controlado (RDC), práctica que puede contribuir a la necesaria sostenibilidad de este sistema agrario.

La generalidad de los trabajos que ponen de manifiesto la buena adaptación del almendro a estrategias de RDC (Goldhamer y Shackel, 1989; Torrecillas et al., 1989a; Girona y Marsal, 1995; Romero et al., 2004a; Girona et al., 2005; Goldhamer et al., 2006) se han realizado con aguas de buena calidad. Sin embargo, en la agricultura de regadío del sudeste español, es frecuente que al problema de la escasez de recursos hídricos vaya unido el de la baja calidad agronómica de sus aguas. Bajo este segundo escenario son escasos los estudios que abordan el efecto combinado del riego con agua salina y la reducción de los aportes hídricos sobre el crecimiento y producción del almendro. Igualmente, y para el caso de almendros jóvenes, son pocos los estudios que versan sobre las relaciones hídricas, crecimiento y desarrollo del árbol bajo estrés hídrico ligero-moderado de larga duración, estudiando la mayoría de ellos la respuesta del almendro a estreses severos de corta duración a partir de ciclos de supresión del riego.

El conocimiento de cada uno de estos tipos de respuesta de la planta a las condiciones del entorno es clave con fines de programación y optimización del riego. Comúnmente, se han utilizado medidas basadas en el suelo o en el clima para la programación y manejo del riego, y aunque ambos métodos presentan la ventaja de la facilidad en la toma de medidas, tienen la limitación de no reflejar con exactitud el estado hídrico de la planta. Además, las medidas en el suelo muestran una gran variabilidad, la que se agrava bajo riego por goteo debido al carácter tridimensional de distribución del agua. Por ello, recientemente se está prestando mucha atención a las técnicas de medida del estado hídrico de la planta, al integrar ésta la influencia del entorno (clima y suelo) y método de riego.

Uno de los indicadores tradicionales del estado energético del agua en la planta es el potencial hídrico foliar y las medidas más útiles con fines de diagnóstico las realizadas al alba y a mediodía, éstas últimas en hojas cubiertas. Distintos autores, trabajando con especies leñosas, han señalado la alta sensibilidad de ambos parámetros al régimen de riego y su relación con la respuesta productiva, sugiriendo su uso como indicadores de referencia en estudios tendentes a evaluar la idoneidad de nuevos indicadores de estrés hídrico de la planta. Aunque el método más práctico para la medida del potencial hídrico foliar es la cámara de presión, presenta el inconveniente de la laboriosidad de las medidas y el no estar adaptado para el registro de datos en continuo y por tanto para la automatización del riego. Sin embargo, el continuo avance en las técnicas de medida e informática, está abriendo grandes posibilidades de futuro a nuevas técnicas de programación en base a 
la información continua y en tiempo real suministrada por sensores colocados en planta.

En relación a este último aspecto, es de destacar que en los últimos años se están llevando a cabo importantes investigaciones tendentes al establecimiento de protocolos de programación del riego, en base a distintos parámetros derivados de la medida de las variaciones continuas de diámetro de tronco, mediante el uso de sensores de desplazamiento variable y respuesta lineal. Un gran número de ensayos en distintas especies arbóreas han confirmado la sensibilidad de éstos a la disponibilidad de agua en el suelo cuando son sometidas a diferentes regímenes hídricos (Ginestar y Castel, 1996; Goldhamer y Fereres, 2001; Fereres y Goldhamer, 2003; Remorini y Massai, 2003; Intrigliolo y Castel, 2004; Moreno et al., 2006; García-Orellana et al., 2007; Vélez et al., 2007), y plantean su uso como indicadores de riego. Sin embargo, la aplicación práctica no es sencilla, ya que sus valores son muy específicos de la especie, edad y estado fenológico, por lo que implica la necesidad de una experimentación previa para buscar los valores de referencia antes de poder aplicarlos en protocolos de programación del riego.

Con la situación descrita anteriormente, las perspectivas de futuro del cultivo del almendro, y por tanto, de continuidad del sector, pasan por incrementar su rentabilidad y competitividad en un escenario de suministro hídrico limitado. Para hacer frente a la escasez de recursos hídricos y maximizar la productividad del agua y otros insumos, el riego deficitario es visto como una herramienta de manejo del riego muy útil y prometedora. Sin embargo, su estado actual requiere de investigaciones adicionales que conduzcan a un manejo óptimo del déficit hídrico a nivel explotación comercial. Para ello, será fundamental poder contar con indicadores de estrés hídrico robustos y sensibles a los cambios del estado hídrico de la planta o/y del suelo.

Por todo ello y con esta idea central, el objetivo global del presente trabajo fue evaluar desde un punto de vista fisiológico y agronómico la respuesta de almendros jóvenes y adultos a la aplicación de distintas estrategias de riego (capítulos IV y V), y estudiar la utilidad y aplicabilidad de indicadores de estrés hídrico en planta con fines de optimización del riego (capítulo VI).

Para la consecución de este objetivo global se plantearon los siguientes objetivos parciales:

i) Analizar la respuesta fisiológica y agronómica de almendros jóvenes y adultos sometidos a diferentes estrategias de riego deficitario y compararla con la correspondiente a un tratamiento bien regado. 
ii) Evaluar el estado hídrico de almendros jóvenes, bajo diferentes regímenes hídricos, a través del registro de las variaciones de diámetro de tronco, usando sensores de desplazamiento variable y respuesta lineal, (LVDT, Linear V ariable Displacement Transducers).

iii) Estudiar la aplicabilidad y limitaciones de los indicadores biológicos del estado hídrico del árbol: máxima contracción diaria y crecimiento diario de tronco, a partir del estudio comparado entre éstos y los tradicionalmente empleados.

iv) Caracterizar, mediante ecuaciones matemáticas, las relaciones entre aporte de agua y comportamiento hídrico del almendro y los parámetros ambientales que influyen en el mismo. 
Antecedentes 



\subsection{El cultivo del almendro}

\section{Origen y medio ambiente}

La especie cultivada en las zonas productoras de almendra es Prunus dulcis (Miller) D.A.Webb (Felipe, 2000). Pertenece a la familia de las Rosáceas, subfamilia Prunoidea. Su origen se sitúa en el proceso de hibridaciones naturales que ocurrieron en las regiones de Azerbaidjan y el Tien Shau en Asia Central a partir de sus tres ancestros salvajes: Prunus fenqliana Fritsh, $P$. bucharica Korschinsky y P. ulmifolia Franch (Vavilov, 1930; Evreinoff, 1952; Grasselly y Crossa-Raynaud, 1984).

El almendro puede cultivarse entre $\operatorname{los} 30^{\circ}$ y $45^{\circ}$ de latitud, abarcando climas templados, cálidos y subtropicales, con temperaturas medias anuales entre 8 y $15{ }^{\circ} \mathrm{C}$ y mínimos riesgos de heladas (López Ritas, 1972). Su adaptación a la sequía le permite sobrevivir en climas semiáridos donde las lluvias no superan los $150 \mathrm{~mm}$ anuales. Bajo estas condiciones y sin el complemento necesario de agua de riego no suele alcanzar producciones medianamente rentables (El-Sharkawi y El-Monayeri, 1976). Altitudes entre 200 y $400 \mathrm{~m}$ son las idóneas para obtener una buena respuesta del cultivo (Felipe, 1999).

El almendro posee una gran capacidad de adaptación edáfica, llegando a crecer en suelos pobres, secos y sin materia orgánica; siempre y cuando sean profundos y permeables (Felipe, 1999), e incluso con un elevado contenido de caliza (Rebour, 1971). El almendro es una especie xerofítica y rústica, adaptada a ecosistemas de reducido valor agrícola. Aunque se han observado diferencias de comportamiento entre variedades y patrones respecto a sequía e iluminación, éste es un cultivo típicamente mediterráneo, y por tanto, condicionado por este tipo de clima (Martin y Kester, 1978; Grasselly y Crossa-Raynaud, 1984).

\section{Aspectos socio-económicos}

El almendro es el cultivo leñoso más extendido en nuestro país después del olivo y la viña. La superficie cultivada en España es de 641600 ha, encontrándose tan sólo el $6 \%$ en regadío (M.A.P.A., 2004), de ahí que sea considerado como uno de los cultivos más representativos de los sistemas leñosos de secano. La producción de almendra cáscara en 2003 fue de 214500 t (MAPA., 2004) lo que nos sitúa como segundo productor mundial $(12.5 \%$ ) después de Estados Unidos (45\%). Sin embargo, España triplica a Estados Unidos en superficie dedicada. Este hecho se debe al carácter marginal del cultivo en España: baja intensificación y tecnificación, escasa 
fertilidad de gran parte de los suelos, deficiente polinización, daños por heladas de primavera, etc.

El mercado de la Unión Europea es deficitario en almendra (Vargas, 1990), con un balance de mercancías netamente importador $(>105000 \mathrm{t}$ almendra grano año ${ }^{-1}$ ) y con tendencia creciente en los últimos años. El nivel de autoabastecimiento comunitario varía, entre el 50 y el $60 \%$ según los años. El resto es suministrado casi en su totalidad por Estados Unidos ( $>95 \%$ \%). De ahí la necesidad de incrementar nuestras producciones para reducir la dependencia externa.

Además, es importante destacar el papel ecológico que desempeña esta especie en la conservación del medio, protegiendo al suelo de la erosión; y como no, el papel jugado en el asentamiento de la población rural. Por todo ello, existe una clara necesidad de incidir en actuaciones tendentes a su modernización, tales como: reducción del número de variedades, aumento de las densidades de plantación, aplicación del laboreo mínimo, mecanización de la recolección, transformación de secano a riego localizado, aplicación de técnicas racionales de fertirrigación y de protección del cultivo, utilización de patrones clonales híbridos (melocotonero x almendro), etc.

\subsection{Estrategias de riego para optimizar el uso del agua}

El desequilibrio entre una demanda hídrica en aumento y una oferta de recursos hídricos estable o en declive expresa el gran problema de la agricultura de regadío (Martín de Santa Olalla y De Juan Valero, 1993). Ante las limitaciones actuales para emprender acciones dirigidas al incremento lineal de los recursos, adquieren prioridad las orientadas al aumento de la eficiencia y del ahorro.

Dentro de esta línea de actuación se encuentra el denominado riego deficitario controlado (RDC). Éste se basa en reducir los aportes hídricos en aquellos períodos fenológicos considerados no críticos para la producción y calidad de la cosecha y cubrir plenamente la demanda de la planta durante el resto del ciclo del cultivo (Torrecillas et al., 1996).

Para la elaboración de estrategias de RDC debe atenderse a la consideración de aquellos factores que puedan condicionar de forma importante su viabilidad. Entre otros, adquiere una especial importancia el conocimiento de los períodos críticos del cultivo, el nivel de coincidencia entre el crecimiento vegetativo y el del fruto, las características del suelo, el sistema de riego, el clima, el material vegetal, los mecanismos de resistencia a la sequía, etc. (Domingo, 1994; Torrecillas et al., 1996).

La separación natural de los períodos durante los cuales los tejidos y los órganos de los frutales crecen activamente da la posibilidad de inhibir un 
órgano o proceso, sin afectar seriamente a otros. En términos de demanda de fotoasimilados, existe una clara separación entre los períodos de activo crecimiento vegetativo y del fruto en numerosos cultivos arbóreos. Esto favorece la aplicación de estrategias de RDC, ya que permite controlar el crecimiento vegetativo sin reducir el tamaño del fruto (Chalmers et al., 1981; Goldhamer y Shackel, 1989; Domingo, 1994; Torrecillas et al., 1996). Además, algunos frutos al recuperarse de un déficit hídrico temporal experimentan un crecimiento compensatorio que les permite alcanzar un tamaño similar al de los frutos que no han sufrido déficit (Chalmers et al., 1986).

De hecho el RDC surge de los experimentos realizados por el equipo del Profesor David J. Chalmers en Australia (1973-1978), sobre la fisiología de melocotoneros con relación al riego y al estrés hídrico. En dichos trabajos identificaron un período del crecimiento del fruto del melocotón (período de crecimiento lento que coincide con el endurecimiento del hueso), en el que dicho crecimiento es bastante independiente del potencial fotosintético del árbol y además poco sensible al déficit hídrico. Sin embargo, el crecimiento de los brotes vegetativos resultó ser muy sensible a la falta de agua durante todo el período de crecimiento del fruto (Chalmers et al., 1981; Mitchell y Chalmers, 1982; Chalmers et al., 1986; Mitchell et al., 1989).

Otra estrategia de riego cuyo uso se ha extendido en los últimos años es el riego por desecación parcial del sistema radicular (PRD, Dry et al., 1996). Con esta técnica, una mitad del sistema radicular se deja en proceso de desecación mediante la alternancia del riego entre ambas mitades del sistema radicular cada cierto período de tiempo. En muchas especies, se ha comprobado que cuando una parte del sistema radicular se expone a desecación se pone en marcha un mecanismo de señales químicas raíz-brote (Dodd, 2005) que es capaz de inducir un cierre parcial estomático. Éste reducirá las pérdidas de agua por transpiración con mínimo impacto sobre la fotosíntesis, aumentando de este modo la eficiencia de uso del agua (Dry et al., 1996; Dry et al., 2000; Loveys et al., 2004). Son numerosas las evidencias que sugieren la implicación de la hormona vegetal ácido abscísico (ABA) en el control de la conductancia estomática cuando el suelo se seca (Davies y Zhang, 1991; Dodd, 2005). Al mismo tiempo, la parte del sistema radicular adecuadamente regada se encarga de mantener un estado hídrico favorable en la parte aérea de la planta (Dry y Loveys, 1999). Otro efecto observado con la aplicación del PRD es la limitación del crecimiento vegetativo (Dry y Loveys, 1999), tal y como observaron Gowing et al. (1990) en plántulas de manzano.

Ahora bien, el éxito de ambas estrategias es muy dependiente de la aplicación correcta del déficit hídrico, exigiendo un control continuado del estado hídrico de la planta o suelo para ajustar en todo momento los aportes de agua, o en su caso, de la alternancia de éstos. Para ello, es fundamental 
apoyarse en indicadores de estrés hídrico robustos y sensibles a los cambios del estado hídrico de la planta o/y del suelo (Domingo et al., 2005).

\section{E1 riego deficitario controlado en frutales}

Resulta difícil señalar con precisión los períodos críticos de cada cultivo. Algunos autores indican como períodos de máxima sensibilidad al déficit hídrico las fases de crecimiento del fruto. Así, en melocotonero el déficit hídrico durante la segunda fase de rápido crecimiento del fruto (Fase III) es más trascendente que en otras (Mitchell y Chalmers, 1982; Cohen et al., 2001; Goldhamer et al., 2002). Sin embargo, Lampinen et al. (1995) y posteriormente Intrigliolo y Castel (2005a) señalan que en ciruelo los efectos de la supresión del riego son más dependientes de la duración y del nivel de coincidencia con períodos de alta demanda evaporativa, que del momento en el que ocurre. Estos autores encontraron una alta sensibilidad a la supresión del riego durante el período de endurecimiento del hueso, contrariamente a lo observado en melocotonero.

Según Torrecillas et al. (2000) el período más crítico al déficit hídrico del albaricoquero es la segunda fase de rápido crecimiento del fruto (fase III). Otro período sensible es el de postcosecha inicial (Ruiz-Sánchez et al., 1999), período en el que se registran altos consumos de agua. La supresión del riego durante este período afecta a la diferenciación floral, lo que provoca un desarrollo tardío de las yemas florales (Brown, 1953), disminución del número y alteración de las mismas, además de largos tallos con hojas pequeñas.

En cítricos, dos son los períodos críticos señalados: uno que abarca desde la floración hasta el cuajado, donde el déficit hídrico condiciona el número de frutos, y otro que corresponde a la fase de rápido crecimiento del fruto y que determina el tamaño final de los mismos (Domingo et al., 1996; Ruiz-Sánchez et al., 1997).

En ensayos realizados en manzano (Naor et al., 1995; Naor et al., 1997; Mpelasoka et al., 2001), el déficit hídrico impuesto durante las fases I y II de crecimiento del fruto redujo el crecimiento vegetativo sin afectar al tamaño de los frutos ni al rendimiento. Igualmente Kilili et al. (1996), a partir de distintos tratamientos de supresión del riego en manzano, observaron que los efectos del estrés hídrico no afectaron a la calidad del fruto y que incluso ésta fue superior a la del control, no viéndose mermados los rendimientos de manera significativa, en ningún caso.

Girona (1992) indica que en el almendro el estrés hídrico después de la cosecha tiene un efecto drástico sobre la producción del año siguiente, ya que reduce el número de frutos por árbol, y que la fase de acumulación rápida en materia seca del grano (fase IV) es muy poco sensible al déficit hídrico. Según 
Marsal et al. (1997), la alta sensibilidad al déficit hídrico del avellano, reflejada tanto en su producción total como en la calidad, aconseja satisfacer sus requerimientos hídricos totales.

Distintos grupos de investigación han llevado a cabo trabajos de riego deficitario en almendro. En ellos se observan diferentes respuestas productivas frente al déficit hídrico en función del momento en que éste se aplica (León et al., 1985; Girona, 1992; Hutmacher et al., 1994; Girona y Marsal, 1995; Torrecillas et al., 1996; Germana, 1997; Girona et al., 1997; Marsal et al., 1997; Shackel et al., 1997; Shackel et al., 1998; Esparza et al., 2001b; Klein et al., 2001; Nanos et al., 2002; Romero et al., 2004b; Girona et al., 2005; Goldhamer et al., 2006).

Entre los ensayos más relevantes de RDC en almendros se encuentran los realizados con la variedad 'Marcona', en Tarragona (Girona y Marsal, 1995) y en Murcia con la variedad 'Cartagenera' (Romero et al., 2004a; 2004b). Ambos equipos, aplicaron una estrategia de RDC consistente en aplicar el $20 \%$ de la ETc durante la fase IV y el $100 \%$ de la ETc en el resto del año. Los resultados obtenidos pusieron de manifiesto una buena adaptación del almendro a la estrategia de RDC planteada, a pesar de la ligera disminución de la producción media del tratamiento de RDC con respecto al control, debido al descenso del peso del grano. El ahorro de agua conseguido fue superior al $60 \%$, y la eficiencia de uso del agua (EUA), expresada en $\mathrm{kg}$ de almendra $\mathrm{m}^{-3}$ de agua, fue superior en el tratamiento de RDC.

En el Valle de San Joaquín (California), Goldhamer y Shackel (1989) observaron una respuesta productiva similar a la del experimento anterior. En este caso, la estrategia de RDC consistió en regar al $80 \%$ de la ETc hasta completar el tamaño exterior del fruto, seguido de un $60 \%$ hasta completar el tamaño de la pepita, para continuar durante la fase de aumento de peso seco de la pepita con un $40 \%$ hasta finales de junio y un $60 \%$ hasta la recolección. El ahorro de agua se cifró en el $58 \%$, obteniéndose producciones similares a las del tratamiento control. Las diferencias entre ambas estrategias de RDC se basan en que las variedades americanas son de cáscara blanda y conviene regar a mayores dosis en el período comprendido entre el inicio de acumulación rápida de materia seca del grano y la recolección, con el fin de evitar la formación de 'pelonas', almendras a las que se les queda adherida la pelarza, dificultando el descascarado y disminuyendo drásticamente su precio de mercado.

\subsection{Programación del riego}

El término de programación del riego es generalmente usado para describir el procedimiento mediante el cual se determina la frecuencia y dosis 
de agua a aplicar en cada riego (Hillel, 1990). La determinación del momento y volumen de agua a aplicar en cada riego es un proceso de toma de decisiones a corto plazo, de tipo 'control operacional'. Habitualmente se ha basado en la experiencia previa y no en procedimientos científico-técnicos. Sin embargo, en la medida en que la conservación del agua de riego pasa a ser un objetivo relevante en el manejo de una explotación de regadío, se hace cada vez más patente la necesidad de disponer de una información precisa que permita programar los riegos de forma eficiente (Fereres y Goldhamer, 2000).

Existen numerosos métodos de programación de riegos pero todos ellos se han agrupado tradicionalmente en tres enfoques basados en:

1. Datos climáticos. Estimaciones de la demanda climática y de las necesidades hídricas de los cultivos (fórmulas empíricas, modelos de evapotranspiración, etc.) y establecimiento del balance hídrico del suelo.

2. Estado hídrico del suelo. Medidas de las características del estado hídrico del suelo (contenido de humedad, potencial hídrico, balance hídrico, etc.).

3. Estado hídrico del cultivo. Medidas del estado fisiológico del cultivo, como temperatura de hoja, variaciones de diámetro, potencial hídrico foliar (hoja cubierta y sin cubrir), flujo de savia, etc.

\subsubsection{Cálculo de las necesidades hídricas del cultivo}

\subsubsection{Métodos climáticos}

Estos métodos estiman las necesidades hídricas máximas del cultivo y se basan en el cálculo de la evapotranspiración de referencia (ETo) y en la utilización de coeficientes de cultivo.

La FAO (Food and Agriculture Organization) definió la ETo como el consumo de agua de una superficie extensa de gramíneas, uniforme, de 8 a 15 $\mathrm{cm}$ de altura, en crecimiento activo, que sombrea la totalidad del suelo y bien provista de agua (Doorenbos y Pruitt, 1977). Posteriormente y debido a la gran variedad de gramíneas y prácticas de cultivo, la FAO propuso cambiar el concepto de cultivo de referencia y revisar los métodos de cálculo. De este modo quedaba definida la ETo como la tasa de evapotranspiración de un cultivo hipotético de altura fija de $12 \mathrm{~cm}$, resistencia de la cubierta vegetal de $70 \mathrm{~s} \mathrm{~m}^{-1}$ y albedo de 0.23 (Smith et al., 1990). Estas características se aproximan a las de superficie extensa de gramíneas. Actualmente, el método más completo, aceptado y recomendado para la determinación de la ETo es el de Penman-Moteith- FAO (Allen et al., 1998), cuya fórmula es: 


$$
\operatorname{ETo}\left(\mathrm{mm} \mathrm{día}{ }^{-1}\right)=\frac{0.408 \Delta\left(\mathrm{R}_{\mathrm{n}}-\mathrm{G}\right)+\gamma \frac{900}{\mathrm{~T}+273} \mathrm{u}_{2}\left(\mathrm{e}_{\mathrm{s}}-\mathrm{e}_{\mathrm{a}}\right)}{\Delta+\gamma\left(1+0.34 \mathrm{u}_{2}\right)}
$$

siendo: $R_{n}$, radiación neta en la superficie del cultivo $\left(M J m^{-2}\right.$ día $\left.^{-1}\right) ; G$,

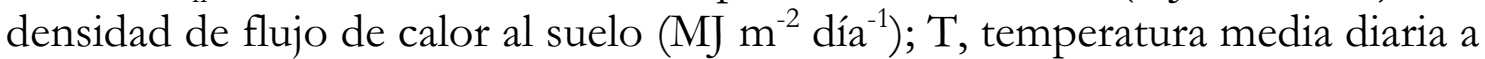
2 metros de altura $\left({ }^{\circ} \mathrm{C}\right) ; \mathrm{u}_{2}$, velocidad del viento a $2 \mathrm{~m}$ de altura $\left(\mathrm{m} \mathrm{s}^{-1}\right) ; \mathrm{e}_{\mathrm{s}}$, presión de vapor a saturación $(\mathrm{kPa})$; $\mathrm{e}_{a}$, presión de vapor actual $(\mathrm{kPa}) ; \Delta$, pendiente de la curva de presión de vapor $\left(\mathrm{kPa}^{\circ} \mathrm{C}^{-1}\right) ; \gamma$, constante psicrométrica $\left(\mathrm{kPa}^{\circ} \mathrm{C}^{-1}\right)$.

Otros métodos de medida directa de la evapotranspiración de los cultivos son:

Modelo de renovación de volúmenes de aire (Snyder y Spano, 1994). La radiación neta puede considerarse como el factor más importante que controla la ET cuando el agua no es un factor limitante (Faci, 1996). El Modelo de renovación de volúmenes de aire calcula el flujo de calor sensible $(\mathrm{H})$ que, junto con la medida de la radiación neta $\left(\mathrm{R}_{\mathrm{n}}\right)$ y el flujo de calor que va al suelo $(G)$, permite obtener una estima de la evapotranspiración. H se obtiene a partir de la medida de la temperatura del aire por encima de la cubierta vegetal en intervalos muy cortos.

Modelo del balance de energía y de la relación de Bowen (Hatfield, 1990). Este método se basa en el balance de energía en la superficie vegetal. En este caso, el reparto de $R_{n}$ entre las componente de calor sensible $(H)$ y el flujo de calor latente $(\lambda \mathrm{E})$ vendrá dado por el gradiente de temperatura y el gradiente de presión de vapor entre la cubierta vegetal y el aire. De este modo, la tasa de evapotranspiración puede ser determinada a partir de los gradientes verticales de temperatura del aire y vapor de agua mediante la relación de Bowen.

Covarianza de torbellinos (eddy covariance). Este método se basa en la medida de los flujos turbulentos de agua transportados verticalmente por porciones de aire, y permite conocer el flujo de calor sensible y de calor latente. La velocidad vertical de viento $\left(\mathrm{u}_{\mathrm{v}}, \mathrm{m} \mathrm{s}^{-1}\right)$ se obtiene con un anemómetro sónico tridimensional y la densidad de vapor de agua $\left(\varrho_{\mathrm{v}}\right)$ se mide con un higrómetro de respuesta rápida. La altura de ubicación de los sensores y la distancia entre ellos influye en la estimación de los flujos de calor sensible y calor latente (Villalobos, 1997).

La precisión con la que se obtiene ET a partir de los diferentes modelos, está estrechamente condicionada por la precisión, resolución y prestaciones de los sensores de temperatura, de humedad y de radiación, y del rigor en el cálculo del flujo de calor. 
Los modelos micrometeorológicos están desarrollados para cultivos de cobertura total, lo que implica que para algunos cultivos como los frutales, presenten problemas de falta de representatividad, discontinuidades de cobertura con gradientes preferenciales suelo-planta-atmósfera y aspectos de rugosidad en la superficie, que conducen a heterogeneidades microclimáticas. Los árboles y el suelo pierden agua de forma diferente al incidir en ellos la radiación, ya que existen diferencias entre las zonas de evaporación y las superficies de intercambio de calor sensible (Valancogne y Nasr, 1989). Todo esto obliga a la aplicación de coeficientes de ajuste para las diferentes especies vegetales, según el tipo de suelo y el volumen de cubierta, principalmente. Estos factores pueden integrarse en un único coeficiente de cultivo (Kc) determinado experimentalmente para cada tipo de plantación. Este coeficiente multiplica a ETo para obtener la evapotranspiración máxima en condiciones estándar del cultivo (ETc).

En general se puede concluir que son métodos muy generalistas, que bien por exceso o defecto pueden alejarse sustancialmente de las necesidades hídricas reales de los cultivos y que, por ello, necesitan de una calibración local. Cabe señalar, que no siempre es fácil separar la evaporación de la transpiración y que el margen de error en el cálculo de las necesidades de riego por métodos microclimáticos puede ser alto.

\section{Balance de agua en el suelo}

El balance de agua en el suelo ha sido uno de los métodos más utilizados para determinar las necesidades hídricas de los cultivos arbóreos. Se trata de cuantificar las cantidades de agua que entran, salen o permanecen en un volumen de suelo durante un tiempo determinado (Domingo, 1994).

El balance de agua se puede representar mediante la siguiente ecuación:

$$
P+R=E T c+D \pm \Delta \theta \pm E
$$

donde: $\mathrm{P}$ es la lluvia, $\mathrm{R}$ el riego, ETc la evapotranspiración del cultivo (a despejar), $\Delta \theta$ la variación de la humedad del suelo en la zona radicular durante el período de medida, D el drenaje neto (percolación profunda menos el ascenso capilar) y E el aporte o pérdida de agua por escorrentía superficial. Todos estos parámetros se expresan en unidades de altura de agua ( $\mathrm{mm})$.

En ausencia de escorrentía superficial (E) y de aportes laterales de humedad, la ETc puede ser calculada como:

$$
E T c=P+R-D \pm \Delta \theta
$$


de modo que si:

$$
\begin{gathered}
\theta_{\mathrm{F}}>\theta_{\mathrm{I}} \Rightarrow+\Delta \theta \\
\theta_{\mathrm{F}}<\theta_{\mathrm{I}} \Rightarrow-\Delta \theta
\end{gathered}
$$

siendo: $\theta_{\mathrm{F}}$ y $\theta_{\mathrm{I}}$ los contenidos volumétricos de agua en el suelo al final e inicio del período de medida.

En los períodos sin riego o lluvia la ecuación del balance se simplificaría a:

$$
-\Delta \theta=\mathrm{ETc}+\mathrm{D}
$$

A pesar de su sencillez existe dificultad en separar la parte del cambio de humedad atribuible a ETc del debido a D. Este problema se puede resolver mediante cálculos del plano de flujo nulo (Daudet y Vachaud, 1977).

Cuando se utilizan sistemas de riego localizado las dificultades aumentan, siendo necesario realizar pruebas para la ponderación de las zonas afectadas y no afectadas por los aportes localizados de agua durante el período de riego (Figura 2.1), así como la realización de un estudio detallado de las características hidrodinámicas del suelo, en especial de la relación entre la conductividad hidráulica y el contenido de humedad del suelo. Una vez establecidas las relaciones funcionales entre conductividad hidráulica y contenido de humedad del suelo, definida la ponderación de áreas en función de los aportes de agua, determinada la profundidad del sistema radical y el gradiente hidráulico, las diferencias de contenido volumétrico pueden ser utilizadas para calcular el flujo de agua a través del perfil y de este modo cuantificar el drenaje durante el ciclo de cultivo.

\section{Lisimetría de pesada}

Los lisímetros de pesada constituyen el método más preciso y directo de medida del consumo de agua de las plantas. Éstos permiten determinar la evapotranspiración real del cultivo a intervalos de tiempo cortos, durante períodos diarios, de horas, e incluso inferiores. Además, bajo condiciones no limitantes de suministro hídrico, permiten la determinación de los coeficientes de cultivo, a partir de la relación:

$$
\mathrm{Kc}=\frac{\mathrm{ETc}}{\mathrm{ETo}}
$$


Para ello, es fundamental que tanto el árbol cultivado en él como los circundantes sean representativos de la explotación frutal. Éste suele ser el problema principal con el que se encuentran los lisímetros de pesada, pero no el único. Allen y Fisher (1990) indicaban nueve recomendaciones para preservar el buen funcionamiento de este tipo de instalaciones.
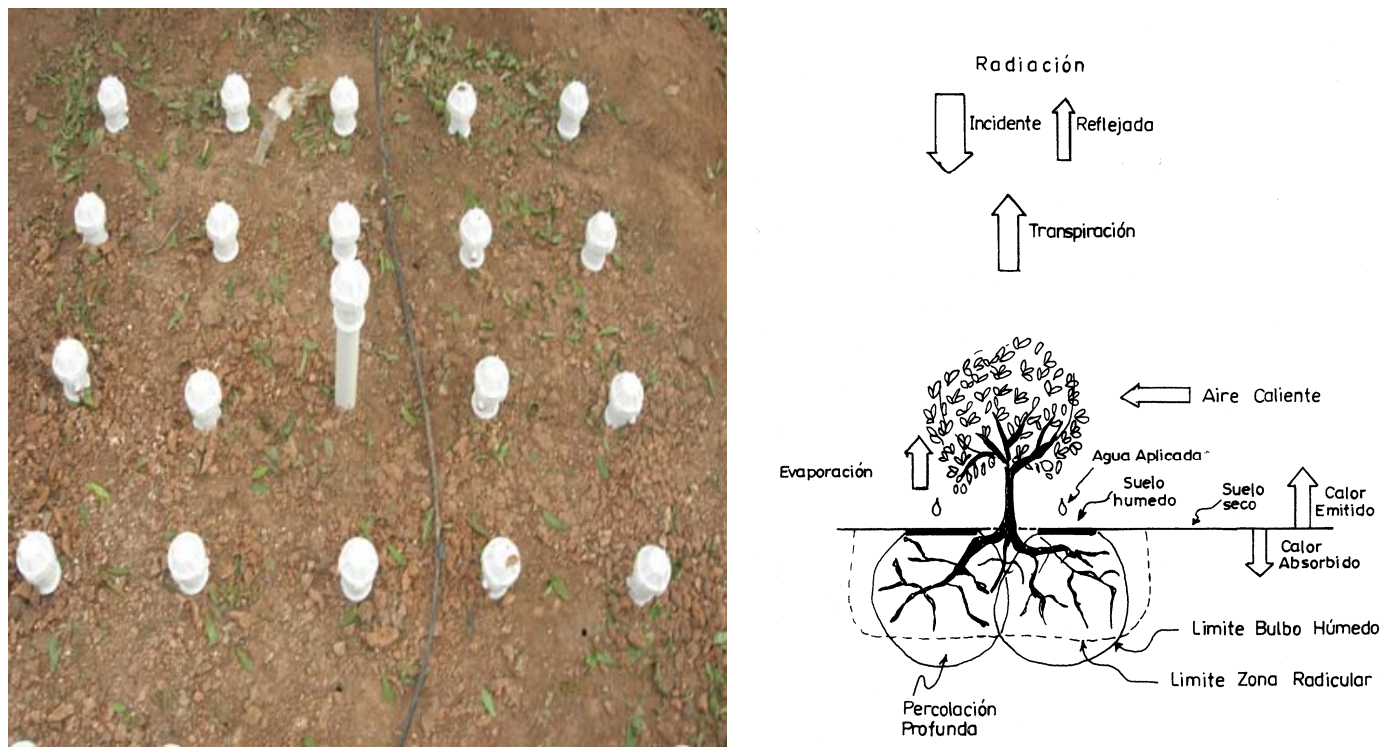

Figura 2.1. Disposición de tubos de acceso para realización de balance hídrico (izquierda) y componentes del balance hídrico y de energía en riego localizado (adaptado de Fereres et al., 1981b) (derecha).

\subsubsection{Métodos basados en el estado hídrico del suelo}

Estos métodos engloban tanto las técnicas de medida del contenido de humedad como del estado energético del agua en el suelo (potencial total o alguna de sus componentes). Las medidas pueden ser discretas o estar automatizadas proporcionando valores continuos y en tiempo real.

\section{Medida del agua en el Suelo}

\section{Muestreo del suelo. Método gravimétrico y volumétrico}

Es un método directo de medida del agua en el suelo y suele ser utilizado para calibrar otros métodos de medida, tales como: sonda de neutrones, equipos basados en sensores dieléctricos, bloques de resistencia eléctrica, etc. El contenido de humedad de la muestra puede ser expresado en forma gravimétrica o volumétrica y ambas formas están relacionadas a través de la densidad aparente del suelo.

El contenido gravimétrico de humedad $\left(\theta_{g}\right)$ viene dado por: 


$$
\theta_{\mathrm{g}}=\frac{\text { Masa de agua }}{\text { Masa de suelo }}=\frac{\mathrm{P}_{\mathrm{f}}-\mathrm{P}_{\mathrm{s}}}{\mathrm{P}_{\mathrm{s}}}
$$

donde $\mathrm{P}_{\mathrm{f}} \mathrm{y} \mathrm{P}_{\mathrm{s}}$ son la masa de la muestra de suelo húmedo y de suelo seco, respectivamente.

La expresión correspondiente al contenido volumétrico de humedad, $\theta_{\mathrm{v}}$, viene dada por:

$$
\theta_{\mathrm{v}}=\frac{\text { Volumen de agua }}{\text { Volumen de suelo }}=\frac{(\mathrm{Mh}-\mathrm{Ms}) / \mathrm{dH}_{2} \mathrm{O}}{\mathrm{Va}}
$$

donde: $\mathrm{Va}$ es el volumen aparente de la muestra. Las unidades vendrán expresadas en $\mathrm{cm}^{3} / \mathrm{cm}^{3}$ (adimensional). Sin embargo, en este caso, es más práctico expresar el contenido de agua del suelo como $\mathrm{mm}$ de lámina de agua por $m$ de profundidad de suelo.

Los dos métodos son sencillos, baratos y muy exactos, en lo que respecta a la muestra reunida. Sin embargo, se les puede achacar algunos inconvenientes, tales como: i) carácter destructivo, en el sentido de que es necesario retirar la muestra del campo, lo que no permite tomar otra medida en el mismo punto, ii) alta demanda de mano de obra, iii) necesidad de tomar un número elevado de muestras, como consecuencia de la gran variabilidad espacial del contenido de agua en el suelo, iv) dificultad para la toma de muestras en suelos pedregosos, v) posibilidad de cometer errores en suelos con alto contenido en materia orgánica, bien por oxidación y/o combustión, en estos casos se recomienda el secado de la muestra a $50-70{ }^{\circ} \mathrm{C}$, vi) pérdida de humedad de las muestras antes de su secado y vii) necesitan como mínimo 24 horas para el secado de la muestra.

\section{Sonda de neutrones}

Es un instrumento que proporciona una metodología indirecta para medir el contenido volumétrico de agua del suelo. Los dos propósitos principales de su uso son: i) medir el contenido de agua del suelo y relacionarlo con otras propiedades físicas del suelo (conductividad hidráulica, tensión del agua del suelo, etc.), y ii) medir cambios del contenido de agua en el suelo. Este segundo uso es más frecuente en estudios de riego y evapotranspiración.

El fundamento de medida consiste en la emisión, por parte de una fuente radioactiva (Americio 241-Berilio), de un haz de neutrones con alta energía cinética (neutrones rápidos), que se propaga a través del suelo (Daudet 
y Vachaud, 1977; Evett y Steiner, 1995). La energía de estos neutrones se pierde rápidamente si colisionan con los átomos de hidrógeno, al ser de similar tamaño y masa. El detector de neutrones lentos registrará, por lo tanto, mayor número de neutrones ralentizados, cuantos más átomos de hidrógeno haya en el medio. En el suelo la principal fuente de átomos de hidrógeno es el agua.

El radio de influencia de la sonda de neutrones es inversamente proporcional al contenido de agua en el suelo. Así, en un suelo de textura media, el radio puede variar de 25 a $30 \mathrm{~cm}$ para contenidos de humedad próximos al punto de marchitez y hasta unos 10 a $20 \mathrm{~cm}$ en saturación. No miden bien en superficie, existiendo peligro de emisión de neutrones al exterior. La precisión de este método depende en gran medida de una correcta calibración de la sonda. Existe una relación lineal entre el cociente de cuentas (cociente entre la lectura que da el apartado al hacer una medida y la lectura estándar) y la humedad volumétrica del suelo.

Los principales inconvenientes de la sonda de neutrones son: técnica cara, no automatizable y necesidad de una curva de calibración para cada tipo de suelo como la descrita en Gardner (1986). Además, si se requieren mediciones en puntos cercanos a la superficie debe procederse a una calibración especial. Sin embargo, presenta claras ventajas respecto a los métodos anteriores, como son: la rapidez en la toma de medidas, medidas en el mismo sitio, volumen de muestreo considerable y medidas no afectadas por la salinidad del suelo.

\section{Reflectometría de dominio del tiempo, TDR}

Esta técnica se basa en la medida del tiempo de propagación de un pulso electromagnético a lo largo de una línea de transmisión (sonda) insertada en el suelo. La velocidad de propagación del pulso depende de la constante dieléctrica del medio $\left(\mathrm{k}_{\mathrm{a}}\right)$, al tiempo que la forma del pulso y el tiempo en que se transmite dependen de las propiedades de los electrodos, de su longitud y de su terminación. Topp et al. (1980) obtuvieron una ecuación empírica que relaciona el contenido volumétrico de humedad $\left(\theta_{\mathrm{V}}\right)$ con la constante dieléctrica del suelo $\left(\mathrm{k}_{\mathrm{a}}\right)$.

$$
\theta_{\mathrm{V}}=-5.3 \cdot 10^{-2}+2.29 \cdot 10^{-2} \mathrm{k}_{\mathrm{a}}-5.5 \cdot 10^{-4} \mathrm{k}_{\mathrm{a}}{ }^{2}+4.3 \cdot 10^{-6} \mathrm{k}_{\mathrm{a}}^{3}
$$

La sonda, en general, se presenta bajo la forma de varillas paralelas (dos o tres) si bien puede encontrarse con otros perfiles. La medida integra la constante dieléctrica entre los dos electrodos a lo largo de toda la sonda, la cual, para ser suficientemente precisa, deberá tener una longitud mínima de 10 
cm (Chanzy et al., 1997). La cantidad de agua presente en el medio influye en la constante dieléctrica de éste, pudiendo determinarse así el contenido volumétrico de agua $(\theta \mathrm{v})$. La relación entre $\theta \mathrm{v}$ y $\mathrm{k}_{\mathrm{a}}$ es poco dependiente de la textura del suelo, densidad, salinidad y temperatura, permitiendo aplicar la técnica a un amplio rango de suelos (Parchomchuck et al., 1997).

El TDR depende de las discontinuidades en los mecanismos de almacenamiento de energía del medio. La presencia de agua en el suelo afecta a la velocidad de propagación de la onda electromagnética disminuyéndola ligeramente.

Existen diversos sensores comerciales que miden el contenido volumétrico de agua en el suelo o sustrato basados en esta técnica. El TDR está formado principalmente por un osciloscopio y un generador de señal que es el que da el pulso eléctrico. Su rango de medida oscila de 0.065 a 0.5 $\mathrm{cm}^{3} \mathrm{~cm}^{-3}$. La ventaja de estos sensores es que son estables y las medidas son repetitivas en el tiempo, además de precisas. Pueden tomarse lecturas en continuo y puntuales y, dentro de unos límites, no se ven afectadas por la salinidad. Se trata de una medida integradora de la humedad de toda la longitud de la sonda y, en principio, para las principales clases de suelo no se requiere una calibración, aunque en el caso de ciertos sustratos, de suelos arcillosos o con elevado contenido de materia orgánica, puede ser necesaria.

Como desventajas principales pueden citarse su complicada electrónica y el tratarse de un equipamiento relativamente caro, si bien las sondas pueden ser fabricadas por el propio usuario (Parchomchuck et al., 1997). Al tratarse de medidas puntuales, con una esfera de influencia mínima, debe considerarse la representatividad de la ubicación de la sonda así como el número de medidas para minimizar la variabilidad espacial. No siempre es fácil la inserción de las sondas en el terreno, al tiempo que es de vital importancia asegurar el contacto entre las sondas y el suelo evitando la formación de cámaras de aire que distorsionarían la medida. Estas cámaras también pueden formarse por la contracción del suelo al secarse. Además, en ciertos suelos con elevados niveles de salinidad, puede perderse la señal reflejada al final de los extremos de la sonda.

La medida de la humedad volumétrica mediante TDR ha sido utilizada en experimentos con objetivos diversos. Pittinelli et al. (1998) demostraron que la técnica es apropiada para estimar el contenido hídrico del suelo a diferentes profundidades; Mastrorilli et al. (1998) indicaron su utilidad para estimar la ET diaria en suelos sin cavidades verticales bajo condiciones de clima mediterráneos. Parchomchuk et al. (1997) programaron el riego de una plantación de manzanos jóvenes a partir de las medidas de contenido de humedad obtenidas con TDR, si bien para ello requirieron de 64 sondas. 


\section{Reflectometría de dominio de frecuencias, FDR}

Son los denominados sensores capacitativos basados, al igual que el TDR, en las diferentes propiedades dieléctricas del aire, del suelo y del agua, y que han venido desarrollándose en las últimas tres décadas. Estos sensores utilizan un oscilador para crear un campo eléctrico y detectar los cambios en las propiedades dieléctricas del mismo en relación con su contenido en agua. El sensor mide la frecuencia de resonancia correspondiente a la capacidad del condensador, formado por un par de electrodos dispuestos en paralelo y que se relaciona con la permitividad dieléctrica relativa del suelo (Gaudu et al., 1993). El método capacitativo puede operar a frecuencia única o en una estrecha banda de frecuencias (Gardner, 1986; Shinn et al., 1998). Los cambios de contenido de agua son detectados como cambios en la frecuencia operacional, disminuyendo ésta al incrementarse la humedad. Para el cálculo de la humedad volumétrica $\left(\theta_{\mathrm{v}}\right)$ se requiere una calibración para los diferentes tipos de suelos y sustratos. Dentro del rango natural de variación de humedad en condiciones de campo, las curvas de calibrado pueden aproximarse a relaciones lineales (Gardner et al., 1998).

La longitud de los electrodos es sensiblemente menor que en el caso del TDR, pudiendo llegar a ser menor de $2 \mathrm{~cm}$ (Hilhorst y Dirksen, 1994). Los sensores capacitativos permiten una mayor flexibilidad de diseño de la geometría del electrodo y de la frecuencia operacional que el TDR, manteniendo una precisión del mismo orden que éste (Hilhorst y Dirksen, 1994). Son sensores más robustos y de más bajo coste que el TDR (Hilhorst y Dirksen, 1994). La conversión analógica de la señal no precisa de un equipo específico para el registro de los datos, por lo que esta técnica se presta fácilmente a la automatización a partir del uso de dataloggers (Gaudu et al., 1993; Chanzy et al., 1997). La mayoría operan a bajas frecuencias (100 MHz o menos) y pueden detectar el agua ligada a partículas finas del suelo. Este tipo de agua fuertemente retenida por las partículas puede llegar a constituir más del $10 \%$ de la humedad del suelo.

Entre los inconvenientes que presentan los sensores FDR pueden citarse: i) están muy influenciados por la humedad de los espacios intersticiales en el volumen de suelo cercano al sensor, y por tanto por los procesos de contracción y expansión en el punto de contacto con el sensor (Gardner et al., 1998), debiendo procurarse un buen contacto con el suelo, ii) sensores con bajas frecuencias operacionales $(<50 \mathrm{MHz})$ por lo que pueden estar más influenciados por la salinidad (Gardner et al., 1998), aunque no siempre se ha observado este efecto (Gaudu et al., 1993). Hilhorst y Dirksen (1994) adoptan un sistema que, operando a $20 \mathrm{MHz}$, mide las componentes real e imaginaria de la permitividad dieléctrica, minimizando así la influencia de la conductividad. La temperatura influye en la permitividad relativa del agua 
(Evett y Steiner, 1995), si bien este efecto puede ser corregido por el propio dispositivo de medida (Gaudu et al., 1993), iii) menor cantidad de información referente al análisis de las curvas espectrales del FDR en comparación con el TDR.

\section{Potencial Hídrico del Suelo}

\section{Tensiómetros}

El tensiómetro fue uno de los primeros instrumentos desarrollados e implementados para la programación del riego (Fereres y Goldhamer, 2000), siendo utilizado por agricultores y técnicos, principalmente en riego localizado.

Los tensiómetros miden la succión o tensión del agua en el suelo. Ahora bien, la lectura obtenida en el vacuómetro corresponde al potencial hidráulico del agua en el suelo $\left(\Psi_{\mathrm{H}}\right)$, si se desprecia la altura del vacuómetro sobre el nivel del suelo. El potencial hidráulico viene dado por la expresión:

$$
\Psi_{\mathrm{H}}=\Psi_{\mathrm{m}}+\Psi_{\mathrm{g}}
$$

donde, $\Psi_{\mathrm{m}}$ y $\Psi_{\mathrm{g}}$ son las componentes matricial y gravitacional del potencial del agua en el suelo.

El fundamento del tensiómetro es que el agua dentro de la cápsula cerámica tiende a adquirir la misma tensión que el agua del suelo en contacto con ella. Esta tensión se transmite dentro del tensiómetro y es medida mediante el vacuómetro. De ahí la necesidad de que exista un buen contacto entre cápsula porosa y suelo.

El rango de medida es de 0 a $-80 \mathrm{kPa}$. Este rango limitado no constituye un obstáculo serio ya que más del $50 \%$ del agua disponible para las plantas está en este rango de tensión. En suelos arenosos esta fracción puede llegar hasta el $75 \%$ o más. Estos sensores presentan las ventajas de: bajo coste, medidas en el mismo sitio, sus lecturas no se ven afectadas por la presencia de sales y no necesitan curva de calibrado. Los inconvenientes principales son: pequeña zona de influencia del elemento sensor, vida limitada, muestra efectos de histéresis y necesidad de reponer el agua perdida.

El vacuómetro del tensiómetro puede sustituirse por un transductor de presión (electrotensiómetros) y de este modo permitir la automatización del riego. Assaf et al. (1989) obtuvieron buenos resultados en una plantación de manzanos adultos automatizada con electrotensiómetros. Sin embargo, otros estudios relativos al riego en frutales donde se compararon diferentes métodos de programación, obtuvieron mejores resultados en tratamientos de riego 
programados a partir de medidas directas en planta con dendrómetros en tronco y ramas, que los programados a partir de tensiómetros (Li et al., 1989a; Huguet et al., 1992; Besset et al., 2001).

\section{Bloques de resistencia eléctrica}

Son sensores formados por una matriz granular y miden indirectamente el potencial matricial del agua en el suelo a partir de su resistencia eléctrica. La matriz granular que va fijada a un soporte de metal o plástico lleva insertados dos electrodos (Eldredge et al., 1993). La resistencia eléctrica entre estos dos electrodos varía en función de la humedad del suelo.

El rango de lectura es superior al del tensiómetro $(10-200 \mathrm{kPa})$ y además, cubre las condiciones de humedad entre capacidad de campo y saturación, limitación presentada por los tradicionales bloques de yeso. Las lecturas pueden ser tomadas con un lector manual o bien de forma automática y continua mediante el uso de dataloggers (Phene et al., 1971; Campbell, 1988; Campbell et al., 2006). La información proporcionada puede servir para el control y revisión de dosis y frecuencias de riego establecidas por otros métodos (Eldredge et al., 1993), o bien, ser directamente responsables de la apertura y cierre de válvulas de acuerdo a valores consigna definidos en estudios previos (Cohen et al., 2001; Intrigliolo y Castel, 2004).

Las principales ventajas son: bajo coste, no requieren mantenimiento, medidas en el mismo sitio, miden tensiones mucho mayores que los tensiómetros, etc. Y como desventajas: lenta respuesta a los cambios de humedad del suelo, muestran fenómenos de histéresis, influencia de la temperatura, pueden requerir calibraciones puntales (Eldredge et al., 1993; Thompson et al., 2006), existe cierto riesgo de que con el tiempo el yeso se deshaga, pequeña zona de influencia del elemento sensor, etc.

\section{Psicrómetro}

$\mathrm{Su}$ funcionamiento se basa en el enfriamiento del aire sobre un termopar por debajo de su punto de condensación. Al calentarse nuevamente, el agua se evapora y el termopar se enfría por debajo de la temperatura del aire. De este modo, se obtiene la diferencia de temperatura entre el bulbo húmedo y el bulbo seco de la que se deriva el potencial hídrico (Campbell y Gardner, 1971; Gaudu et al., 1993; Chanzy et al., 1997). El vapor en el condensador se encuentra en equilibrio con el potencial de la muestra.

Este sistema mide el potencial total de la muestra en un amplio rango de medida que va desde -0.02 $\mathrm{MPa}$ a $-10 \mathrm{MPa}$. Estas lecturas pueden ser muy precisas, al tiempo que automatizadas. La calibración de estos sensores y su lectura es independiente del tipo de suelo y de su tamaño de partícula. Sin 
embargo se trata de un sistema de elevado coste, fuera del alcance no sólo del agricultor o técnico sino también para su uso en la agricultura experimental o de investigación (Itier, 1996). Uno de sus principales inconvenientes es que se ve ampliamente influenciado por los gradientes preferenciales de temperatura en el suelo. La salinidad también puede condicionar la validez de las medidas.

\subsubsection{Métodos basados en el estado hídrico de la planta}

\section{Potencial hídrico foliar y de tallo}

El potencial hídrico foliar $(\Psi)$ es, quizás, el parámetro más utilizado para definir el estado hídrico de las plantas (Klepper et al., 1971; Goode y Higgs, 1973) y determinar el momento de riego (Peretz et al., 1984). Es comúnmente utilizado como indicador del estado hídrico de los frutales, y resulta afectado tanto por factores de origen ambiental como de carácter endógeno (Jones, 1990). Esto provoca variaciones en sus niveles en base al momento del día (Elfving et al., 1972), estación de crecimiento (Winkel y Rambal, 1993), edad de las hojas (Knipling, 1967) y de la orientación y posición de las mismas en el árbol. Esta situación puede restringir su uso para indicar sólo la dirección del flujo del agua en el árbol, siendo cuestionado como indicador del estado hídrico (Garnier y Berger, 1985). No obstante, la medida de $\Psi$ es universalmente admitida, como la forma más rápida, fiable y económica de evaluar el estado hídrico de las plantas (Elfving et al., 1972; Garnier y Berger, 1985; Ameglio et al., 1998; McCutchan y Shackel, 1992; Lampinen et al., 2001; Girona et al., 2006).

La medida del potencial hídrico foliar antes del alba $\left(\Psi_{a}\right)$, proporciona información indirecta del nivel energético del agua en el suelo, así como del grado de estrés con el que la planta comienza el día (Aussenac y Valette, 1982). Esto se debe a que la transpiración es mínima durante la noche, por lo que la planta alcanzará, teóricamente, el equilibrio con el suelo en ese momento (Slatyer, 1967).

El instrumento utilizado para la medida de $\Psi$ en campo es la cámara de presión (Scholander et al., 1965). Según Hsiao (1990) la designación del $\Psi$ medido con la cámara de presión como $\Psi$ del xilema es erróneo, excepto en aquellos casos donde el equilibrio hídrico existía antes de la escisión; en este caso el $\Psi$ de la hoja es igual al $\Psi$ del xilema y la presión medida en la cámara (P) representa la tensión a la que se encontraba la savia en el xilema antes del corte. Como el potencial osmótico $\left(\Psi_{\mathrm{o}}\right)$ de la savia es muy pequeño generalmente se desprecia con lo que:

$$
\text { - P }=\Psi_{\text {xilema }}=\Psi_{\text {hoja }}(\text { sin transpiración })
$$


Fundamentalmente se han utilizado como indicadores del estado hídrico de la planta el potencial hídrico foliar a mediodía $\left(\Psi_{\mathrm{md}}\right)$, y el potencial hídrico foliar antes del alba $\left(\Psi_{2}\right)$. Los valores de $\Psi_{\text {md }}$ son muy variables ya que dependen de las condiciones climáticas reinantes en el momento de la medida, mientras que $\Psi_{a}$ es más estable, pero con la limitación de que no es indicativo del estado al que llega la planta en el momento de máxima demanda. Más recientemente, Shackel et al. (1997) propusieron la utilización del potencial de xilema o de tallo $\left(\Psi_{t}\right)$ como indicador del estado hídrico de la planta. Para su determinación se cubren las hojas con bolsas de plástico y papel de aluminio, al menos durante 2 horas. El objetivo es impedir la transpiración de la hoja, de modo que se alcanza el equilibrio hídrico entre la hoja y el tallo. Entre sus ventajas destacan su menor variabilidad, mejor correlación con el déficit de presión de vapor (DPV) y que refleja mejor la falta de agua en el suelo que el potencial hídrico foliar ( $\Psi$ ) (McCutchan y Shackel, 1992; Naor et al., 1995; Shackel et al., 2000; Chone et al., 2001; Fulton et al., 2001; Fereres y Goldhamer, 2003; Intrigliolo et al., 2005; Intrigliolo y Castel, 2005b; Ortuño et al., 2006a; Vélez et al., 2007). En cuanto a sus desventajas, destaca el hecho de que es una técnica destructiva, muy laboriosa y que no permite la automatización de su medida (Hsiao, 1990).

\section{Variaciones de diámetro de tronco o frutos}

Las variaciones estacionales del diámetro del tronco dependen principalmente del crecimiento (Kozlowsky y Winget, 1964). Sin embargo, a escala diaria también tienen lugar ciclos de contracción y expansión del diámetro del tronco (Kozlowski, 1967), resultado del desequilibrio entre transpiración y absorción de agua durante el día (Simonneau et al., 1993). Los aumentos de diámetro durante la noche y en días nublados son debidos a una mayor proporción en la absorción de agua (Kozlowski, 1966), permitiéndose una redistribución interna de la misma en los distintos tejidos vegetales (Kozlowski, 1968). Dado que el xilema es prácticamente inelástico (Gènard et al., 2001), los cambios en el diámetro de los troncos parecen deberse a cambios en el estado hídrico del floema (Molz et al., 1973). Irvine y Grace (1997) determinaron que más del $90 \%$ de las fluctuaciones diarias del diámetro del tronco tienen lugar en los tejidos del floema.

Estas variaciones diarias, cifradas en decenas de micras pueden ser determinadas mediante sensores de desplazamiento lineal montados en materiales fabricados con aleaciones no dilatables por efecto de la temperatura (Huguet et al., 1992). Uno de estos sensores es el LVDT o "Linear Variable Differential Transformer", capaces de detectar variaciones micrométricas del tallo con una precisión de 1 a 10 micras. 
Las variaciones diarias de los tejidos se encuentran directamente relacionadas con variables climáticas y con la disponibilidad de agua que determina el estado hídrico de la planta. Por esta razón, ha suscitado un gran interés la utilización de este indicador, tanto para evaluar el comportamiento hídrico de la planta como para gestionar el agua de riego de una forma más precisa (Katerji et al., 1990; Simonneau et al., 1993; Tardieu y Simonneau, 1998; Fereres y Goldhamer, 2003; Goldhamer y Fereres, 2004; Intrigliolo y Castel, 2004; 2005b; Ortuño et al., 2004; Moreno et al., 2006; García-Orellana et al., 2007).

La amplitud de las variaciones determina la intensidad con que la planta utiliza sus reservas internas como aporte a la transpiración. En diversas especies frutales se ha encontrado que la magnitud de la amplitud se incrementa en condiciones hídricas adversas (Li et al., 1989b; 1989a; Cohen et al., 2001; Fereres y Goldhamer, 2003; Naor y Cohen, 2003; Goldhamer y Fereres, 2004; Intrigliolo y Castel, 2004; Vélez et al., 2007), aunque en manzano se ha comprobado que el efecto puede ser contrario (Huguet et al., 1992). De la evolución del diámetro del tallo pueden obtenerse diversos parámetros que describen el estado hídrico del vegetal: la máxima contracción diaria, el crecimiento diario y el crecimiento acumulado. La máxima contracción diaria, viene dada por la diferencia entre el máximo diámetro que se produce cuando el órgano se encuentra más hidratado (normalmente a primera hora de la mañana, tras la absorción radicular nocturna) y el mínimo diámetro del órgano que generalmente se da una vez transcurrida la transpiración máxima (a primera hora de la tarde). La diferencia entre dos diámetros máximos diarios consecutivos determina el crecimiento diario del órgano, y la suma de éste proporciona el crecimiento acumulado.

\section{Medida Térmica del Flujo de Savia}

La medida térmica del flujo de savia que circula por el interior de los elementos conductores de los vegetales proporciona una estimación directa de la transpiración. Se basa en la aplicación y transporte de calor como indicador del movimiento de la savia en el tejido xilemático. Huber (1932) fue el primero en utilizar esta técnica para estimar la velocidad de circulación de la savia a partir de la medida de la velocidad del calor a través del tallo.

En los últimos años se han desarrollando y perfeccionando diferentes métodos basados en la interacción entre el flujo de savia bruta y el transporte de calor suministrado por estas técnicas. Las posibilidades de aplicación de estos métodos han aumentado paralelamente con la mejora de los sistemas de detección de la temperatura y desarrollo de la informática ligada a la agricultura. En general, se basan en la gran capacidad calorífica de la savia en comparación con la del aire y de la madera húmeda. Las principales técnicas 
de medida del flujo de savia pueden agruparse en tres métodos: fuente de calor radial constante (Granier, 1985), balance de calor (Valancogne y Nasr, 1989) y pulso de calor (Green y Clothier, 1988; Fernández et al., 2001; Giorio y Giorio, 2003; Nicolás et al., 2005). La elección de una u otra técnica dependerá principalmente de la especie considerada y del tamaño del tallo o tronco.

\section{Cavitación}

Se puede definir la cavitación como una interrupción del paso del agua en los vasos conductores del xilema funcional a consecuencia de la entrada de aire. Esta interrupción en las columnas de agua libera energía en forma de emisiones acústicas, sonidos audibles $\mathrm{y} / \mathrm{o}$ ultrasonidos que pueden ser registrados (Cochard, 1992; 2006; Cruiziat et al., 2002). Dichos registros podrían servir en un futuro para programar el riego (Jones y Sutherland, 1991), dado que el número de procesos de cavitación es directamente proporcional al grado de déficit hídrico sufrido por la planta. En cualquier caso, es importante apuntar que el estrés hídrico no es el único factor que puede causar la cavitación en los vasos del xilema, también las heladas y los agentes patógenos pueden influir en la aparición de la cavitación.

Se han propuesto varios mecanismos, para explicar cómo el estrés hídrico causa la cavitación (Tyree y Sperry, 1989). Se ha comprobado que el desarrollo de procesos de cavitación no está directamente relacionado con el diámetro del elemento conductor (Tyree y Sperry, 1989), sino con el diámetro de las punteaduras del vaso. Los conductos con poros más pequeños son menos vulnerables a la cavitación debido a que el paso del aire a través de sus poros está dificultado, en contrapartida, este tipo de conductos tendrán una conductividad hidráulica menor.

\section{Conductancia foliar}

La conductancia foliar $\left(\mathrm{g}_{\mathrm{l}}\right)$ es un índice del grado de apertura de los estomas, estructuras foliares que juegan un papel esencial en la fisiología de la planta ya que regulan el intercambio gaseoso. Al igual que el potencial hídrico, $\mathrm{g}_{1}$ sigue un ritmo circadiano y está influenciada por la intensidad luminosa, la temperatura, el incremento de humedad absoluta entre la hoja y el aire, la edad de la hoja, la concentración de $\mathrm{CO}_{2}$ y el propio potencial hídrico (Jones, 1983). Las revisiones realizadas por Lösch (1979) y Schuzle y Hall (1982) pusieron de manifiesto la influencia del déficit de presión de vapor sobre $g_{1}$. Así en la mayoría de las especies, pero no en todas, el aumento del déficit de presión de vapor en el entorno de la hoja o planta se traduce en cierre estomático. Sin embargo, la forma en cómo el déficit de presión de vapor influye sobre la conductancia foliar no está clara (Turner et al., 1984). 
Dada la influencia del estrés hídrico sobre $g_{1}$, éste puede ser considerado como un buen índice del estado hídrico de la planta. Además g, está bien correlacionada con la tasa de fotosíntesis (Farquhar y Sharkey, 1982; Wong et al., 1985; Torrecillas et al., 1999), la cual depende también del estado hídrico. Como el estoma responde también a otros factores ambientales y fisiológicos (Hsiao, 1973) es necesario realizar muestreos continuos de gara poder separar el efecto del estrés hídrico de los debidos a otras variables. La medida de $g_{1}$ es útil para evaluar la recuperación de las plantas después de un estrés hídrico (Gebre y Kuhns, 1993).

Por otro lado, la gran variabilidad entre hojas del mismo árbol (Leverenz et al., 1982), la diferencia en la apertura estomática entre ciertas áreas de la hoja (Pospisilova y Santrucek, 1994), la necesidad de hacer un escalonamiento de toda la copa, etc., dificulta la posibilidad de determinar la transpiración del árbol en función de las medidas de $g_{1}$. Sin embargo, existen modelos más o menos complejos de estimación de la transpiración en base a un reducido número de medidas de conductancia foliar (Williams et al., 1996).

\section{Temperatura del cultivo}

Desde hace años se conoce que las medidas de temperatura foliar son un método fiable para evaluar el estado hídrico de la planta (Idso et al., 1981; Jackson, 1982). El desarrollo de aparatos más precisos y con mayor resolución espacial para medir la temperatura foliar (radiotermómetros ubicados in situ, o a partir de datos procedentes de satélite) ha impulsado el uso de métodos térmicos para evaluar la respuesta de las plantas a condiciones de estrés (Moran et al., 1994; Jones, 2004; Jones, 2007). La mayoría de los métodos térmicos están basados en el cálculo de un índice de estrés (Idso et al., 1981), partiendo de la base que las diferencias que presentan las superficies en el nivel de cobertura vegetal y en su tasa de transpiración resultan en diferencias de temperatura (de índice de estrés) inducidas por el proceso de enfriamiento por evaporación. Sin condiciones de estrés, el agua que transpira la planta se evapora contribuyendo a enfriar las hojas. Bajo condiciones de restricción hídrica, la tasa de transpiración disminuye y la temperatura foliar aumenta. Sin embargo, la dificultad que conlleva la medida de la temperatura de la vegetación cuando ésta no alcanza un nivel de cobertura cercano al 100 \%, ha limitado su aplicación a estos casos.

El cálculo del "Crop Water Stress Index" o CWSI se basa en la ecuación de Penman-Monteith y el balance de energía (Penman, 1948; Monteith, 1965; 1973) para estimar las temperaturas teóricas máxima y mínima de una cubierta vegetal que están asociadas con condiciones de transpiración mínima y máxima, respectivamente. Estos valores extremos, junto con la medida de la temperatura foliar de la vegetación y de datos 
climáticos, dan acceso a evaluar el índice CWSI, función de la tasa de evapotranspiración actual y potencial del cultivo, que ha tenido aplicaciones importantes en agricultura entre las que cabe destacar la gestión de la frecuencia de riego. 
Métodos y técnicas utilizadas 



\subsection{Introducción}

En este capítulo se recoge el instrumental, técnicas y metodologías utilizadas en la obtención de datos y determinación de los parámetros de clima, suelo y planta analizados en los diferentes ensayos realizados y que conforman la presente Memoria de Tesis.

\subsection{Medida de las variables climáticas}

\section{Estación climática automática}

Se utilizó una estación climática automática para la toma de datos de las variables climáticas reinantes en el ensayo de almendros cv. 'Marta', ubicada en el centro de una parcela de $25 \mathrm{~m}$ x $25 \mathrm{~m}$, cultivada de césped, perteneciente a la Estación Experimental Agroalimentaria 'Tomás Ferro' (ESEA) Universidad Politécnica de Cartagena (Figura 3.1). La finca experimental de almendros dista tan sólo $100 \mathrm{~m}$ de dicha estación. Para el ensayo de almendros cv. 'Colorada' se emplearon los datos de la estación 'El Campillo' (CA91) de la red de estaciones meteorológicas del SIAM situada a $1 \mathrm{~km}$ de la parcela.

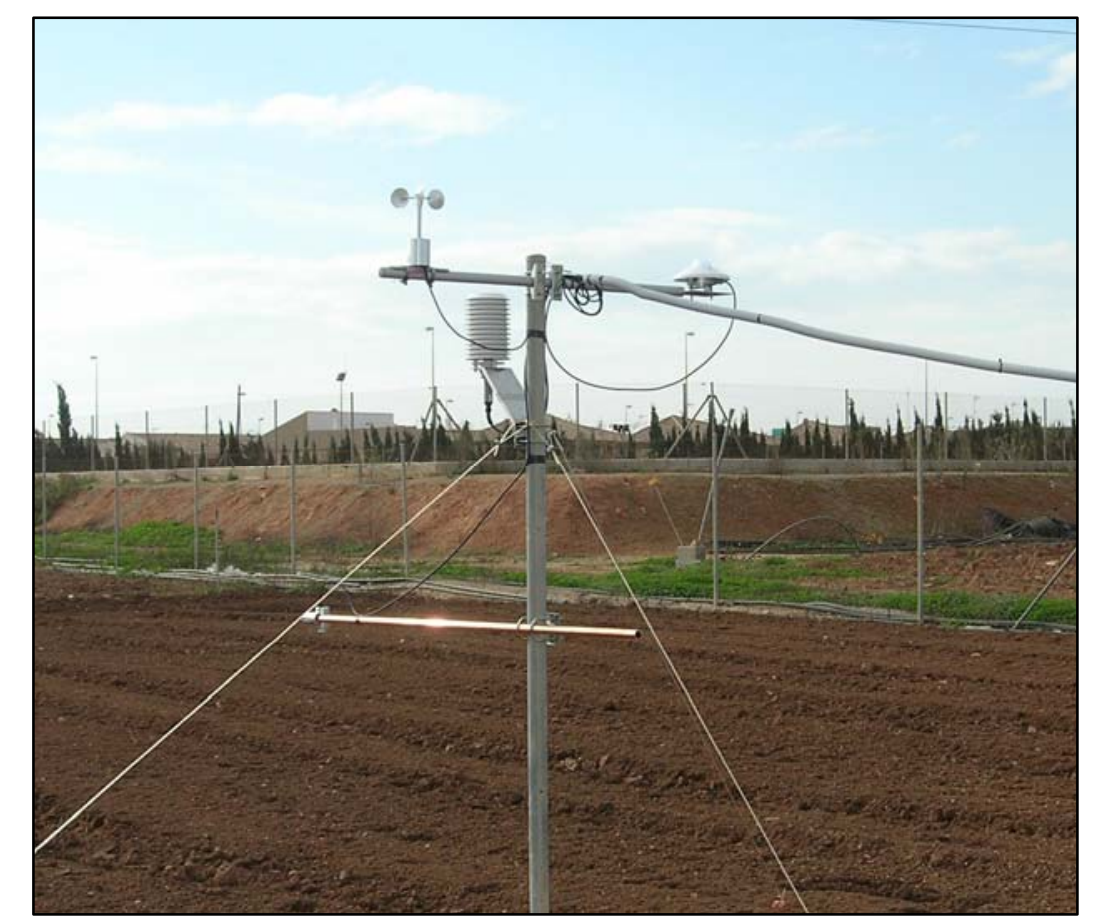

Figura 3.1. Estación climática automática de la ESEA ‘Tomás Ferro’ y disposición de los distintos sensores. 


\section{Sensores de temperatura y humedad relativa del aire}

La temperatura y humedad relativa del aire fue obtenida a partir de una sonda HMP45C, colocada a $2 \mathrm{~m}$ de altura. Esta sonda consta de dos sensores: i) de temperatura ambiente, Pt 1000, que es un tipo sensor RTD (resistance temperature detector) basado en el platino y que se fundamenta en la variación de la resistencia del metal conductor con la temperatura, y ii) de humedad relativa, sensor capacitivo modelo HUMICAP 180, que es un polímero de plástico que tiende a absorber la humedad y que cambia sus características eléctricas en función de la humedad ambiental (Figura 3.2).

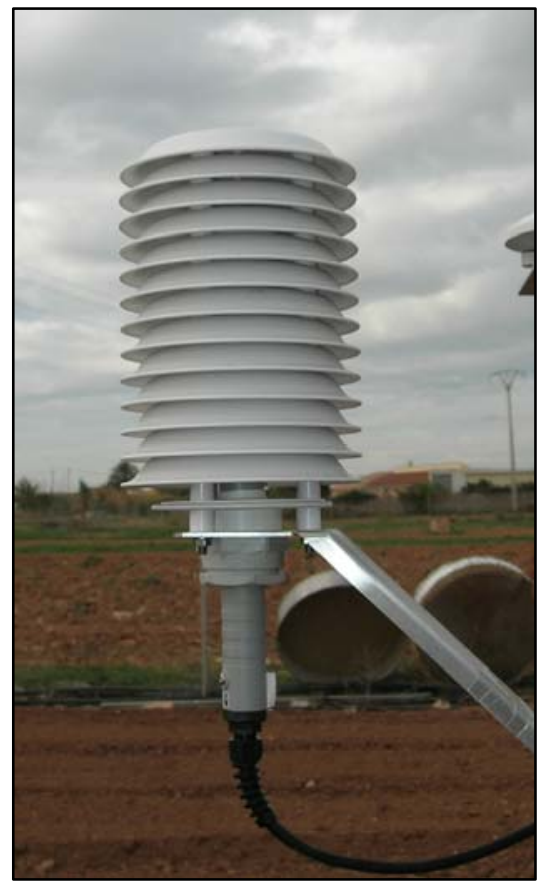

Figura 3.2. Sensor de humedad relativa, modelo HUMICAP 180.

La sonda HMP45C lleva como accesorio un protector (Figura 3.2) a fin de evitar el efecto de la radiación directa y difusa sobre el sensor de temperatura, y por tanto los posibles efectos de histéresis que podrían producirse.

A partir de la información proporcionada por estos sensores: temperatura seca (Ts) y humedad relativa (HR) del aire, se calculó el déficit de presión de vapor (DPV) del aire, según las siguientes ecuaciones.

$$
D P V=e_{s}-e_{a} \quad(k P a)
$$


donde, $\mathrm{e}_{\mathrm{s}}$ es la tensión de vapor saturante a la temperatura seca $(\mathrm{kPa})$ y $\mathrm{e}_{\mathrm{a}}$ la tensión de vapor actual $(\mathrm{kPa})$, que fueron determinadas a partir de:

$$
\begin{gathered}
\mathrm{e}_{\mathrm{s}}=0.6107 \cdot\left[1+\sqrt{2} \cdot \operatorname{sen}\left(\frac{\mathrm{T}_{\mathrm{s}}}{3}\right)\right]^{8.827} \quad(\mathrm{kPa}) \\
\mathrm{e}_{\mathrm{a}}=\mathrm{HR} * \mathrm{e}_{\mathrm{s}}
\end{gathered}
$$

Así mismo, y a partir de los modelos propuestos por Richardson et al. (1976), se estimaron las necesidades de calor requeridas para completar los distintos períodos fenológicos del cultivo.

Richardson et al. (1976), para el cultivo del melocotonero definieron una hora grado de crecimiento Celsius $\left(1{ }^{\circ} \mathrm{C}\right.$ GDH) como una hora a una temperatura de $1{ }^{\circ} \mathrm{C}$ por encima de la temperatura base de $4.5^{\circ} \mathrm{C}$. Es decir, cada $\mathrm{GDH}{ }^{\circ} \mathrm{C}$ se obtiene restando $4.5^{\circ} \mathrm{C}$ a cada temperatura media horaria $\left(\mathrm{T}_{\mathrm{mh}}\right)$ en el intervalo comprendido entre 4.5 y $25^{\circ} \mathrm{C}$. Considerando iguales aquellas temperaturas superiores a $25^{\circ} \mathrm{C}$.

De esta forma los $\mathrm{GDH}{ }^{\circ} \mathrm{C}$ se calculan, según la siguiente expresión:

$$
G D H=\sum_{1}^{24}\left(T_{m h}-T_{\text {base }}\right)
$$

donde, $\mathrm{T}_{\mathrm{mh}}$ es la temperatura media horaria $\left({ }^{\circ} \mathrm{C}\right)$.

En el ensayo con almendros jóvenes se modificó ligeramente la metodología de Richardson et al. (1976) para adaptarla al clima de la finca, más suave que el de Utah. Esta modificación consistió en la eliminación del límite superior de $25{ }^{\circ} \mathrm{C}$ para el computo del calor acumulado y en fijar la temperatura base del almendro en $6{ }^{\circ} \mathrm{C}$, tal y como sugirieron Tabuenca y Herrero (1966).

\section{Sensor radiación solar global}

La radiación solar global fue registrada mediante un piranómetro modelo SP1110 (Figura 3.3). La parte superior del sensor está formada por una fotocélula con un recubrimiento especial de silicona, asegurando una respuesta en la banda espectral entre 350 y $1100 \mathrm{~nm}$. 


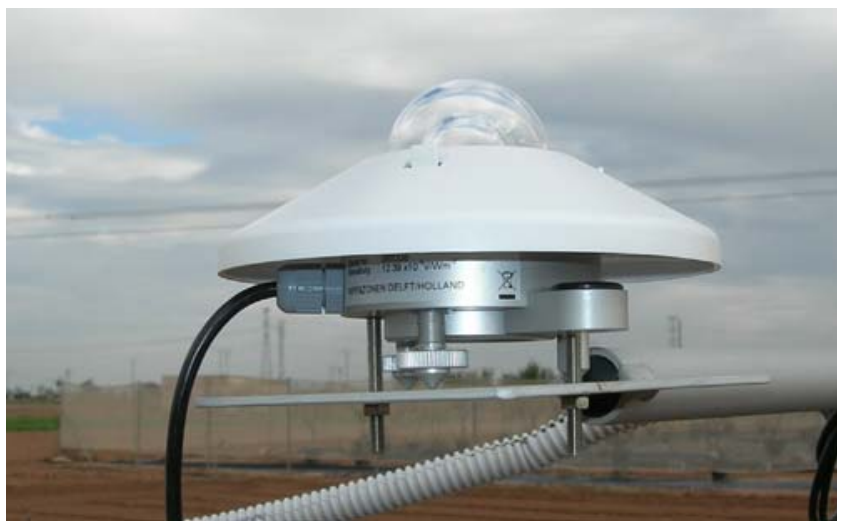

Figura 3.3. Sensor de radiación global.

\section{Sensor de radiación neta}

La radiación neta fue registrada a partir de un sensor Q-7.1 Net Radiometer (Figura 3.4). Este sensor registra la suma algebraica de todas las longitudes de onda (componentes de onda corta y onda larga) entrantes y salientes. La radiación entrante se compone de la radiación solar directa y de la difusa más la radiación de onda larga de la bóveda celeste. La radiación saliente está compuesta por la radiación solar reflejada más la componente terrestre de onda larga emitida por la superficie.

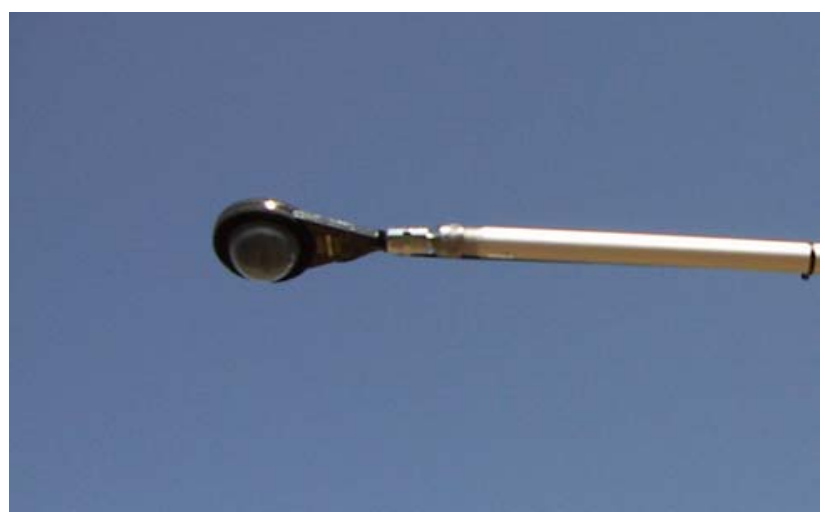

Figura 3.4. Sensor de radiación neta.

\section{Pluviometría}

La precipitación fue registrada a partir de un sensor FSS500. Éste consiste en un balancín que oscila sobre su eje, de forma que cada vez que gira para verter el agua cierra el circuito, hecho que es registrado por el sistema de adquisición de datos (Figura 3.5). El sensor realiza medidas a partir de incrementos de $0.1 \mathrm{~mm}$. 


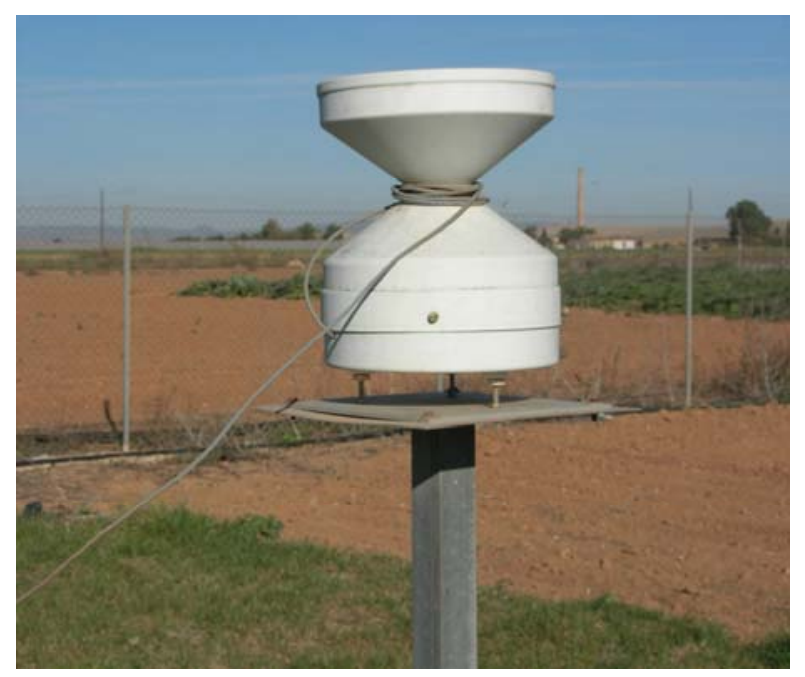

Figura 3.5. Pluviómetro con sensor FSS500 colocado a 1.5 m del suelo.

\section{Sensores de velocidad y dirección del viento}

Para la determinación de la velocidad del viento se empleó un anemómetro de cazoletas modelo A100R, situado a 2 metros de altura (Figura 3.6).

Su fundamento se basa en un imán que gira sobre el eje del molinete generando un campo variable, que provoca el cierre de un contacto tipo lengüeta para cada revolución del rotor, este sensor no precisa de alimentación externa ya que es alimentado por la propia energía eólica.

Para la medida de la dirección del viento se utilizó una veleta modelo W200P, se trata de un potenciómetro de $1 \mathrm{kohm}$, que es un resistor con un contacto móvil, en el que el desplazamiento es función del recorrido entre dos terminales (Figura 3.6). El rango de medida es de $0-360^{\circ}$ con una precisión de $\pm 3^{\circ}$.

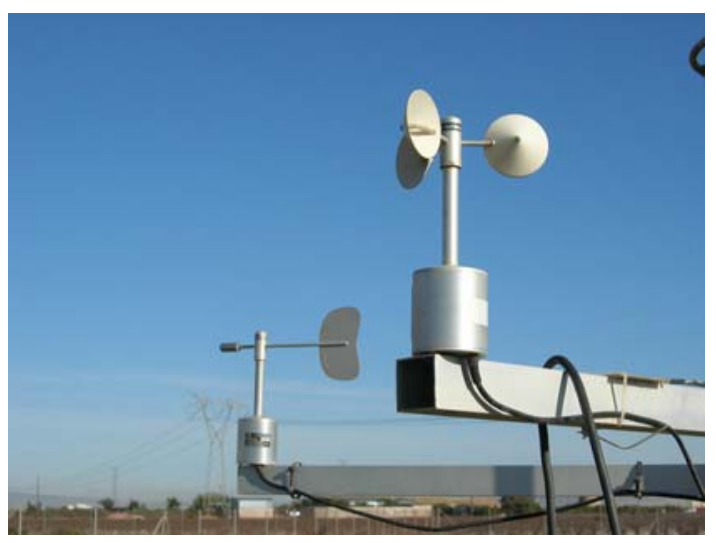

Figura 3.6. Sensor de velocidad y dirección de viento. 
Las principales características de los sensores descritos anteriormente, rango de señal, tipo de salida, precisión y modelo empleado aparecen descritas en la tabla 3.1.

Tabla 3.1. Características de los sensores utilizados.

\begin{tabular}{|c|c|c|c|c|}
\hline $\begin{array}{c}\text { Variable } \\
\text { Climática }\end{array}$ & $\begin{array}{c}\text { Rango de } \\
\text { Señal }\end{array}$ & Tipo de Salida & Precisión & Sensor \\
\hline Temperatura & $0-1 \mathrm{~V}$ & $-40 a+60^{\circ} \mathrm{C}$ & $\pm 2{ }^{\circ} \mathrm{C}$ & Pt 1000 \\
\hline $\begin{array}{c}\text { Humedad } \\
\text { Relativa }\end{array}$ & $0-1 \mathrm{~V}$ & 0 a $100 \%$ HR & $\pm 1 \% \mathrm{HR}$ & $\begin{array}{c}\text { HUMICAP } \\
180\end{array}$ \\
\hline $\begin{array}{c}\text { Radiación } \\
\text { Global }\end{array}$ & & $1 \mathrm{mV}$ por $100 \mathrm{~W} \mathrm{~m}^{-2}$ & $3 \%$ & SP1110 \\
\hline $\begin{array}{c}\text { Radiación } \\
\text { Neta }\end{array}$ & & $10 \mathrm{mV}$ por $\mathrm{W} \mathrm{m}^{-2}$ & $1 \%$ & $\begin{array}{l}\text { Q-7.1 Net } \\
\text { Radiometer }\end{array}$ \\
\hline Lluvia & & $12 \mathrm{~mA}-0.2 \mathrm{~mm}$ & $0.2 \mathrm{~mm}$ & FSS500 \\
\hline $\begin{array}{l}\text { Velocidad } \\
\text { viento }\end{array}$ & $0.2-75 \mathrm{~ms}^{-1}$ & & $\begin{array}{c} \pm 0.1 \% \mathrm{~ms}^{-1} \text { para } 0.3-10 \\
\mathrm{~ms}^{-1} \\
\pm 1 \% \mathrm{~ms}^{-1} \text { para } 10-55 \mathrm{~ms}^{-1} \\
\pm 2 \% \mathrm{~ms}^{-1} \text { para }>55 \mathrm{~ms}^{-1}\end{array}$ & A100R \\
\hline
\end{tabular}

\section{Sistema de adquisición de datos}

La adquisición de datos de todos los sensores se realizó a partir de un datalogger Campbell modelo CR10X (Figura 3.7), cuyo voltaje diferencial máximo de salida es de $\pm 2.5 \mathrm{~V}$. Todas las variables fueron registradas cada minuto y se almacenó la media de las lecturas cada quince minutos.

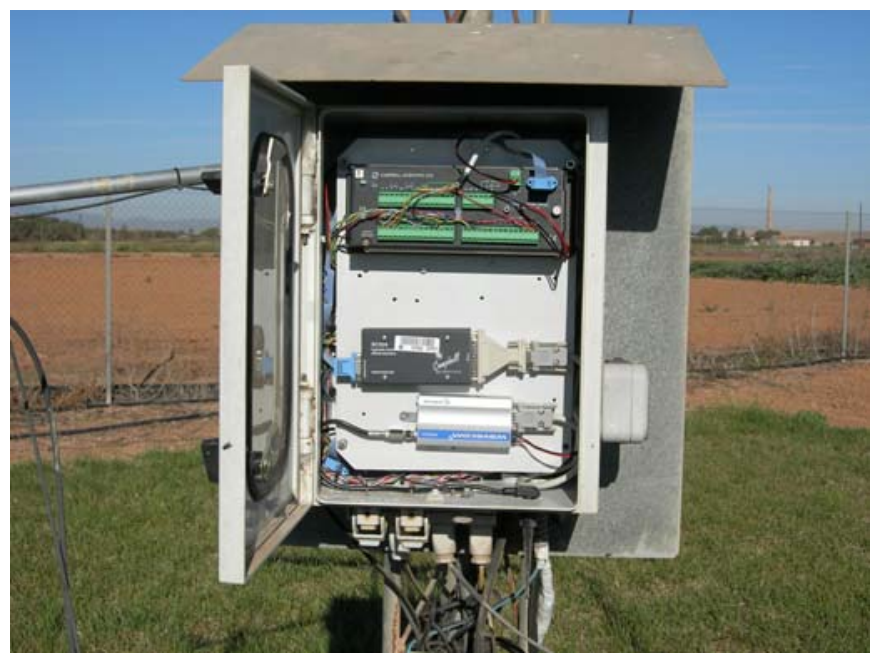

Figura 3.7. Sistema de gestión de datos. 


\subsection{Medida del estado hídrico del suelo}

\section{Potencial matricial}

El seguimiento del potencial matricial del agua en el suelo, $\Psi_{\mathrm{m}}$, se realizó mediante baterías de tensiómetros con vacuómetro tipo Bourdon (mod. Irrometer INC) y sensores de matriz granular (Watermark, mod. 200ss, Irrometer Co.), colocados a 30, 60 y $90 \mathrm{~cm}$ de profundidad y a $30 \mathrm{~cm}$ del emisor (Figura 3.8).
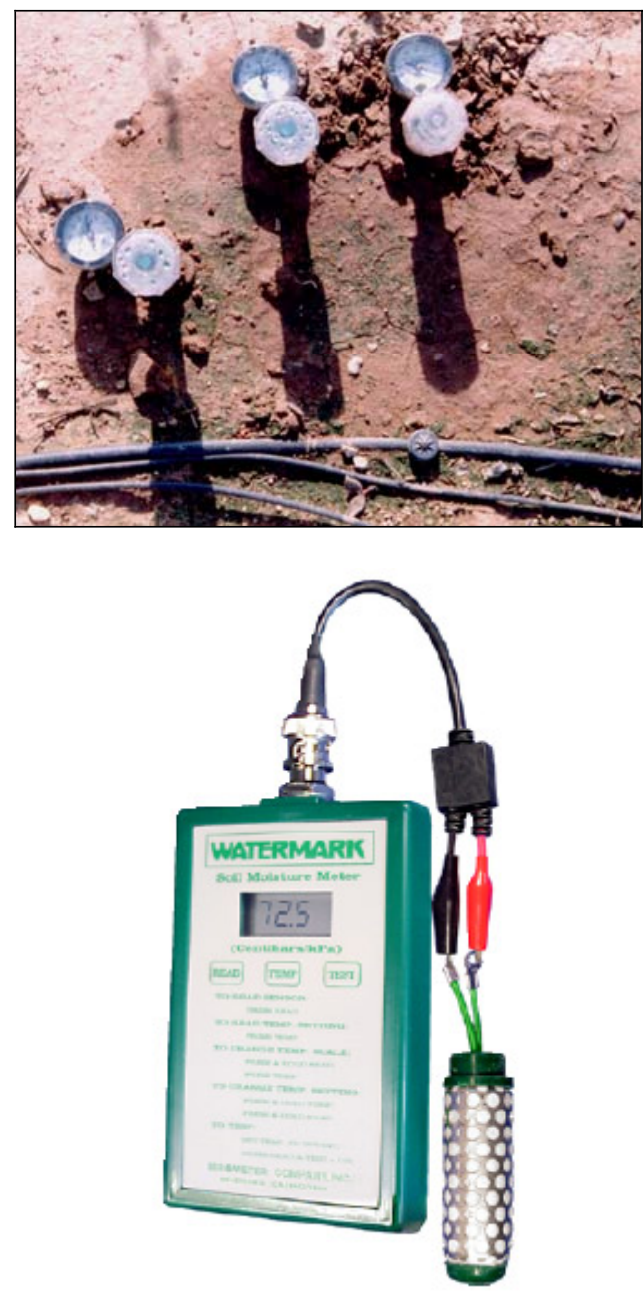

Figura 3.8. Batería de tensiómetros y sensor Watermark con medidor digital.

\section{Contenido de humedad del suelo}

El contenido volumétrico de agua en el suelo fue evaluado a partir de sensores TDR, reflectometría en el dominio del tiempo (Moisture Point, mod. MP-917) y FDR, reflectometría en dominio de la frecuencia (EnviroSCAN) (Figura 3.9). 

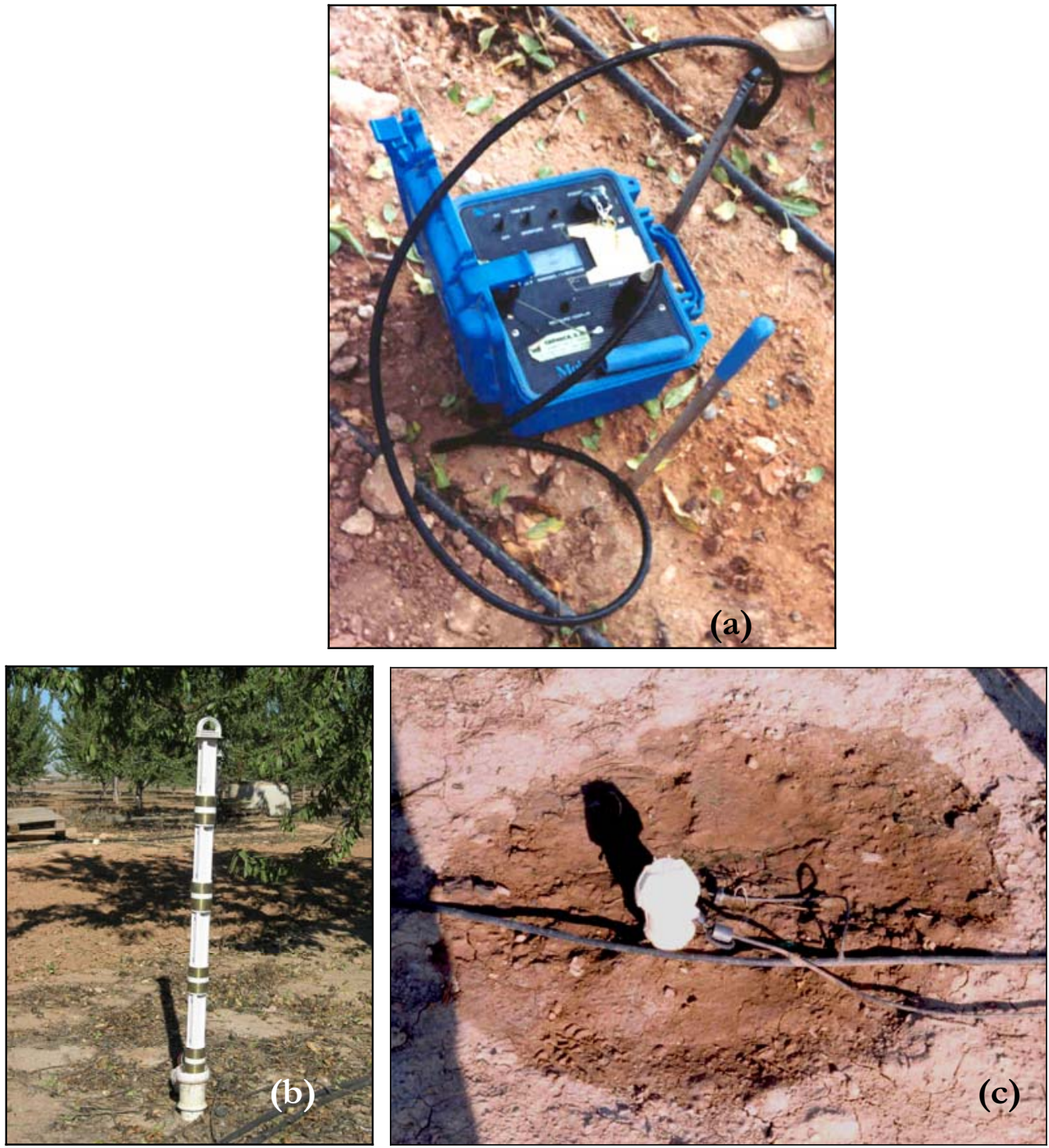

Figura 3.9. a) Equipo TDR y sondas instaladas en suelo, b) sensores FDR sobre guía c) sensores FDR instalados en campo.

\subsection{Medida del estado hídrico de la planta}

\section{Potencial hídrico foliar y potencial de hoja cubierta}

El estado hídrico de la planta fue evaluado a partir de medidas del potencial hídrico foliar antes del alba $\left(\Psi_{\mathrm{a}}\right)$ y a mediodía $\left(\Psi_{\mathrm{md}}\right)$ (Scholander et al., 1965), y potencial hídrico de hoja cubierta o tallo $\left(\Psi_{\text {t }}\right.$ a mediodía (McCutchan y Shackel, 1992), con cámara de presión (Soil Moisture Equipment Corp. modelo 3000) (Figura 3.10). Las medidas de $\Psi_{\mathrm{a}}$ y $\Psi_{\mathrm{md}}$ se realizaron sobre hojas sanas y adultas, procedentes del tercio medio de las 
ramas del árbol en su orientación sur, según el procedimiento descrito por Scholander et al. (1965) y Turner (1981).

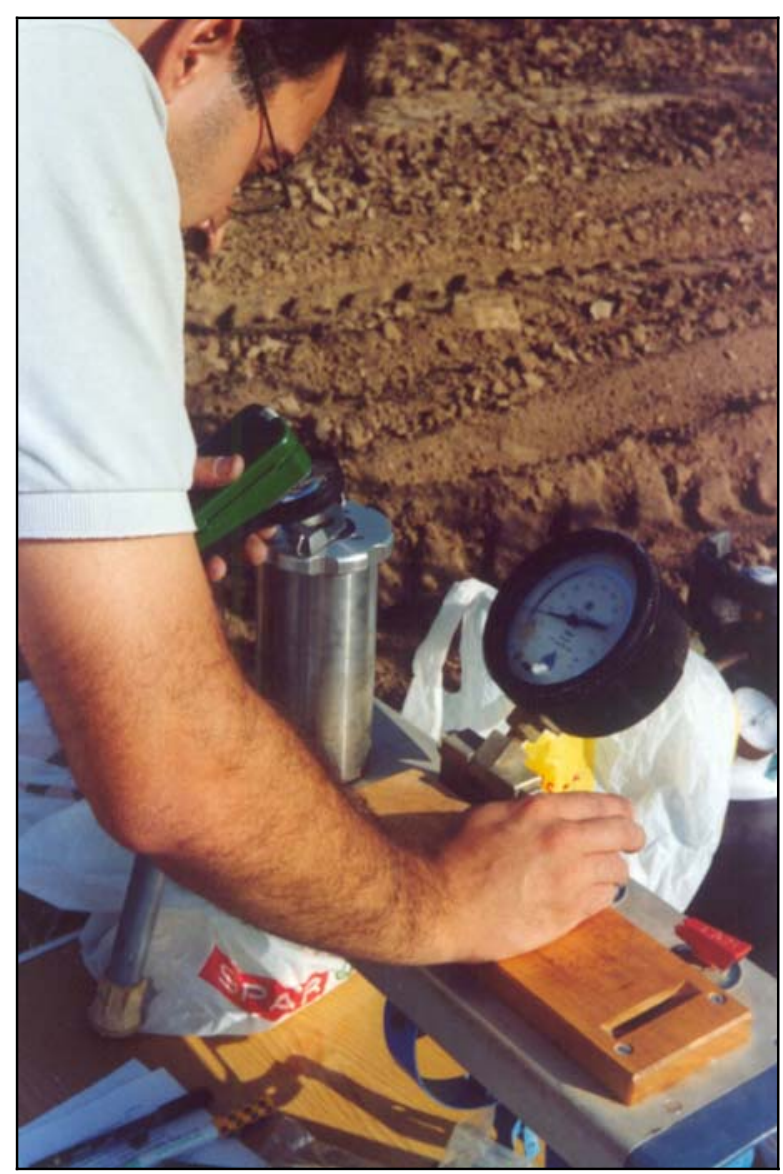

Figura 3.10. Cámara de presión.

Las medidas de $\Psi_{\mathrm{t}}$ se realizaron sobre hojas sanas, adultas y sombreadas, próximas a ramas principales, las cuales fueron envueltas dos horas antes de cada medida con una bolsa de plástico negro y cubiertas con papel de aluminio, a fin de evitar la transpiración e igualar su estado energético con el del tronco o tallo donde se encuentra insertada (Passioura, 1988; McCutchan y Shackel, 1992). La figura 3.11 ilustra los pasos a seguir para la preparación de las hojas seleccionadas para la determinación de $\Psi_{\mathrm{t}}$.

La fiabilidad y rapidez de la medición, así como la facilidad para interpretar sus resultados hacen de este método uno de los más usados para determinar el estado hídrico de la planta. Sin embargo, es un método destructivo y no automatizable lo que limita en cierta medida su uso. 


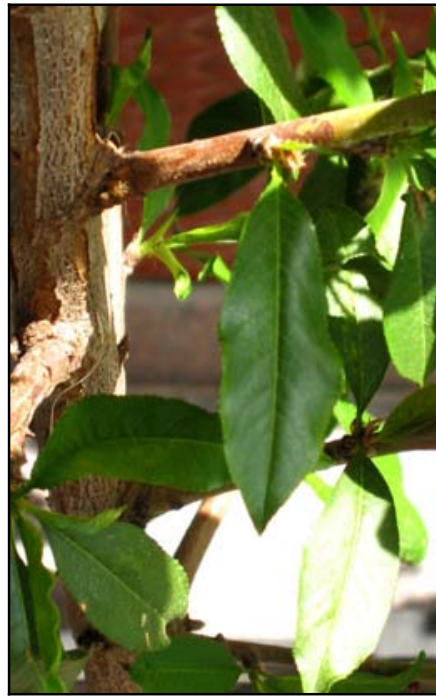

(a)

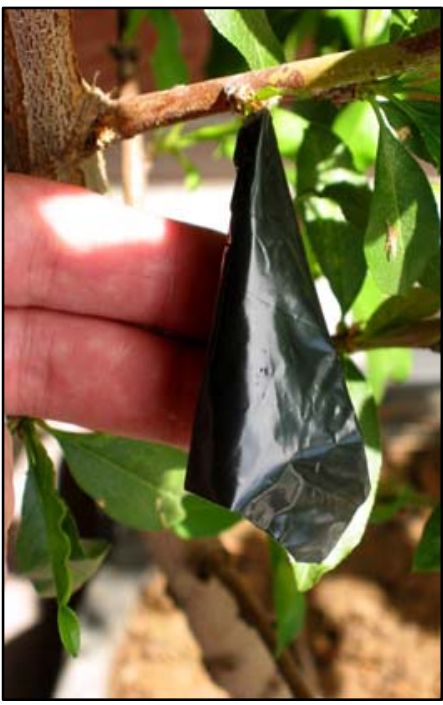

(b)

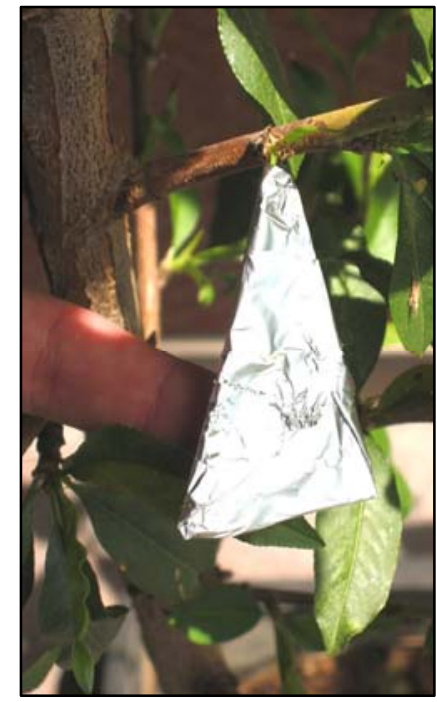

(c)

Figura 3.11. a) Elección de las hojas, b) colocación de plástico negro y c) envoltura con papel de aluminio.

Así mismo, se evalúo la intensidad y duración del déficit hídrico a partir de la integral de estrés $\left(\mathrm{S}_{\Psi}\right)$, determinada a partir de las medidas de potencial hídrico foliar al alba y de tallo, según la ecuación de Myers (1988):

$$
S_{\Psi}=\left|\sum_{i=0}^{i=t}\left(\bar{\Psi}_{i, i+1}-C\right) n\right| \quad \text { (MPa día) }
$$

donde: $\bar{\Psi}_{i, i+1}$ es la media del potencial hídrico para el intervalo $i, i+1$ y C, es el valor máximo del potencial hídrico medido durante cada periodo y $\mathrm{n}$ el número de días del intervalo.

\section{Potencial osmótico y potencial de presión}

El potencial osmótico foliar $\left(\Psi_{\mathrm{o}}\right)$ fue medido con un osmómetro Roebling mod. 13DR (Figura 3.12), calibrado con una solución patrón de osmolalidad conocida $\left(300 \mathrm{mmol} \mathrm{kg}^{-1}\right)$ y agua destilada $\left(0 \mathrm{mmol} \mathrm{kg}^{-1}\right)$. Para ello y en días señalados, tras la medida del potencial hídrico foliar las hojas fueron inmediatamente envueltas en papel de aluminio, introducidas en nitrógeno líquido y almacenadas a $-20{ }^{\circ} \mathrm{C}$. La determinación de $\Psi_{\mathrm{o}}$ se realizó a partir del jugo celular extraído mediante centrifugación a $10000 \mathrm{rpm}$ de la muestra previamente descongelada a temperatura ambiente.

El potencial de presión $\left(\Psi_{\mathrm{p}}\right)$ fue obtenido por diferencia entre el potencial hídrico foliar $\left(\Psi_{1}\right)$ y el potencial osmótico:

$$
\Psi_{\mathrm{p}}=\Psi_{1}-\Psi_{\mathrm{o}}
$$


El potencial osmótico a máxima saturación $\left(\Psi_{\mathrm{os}}\right)$ fue determinado en hojas tomadas antes del alba, adyacentes a las de la medida del potencial hídrico, las cuales eran saturadas inmediatamente después de ser muestreadas, introduciendo los pecíolos en vasos de agua destilada y mantenidas en oscuridad durante $24 \mathrm{~h}$, tras lo cual eran congeladas en nitrógeno líquido. Las medidas se realizaron igualmente con un osmómetro Roebling mod. 13DR.

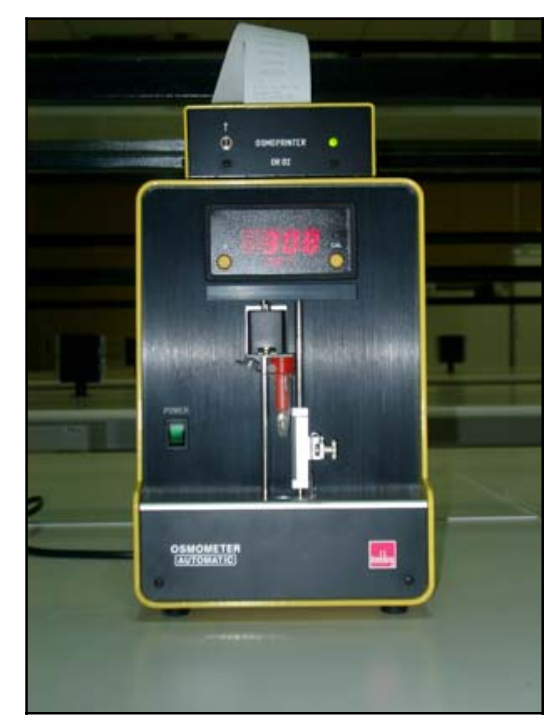

Figura 3.12. Osmómetro ROEBLING mod. 13DR.

\section{Conductancia foliar}

La conductancia foliar $\left(\mathrm{g}_{\mathrm{l}}\right)$ fue medida en el mismo tipo de hojas que $\Psi_{\mathrm{l}}$, usando un porómetro de estado estacionario (LI-COR Inc., modelo LI-1600) (Figura 3.13). El sensor de humedad se calibró regularmente con soluciones salinas de referencia y el material desecante se sustituyó antes de cada medida.

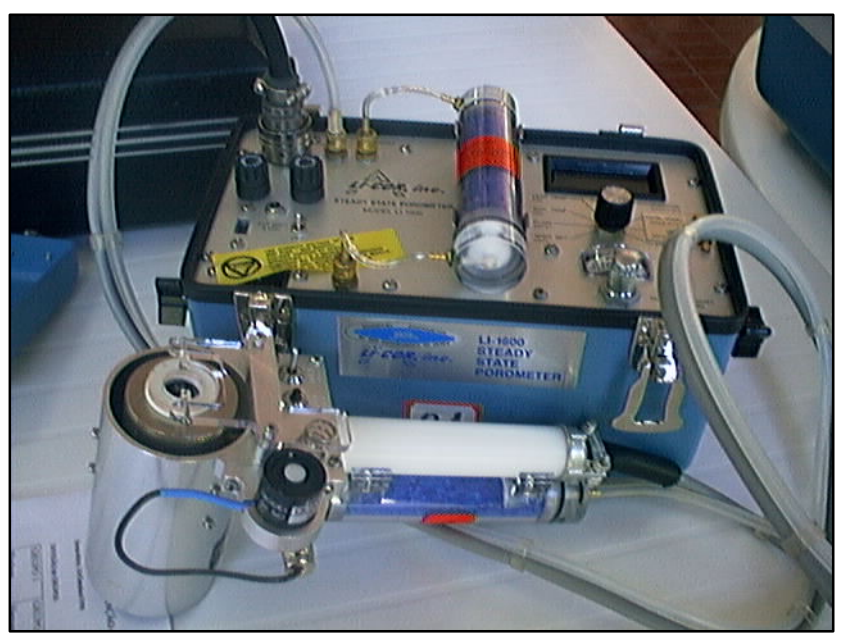

Figura 3.13. Porómetro LICOR LI-1600. 


\section{Variaciones de diámetro de tronco}

Las variaciones de diámetro de tronco fueron medidas con sensores de desplazamiento variable y de respuesta lineal tipo LVDT o "Linear Variable Differential Transformer" de la marca Solartron, con un rango de medida lineal de $5 \mathrm{~mm}$ y 1 a 10 micras de precisión (Figura 3.14). Estos sensores constan de un núcleo magnético que se mueve impulsado por una aguja en contacto con el tronco. Dicho núcleo discurre por el interior de un cilindro, entre un embobinado primario y otro secundario. A la bobina primaria se le aplica una señal portadora (corriente alterna $\approx 10 \mathrm{~V}$ ) que produce un campo magnético alrededor del núcleo, y este campo magnético induce un voltaje en la bobina secundaria, que es proporcional al desplazamiento experimentado por el órgano vegetal donde esté instalado.

A partir de las variaciones de diámetro de tronco se determinaron los parámetros indicadores del estado hídrico propuestos por Kozlowski (1967): máxima contracción diaria de tronco (MCD), tasa de crecimiento diaria de tronco (TCD) y crecimiento acumulado (CA). MCD se calculó como la diferencia entre el diámetro máximo alcanzado antes del alba y el mínimo a mediodía (Fereres y Goldhamer, 2000). TCD a partir de la diferencia entre el máximo diámetro de dos días consecutivos y CA como la suma de los TCD en un intervalo de tiempo determinado (Figura 3.15).

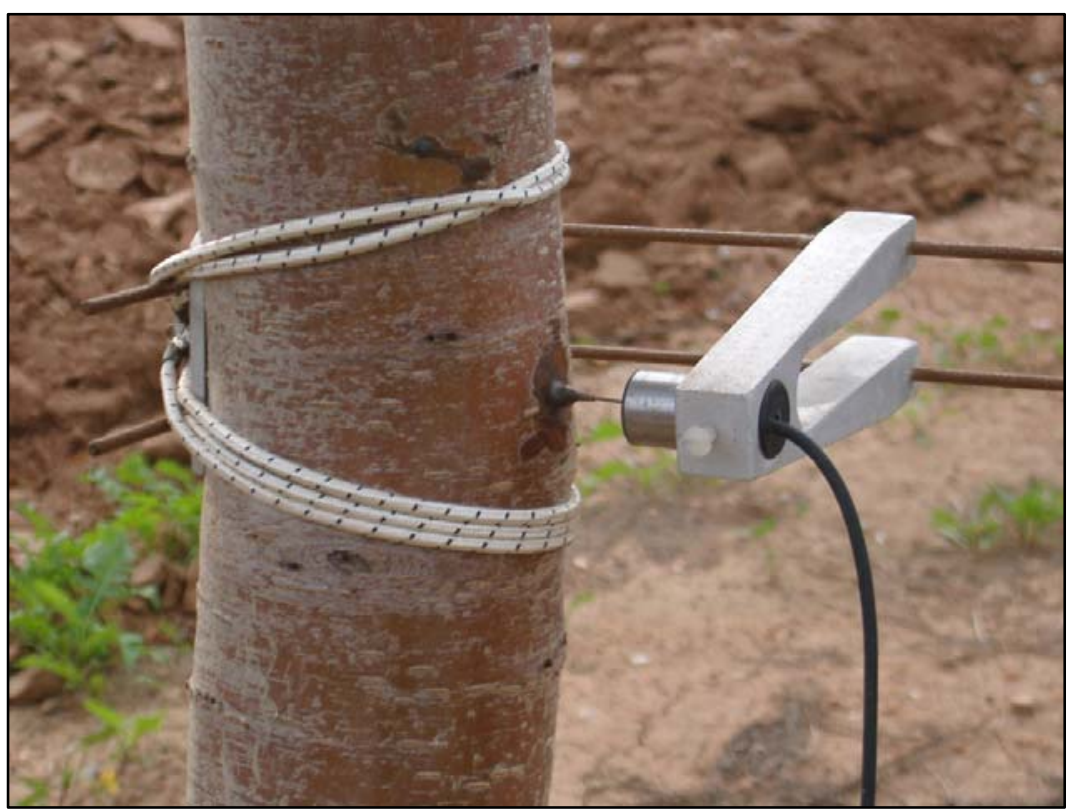

Figura 3.14. Sensor LVDT y portasensor en tronco. 


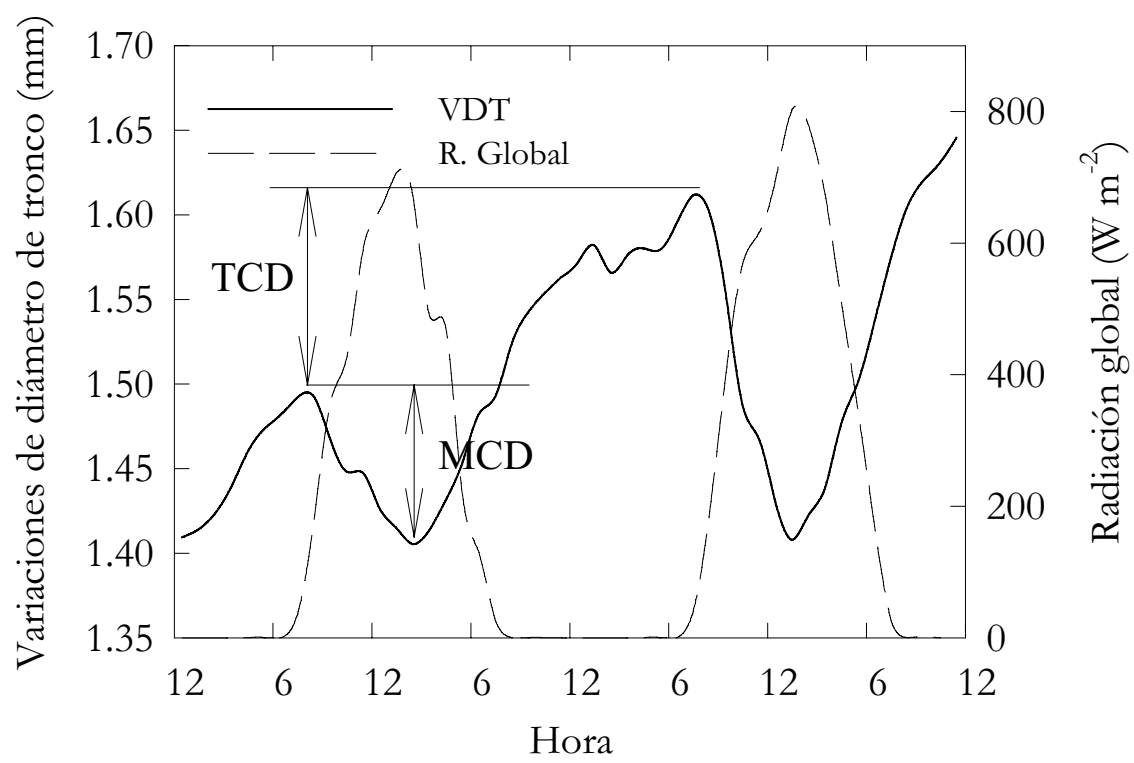

Figura 3.15. Representación gráfica de la máxima contracción diaria (MCD) y tasa de crecimiento diaria de tronco (TCD) a partir de la variación del diámetro de tronco (VDT) en almendros.

\section{Sistema de adquisición de datos}

Los sensores LVDT fueron conectados a 4 dataloggers MicroIsis, conectados entre si mediante comunicación RS-485 (Figura 3.16), los datos fueron registrados cada 10 minutos y recogidos vía módem GSM.

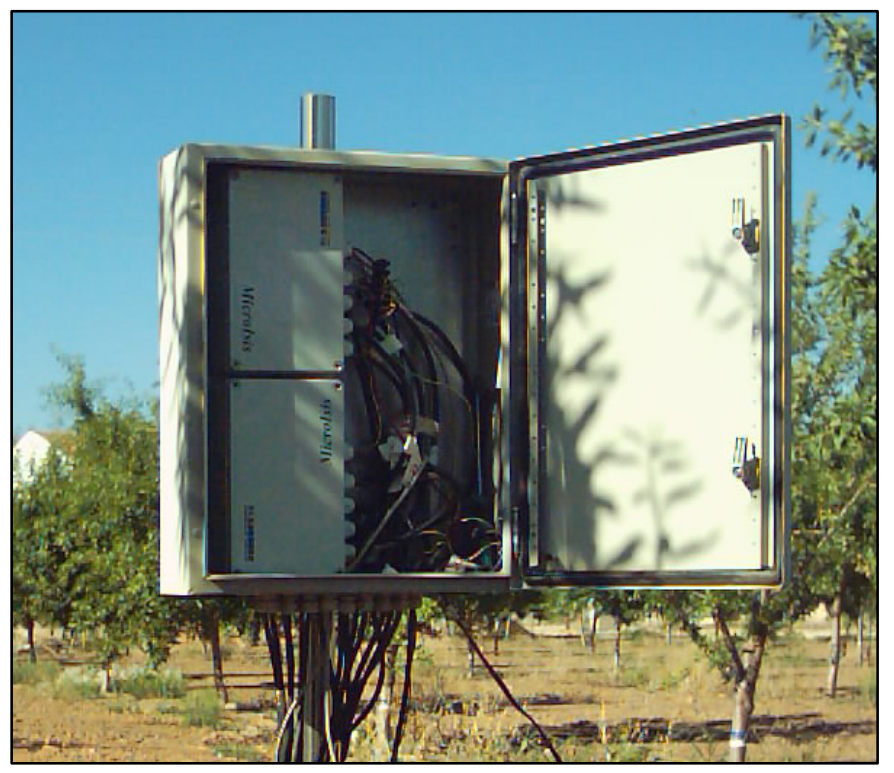

Figura 3.16. Equipos MicroIsis en parcela experimental. 

Respuesta agronómica y fisiológica de almendros jóvenes al riego deficitario 



\subsection{Introducción}

El riego deficitario controlado (RDC) se ha constatado como una estrategia de riego altamente eficiente en numerosos especies leñosas, especialmente cuando son cultivadas en zonas semiáridas. Su objetivo principal es reducir los aportes de agua de modo que la producción y calidad de las cosechas sean poco o nada afectadas.

El almendro, considerado como un cultivo tolerante al estrés hídrico (Fereres y Goldhamer, 1990; Hutmacher et al., 1994; Torrecillas et al., 1996) es uno de los cultivos en el que, tanto los riegos deficitarios constantes (RD) (León et al., 1985; Ruiz-Sánchez et al., 1988), como el RDC (Girona, 1992; Girona y Marsal, 1995) han sido más exitosos. Los porcentajes de ahorro de agua en RDC rondan el $50 \%$ respecto a las máximas necesidades del cultivo (Girona, 1992; Girona et al., 1993a; 1997; 1995; Nortes et al., 2002; Romero et al., 2004a; Girona et al., 2005), siendo el período más adecuado para la aplicación de un déficit hídrico la fase IV del cultivo. Además, los resultados derivados de estudios realizados en diferentes ubicaciones y con variedades distintas son muy similares en cuanto ahorro de agua y producciones obtenidas con respecto a árboles bajo condiciones no limitantes de agua en el suelo (Goldhamer y Viveros, 2000; Esparza et al., 2001b; Nortes et al., 2002; Romero et al., 2004a; Girona et al., 2005; Goldhamer et al., 2006).

Aunque existe un gran número de trabajos sobre riego deficitario en almendro, la generalidad de ellos se ha realizado en plantaciones adultas. De ahí, la conveniencia de evaluar los efectos del riego deficitario a corto y medio plazo sobre la respuesta agronómica y fisiológica de plantaciones jóvenes, y de este modo, poder prever su posible influencia a más largo plazo.

\subsection{Material y métodos}

\section{Material vegetal condiciones experimentales y tratamientos}

Los ensayos se realizaron durante el periodo 2001-2004 en una parcela experimental de almendros (Prunus dulcis (Mill.) Webb, cv 'Marta' injertada sobre el portainjerto 'Mayor'). La parcela, de aproximadamente 1 ha (Figura 4.1, 4.2 y 4.3), pertenece a la Estación Experimental Agroalimentaria (ESEA) 'Tomás Ferro' de la Universidad Politécnica de Cartagena (UPCT) situada en La Palma, Cartagena ( $37^{\circ} 41^{\prime} \mathrm{N}, 0^{\circ} 57^{\prime} \mathrm{E}$; Figura 4.1). La plantación, inicialmente de patrón 'Mayor', se realizó en 1999 y en la primavera de 2000 se injertó con yemas de la variedad 'Marta'. Los árboles dispuestos a marco de 7 $\mathrm{m} \times 6 \mathrm{~m}$, se regaron por goteo, a partir de un único lateral por hilera de árboles con 4 goteros por árbol, y desde mediados de 2002, momento en el que se alcanzó la situación definitiva del diseño agronómico planteado, a partir 
de 6 goteros árbol ${ }^{-1}$ de $4 \mathrm{~L} \mathrm{~h}^{-1}$, con los que se alcanzó un porcentaje de humectación del suelo del $25 \%$.

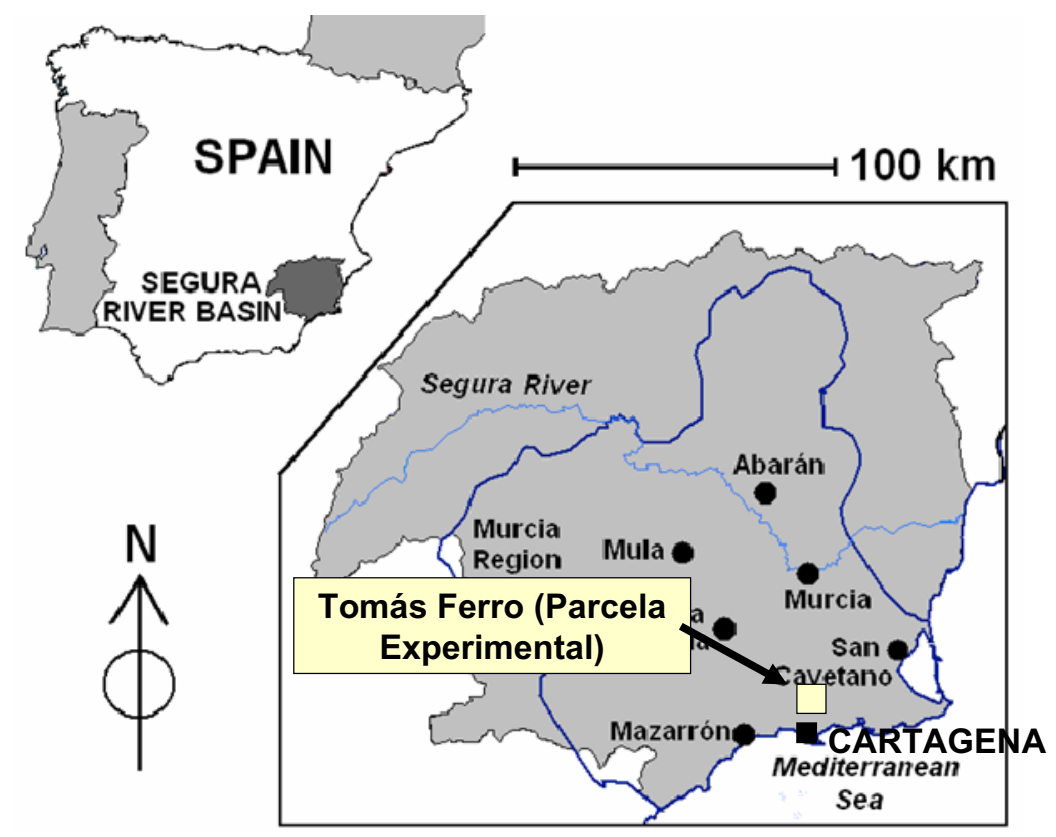

Figura 4.1. Plano de localización de la parcela experimental.

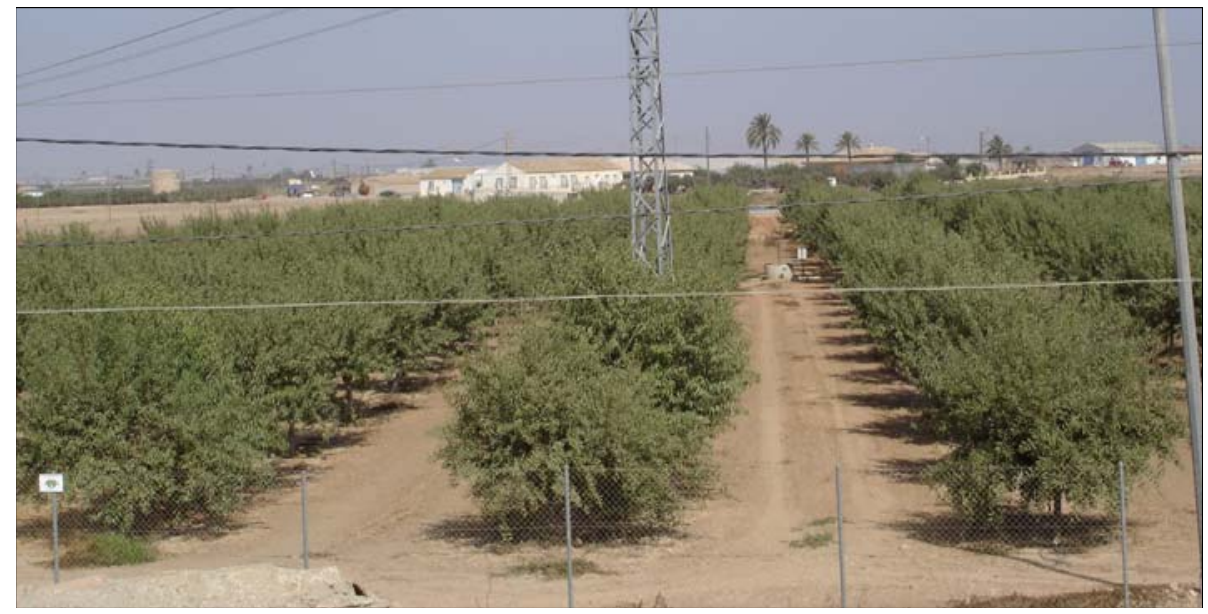

Figura 4.2. Vista general de la parcela experimental de almendros (ETSIA-UPCT).

La climatología, de acuerdo con los datos registrados en una estación climática automática situada a $100 \mathrm{~m}$ de la parcela experimental, fue típicamente mediterránea, con una evapotranspiración de referencia (ETo) y precipitación media anual de 1200 y 350 mm, respectivamente (Figura 4.4).

El suelo, de textura franco-arcillo-limosa, con un contenido de agua útil de $0.18 \mathrm{~m} \mathrm{~m}^{-1} \mathrm{y}$ densidad aparente entre $1.3 \mathrm{y} 1.55 \mathrm{~g} \mathrm{~cm}^{-3}$, es pobre en potasio (120 ppm) y materia orgánica $(0.77 \%$ ), rico en fósforo (82 ppm) y no presenta problemas de salinidad (CE extracto de saturación $1.4 \mathrm{dS} \mathrm{m} \mathrm{m}^{-1}$ ). El agua de 
riego mantuvo una conductividad eléctrica media $\left(\mathrm{CE}_{25^{\circ} \mathrm{C}}\right)$ de $1.2 \mathrm{dS} \mathrm{m}^{-1}$. Todos los árboles recibieron idénticos cuidados agrícolas a excepción del riego que varió de acuerdo con el tratamiento.

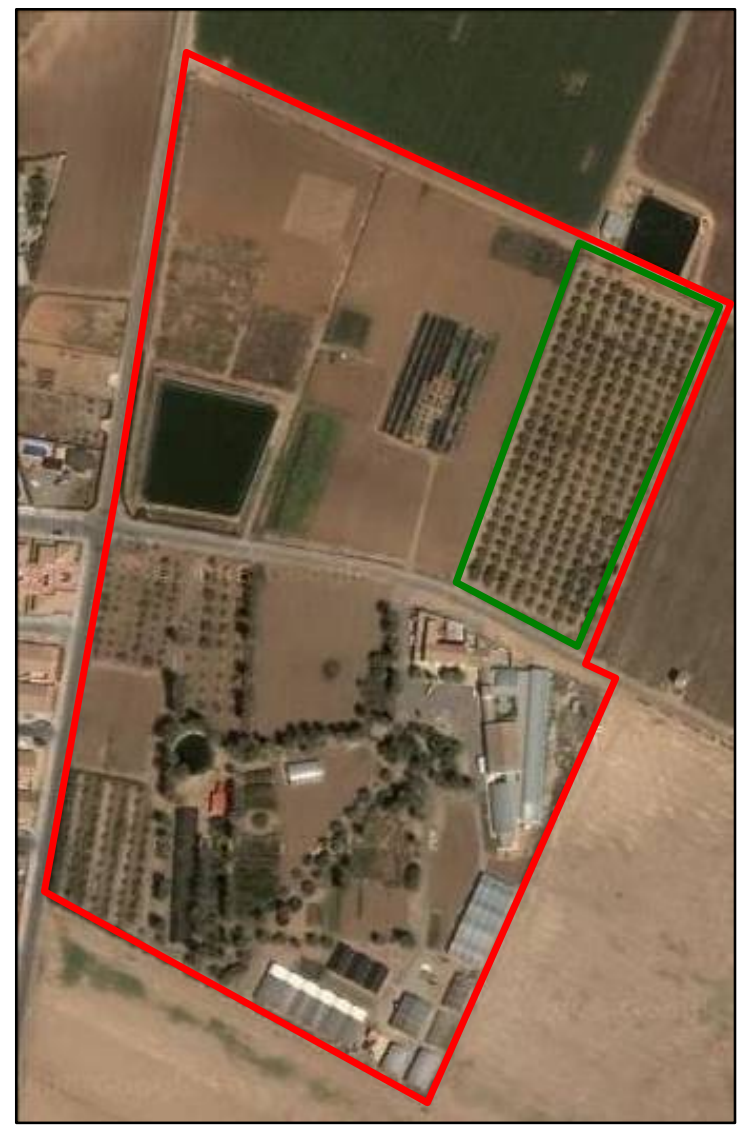

Figura 4.3. Vista aérea de la Estación Experimental Agroalimentaria (ESEA) 'Tomás Ferro'.

Se ensayaron 5 tratamientos de riego (Figura 4.5): un control, $\mathrm{T}_{\text {CTL }}$, regado al $120 \%$ de la evapotranspiración del cultivo (ETc) durante toda la campaña de riego; dos de riego deficitario continuo (RD), $\mathrm{T}_{\mathrm{RD} 80}$ y $\mathrm{T}_{\mathrm{RD} 60}$, regados al 80 y $60 \%$ de la ETc, respectivamente; y dos de riego deficitario controlado (RDC), $\mathrm{T}_{\mathrm{RDC} 40}$ y $\mathrm{T}_{\mathrm{RDC} 20}$, regados al $100 \%$ de la ETc durante todo el año, excepto en la fase IV del crecimiento de fruto, período considerado no crítico (Girona y Marsal, 1995), que se regó al 40 y $20 \%$ de la ETc, respectivamente. La ETc fue calculada a partir de la ETo de PenmanMonteith (Allen et al., 1998), de los coeficientes de cultivo (Kc) proporcionados por la FAO (Doorenbos y Pruitt, 1986) y del coeficiente de corrección debido al área sombreada por el cultivo $(\mathrm{Kr})$, tomado de Fereres et al. (1981a). El diseño experimental fue de bloques al azar, con tres repeticiones por tratamiento, cada una formada por 3 hileras de 4 árboles, siendo la central la utilizada para las medidas experimentales y el resto actuaron como bordes. 
Durante el primer año de ensayo el tratamiento $\mathrm{T}_{\mathrm{RDC} 20}$, recibió idéntica dotación hídrica que $\mathrm{T}_{\text {СтL }}$ (Tabla 4.1), al considerarse el 20\% de la ETc como déficit muy severo para el primer año de injerto.

La figura 4.4 recoge los volúmenes de riego aplicados al tratamiento control y las precipitaciones mensuales ocurridas durante todo el periodo experimental. En los cuatro años de ensayo, el inicio de la campaña de riego tuvo lugar en abril y finalizó en octubre, mientras que las lluvias más importantes tuvieron lugar, fundamentalmente, en otoño e invierno.

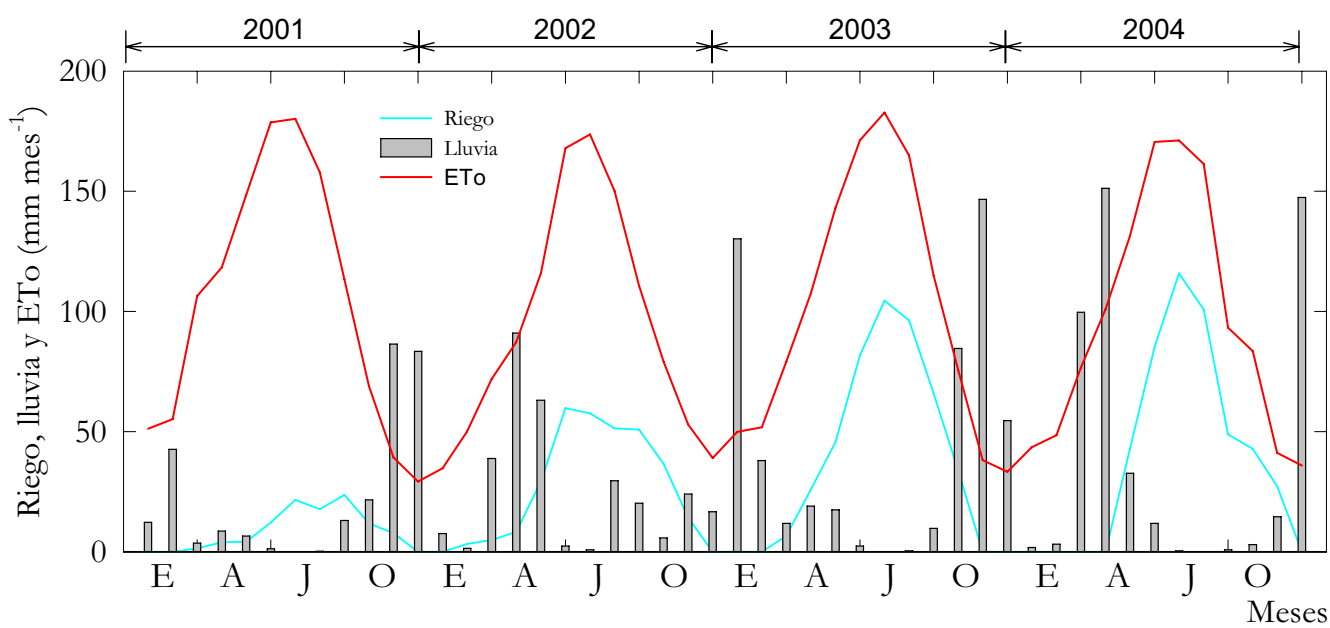

Figura 4.4. Tasas de evapotranspiración de referencia, precipitación y riego mensual aplicado al tratamiento control durante el período 2001-2004.

Tabla 4.1. Volúmenes de agua aplicados durante el período experimental $\left(\mathrm{m}^{3} \mathrm{ha}^{-1}\right)$ y porcentaje respecto al control, para los 5 tratamientos de riego.

\begin{tabular}{cccccccccc}
\hline \multicolumn{8}{c}{ Volumen de riego $\left(\mathrm{m}^{3} \mathbf{h a}^{-1}\right)$} \\
\hline Año & $\mathbf{T}_{\mathrm{CTL}}$ & $\mathbf{T}_{\mathrm{RD} 80}$ & $\mathbf{0}$ & $\mathbf{T}_{\mathrm{RD} 60}$ & $\mathbf{\%}$ & $\mathbf{T}_{\mathrm{RDC} 40}$ & $\%$ & $\mathbf{T}_{\mathrm{RDC} 20}$ & $\%$ \\
\hline $\mathbf{2 0 0 1}$ & 1045 & 881 & 84 & $\mathbf{6 7 8}$ & $\mathbf{6 5}$ & 548 & 52 & 1049 & 100 \\
$\mathbf{2 0 0 2}$ & 3167 & 1936 & 61 & 1524 & 48 & 1437 & 45 & 1403 & 44 \\
$\mathbf{2 0 0 3}$ & 4610 & 3405 & 74 & 2662 & 58 & 2413 & 52 & 2079 & 45 \\
$\mathbf{2 0 0 4}$ & 4638 & 3053 & $\mathbf{6 6}$ & 2729 & 59 & 2708 & 58 & 2196 & 47 \\
\hline Medio & $\mathbf{3 3 6 5}$ & $\mathbf{2 3 1 8}$ & $\mathbf{6 9}$ & $\mathbf{1 8 9 8}$ & $\mathbf{5 6}$ & $\mathbf{1 7 7 6}$ & $\mathbf{5 3}$ & $\mathbf{1 6 8 1}$ & $\mathbf{5 0}$
\end{tabular}

El volumen medio de agua aplicado al tratamiento control durante los 4 años de ensayo fue de $3365 \mathrm{~m}^{3} \mathrm{ha}^{-1}$. Éste fue incrementándose en relación al crecimiento de los árboles, siendo el ahorro medio de agua respecto al control del 31, 44, 47 y $50 \%$ en $\mathrm{T}_{\mathrm{RD} 80}, \mathrm{~T}_{\mathrm{RD} 60}, \mathrm{~T}_{\mathrm{RDC} 40}$ y $\mathrm{T}_{\mathrm{RDC} 20}$, respectivamente (Tabla 4.1). 


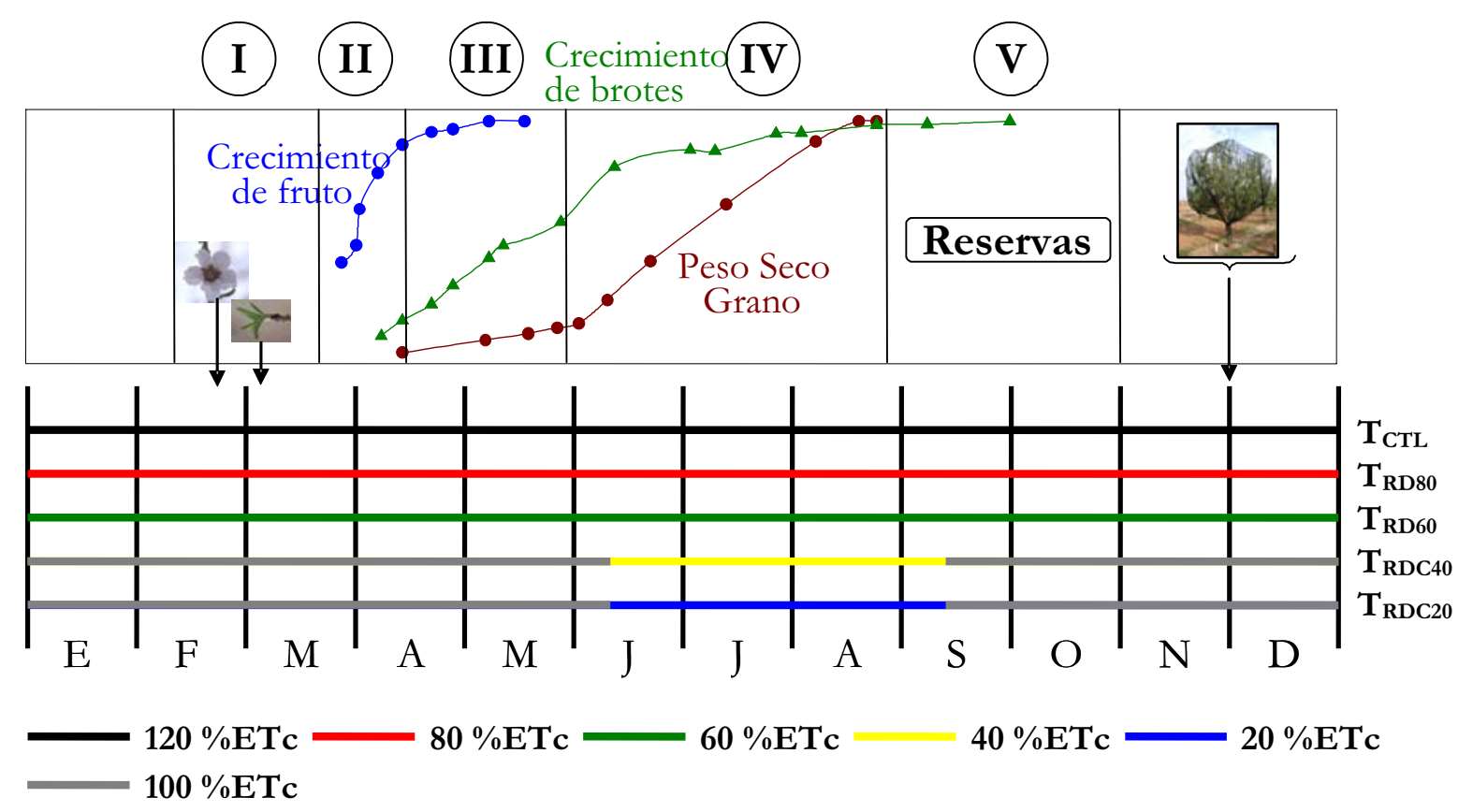

Figura 4.5. Porcentaje de la ETc aplicado en cada tratamiento de riego y período fenológico del cultivo.

\section{Medidas}

\section{Agua-Suelo}

El potencial matricial de agua en el suelo $\left(\Psi_{\mathrm{m}}\right)$ se determinó mediante tensiómetros con vacuómetro tipo Bourdon colocados a 30, 60 y $90 \mathrm{~cm}$ de profundidad, en tres árboles por tratamiento. Las lecturas fueron tomadas de forma periódica 2-3 veces por semana. El contenido volumétrico de agua en el suelo $\left(\theta_{\mathrm{v}}\right)$ se determinó de forma continua con sensores FDR, a partir de 1 sonda por repetición situada a $15 \mathrm{~cm}$ del emisor y 6 sensores colocados a 10 , $20,30,40,50$ y $90 \mathrm{~cm}$ de profundidad.

\section{Agua-Planta}

El potencial hídrico foliar al alba $\left(\Psi_{\mathrm{a}}\right)$ y a mediodía $\left(\Psi_{\mathrm{md}}\right)$ se midió cada dos semanas en 2002 y semanalmente en 2003, con cámara de presión. Para ello, se tomaron dos hojas adultas por árbol y 2 árboles por repetición. Adicionalmente a los seguimientos estacionales, se realizaron dos evoluciones diarias en 2002 y 2003, coincidiendo con el final del período de déficit en los tratamientos de RDC, del potencial de tallo a mediodía $\left(\Psi_{t}\right)$ y conductancia foliar $\left(\mathrm{g}_{\mathrm{j}}\right)$ en idéntico número de hojas que en las medidas estacionales.

El potencial osmótico actual $\left(\Psi_{\mathrm{o}}\right)$ se determinó quincenalmente con osmómetro (Roebling, mod. 13 DR), a partir de las hojas utilizadas en la 
determinación de $\Psi_{\text {a }}$, las cuales fueron envueltas con papel aluminio e introducidas en nitrógeno líquido, y posteriormente, almacenadas a $-20{ }^{\circ} \mathrm{C}$ hasta su determinación. El potencial de presión $\left(\Psi_{\mathrm{p}}\right)$ se calculó como diferencia entre $\Psi_{\mathrm{a}}$ y $\Psi_{\mathrm{o}}$. El potencial osmótico a máxima saturación $\left(\Psi_{\mathrm{os}}\right)$ se midió en hojas recogidas antes del alba, las cuales fueron saturadas inmediatamente, introduciendo sus pecíolos en vasos con agua destilada y mantenidas en oscuridad durante $24 \mathrm{~h}$, tras lo cual fueron congeladas en nitrógeno líquido.

\section{Fenología}

Durante los años 2002 y 2003 se realizó el seguimiento de los estados fenológicos de yemas de flor descritos por Fleckinger (1945), dos veces por semana desde el mes de febrero (yemas en 'estado A' o de reposo), en todos los tratamientos de riego, y a partir de una rama seleccionada por árbol y repetición de $1 \mathrm{~m}$ de longitud y $1.5 \mathrm{~cm}^{2}$ de sección en su base.

\section{Crecimiento vegetativo}

El crecimiento vegetativo se evaluó en base a: i) distribución radical, ii) longitud de brotes, iii) diámetro de tronco, iv) superficie sombreada, v) área foliar, y vi) peso de la madera eliminada durante la poda.

El patrón de enraizamiento del almendro se estudió el invierno de 2002 y 2003, a partir de dos árboles control. Para ello se excavó una zanja de $2 \mathrm{~m}$ de profundidad y $4 \mathrm{~m}$ de largo, perpendicular a la línea portagoteros y en la zona de proyección de la copa (Figura 4.6). Se lavó con agua a presión una banda de $30 \mathrm{~cm}$ en todo el perfil descubierto y a través de una malla tridimensional de celda de $20 \mathrm{~cm}$ × $20 \mathrm{~cm}$ × $30 \mathrm{~cm}$ se realizó el muestreo radical. Las raíces fueron clasificadas por diámetros: $<1 \mathrm{~mm}$ y $>1 \mathrm{~mm}$ a partir de un sistema de análisis de imágenes (WIN RHIZO v4.0b). Los resultados fueron expresados como densidad de longitud radicular (DLR, $\mathrm{cm}$ de raíz por $\mathrm{cm}^{-3}$ de suelo) y densidad de peso radicular (DPR, g de peso seco de raíz por $\mathrm{cm}^{-3}$ de suelo).
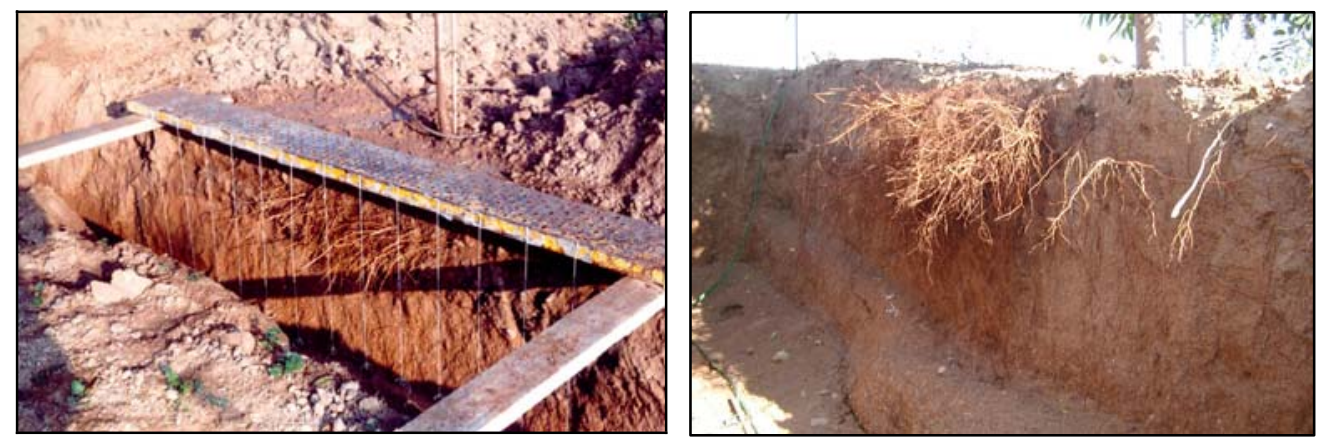

Figura 4.6. Detalle del método de la recogida de raíces. 'Trinchera'. 
El diámetro del tronco se determinó dos veces al año (antes del inicio y final de la actividad del cambium, enero y noviembre, respectivamente) y en los cuatro años de estudio, a partir de medidas del perímetro de tronco, de todos los árboles testigo, y a una altura sobre el suelo de $40 \mathrm{~cm}$ (Figura 4.7). A partir de estos datos se obtuvo el área de la sección transversal del tronco $(\Delta \mathrm{STT})$.

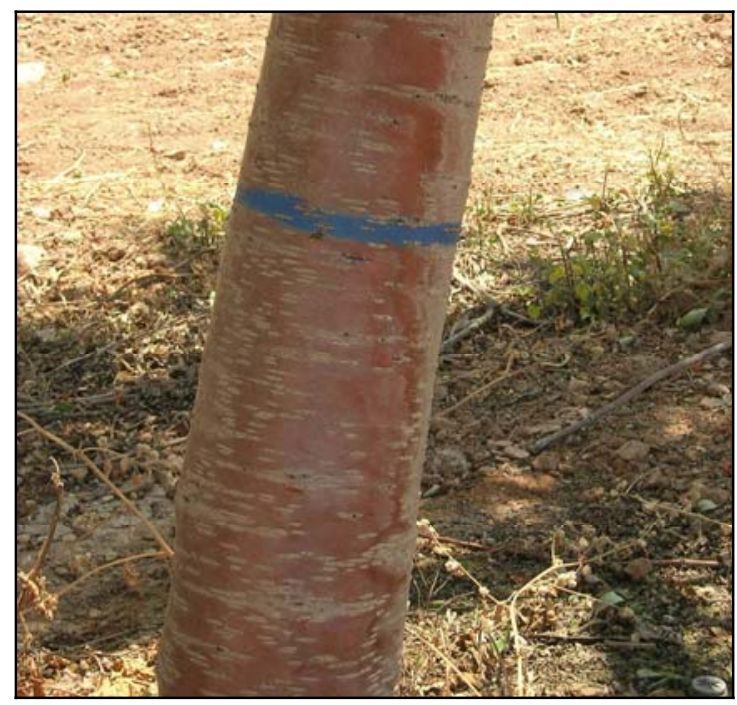

Figura 4.7. Detalle del punto de medida del tronco.

La superficie sombreada fue calculada a partir de los diámetros de copa de todos los árboles testigo, tanto en la dirección de las hileras como en la de las calles, asumiendo que la proyección de la copa describe un área circular.

Para la determinación del área foliar total se envolvió un árbol representativo de cada tratamiento con una malla (Figura 4.8), a fin de recoger la totalidad de sus hojas y determinar el peso seco total. Previamente, se evaluó mediante un sistema de análisis de imagen el área foliar de una muestra de 150 hojas por repetición y tratamiento, y posteriormente su peso seco. La superficie foliar total del árbol fue obtenida mediante el producto del área específica foliar por el peso seco total.

Anualmente, en invierno se realizó la poda de formación y de mantenimiento. Las ramas eliminadas de cada árbol fueron inmediatamente e independientemente pesadas con una balanza Scaltec Mod. SSH91 (capacidad $150 \mathrm{~kg}$, repetibilidad $\leq \pm 5 \mathrm{~g}$ ). Adicionalmente, en 2003 se determinó el peso seco de la poda total de dos árboles por tratamiento. A partir de la relación obtenida entre el peso fresco y seco total se estimó el peso seco de las ramas de poda para el resto del período experimental (Figura 4.9). 


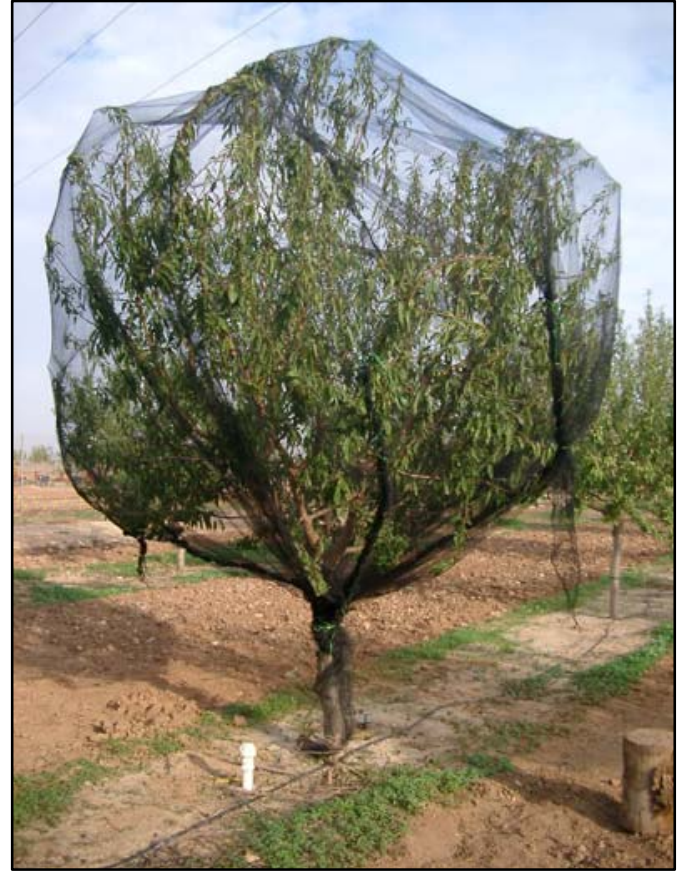

Figura 4.8. Recogida de hojas al final de la estación.

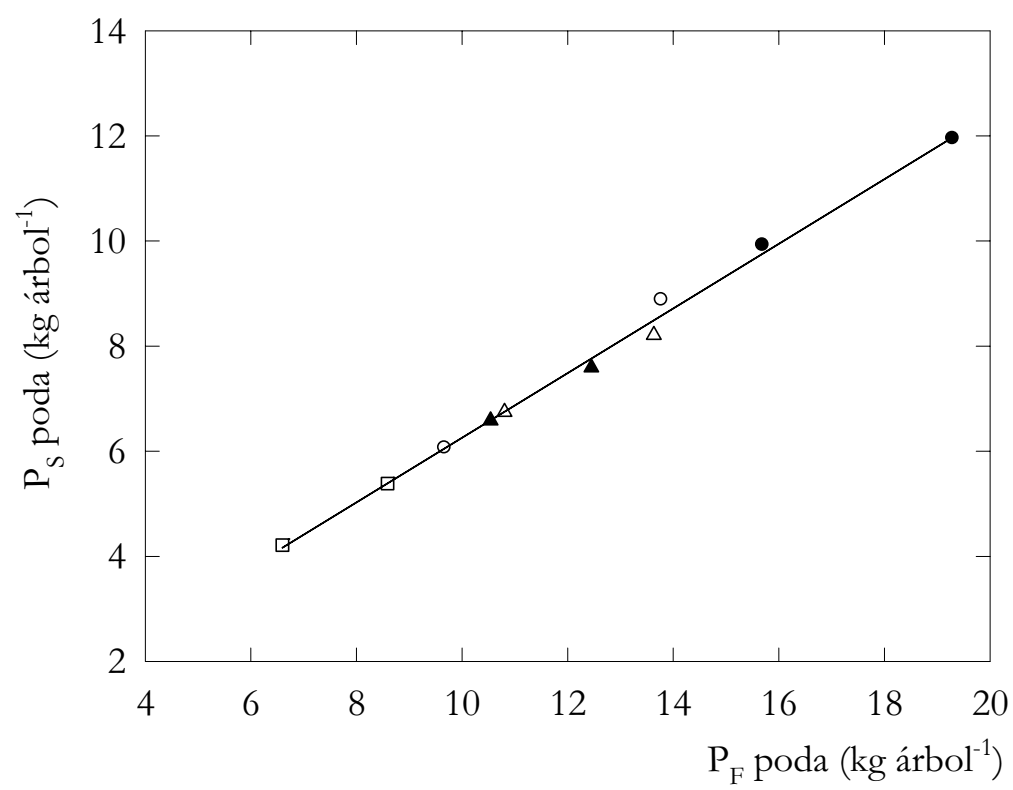

Figura 4.9. Relación peso fresco us peso seco de los restos de poda, para los cinco tratamientos de riego $\mathrm{T}_{\mathrm{CTL}}(\bullet), \mathrm{T}_{\mathrm{RD} 80}(\Delta), \mathrm{T}_{\mathrm{RD} 60}(\Delta), \mathrm{T}_{\mathrm{RDC} 40}(\square)$ y $\mathrm{T}_{\mathrm{RDC} 20}(\mathrm{o})$ en 2003. $\left(\mathrm{P}_{\mathrm{S}}\right.$ $\left.=0.61 \mathrm{P}_{\mathrm{F}}+0.10 ; \mathrm{R}^{2}=0.99 ; \mathrm{P}<0.001\right)$.

\section{Desarrollo del fruto y cosecha}

Durante los años 2002, 2003 y 2004 se realizó el seguimiento de la dinámica de crecimiento del fruto desde el cuajado (marzo) hasta el tamaño definitivo del fruto (junio), midiendo semanalmente los diámetros: longitudinal $\left(\varnothing_{\mathrm{I}}\right)$, ecuatorial $\left(\varnothing_{\mathrm{e}}\right)$ y transversal $\left(\varnothing_{\mathrm{t}}\right)$ con un calibre digital 
Crafstman, en 25 frutos elegidos al azar en dos árboles por repetición y tratamiento.

De forma paralela a las medidas realizadas 'in situ', se escogieron al azar 15 frutos por repetición, que fueron llevados al laboratorio para determinar los diferentes diámetros, peso fresco y seco (estufa ventilada a $65{ }^{\circ} \mathrm{C}$, hasta peso constante), tanto de la pepita como de la cáscara, con balanza (MetLer PJ Delta Range) de $0.001 \mathrm{~g}$ de precisión.

La recolección fue controlada de forma individual en 15 árboles por tratamiento (Figura 4.10). Para ello, se pesó la producción total de cada árbol y posteriormente se tomó una muestra de aproximadamente $500 \mathrm{~g}$ por árbol, en la que se determinó el número total de almendras, peso medio de la almendra y pepita, rendimiento, porcentaje de semillas dobles, vacías y pelonas.

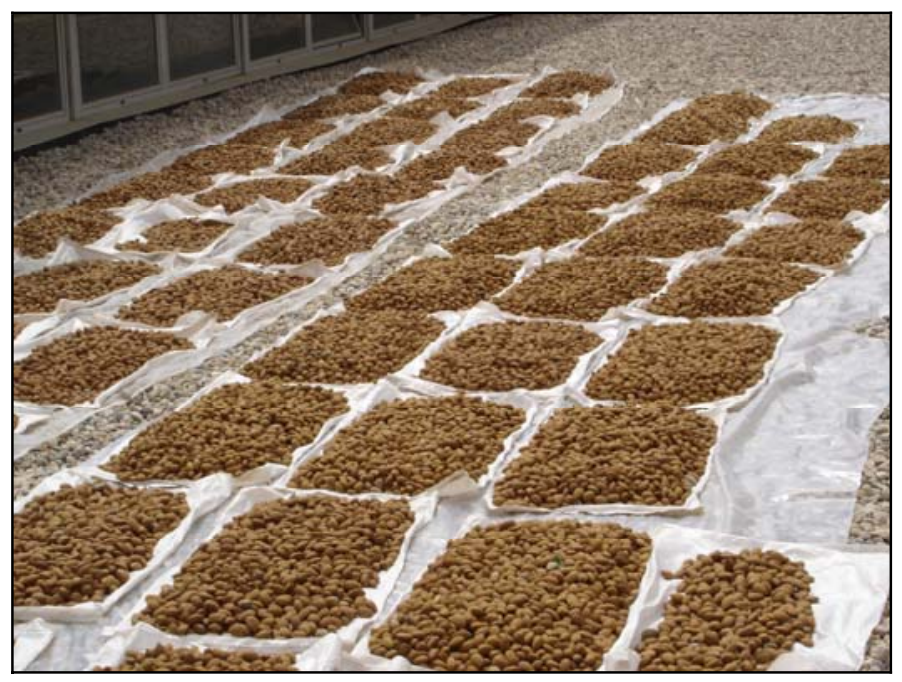

Figura 4.10. Secado al aire de la cosecha individualmente.

\subsection{Resultados y discusión}

\section{Estado hídrico del agua en el suelo}

Los valores del potencial matricial del agua en el suelo $\left(\Psi_{\mathrm{m}}\right)$, en las profundidades de 30,60 y $90 \mathrm{~cm}$, reflejaron la influencia del régimen de riego aplicado (Figura 4.11 y Tabla 4.2). El tratamiento control ( $\mathrm{T}_{\text {СТL }}$ ) mantuvo durante casi todo el año valores medios correspondientes a capacidad de campo (aproximadamente $-20 \mathrm{kPa}$ ) en todas las profundidades estudiadas (Figura 4.11).

Los tratamientos de riego deficitario (RD), regados al 80 y $60 \%$ de la ETc durante todo el año ( $\mathrm{T}_{\mathrm{RD} 80} \mathrm{y} \mathrm{T}_{\mathrm{RD} 60}$, respectivamente), registraron valores medios, en torno a $-50 \mathrm{kPa}$ para $\mathrm{T}_{\mathrm{RD} 80} \mathrm{y}-65 \mathrm{kPa}$ en $\mathrm{T}_{\mathrm{RD} 60}$, en todo el perfil estudiado, incluso con valores fuera de rango $(<-80 \mathrm{kPa})$ en algún momento 
del año. Las precipitaciones ocurridas en otoño unidas a la menor demanda evaporativa (Figura 4.4) fueron insuficientes para recargar el perfil del suelo (Tabla 4.2).

En los tratamientos de RDC $\left(\mathrm{T}_{\mathrm{RDC} 40} \mathrm{y} \mathrm{T}_{\mathrm{RDC} 20}\right)$, con una aplicación del $100 \%$ de la ETc durante las fases II y III (Figura 4.5), $\Psi_{\mathrm{m}}$ mostró valores similares al control a $30 \mathrm{~cm}$, e inferiores con el aumento de la profundidad. Esto es acorde con la ausencia de aplicación de la fracción de lavado. Durante la fase IV, período de reducción del riego en los tratamientos de RDC (Figura 4.5), $\Psi_{\mathrm{m}}$ experimentó una rápida y constante disminución, llegando a valores fuera de rango, los que se mantuvieron durante todo el verano (Figura $4.11 \mathrm{y}$ Tabla 4.2), debido a la elevada demanda evaporativa y ausencia de lluvias (Figura 4.4). Posteriormente y tras la restitución del riego al $100 \%$ de la ETc, mediados de septiembre (Figura 4.5), $\Psi_{\mathrm{m}}$ alcanzó valores similares a $\mathrm{T}_{\mathrm{CTL}}$ a los 4 días a $30 \mathrm{~cm}$ y un mes más tarde a 60 y $90 \mathrm{~cm}$ de profundidad.

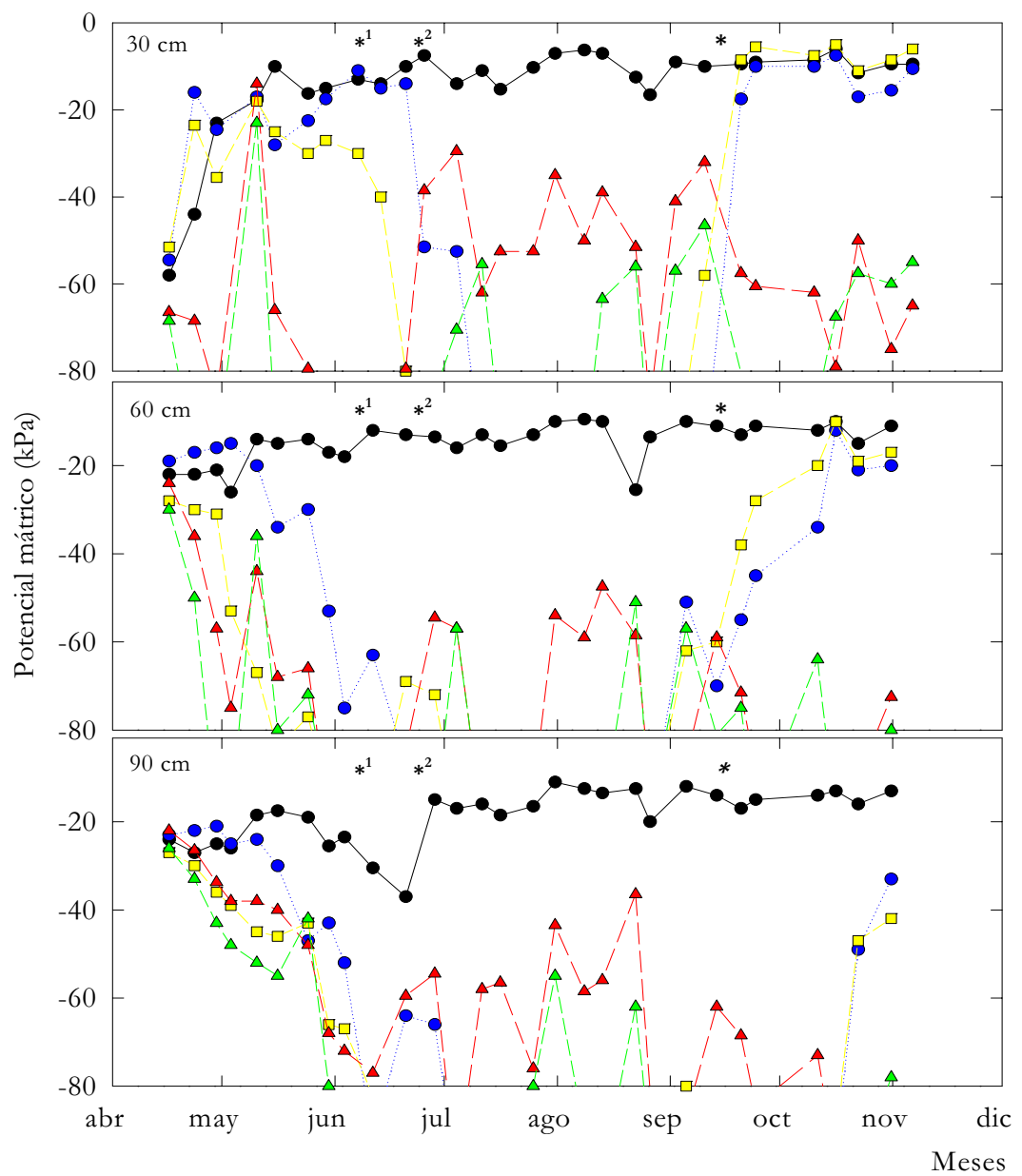

Figura 4.11. Evolución del potencial matricial $\left(\Psi_{\mathrm{m}}\right)$ en los 5 tratamientos de riego: $\mathrm{T}_{\text {CTL }}$

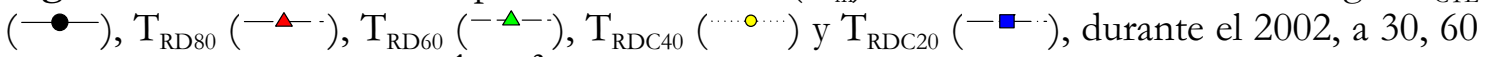
y $90 \mathrm{~cm}$ de profundidad. $*^{1}$ y $*^{2}$ indican el cambio de riego en los tratamientos $\mathrm{T}_{\mathrm{RDC} 40} \mathrm{y}$ $\mathrm{T}_{\mathrm{RDC} 20}$ al $40 \%$ y $20 \%$ de la $\mathrm{ET}_{\mathrm{c}}$ respectivamente; $*$ indica la restitución del riego al $100 \%$. 
Teniendo en cuenta que la porción de suelo humectado por el sistema de riego localizado se encuentra por debajo del $30 \%$, los valores de $\Psi_{\mathrm{m}}$ registrados durante los períodos de reducción del riego, se pueden considerar muy bajos y capaces de inducir un déficit hídrico significativo en la planta (Fereres et al., 1981b; Du Plessis, 1988).

Tabla 4.2. Valores medios prerriego de $\Psi_{\mathrm{m}}$ en tres momentos característicos de 2002, según la estrategia de riego y para los 5 tratamientos, a 30, 60 y $90 \mathrm{~cm}$ de profundidad.

\begin{tabular}{|c|c|c|c|c|}
\hline \multirow{2}{*}{ Tratamiento } & \multirow{2}{*}{$\begin{array}{l}\text { Profundidad } \\
\qquad(\mathrm{cm})\end{array}$} & \multicolumn{3}{|c|}{$\Psi \mathrm{m}$ prerriego $(\mathrm{kPa})$} \\
\hline & & Abr - May & Jun - Ago & Sep - Nov \\
\hline $\mathbf{T}_{\mathrm{CTL}}$ & & $-16.4 \mathrm{a}$ & $-11.1 \mathrm{a}$ & $-9.17 \mathrm{a}$ \\
\hline $\mathbf{T}_{\mathrm{RD} 80}$ & & $-68.0 \mathrm{~b}$ & $-64.1 b$ & $-59.0 \mathrm{~b}$ \\
\hline $\mathbf{T}_{\mathrm{RD} 60}$ & 30 & $-79.6 \mathrm{~b}$ & $<-80 \mathrm{c}$ & $-59.4 b$ \\
\hline $\mathbf{T}_{\mathrm{RDC} 40}$ & & $-26.8 \mathrm{a}$ & $<-80 \mathrm{~d}$ & $-8.3 \mathrm{a}$ \\
\hline $\mathbf{T}_{\mathrm{RDC} 20}$ & & $-18.4 \mathrm{a}$ & $<-80 \mathrm{~d}$ & $-12.6 \mathrm{a}$ \\
\hline $\mathbf{T}_{\mathrm{CTL}}$ & & -18.9 a & $-14.0 \mathrm{a}$ & $-11.6 \mathrm{a}$ \\
\hline $\mathbf{T}_{\mathrm{RD} 80}$ & & $-58.5 \mathrm{bc}$ & $-76.9 \mathrm{~b}$ & $<-80 \mathrm{~b}$ \\
\hline $\mathbf{T}_{\mathrm{RD} 60}$ & 60 & $-70.4 \mathrm{c}$ & $<-80 \mathrm{c}$ & $<-80 \mathrm{~b}$ \\
\hline $\mathbf{T}_{\mathrm{RDC} 40}$ & & $-35.5 a b$ & $<-80 \mathrm{c}$ & $-22.0 \mathrm{a}$ \\
\hline $\mathbf{T}_{\mathrm{RDC} 20}$ & & $-21.6 \mathrm{a}$ & $<-80 \mathrm{c}$ & $-21.8 \mathrm{a}$ \\
\hline $\mathbf{T}_{\mathrm{CTL}}$ & & $-22.8 \mathrm{a}$ & $-18.7 \mathrm{a}$ & $-14.3 \mathrm{a}$ \\
\hline $\mathbf{T}_{\mathrm{RD} 80}$ & & $-39.3 b$ & $-64.5 b$ & $<-80 \mathrm{~b}$ \\
\hline $\mathbf{T}_{\mathrm{RD} 60}$ & 90 & $-47.4 b$ & $<-80 \mathrm{c}$ & $<-80 \mathrm{c}$ \\
\hline $\mathbf{T}_{\mathrm{RDC} 40}$ & & $-44.3 b$ & $<-80 \mathrm{~d}$ & $-44.5 d$ \\
\hline $\mathbf{T}_{\mathrm{RDC} 20}$ & & $-37.9 b$ & $<-80 \mathrm{~d}$ & $-41.0 \mathrm{~d}$ \\
\hline
\end{tabular}

$\overline{\text { Los valores medios de cada profundidad y período de estudio, seguidos }} \overline{\text { de letras distintas }}$ indican la existencia de diferencias significativas a nivel de columna por cada profundidad y tratamiento, según el test de Tukeyo.05.

La evolución de la humedad volumétrica expresada de forma relativa al máximo valor obtenido tras una lluvia de $80 \mathrm{~mm}$, y de acuerdo con los registros obtenidos a partir de sondas capacitivas, presentó durante el mes de julio un mayor agotamiento del agua en el suelo en los tratamientos deficitarios que en el control, 50-60\% frente al 10-15\% del control en los 
primeros $30 \mathrm{~cm}$ de profundidad (Figura 4.12). La alta demanda evaporativa de este período (Figura 4.4) y la elevada actividad radicular en esta profundidad (Figuras 4.16 y 4.17) acentuaron los cambios de contenido de humedad entre los diferentes regímenes de riego. El registro continuo de la humedad volumétrica del suelo fue fiel reflejo tanto de la ocurrencia de los riegos programados como de la profundidad efectiva del riego (Figura 4.12).

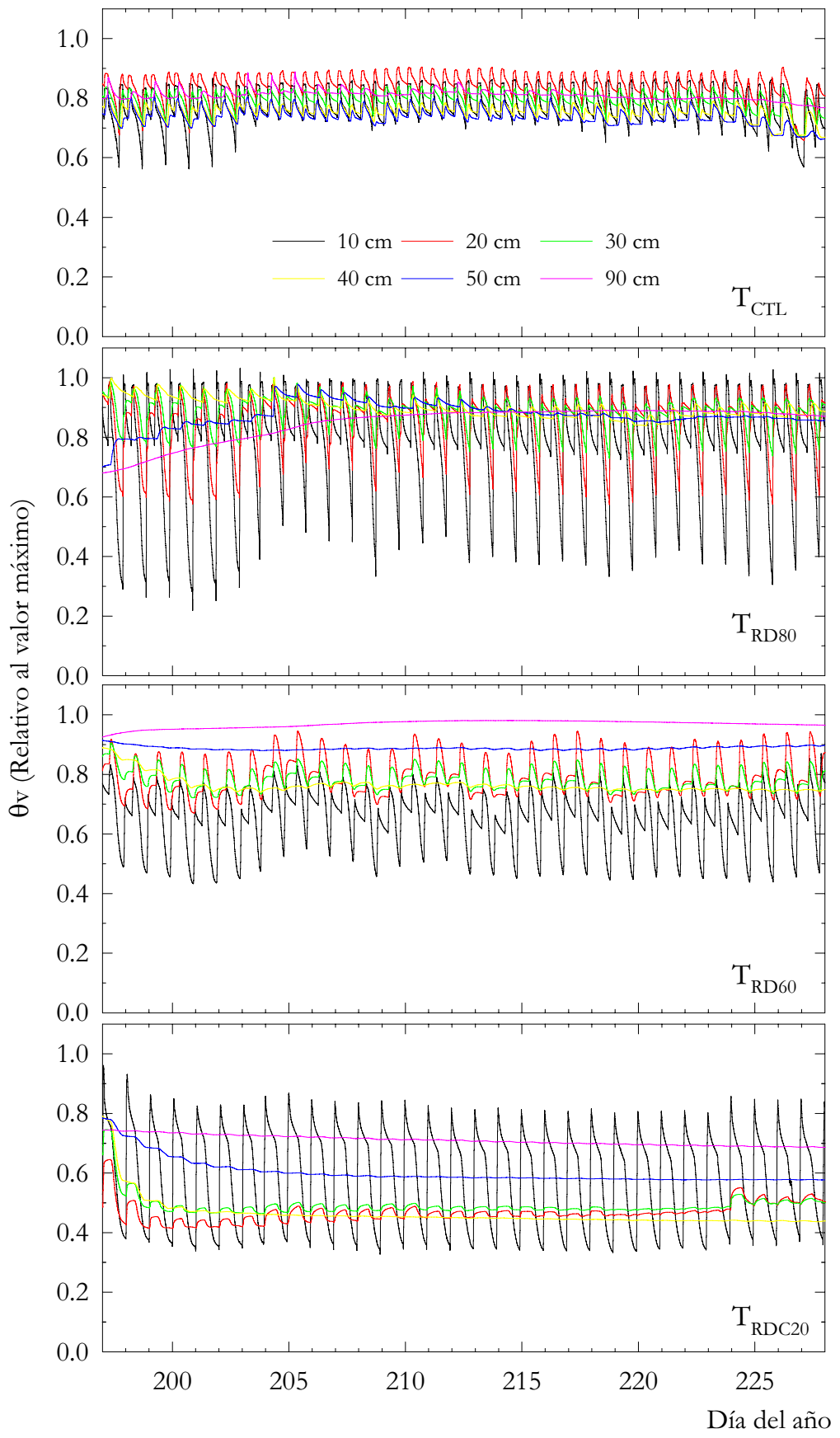

Figura 4.12. Evolución del contenido de humedad volumétrica relativa al valor máximo obtenido tras una lluvia de $80 \mathrm{~mm}$, en 4 tratamientos de riego y para 6 profundidades diferentes. Julio de 2002. 


\section{Estado hídrico del agua en la planta}

Durante la mayor parte del período experimental el tratamiento control $\left(\mathrm{T}_{\text {СтL }}\right)$ mostró valores medios de potencial hídrico foliar antes del alba $\left(\Psi_{2}\right)$ en torno a $-0.41 \mathrm{MPa}$ (Figura 4.13 a y d), lo que indica que estos árboles no presentaron condiciones limitantes en su transpiración (Castel y Fereres, 1982; Torrecillas et al., 1989b; 1989a; Girona et al., 2004; Romero et al., 2004b). En octubre de 2002 se alcanzó un valor mínimo de -0.60 $\mathrm{MPa}$, como consecuencia de la supresión del riego, tras la ocurrencia de lluvias, al objeto de mejorar la eficiencia de uso de las lluvias acaecidas.

Los tratamientos $T_{R D 80}$ y $T_{R D 60}$ registraron en la primavera de 2002 valores de $\Psi_{\text {a }}$ cercanos a -0.5 , no siendo significativamente diferentes entre ellos, pero sí con respecto a $\mathrm{T}_{\text {СтL }}$ (Figura 4.13 a). La elevada pluviometría en la primavera de este año $(193 \mathrm{~mm})$ junto a una menor demanda evaporativa pueden explicar el ligero déficit alcanzado.

Durante la fase IV, período de elevada demanda climática, el tratamiento $\mathrm{T}_{\mathrm{RD} 60}$ alcanzó valores de $\Psi_{\mathrm{a}}$ inferiores a $\mathrm{T}_{\mathrm{RD} 80}$ (Figura 4.13 a y d). En ambos tratamientos, los valores fueron ligeramente más altos en 2002 que en 2003 , lo que fue asociado al mayor agotamiento del agua del suelo, al tratarse del tercer año de aplicación de los tratamientos, y a la menor presencia de lluvias durante este último año, tanto previas como durante el período (Figura 4.4). Los tratamientos de déficit hídrico durante los meses de máxima demanda evaporativa $\left(\mathrm{T}_{\mathrm{RDC} 40}\right.$ y $\left.\mathrm{T}_{\mathrm{RDC} 20}\right)$ mantuvieron valores de $\Psi_{\text {a }}$ próximos a $\mathrm{T}_{\text {СтL }}$ durante el periodo de riego al $100 \%$ de la ETc, mientras que durante la reducción del riego (Fase IV, Figura 4.5) alcanzaron valores mínimos de -0.8 y $-1.0 \mathrm{MPa}$, respectivamente. Estos valores fueron menores a los obtenidos por $\mathrm{T}_{\mathrm{RD} 80}$ y $\mathrm{T}_{\mathrm{RD} 60}$ (Figura 4.13). Niveles de estrés hídrico muy superiores a éstos $\left(\Psi_{\mathrm{a}}<-2 \mathrm{MPa}\right)$ han sido observados en esta fase en almendro adultos sometidos a RDC (Goldhamer, 1996; Romero et al., 2004b). Durante la fase postcosecha y tras la restitución del riego al $100 \%$ de la ETc en ambos tratamientos, $\Psi_{\text {a }}$ alcanzó niveles similares a los del control, al siguiente día de medida (Figura 4.13 a y d). En ningún caso se alcanzaron durante esta fase valores de $\Psi_{a}$ inferiores o dentro del rango $[-1.0,-1.5 \mathrm{MPa}]$, los que son considerados perjudiciales para el cultivo (Girona y Marsal, 1995).

El déficit hídrico alcanzado en 2002 no generó situaciones de pérdida de turgencia foliar en ningún tratamiento. El mayor déficit generado por el tratamiento $\mathrm{T}_{\mathrm{RDC} 20}$ disminuyó significativamente sus niveles de potencial de presión $\left(\Psi_{\mathrm{p}}\right)$ (Figura 4.13 b), lo que indica que el potencial osmótico actual no disminuyó lo suficiente como para mantener la turgencia foliar en los mismos niveles que el control. Sin embargo, los tratamientos de RDC con valores de 
$\Psi_{a} \leq-0.8 \mathrm{MPa}$ durante más de dos meses, fueron capaces de desarrollar mecanismos de ajuste osmótico. Las diferencias de potencial osmótico saturado $\left(\Psi_{\text {оs }}\right)$ respecto a $\mathrm{T}_{\text {СтL }}$ fueron muy similares para ambos tratamientos y del orden de $0.30 \mathrm{MPa}$ (Figura $4.13 \mathrm{c}$ ). Este grado de ajuste osmótico parece ser el responsable del mantenimiento de la turgencia celular (Kramer, 1983; 1988) al final de la fase IV en $\mathrm{T}_{\mathrm{RDC} 40} \mathrm{y}_{\mathrm{RDC} 20}$ (Figura $4.13 \mathrm{c}$ ). Albaricoqueros adultos necesitaron valores inferiores a $-1.5 \mathrm{MPa}$ de $\Psi_{\text {a }}$ para desarrollar este mecanismo de tolerancia a la sequía (Torrecillas et al., 1999).

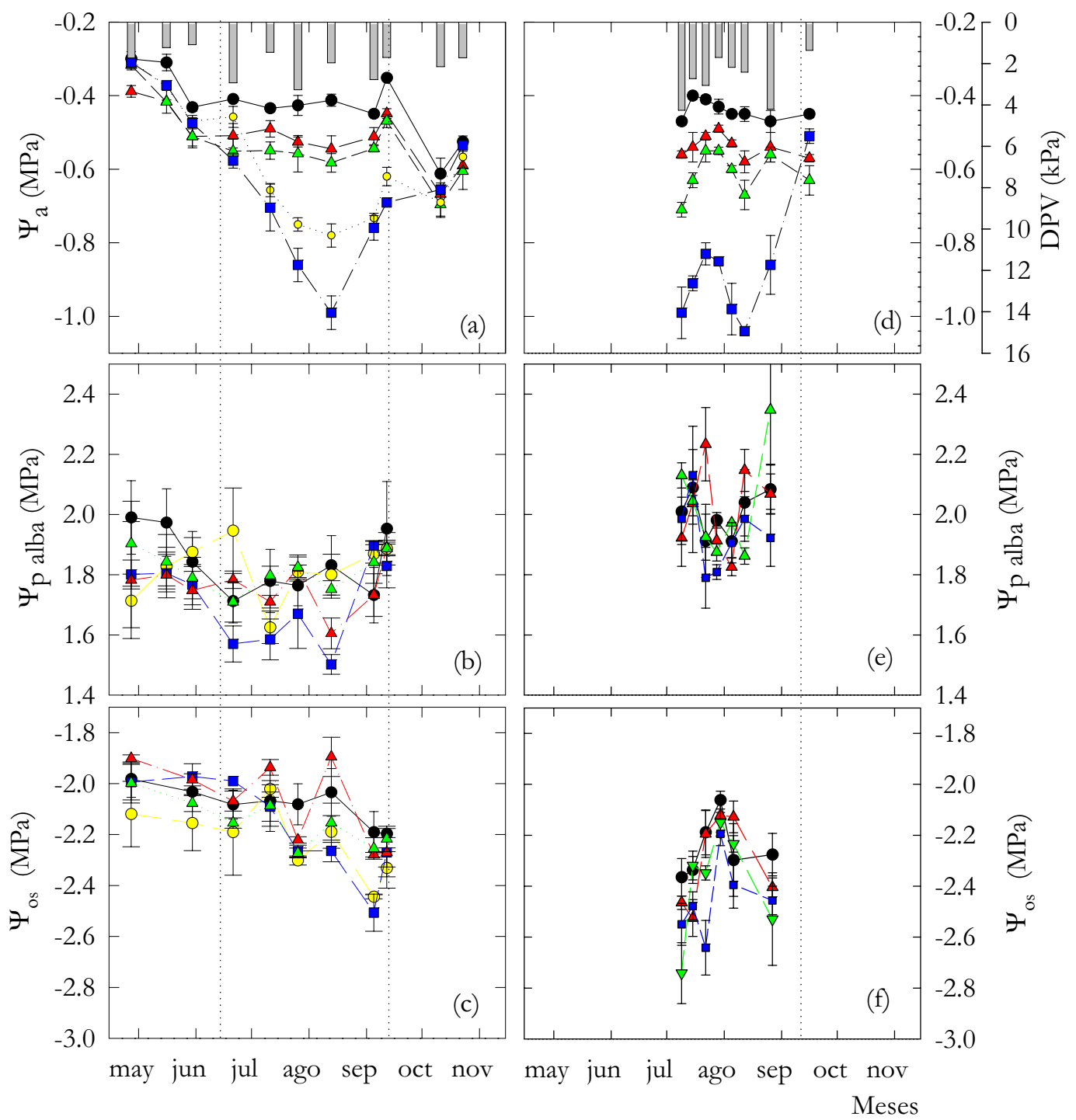

Figura 4.13. Evolución estacional de potencial hídrico al alba $\left(\Psi_{2}\right)$, potencial de presión $\left(\Psi_{\mathrm{p}}\right)$ y potencial osmótico saturado $\left(\Psi_{\mathrm{OS}}\right)$ de los tratamientos de riego ensayados: $\mathrm{T}_{\mathrm{CTL}}$

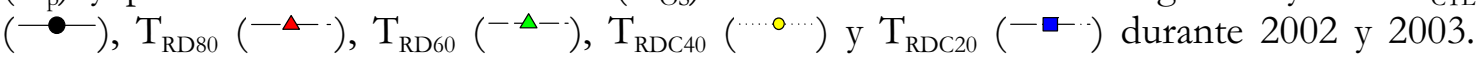
Cada punto corresponde a la media de 3 repeticiones \pm ES. La línea de puntos delimita el período de aplicación del RDC. Las barras indican los valores del déficit de presión de vapor máximo diario (DPV). 
Durante 2003, el mayor estrés hídrico alcanzado en el tratamiento $\mathrm{T}_{\mathrm{RDC} 20}$ promovió un ajuste osmótico a mediados de julio, con una diferencia de $0.40 \mathrm{MPa}$ con respecto al control (Figura $4.13 \mathrm{f}$ ). En el resto de tratamientos el déficit hídrico no generó diferencias significativas en las componentes del potencial hídrico foliar antes del alba (Figura 4.13 e y f). Similares valores de ajuste osmótico $(\approx-0.3 \mathrm{MPa})$ se han encontrado en almendro sometido a estrés hídrico (Castel y Fereres, 1982; Romero et al., 2004b).

El estudio del estado hídrico de la planta se completó con dos evoluciones diarias de $\Psi_{\mathrm{t}}$ y gi: una realizada en septiembre de 2002 y otra en agosto de 2003 (Figura 4.14 a y b).

$\Psi_{\mathrm{t}}$ mostró un ritmo circadiano característico, con valores máximos al alba y mínimos a mediodía. En $\mathrm{T}_{\text {СТL }}$ el descenso de $\Psi_{\mathrm{t}}$ en las horas centrales del día fue más acusado en la evolución realizada en agosto de 2003 que en la de septiembre de 2002 (Figura 4.14 b), lo que puede estar asociado a una mayor demanda evaporativa (McCutchan y Shackel, 1992; Romero y Botía, 2006). Los tratamientos de riego deficitario constante mostraron valores similares a $T_{\text {СТL }}$ en 2002 e inferiores en 2003, excepto los de las primeras horas del día de $\mathrm{T}_{\mathrm{RD} 80}$ que fueron similares a $\mathrm{T}_{\mathrm{CTL}}$. Hecho que puede estar ligado a un mayor agotamiento de las reservas de agua del suelo con el avance del ensayo. Los tratamientos de RDC, regados al 40 y $20 \%$ de la ETc presentaron valores de $\Psi_{\mathrm{t}}$ inferiores a $\mathrm{T}_{\mathrm{CTL}}$ (Figura 4.14 a y b). Las reducciones en $\mathrm{T}_{\mathrm{RDC} 20}$ fueron del orden de 0.4 y $0.6 \mathrm{MPa}$ antes del alba y de 0.8 y $1.5 \mathrm{MPa}$ a mediodía en 2002 y 2003, respectivamente (Figura 4.14 a y b).

En $\mathrm{T}_{\text {CTL }}$ la conductancia foliar $\left(\mathrm{g}_{\mathrm{I}}\right)$, durante las horas centrales del día alcanzó valores superiores a $250 \mathrm{mmol} \mathrm{m}^{-2} \mathrm{~s}^{-1}$, indicadores de un período de alta demanda hídrica y elevada radiación fotosintéticamente activa (RFA) (Figura 4.14). La conducta del estoma fue la típica de árboles bien regados con valores altos y relativamente constantes en el período de máxima RFA. Similares valores de $g_{1}$, en almendros bien regados, fueron obtenidos por otros autores (Marsal et al., 1997; Romero et al., 2004b; Girona et al., 2005). 


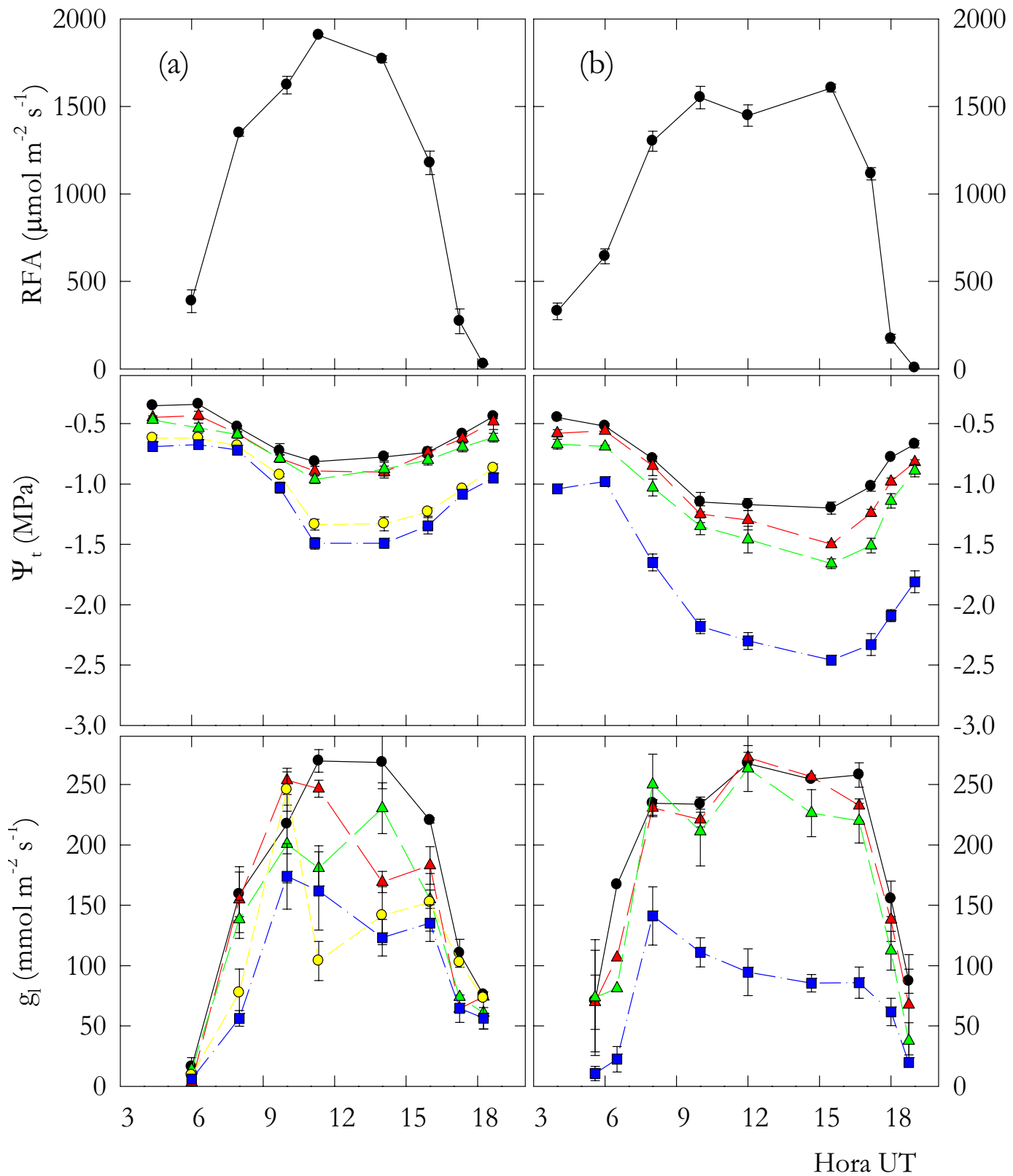

Figura 4.14. Evolución diaria de la radiación fotosintéticamente activa (RFA $\bullet$ ), potencial hídrico de tallo $\left(\Psi_{t}\right)$ y conductancia foliar $\left(g_{t}\right)$ en los distintos tratamientos de riego: $\mathrm{T}_{\mathrm{CTL}}(-\bullet), \mathrm{T}_{\mathrm{RD} 80}\left(-\boldsymbol{-}^{-}\right), \mathrm{T}_{\mathrm{RD} 60}\left({ }^{-\Delta-}\right), \mathrm{T}_{\mathrm{RDC} 40}(\cdots \cdots \cdots)$ y $\mathrm{T}_{\mathrm{RDC} 20}(--\cdots)$. (a) septiembre de 2002 y (b) agosto de 2003. Cada punto corresponde a la media de tres repeticiones $\pm \mathrm{ES}$.

Los tratamientos deficitarios alcanzaron la máxima apertura estomática antes de las $10.00 \mathrm{UT}$. Ahora bien, el comportamiento de $\mathrm{T}_{\mathrm{RD} 80}$ y $\mathrm{T}_{\mathrm{RD} 60}$ fue muy distinto en septiembre de 2002 que en agosto de 2003. Mientras que en 2002 mostraron una clara regulación estomática a partir de las 10.00 UT, en 2003 tan sólo $\mathrm{T}_{\mathrm{RD} 60}$ redujo ligeramente sus tasas a partir del mediodía solar. $\mathrm{El}$ mayor déficit hídrico alcanzado en $\mathrm{T}_{\mathrm{RDC} 40}$ y $\mathrm{T}_{\mathrm{RDC} 20}$ quedó reflejado en su comportamiento estomático. Este hecho ha sido observado por Henson et al. 
(1982) en peral y Torrecillas et al. (1988b) en almendro. La mayor regulación estomática fue observada en $\mathrm{T}_{\mathrm{RDC} 20}$, que mostró valores muy bajos durante todo el día en los dos años de medida, siendo su valor máximo de aproximadamente $150 \mathrm{mmol} \mathrm{m}^{-2} \mathrm{~s}^{-1}$ (Figura 4.14).

De acuerdo con los resultados obtenidos, el potencial hídrico y la conductancia foliares han mostrado ser indicadores sensibles y consistentes del estado hídrico del almendro, por lo que ambos podrían ser usados como herramienta de ayuda para la programación del riego, tal y como sugieren Hutmacher et al. (1994).

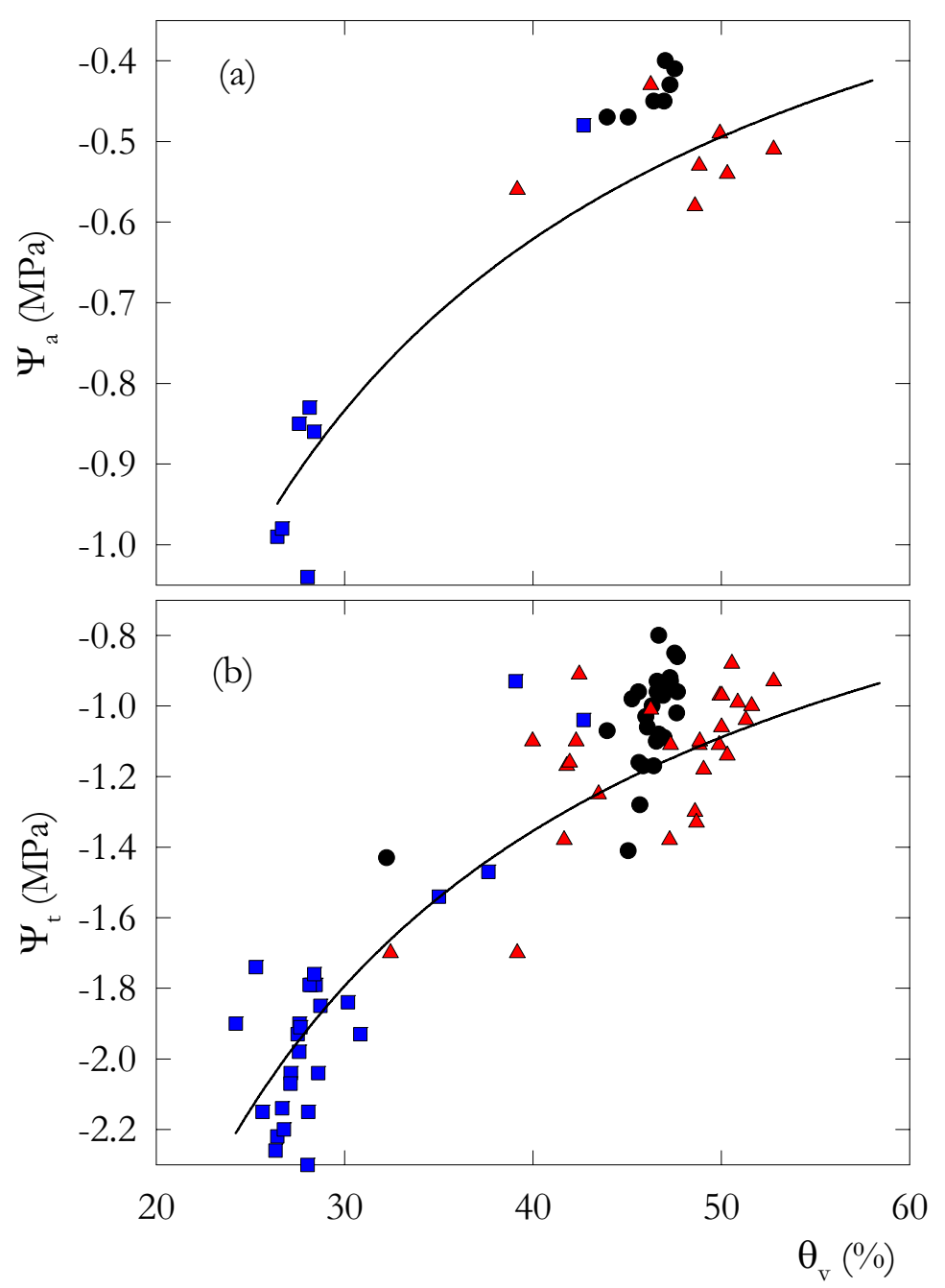

Figura 4.15. a) Relación entre el potencial hídrico foliar antes del alba $\left(\Psi_{\mathrm{a}}\right)$ y la humedad volumétrica en el perfil de suelo $0-90 \mathrm{~cm}\left(\theta_{\mathrm{v}}\right)\left(\Psi_{\mathrm{a}}=-27.01 \theta_{\mathrm{v}}^{-1.022} ;\left(\mathrm{R}^{2}=0.77\right) \mathrm{P}<0.05\right)$. b) Relación entre el potencial de tallo a mediodía $\left(\Psi_{t}\right)$ y la humedad volumétrica en el perfil de suelo $0-90 \mathrm{~cm}\left(\theta_{\mathrm{v}}\right)\left(\Psi_{\mathrm{t}}=-49.76 \theta_{\mathrm{v}}^{-0.977} ;\left(\mathrm{R}^{2}=0.74\right) \mathrm{P}<0.001\right)$. Para los tratamientos de riego, $\mathrm{T}_{\mathrm{CTL}}(\bullet), \mathrm{T}_{\mathrm{RD} 80}(\boldsymbol{\bullet}) \mathrm{y}_{\mathrm{RDC} 20}(\boldsymbol{\bullet})$. 
La relación encontrada entre el contenido volumétrico de agua en el suelo en el perfil de 0 a $90 \mathrm{~cm}$ de profundidad y el potencial hídrico foliar antes del alba y de tallo a mediodía (Figura 4.15) fue similar a la encontrada en almendro por Romero et al. (2004b), en melocotonero por Goldhamer et al. (1999) y en albaricoquero por Pérez-Pastor (2001) bajo RDC, y en la que, a pesar de la dispersión típica de este tipo de relaciones, se sugiere un valor de $\theta_{v}$ de aproximadamente $40 \%$ por debajo del cual $\Psi_{\mathrm{a}}$ y $\Psi_{\mathrm{t}}$ disminuyen en mayor medida en respuesta a las reducciones de $\theta_{\mathrm{v}}$. Este valor correspondería a valores de $\Psi_{\mathrm{a}}$ y $\Psi_{\mathrm{t}}$ de -0.55 y $-1.2 \mathrm{MPa}$, respectivamente, que podrían ser calificados como de óptimos para el cultivo de almendros jóvenes.

\section{Crecimiento vegetativo}

\section{Patrón de enraizamiento}

En el tratamiento control y en los dos muestreos realizados en 2002, la mayor densidad de longitud radical (DLR) se encontró en los primeros $20 \mathrm{~cm}$ de profundidad, en la misma línea portagoteros y en raíces menores de $1 \mathrm{~mm}$ de diámetro (Figura 4.16 a). En 2003, el valor más elevado se dio a $30 \mathrm{~cm}$ de profundidad $\left(0.70 \mathrm{~cm} \mathrm{~cm}^{-3}\right)$ y fue del orden de 9 veces superior al obtenido en el año anterior (Figura $4.16 \mathrm{a} \mathrm{y} \mathrm{b).} \mathrm{Este} \mathrm{incremento} \mathrm{en} \mathrm{profundidad} \mathrm{en} \mathrm{los}$ valores de DLR también se produjo en extensión horizontal. Así, mientras que en 2002 la practica totalidad del sistema radicular se encontraba en una banda de $140 \mathrm{~cm}$ de ancho, en 2003 el $15 \%$ se encontraba fuera de dicha banda (Figuras 4.16 a, b, c y d). El peso seco total de raíces también se vio incrementado entre un 80-90\% en 2003 con respecto a 2002, principalmente en la zona humectada (Figuras 4.16 y 4.17). En un sistema de riego localizado, el efecto hidrotrópico predomina sobre el geotrópico modificando el patrón de distribución radicular tal y como ha sido comentado en numerosos estudios en cítricos y frutales (Del Amor et al., 1987; Fernández et al., 1992; Franco y Abrisqueta, 1997; Romero et al., 2004b; Ruiz-Sánchez et al., 2005).

Estos valores de DLR muestran una elevada concentración de raíces de diámetro inferior a $1 \mathrm{~mm}$ (aproximadamente un $85 \%$ del total de raíces tanto en 2002 como 2003), lo que confiere al almendro una gran capacidad de absorción de agua (Figura 4.16), y por tanto de uso eficiente del agua y los fertilizantes (Brown y Uriu, 1996). Por otro lado, se observa que el $90 \%$ del total de raíces se encuentra en los primeros $50 \mathrm{~cm}$ de profundidad, con mayor densidad en la zona humectada (Figuras 4.16 y 4.17). De ahí que con fines de programación del riego, y cuando se utilicen aguas de baja salinidad sería recomendable ajustar la profundidad de riego a esos $50 \mathrm{~cm}$ de suelo. Una distribución radicular muy similar fue encontrada en almendro por Catlin (1996). 


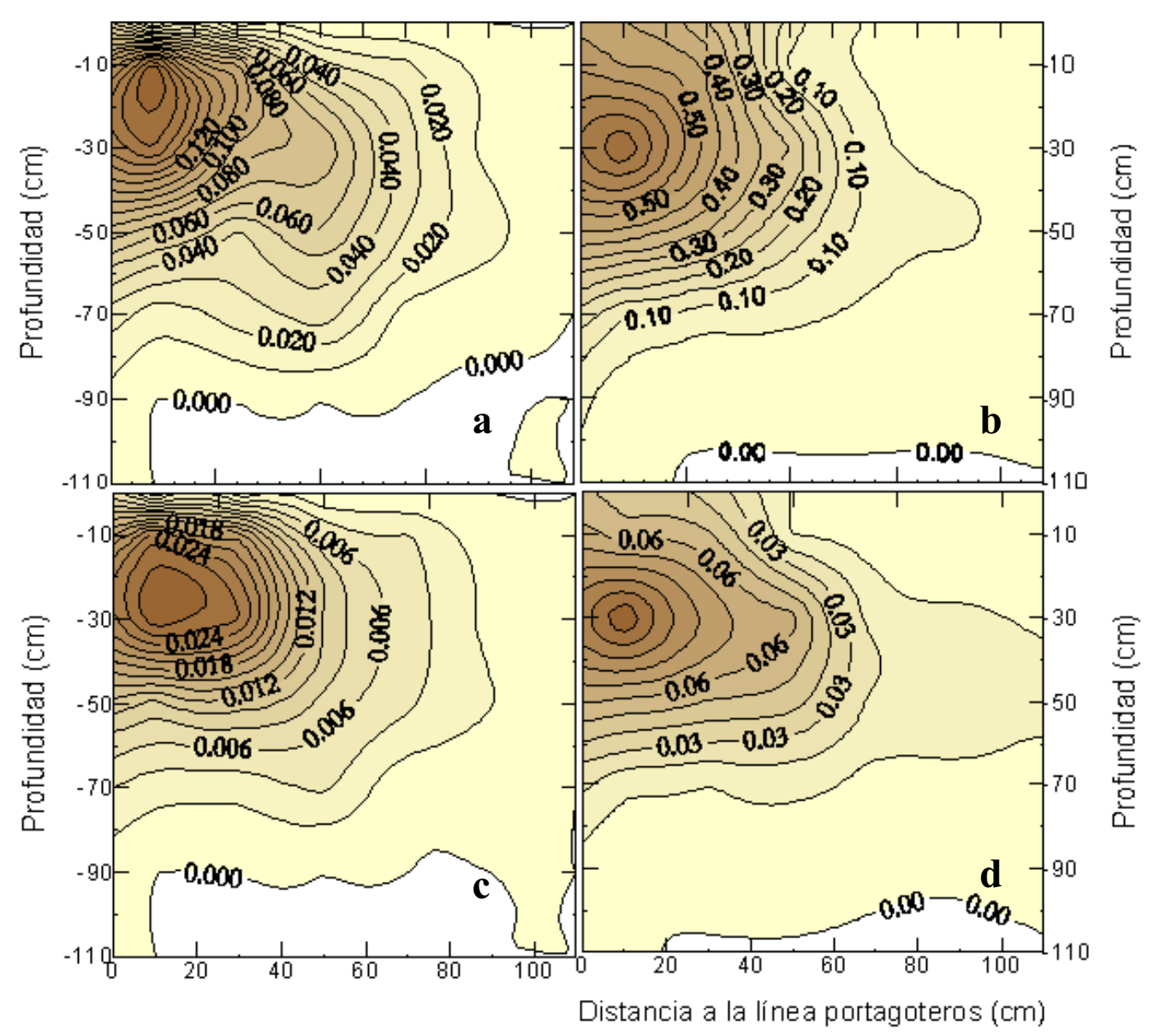

Figura 4.16. Distribución de la densidad de longitud de raíces (DLR, $\mathrm{cm}_{\text {de }}$ raíz $\mathrm{cm}^{-3} \mathrm{de}$ suelo) en el tratamiento control, para la profundidad y distancia perpendicular a la línea portagoteros de 0 a $110 \mathrm{~cm}$. Las figuras a y b corresponden a raíces menores de $1 \mathrm{~mm}$ de diámetro y c y d, a mayores de $1 \mathrm{~mm}$, en 2002 y 2003, respectivamente.
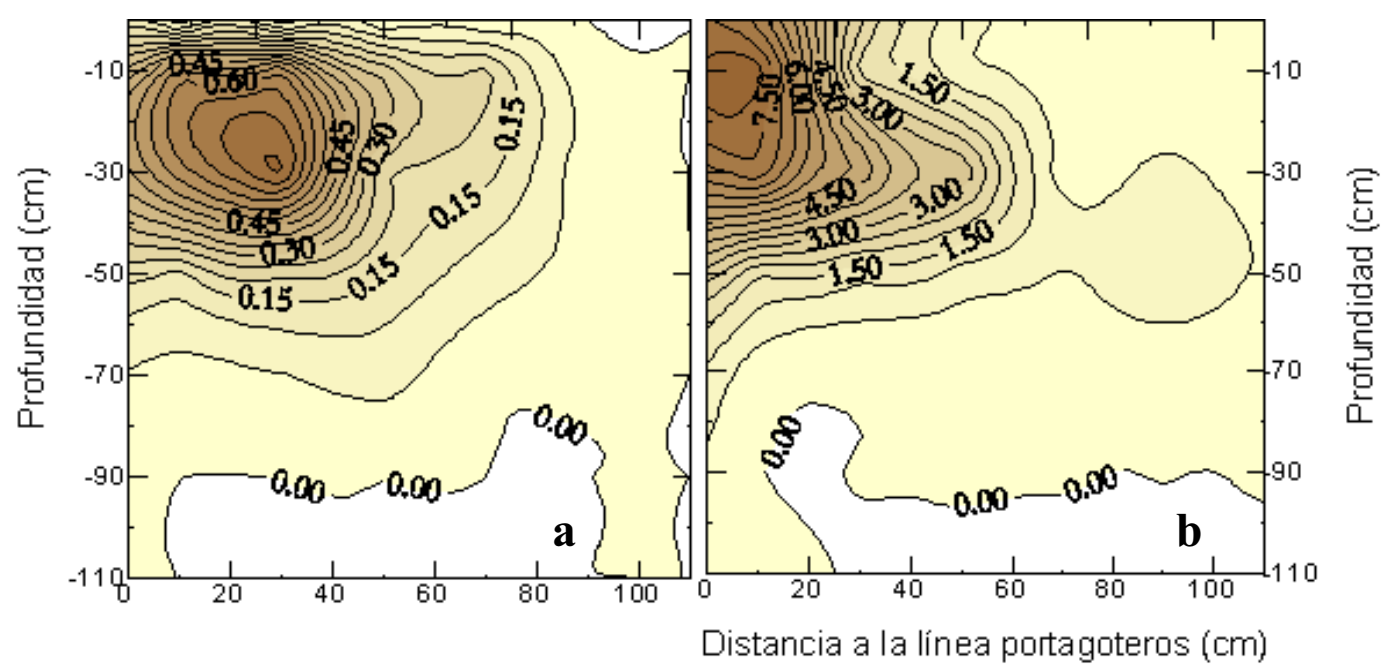

Figura 4.17. Distribución de la densidad de peso seco del total de raíces (mg de raíz $\mathrm{cm}^{-3}$ de suelo) en el tratamiento control, para la profundidad y distancia perpendicular a la línea portagoteros de 0 a $110 \mathrm{~cm}$, en 2002 (a) y 2003 (b). 


\section{Brotes}

El crecimiento longitudinal de los brotes disminuyó con la edad del árbol y carga productiva. Así mismo, y coincidiendo con el inicio de la fase IV de 2002 y 2003 (primeros de junio) se produjo una clara ralentización del crecimiento (Figura 4.18). Estas observaciones coinciden con otros estudios en los que se señalan los meses de marzo a mayo como los de mayor tasa de crecimiento de brotes en almendros jóvenes (Hutmacher et al., 1994) y en adultos (Romero et al., 2004b). Incluso en éstos últimos se manifiesta que los brotes experimentaron un crecimiento en grosor durante la fase IV.

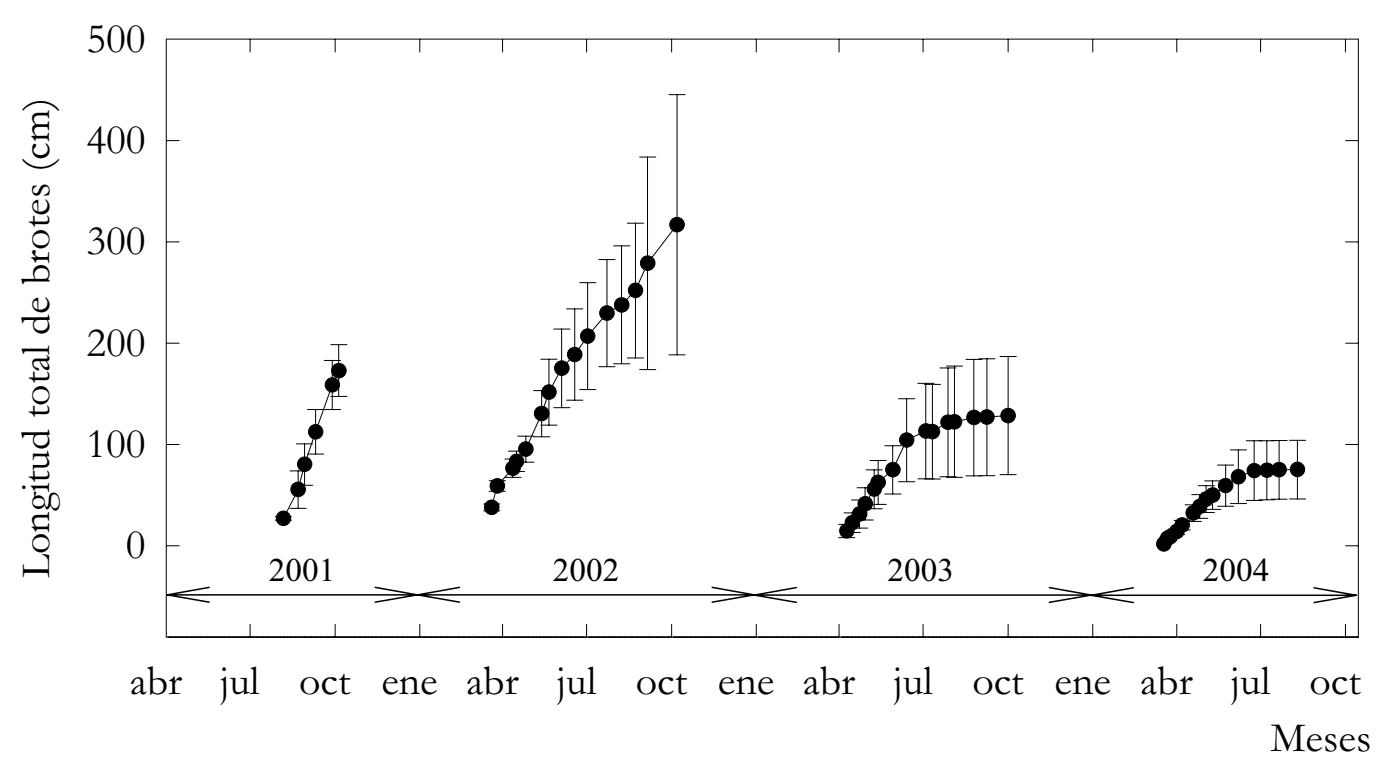

Figura 4.18. Dinámica de crecimiento en longitud de los brotes del tratamiento control. Cada punto corresponde a la media de 3 repeticiones \pm ES.

Aunque en 2002 la dinámica de crecimiento en el tratamiento control fue diferente al resto de los tratamientos, no se detectó efecto del régimen de riego sobre el crecimiento de los brotes. Posiblemente y al igual que en 2003, debido a la alta variabilidad de esta medida y al número de determinaciones realizadas (Figura 4.19).

La reducción del riego en los tratamientos de $\mathrm{RD}$ provocó una caída de $\Psi_{\mathrm{m}}$ por debajo de $-60 \mathrm{kPa}$, tanto a 30 como a $60 \mathrm{~cm}$ de profundidad, poco después del inicio de la campaña de riegos de 2002 (Figura 4.11 y Tabla 4.2). Este déficit hídrico en suelo (Du Plessis, 1988; Fereres et al., 1981b) se correspondió con valores de $\Psi_{\text {a }}$ de $-0.55 \mathrm{MPa}$, (Figura 4.13 a), $0.1 \mathrm{MPa}$ inferiores al control. Estas diferencias fueron insuficientes para reducir el crecimiento de los ramos de los árboles RD, tanto en 2002 como en 2003. Similar disminución fue observada en los tratamientos de RDC. De modo que éstos redujeron su crecimiento a partir de la aplicación del déficit hídrico en la fase IV (Figura 4.19). En 2003 el efecto del tratamiento sobre el crecimiento 
longitudinal de los brotes fue menos notorio (Figura 4.19). Diversos frutales caducifolios han mostrado una elevada sensibilidad al estrés hídrico en el crecimiento de sus brotes (Mitchell y Chalmers, 1982; Dejong et al., 1987; Olien y Flore, 1990; Caspari et al., 1994; Girona y Marsal, 1995). En cambio, en nuestro ensayo, no se detectaron diferencias significativas al no generar un estrés hídrico severo en la planta, durante el principal periodo de crecimiento, hasta finales de mayo (Figuras 4.5, 4.13 y Tabla 4.2). En almendro, Girona et al. (1993a) no observaron tampoco diferencias significativas tras dos años de aplicación de RDC, pero Hutmacher et al. (1994) sí las detectaron tras cinco años de experimentación.

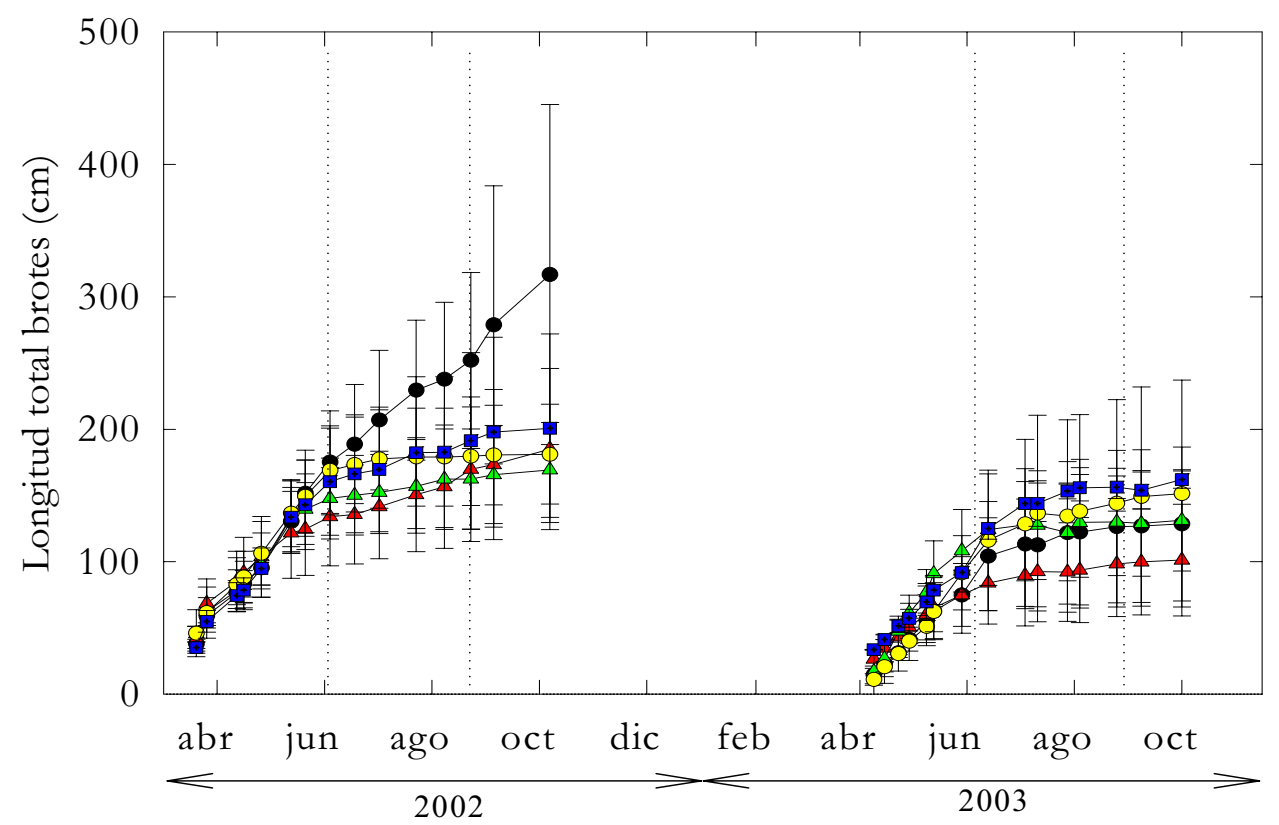

Figura 4.19. Dinámica de crecimiento en longitud de los brotes en los 5 tratamientos de

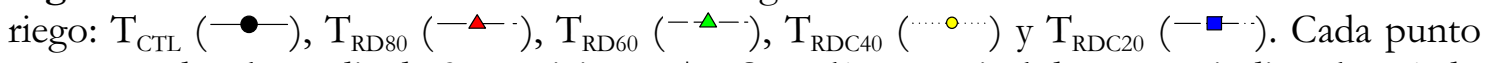
corresponde a la media de 3 repeticiones \pm ES. La línea vertical de puntos indica el período de aplicación del déficit en los tratamientos $\mathrm{T}_{\mathrm{RDC} 40} \mathrm{y}_{\mathrm{RDC} 20}$.

\section{Tronco}

La evolución continua del diámetro de tronco obtenida a partir de sensores LVDT durante el periodo 2001-2004, reflejó la influencia del régimen de riego sobre el crecimiento del tronco (Figura 4.20 y Tablas 4.1 y 4.3). Así, mientras que en los tratamientos $\mathrm{T}_{\mathrm{CTL}}, \mathrm{T}_{\mathrm{RD} 80}$ y $\mathrm{T}_{\mathrm{RD} 60}$ el patrón de crecimiento fue sigmoidal en $\mathrm{T}_{\mathrm{RDC} 40}$ y $\mathrm{T}_{\mathrm{RDC} 20}$ fue de doble sigmoide, consecuencia del déficit hídrico aplicado durante la fase IV (Figura 4.20). 


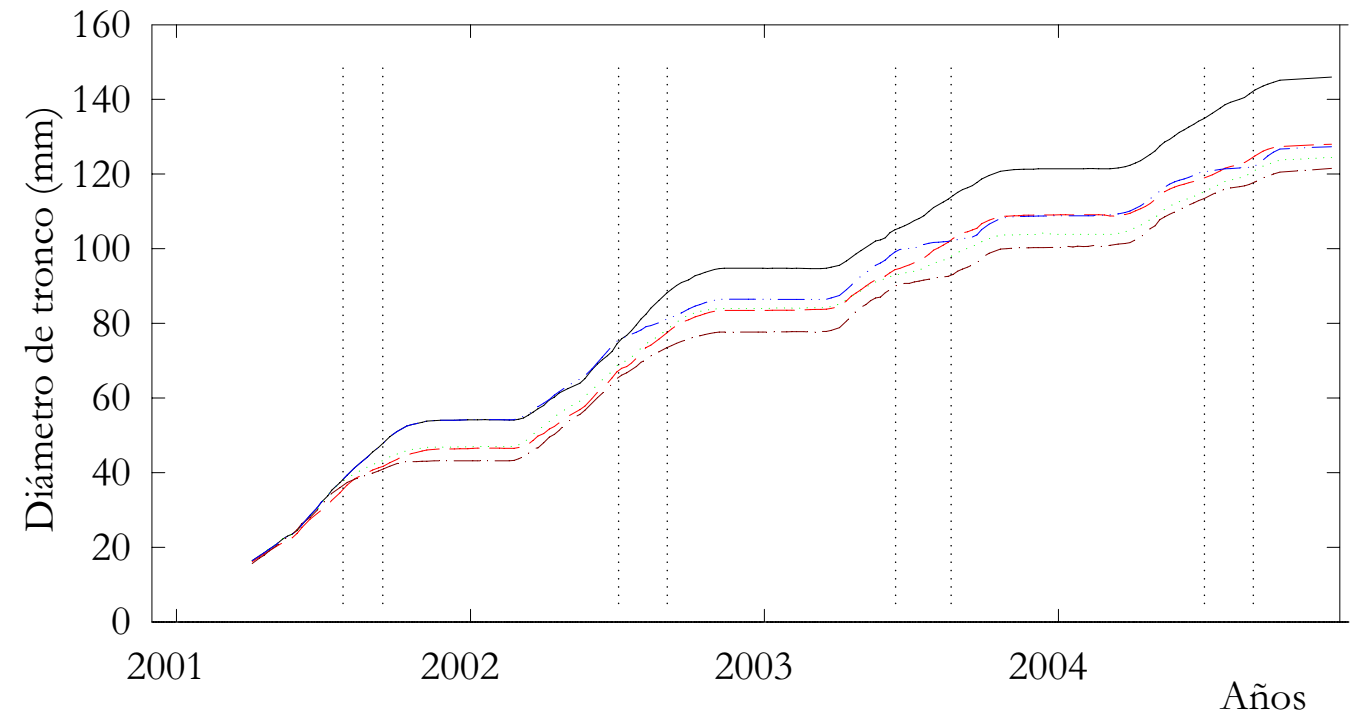

Figura 4.20. Evolución del diámetro de tronco en los 5 tratamientos de riego durante el periodo experimental. $\mathrm{T}_{\mathrm{CTL}}(-), \mathrm{T}_{\mathrm{RD} 80}(--), \mathrm{T}_{\mathrm{RD} 60}(\cdots), \mathrm{T}_{\mathrm{RDC} 40}(--)$ y $\mathrm{T}_{\mathrm{RDC} 20}$ $(-\cdots)$. Las líneas verticales de puntos indican los períodos de aplicación del déficit en los tratamientos $\mathrm{T}_{\mathrm{RDC} 40} \mathrm{y} \mathrm{T}_{\mathrm{RDC} 20}$.

Desde el primer año de ensayo, los tratamientos deficitarios disminuyeron significativamente el diámetro de tronco con respecto al control (Figura 4.20 y Tabla 4.3). Las reducciones respecto al crecimiento global de $\mathrm{T}_{\text {CTL }}(146 \mathrm{~mm})$, fueron 18, 21, 24 y $17 \mathrm{~mm}$ en $\mathrm{T}_{\mathrm{RD} 80}, \mathrm{~T}_{\mathrm{RD} 60}, \mathrm{~T}_{\mathrm{RDC} 40}$ y $\mathrm{T}_{\mathrm{RDC} 20}$ respectivamente. Sin embargo, las diferencias de diámetro de tronco entre tratamientos deficitarios no fueron significativamente diferentes (Figura 4.20). En $T_{R D C 20}$ la demora de un año en el inicio del tratamiento mitigó la reducción global de diámetro de tronco. Estos resultados concuerdan con el hecho de que el crecimiento del tronco sea considerado como un parámetro sensible e integrador de los efectos del déficit hídrico (Hilgeman y Sharp, 1970; Hsiao, 1973; Kramer, 1988). Así, reducciones del crecimiento del tronco por efecto del estrés hídrico han sido recogidas por distintos autores y en diversas especies frutales (Boland et al., 1993; Chalmers et al., 1986; Irving y Drost, 1987; Mitchell et al., 1989; Domingo et al., 2001; Romero, 2002).

El crecimiento total en diámetro de tronco, expresado como incremento de sección transversal $\left(\Delta \mathrm{STT}\right.$, en $\left.\mathrm{cm}^{2}\right)$, estuvo altamente correlacionado con el volumen de agua aplicado $\left(\mathrm{R}\right.$, en $\left.\mathrm{m}^{3} \mathrm{ha}^{-1}\right),(\Delta \mathrm{STT}=$ $\left.0.0077 \mathrm{R}+15.7 ; \mathrm{R}^{2}=0.73\right)$. Correlaciones similares fueron obtenidas por Hutmacher et al. (1994) y Romero et al. (2004b) en almendros, e incluso, estos últimos autores fijaron un valor umbral de $450 \mathrm{~mm}$ de agua de riego, a partir del cuál el crecimiento del tronco no se vio afectado en almendros de 9-13 años de edad. 
Tabla 4.3. Incremento anual de la sección transversal del tronco $\left(\Delta \mathrm{ST}^{\top} \mathrm{T}\right)$ y pendiente media de crecimiento $(\mathrm{m})$ durante el periodo abril-octubre.

\begin{tabular}{|c|c|c|c|c|c|c|c|c|}
\hline & \multicolumn{2}{|c|}{2001} & \multicolumn{2}{|c|}{2002} & \multicolumn{2}{|c|}{2003} & \multicolumn{2}{|c|}{2004} \\
\hline Trat. & $\begin{array}{l}\Delta \mathrm{ST} \\
\left(\mathrm{cm}^{2}\right)\end{array}$ & $\begin{array}{c}\mathrm{m} \\
\left(\mathrm{mm} \mathrm{d}^{-1}\right)\end{array}$ & $\begin{array}{l}\Delta \mathrm{ST} \\
\left(\mathrm{cm}^{2}\right)\end{array}$ & $\underset{\left(\mathrm{mm} \mathrm{d}^{-1}\right)}{\mathrm{m}}$ & $\begin{array}{l}\Delta \mathrm{ST} \\
\left(\mathrm{cm}^{2}\right)\end{array}$ & $\underset{\left(\mathrm{mm} \mathrm{d}^{-1}\right)}{\mathrm{m}}$ & $\begin{array}{l}\Delta \mathrm{ST} \\
\left(\mathrm{cm}^{2}\right)\end{array}$ & $\begin{array}{c}\mathrm{m} \\
\left(\mathrm{mm} \mathrm{d}^{-1}\right)\end{array}$ \\
\hline $\mathbf{T}_{\mathrm{CTL}}$ & $20.91 \mathrm{a}$ & $0.205 \mathrm{a}$ & $47.49 \mathrm{a}$ & $0.200 \mathrm{a}$ & $45.17 \mathrm{a}$ & $0.128 \mathrm{a}$ & $52.19 \mathrm{a}$ & $0.126 \mathrm{a}$ \\
\hline $\mathbf{T}_{\mathrm{RD} 80}$ & $14.90 \mathrm{~b}$ & $0.166 \mathrm{~b}$ & $37.72 \mathrm{~b}$ & $0.177 \mathrm{~b}$ & $38.63 \mathrm{~b}$ & $0.117 \mathrm{ab}$ & $35.22 \mathrm{~b}$ & $0.093 \mathrm{~b}$ \\
\hline$T_{\mathrm{RD} 60}$ & $15.16 \mathrm{~b}$ & $0.173 \mathrm{~b}$ & $38.05 \mathrm{~b}$ & $0.167 \mathrm{~b}$ & $29.28 \mathrm{c}$ & $0.083 \mathrm{~b}$ & $38.14 \mathrm{~b}$ & $0.098 \mathrm{~b}$ \\
\hline $\mathbf{T}_{\mathrm{RDC} 40}$ & $12.70 \mathrm{c}$ & $0.159 \mathrm{c}$ & $32.76 \mathrm{c}$ & $0.156 \mathrm{bc}$ & $31.67 \mathrm{c}$ & $0.082 \mathrm{~b}$ & $36.96 \mathrm{~b}$ & $0.095 \mathrm{~b}$ \\
\hline $\mathbf{T}_{\mathrm{RDC} 20}$ & $20.91 \mathrm{a}$ & $0.200 \mathrm{a}$ & $35.69 \mathrm{bc}$ & $0.1414 \mathrm{c}$ & $34.22 \mathrm{bc}$ & $0.079 \mathrm{~b}$ & $36.71 \mathrm{~b}$ & $0.073 \mathrm{~b}$ \\
\hline
\end{tabular}

Columnas seguidas de letras diferentes indican diferencias significativas entre tratamientos según el test de Tukey0.05.

Durante los dos primeros años de estudio el tratamiento control mostró tasas de crecimiento diario prácticamente constantes, con un valor medio de $0.2 \mathrm{~mm} \mathrm{día}^{-1}$ en todo el periodo de crecimiento (abril - octubre). En los dos años siguientes y coincidiendo con la entrada en producción, estas tasas disminuyeron, alcanzando valores de $0.125 \mathrm{~mm}$ día $^{-1}$ en 2004 (Tabla 4.3). Este descenso puede ser atribuido a la competencia por los fotoasimilados entre el crecimiento vegetativo y generativo. Hecho constatado en melocotoneros por Dejong et al. (1987) y Dejong y Grossman (1994) y en almendros jóvenes por Shackel et al. (1998). El tratamiento $T_{\mathrm{RDC} 20}$ presentó los valores medios de crecimiento del tronco más bajos desde su inicio en 2002, con reducciones significativas con respecto a $\mathrm{T}_{\mathrm{CTL}}$ del 30, 39 y $42 \%$ en 2002, 2003 y 2004, respectivamente (Tabla 4.3). Romero (2002) encontró una ralentización del crecimiento del tronco de almendros de 9 años de edad en los meses de junio y julio, achacándolo a la mayor actividad radical encontrada en este período (Abrisqueta et al., 1994; Catlin, 1996). En nuestro ensayo y debido a la edad de los árboles no se aprecia esta ralentización (Figura 4.20).

El incremento anual del diámetro de tronco $(\Delta \mathrm{DT})$ correlacionó negativamente con la integral de estrés y mostró $\mathrm{R}^{2}$ altos, tanto al alba como a mediodía (Figura 4.21). Las pendientes de las rectas indican el alto nivel de sensibilidad del crecimiento del tronco al aumento de la integral de estrés. Realidad acorde con las reducciones del crecimiento de tronco observadas en diversos estudios sobre el déficit hídrico (Uriu et al., 1970; Fereres et al., 1981a; Goldhamer y Smith, 1995; Girona et al., 1997; Domingo et al., 2001; Romero, 2002; Vélez et al., 2007). El mayor coeficiente de correlación obtenido en 2002 que en 2003 puede explicarse a partir de la incorporación de una nueva 
variable, producción de almendra, la que afectaría a la relación crecimiento vegetativo $v$ s déficit hídrico soportado (Figura 4.21).

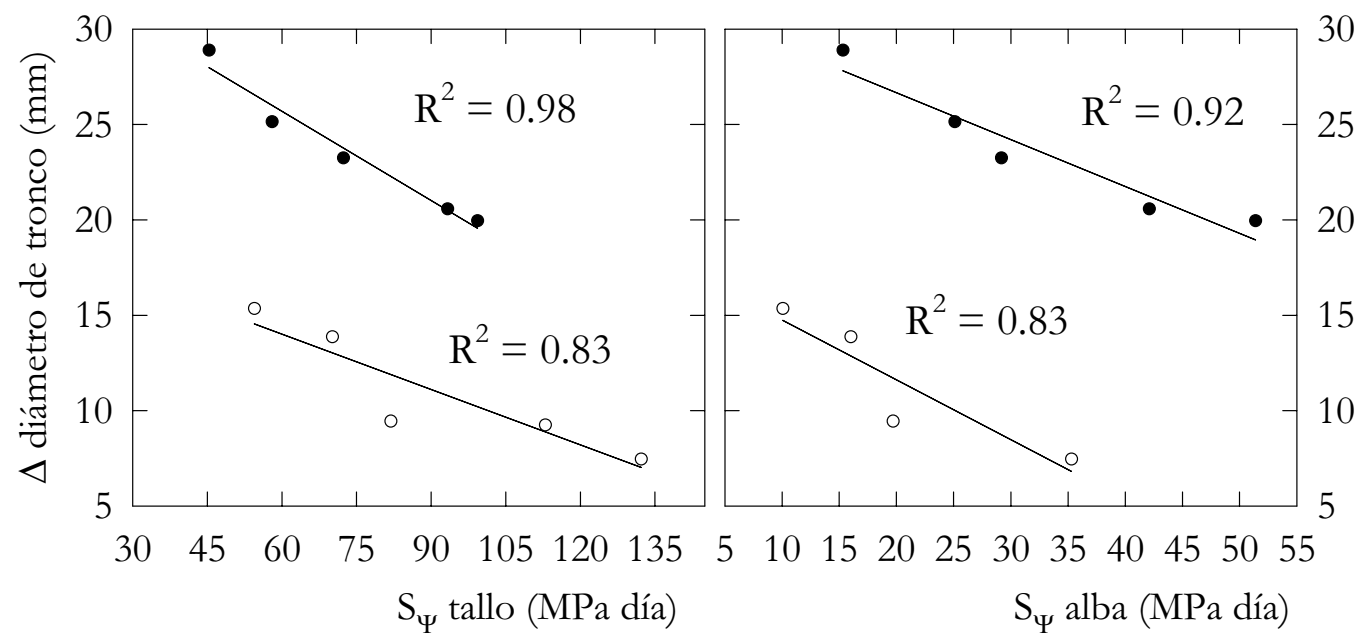

Figura 4.21. Relaciones entre el incremento de diámetro de tronco y la integral de estrés. $\Delta \mathrm{DT}=-0.16 \mathrm{~S}_{\Psi_{\text {tallo }}}+0.96, \mathrm{R}^{2}=0.96$, en $2002(\bullet) ; \Delta \mathrm{DT}=-0.01 \mathrm{~S}_{\Psi_{\text {tallo }}}+19.8, \mathrm{R}^{2}=0.83$, en $2003(\circ)$ y $\Delta \mathrm{DT}=-0.246 \mathrm{~S}_{\Psi_{\text {alba }}}+31.57, \mathrm{R}^{2}=0.92$, en $2002(\bullet)$ y $\Delta \mathrm{DT}=-0.313 \mathrm{~S}_{\Psi_{\text {alba }}}+$ $17.88, R^{2}=0.83$, en $2003(\circ) . S_{\Psi_{\text {tallo }}}$ corresponde al periodo días $140-270$ y $S_{\Psi_{\text {alba }}}$ al periodo $190-270$.

$\mathrm{Al}$ estar estrechamente relacionada la sección del tronco con el peso de la parte aérea del árbol (Westwood y Roberts, 1970), la disminución de $\Delta$ STT por efecto del estrés hídrico implica una disminución del tamaño total del árbol.

\section{Superficie sombreada}

La superficie sombreada (SS) por la cubierta vegetal experimentó un importante incremento anual, al tratarse de árboles en sus primeros años de plantación (Figura 4.22). El efecto de los tratamientos de riego deficitario sobre SS tuvo un marcado carácter acumulativo de disminución relativa, al igual que sucedió con el crecimiento en diámetro del tronco (Figura 4.20). Las diferencias respecto a $\mathrm{T}_{\text {CTL }}$ fueron significativas a partir del segundo año de ensayo en todos los tratamientos (Figura 4.22). En 2001 la inexistencia de diferencias de crecimiento en SS pudo deberse a que el ensayo se inicio en el mes de junio, momento en el que la mayor parte del crecimiento vegetativo ya había tenido lugar (Figuras 4.25, 4.18 y 4.22). La superficie sombreada al final del periodo experimental alcanzó el $37 \%$ en el tratamiento control, siendo del 26, 24, 23.5 y $25.8 \%$ en $\mathrm{T}_{\mathrm{RD} 80}, \mathrm{~T}_{\mathrm{RD} 60}, \mathrm{~T}_{\mathrm{RDC} 40}$ y $\mathrm{T}_{\mathrm{RDC} 20}$, respectivamente (Figura 4.22). Numerosos estudios mencionan que una elevada reducción del tamaño de copa, por efecto del déficit hídrico, en los primeros años de la plantación, puede ser perjudicial para la producción a largo plazo (Torrecillas et al., 1989a; 
Goldhamer y Viveros, 2000; Romero, 2002; Girona, 2006; Goldhamer et al., 2006).

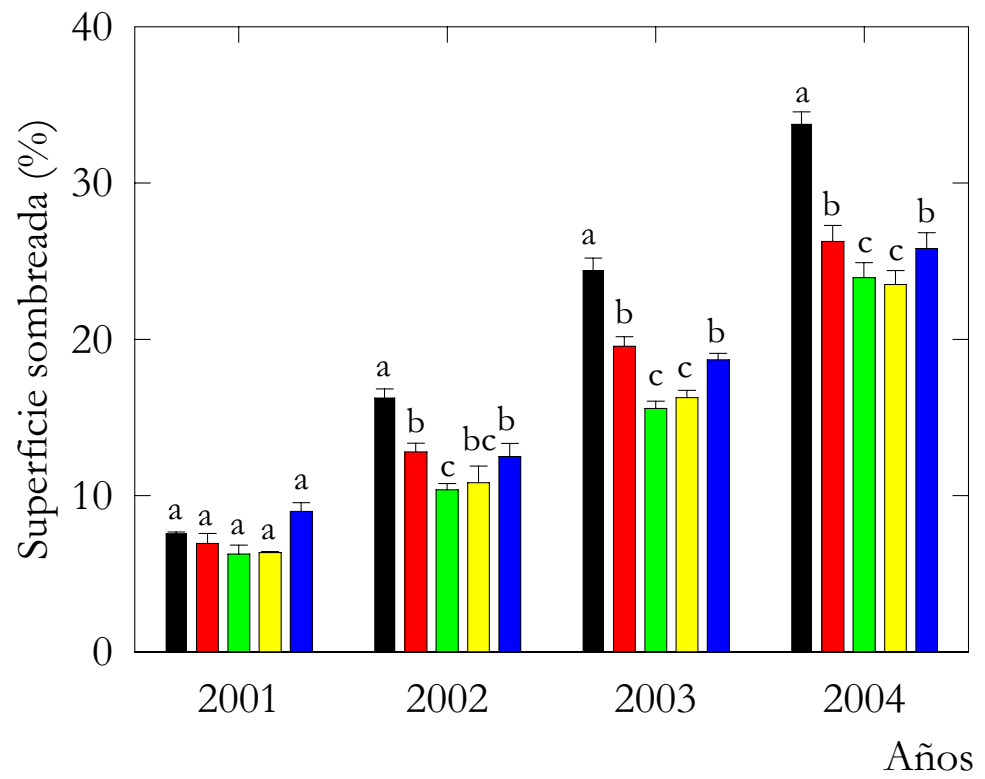

Figura 4.22. Porcentaje de superficie sombreada durante el periodo experimental, en los cinco tratamientos de riego: $\mathrm{T}_{\mathrm{CTL}}(\square), \mathrm{T}_{\mathrm{RD} 80}(\square), \mathrm{T}_{\mathrm{RD} 60}(\square), \mathrm{T}_{\mathrm{RDC} 40}(\square) \mathrm{y}$ $\mathrm{T}_{\mathrm{RDC} 20}(\mathbf{m})$. Columnas del mismo año seguidas de letras diferentes indican diferencias significativas entre tratamientos según el test de Tukey ${ }_{0.05}$.

Durante el periodo 2001-2003 el área foliar (AF) de los árboles control pasó de 6 a $30 \mathrm{~m}^{2}$ (Tabla 4.4). Sus valores respecto a los de los tratamientos deficitarios fueron diferentes en los tres años de medidas. De modo que, en 2003 la reducción de AF debida al tratamiento era de $6 \mathrm{~m}^{2}$ en $\mathrm{T}_{\mathrm{RD} 80}$ y de aproximadamente $15 \mathrm{~m}^{2}$ en $\mathrm{T}_{\mathrm{RD} 60}, \mathrm{~T}_{\mathrm{RDC} 40}$ y $\mathrm{T}_{\mathrm{RDC} 20}$. En cambio, no se observaron diferencias de tamaño de hoja debidas al tratamiento (datos no mostrados), lo que contrasta con la reducción del crecimiento foliar observada por Romero et al (2004b) en almendros adultos sometidos a RDC durante la fase IV.

El área foliar presentó una alta correlación positiva con el volumen de agua aplicado (Figura 4.23 a). Este hecho es coincidente con las observaciones de Fereres et al. (1981a) y Torrecillas et al. (1989a) en almendro. La correlación negativa $\mathrm{AF}$ vs $\mathrm{S}_{\Psi_{\text {tallo }}}$ a mediodía (Figura $4.23 \mathrm{~b}$ ), aunque presentó menores $\mathrm{R}^{2}$ que la anterior relación, incide igualmente en el efecto negativo de la infradotación hídrica sobre el crecimiento foliar. Por su parte, el incremento de diámetro de tronco frente a $S_{\Psi_{\text {tallo }}}$, mostró un coeficiente de determinación superior (Figura 4.21) denotándose una mayor sensibilidad de éste al déficit hídrico (Figura 4.21). 
Tabla 4.4. Evolución del número de hojas y área foliar (AF) del árbol en los cinco tratamientos de riego. Período 2001 - 2003.

\begin{tabular}{ccccccc}
\hline & \multicolumn{2}{c}{2001} & \multicolumn{2}{c}{2002} & \multicolumn{2}{c}{2003} \\
\hline Trat. & $\mathbf{N}^{\mathbf{o}}$ hojas & AF $\left(\mathbf{m}^{2}\right)$ & $\mathbf{N}^{\mathbf{o}}$ hojas & AF $\left(\mathbf{m}^{2}\right)$ & $\mathbf{N}^{\mathbf{o}}$ hojas & AF $\left(\mathbf{m}^{2}\right)$ \\
\hline $\mathbf{T}_{\text {CTL }}$ & 4115 & 6.63 & 13029 & 13.62 & 26497 & 30.13 \\
$\mathbf{T}_{\text {RD80 }}$ & 2307 & 5.63 & 14621 & 13.69 & 19056 & 24.70 \\
$\mathbf{T}_{\text {RD60 }}$ & 1854 & 2.64 & 7213 & 7.50 & 15226 & 15.48 \\
$\mathbf{T}_{\text {RDC40 }}$ & 1157 & 1.53 & 5421 & 6.39 & 14146 & 16.66 \\
$\mathbf{T}_{\text {RDC20 }}$ & & & 10076 & 10.03 & 14345 & 16.85 \\
\hline
\end{tabular}

La superficie sombreada (SS) por el cultivo, a lo largo del período experimental, estuvo bien correlacionada con el índice de área foliar (IAF) (Figura 4.24). Esto permite estimar IAF a partir de la relación IAF vs SS. Este índice adimensional de densidad foliar (Chen y Black, 1992) es muy útil para estimar la radiación y la precipitación interceptada por el cultivo, así como para el intercambio gaseoso entre la cubierta vegetal y la atmósfera (Breda, 2003).

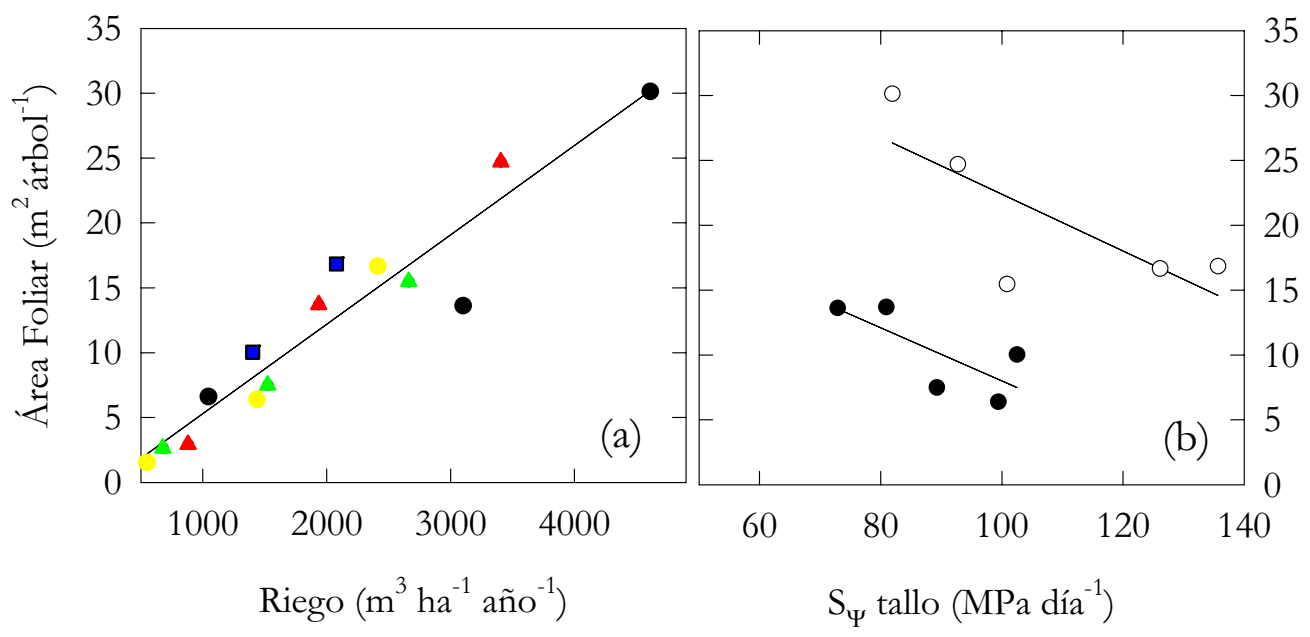

Figura 4.23. (a) Relación entre el área foliar (AF) y la dotación de agua de riego (R) durante el periodo 2001-2003 (AF $\left.=6.89 \mathrm{R}-1.58 ; \mathrm{R}^{2}=0.91 ; \mathrm{P}<0.05\right) . \mathrm{T}_{\mathrm{CTL}}(\bullet), \mathrm{T}_{\mathrm{RD} 80}$ $(\Delta), \mathrm{T}_{\mathrm{RD} 60}(\Delta), \mathrm{T}_{\mathrm{RDC} 40}(\mathrm{O}) \mathrm{y} \mathrm{T}_{\mathrm{RDC} 20}(\boldsymbol{\bullet})$. (b) Área foliar en función de la integral de estrés $\left(\mathrm{S}_{\Psi_{\text {tallo }}}\right)$ obtenida a partir de los valores de potencial de tallo a mediodía: $\mathrm{AF}=18.24-$ $0.11 \mathrm{~S}_{\Psi_{\text {tallo }}}\left(\mathrm{R}^{2}=0.54 ; \mathrm{P}<0.05\right) ; \mathrm{AF}=34.81-0.16 \mathrm{~S}_{\Psi_{\text {tallo }}}\left(\mathrm{R}^{2}=0.601 ; \mathrm{P}<0.05\right)$, en $2002(\bullet) \mathrm{y}$ 2003 (० ), para el período de días 140-270.

\section{Poda}

El peso de la poda, como medida indirecta del crecimiento vegetativo, fue sensible al régimen de riego. El tratamiento con mayor peso de poda fue 
$\mathrm{T}_{\mathrm{CTL}}$, seguido de $\mathrm{T}_{\mathrm{RD} 80}$, y a excepción del año 2002, los tres tratamientos restantes generaron cantidades similares de poda (Figura 4.25). La variable peso seco de poda presentó una alta correlación positiva con el volumen de agua de riego (Figura 4.26).

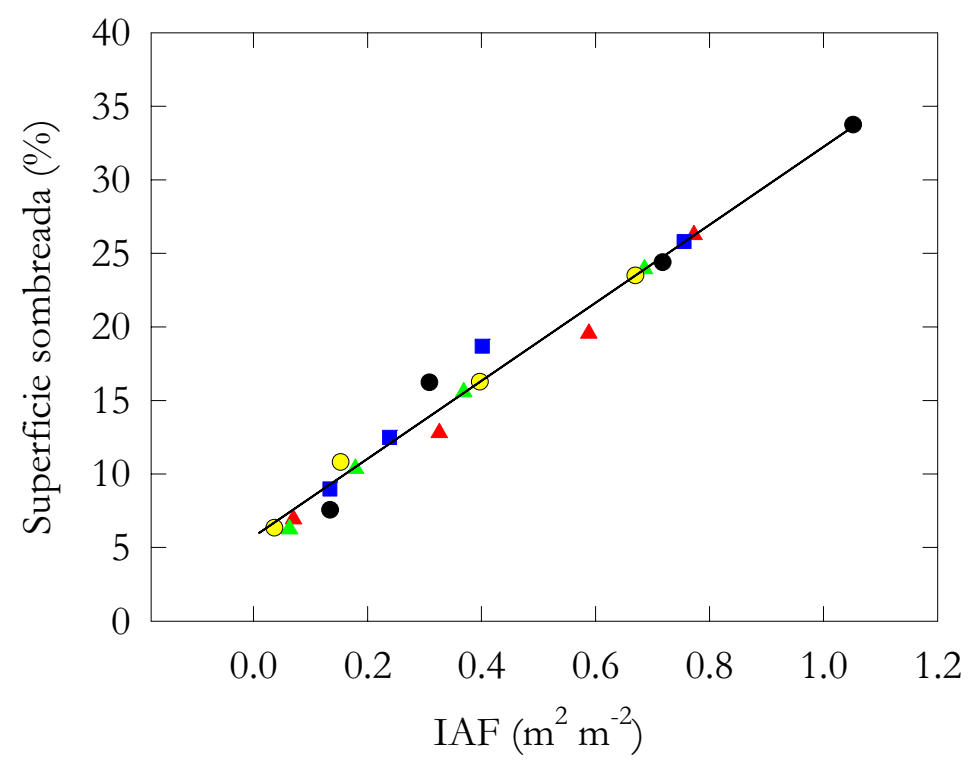

Figura 4.24. Relación entre el porcentaje de área sombreada (SS) y el índice de área foliar (IAF) a partir de los 4 años de ensayo y para los 5 tratamientos de riego. $\mathrm{T}_{\mathrm{CTL}}(\bullet), \mathrm{T}_{\mathrm{RD} 80}$ $(\Delta), \mathrm{T}_{\mathrm{RD} 60}(\Delta), \mathrm{T}_{\mathrm{RDC} 40}(\circ) \mathrm{y} \mathrm{T}_{\mathrm{RDC} 20}(\boldsymbol{\bullet})$. SS $=26.5 \mathrm{IAF}+5.74 ; \mathrm{R}^{2}=0.98 \mathrm{P}<0.001$.

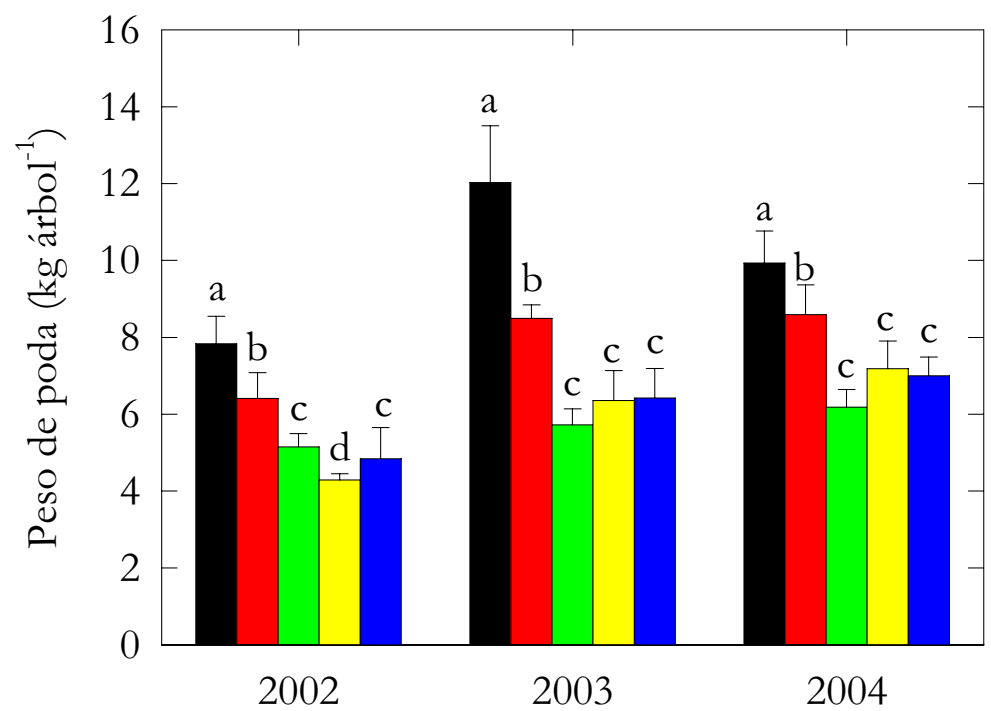

Figura 4.25. Peso seco de poda en los 5 tratamientos de riego: $T_{\text {CTL }}(\boldsymbol{m}), T_{R D 80}$ $(\square), \mathrm{T}_{\mathrm{RD} 60}(\square), \mathrm{T}_{\mathrm{RDC} 40}(\square) \mathrm{y}_{\mathrm{RDC} 20}(\square)$ durante el periodo experimental. Cada barra corresponde a la media de tres repeticiones \pm ES. Letras diferentes dentro del mismo año indican diferencias significativas entre tratamientos según el test de Tukey ${ }_{0.05}$.

Al final del período experimental el peso seco de poda acumulado en el tratamiento control fue de $30 \mathrm{~kg}$ árbol $^{-1}$ con reducciones del $20 \%$ en $\mathrm{T}_{\mathrm{RD} 80} \mathrm{y}$ $40 \%$ en el resto de tratamientos. Reducciones de peso de poda por 
aplicación de estrategias de riego deficitario han sido descritas por otros autores en especies como el peral (Mitchell et al., 1989), melocotonero (Boland et al., 1993; Girona et al., 1993b) albaricoquero (Pérez-Pastor, 2001) y almendro (Prichard et al., 1992; Girona et al., 1993a; Romero et al., 2004b).

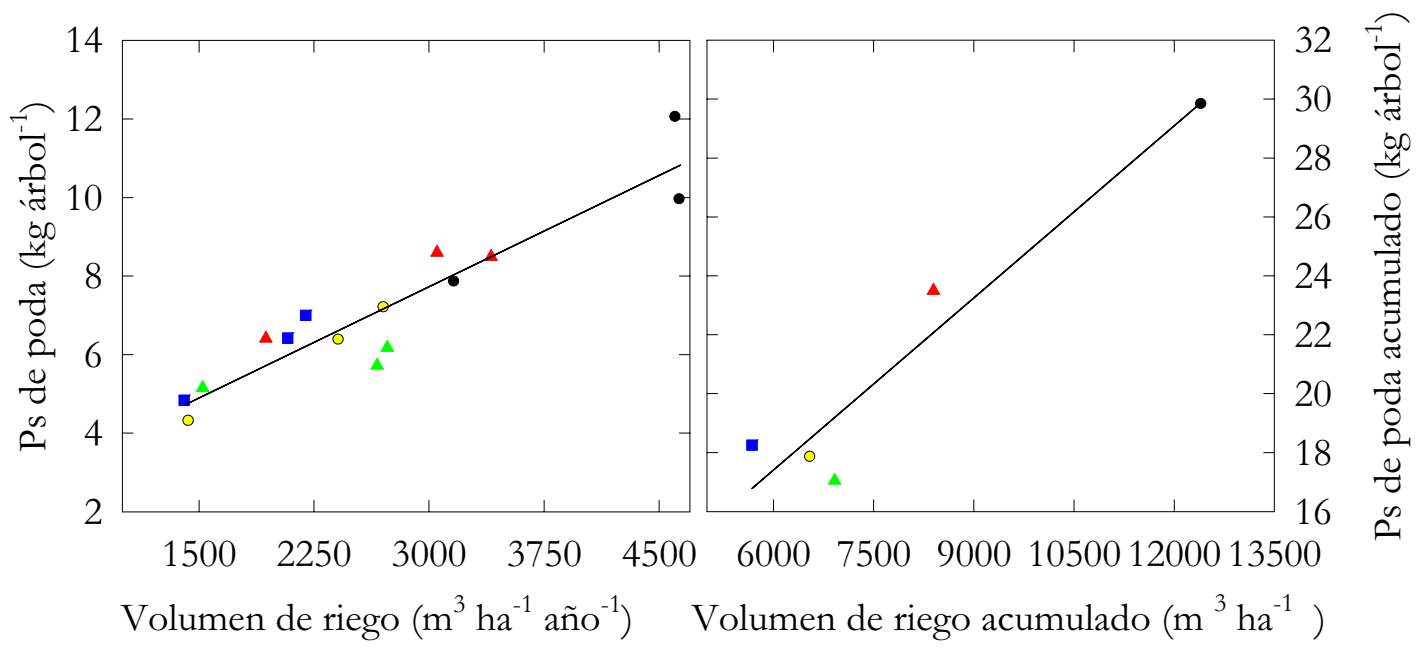

Figura 4.26. Relación entre el peso seco de poda (Ps) frente al volumen de riego anual $(\mathrm{R})$, durante el periodo 2002-2004 (Ps $\left.=0.002 \mathrm{R}+2.07 \mathrm{R}^{2}=0.87 \mathrm{P}<0.05\right)$ y al volumen de riego acumulado ( $\mathrm{Ps}=0.002 \mathrm{R}+5.73 \mathrm{R}^{2}=0.92 \mathrm{P}<0.05$ ). Cada punto corresponde a la media de 30 árboles por tratamiento en cada año, $\mathrm{T}_{\mathrm{CTL}}(\bullet), \mathrm{T}_{\mathrm{RD} 80}(\Delta), \mathrm{T}_{\mathrm{RD} 60}(\Delta), \mathrm{T}_{\mathrm{RDC} 40}$ ( ०) $\mathrm{y} \mathrm{T}_{\mathrm{RDC} 20}(\boldsymbol{\bullet})$.

\section{Desarrollo reproductivo}

\section{Floración y fructificación}

La ruptura del reposo de las yemas de flor se adelantó en 2002 con respecto al 2003, estando el $50 \%$ de las yemas en estado B a mediados de enero en 2002 y a principios de febrero en 2003 (Figuras 4.27 y 4.28). El estado F, máxima floración, se alcanzó en el tratamiento control después de unos 30 días del inicio del estado B, de yema hinchada, y tras acumular 4878 y $4667{ }^{\circ} \mathrm{C}$ GDH en 2002 y 2003, respectivamente (Tabla 4.5). En melocotonero cv. 'Alberta' Richardson et al. (1976) y en albaricoquero cv. 'Búlida' PérezPastor et al. (2004) emplearon igualmente la integral térmica para caracterizar el inicio de la máxima floración.

Según los datos mostrados en la tabla 4.5, la integral térmica parece un buen indicador para predecir la duración del periodo comprendido entre la ruptura de las yemas, máxima floración e inicio de la fase de acumulación rápida de materia seca del grano en almendro (Tabla 4.5). Christen (1969) y Williams (1987) en parral y Pérez-Pastor et al. (2004) en albaricoquero, notificaron el interés de este parámetro con idénticos fines de predicción. De esta forma se pueden extrapolar los resultados obtenidos a otras condiciones 
de cultivo y a otros años, llegando a poder predecir el inicio de un determinado estado fenológico. En cambio, La maduración del fruto va a depender en gran medida, de las técnicas culturales, de la disponibilidad de agua y de la competencia entre los propios frutos (Morris y Cawthon, 1982; González-Altozano y Castel, 1999; Pérez-Pastor, 2001; Hueso, 2005).

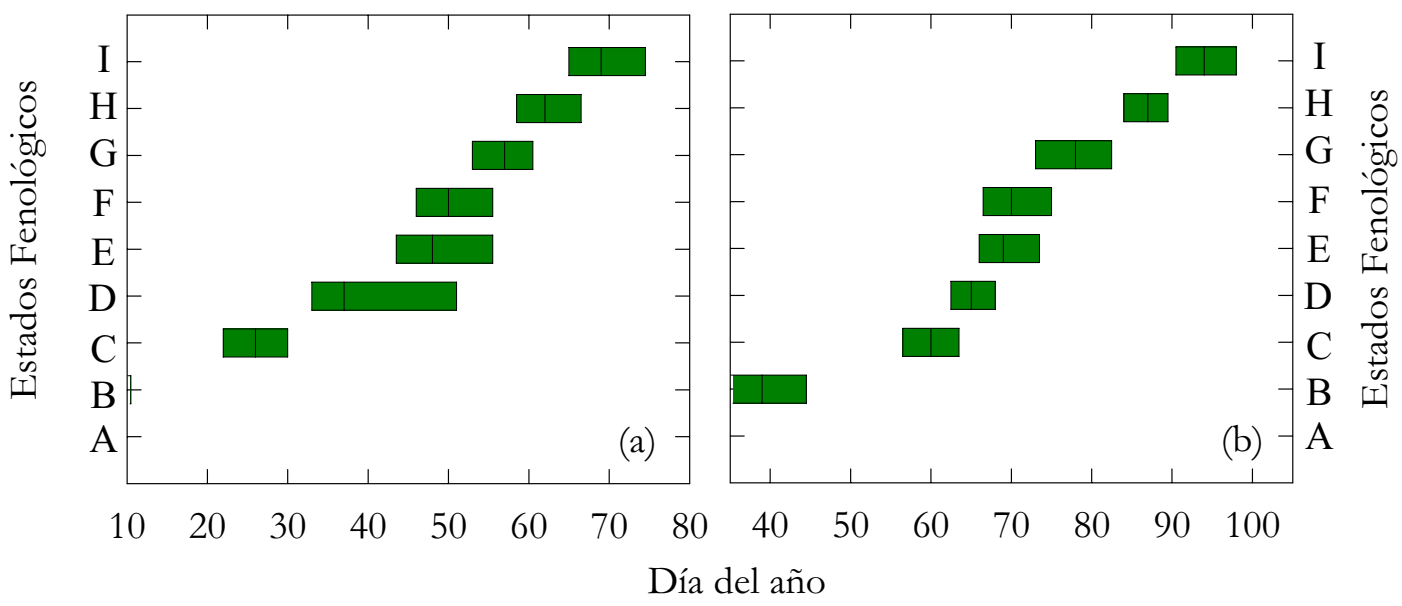

Figura 4.27. Evolución de los estados fenológicos de yemas de flor (A-I), bajo condiciones de adecuado suministro hídrico en 2002 (a) y 2003 (b). Las cajas horizontales indican el inicio y final de cada fase fenológica, y la línea vertical interior de cada caja indica el momento en el que el $50 \%$ de las yemas han alcanzado dicho estado.

Tabla 4.5. Periodos de predominio y ${ }^{\circ} \mathrm{C}$ GDH acumulados en los distintos estados fenológicos del almendro 'Marta', bajo condiciones de adecuado suministro hídrico.

\begin{tabular}{lcccc}
\hline \multirow{2}{*}{ Estado de desarrollo } & \multicolumn{2}{c}{ Período } & \multicolumn{2}{c}{${ }^{\mathbf{O}} \mathbf{C}$ GDH } \\
\cline { 2 - 5 } & 2002 & $\mathbf{2 0 0 3}$ & $\mathbf{2 0 0 2}$ & $\mathbf{2 0 0 3}$ \\
\hline $50 \%$ de yemas en Estado "B" & 13/Ene. & $7 /$ Feb. & 508 & 495 \\
$50 \%$ de yemas en Estado "D" & 4/Feb. & $6 /$ Mar. & 3115 & 4010 \\
$50 \%$ Floración "F" & 19/Feb. & 11/Mar. & 4878 & 4667 \\
$50 \%$ de frutos en Estado "I" & 10/Mar. & 4/Abr. & 7957 & 8850 \\
$\begin{array}{l}\text { Inicio Fase IV (acumulación de materia seca en } \\
\text { el grano) }\end{array}$ & 4/Jun. & 9/Jun. & 26705 & 27129 \\
\hline
\end{tabular}



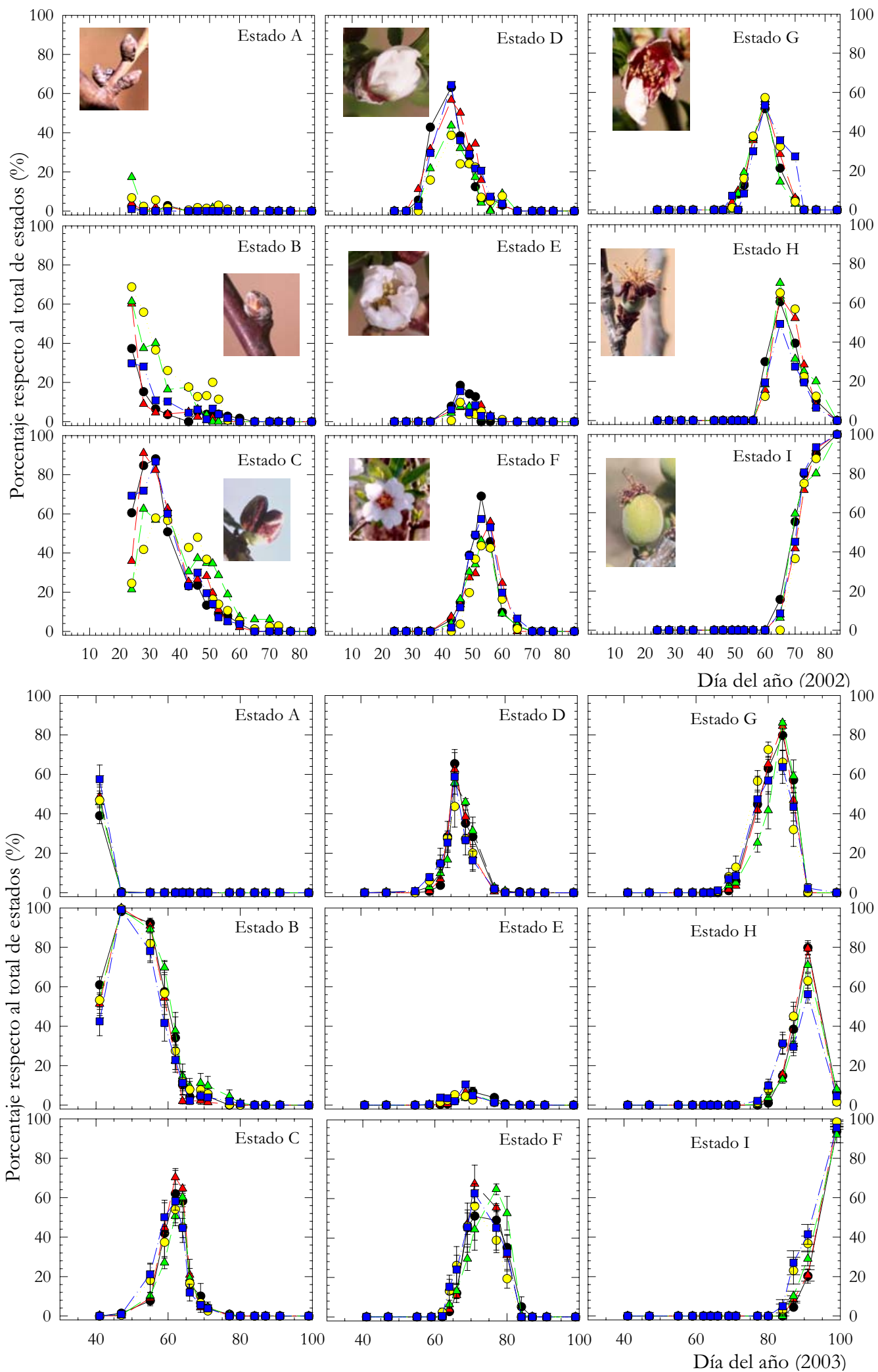

Figura 4.28. Evolución de los estados fenológicos de las yemas de flor en almendro 'Marta', durante los años 2002 y 2003, en los tratamientos ensayados: $\mathrm{T}_{\mathrm{CTL}}\left(\bullet-\boldsymbol{C}^{-}, \mathrm{T}_{\mathrm{RD} 80}\right.$ $\left(-\Delta^{-}\right), \mathrm{T}_{\mathrm{RD} 60}\left({ }^{-\Delta^{-}}\right), \mathrm{T}_{\mathrm{RDC} 40}(\cdots . . \cdots \cdots)$ y $\mathrm{T}_{\mathrm{RDC} 20}(-\cdot)$. Cada punto corresponde a la media de tres repeticiones $\pm \mathrm{ES}$. 
El ligero déficit hídrico alcanzado en la primavera de los años 2002 y 2003 en los tratamientos de riego deficitario constante (Figura 4.13), en parte debido a las lluvias ocurridas en otoño de $2002(55.6 \mathrm{~mm})$ y en invierno de 2002 y 2003, 131.4 y 179.8 mm, respectivamente (Figura 4.4), puede explicar la similitud de la evolución de las yemas de flor con el tratamiento control (Figura 4.28). La inexistencia de diferencias entre los tratamientos $\mathrm{T}_{\mathrm{RDC} 40} \mathrm{y}$ $\mathrm{T}_{\mathrm{RDC} 20} \mathrm{y} \mathrm{T}_{\mathrm{CTL}}$ era esperable en la medida de que fueron programados con el fin de mantener un adecuado estado hídrico de la planta durante los períodos de floración, cuajado del fruto y postcosecha (Figura 4.28). Estudios realizados en almendros sometidos a un déficit hídrico moderado no presentaron efectos negativos en la densidad floral (Ruiz-Sánchez et al., 1988) ni en la fructificación (Goldhamer y Viveros, 2000; Esparza et al., 2001b; Goldhamer et al., 2006). En cambio, otros estudios realizados en frutales sometidos a un déficit hídrico severo durante la floración (Brun et al., 1985) y durante el período de inducción-diferenciación floral (Torrecillas et al., 2000) señalan una reducción del cuajado, de lo que se desprende el interés de cuantificar la duración e intensidad del déficit en los efectos derivados.

\section{Fruto}

El tratamiento control alcanzó el tamaño exterior máximo del fruto a mediados de abril en los tres años de estudio (Figura 4.5 y 4.29). Los frutos de 2002 fueron los de mayor tamaño dada la menor carga productiva de este año, aproximadamente, una décima parte del 2003 y 2004 (Tabla 4.6). Un retraso de 21 días en la floración de 2003 se tradujo en un claro desfase durante la primera mitad de la evolución del pericarpio (Tabla 4.5 y Figura 4.29).

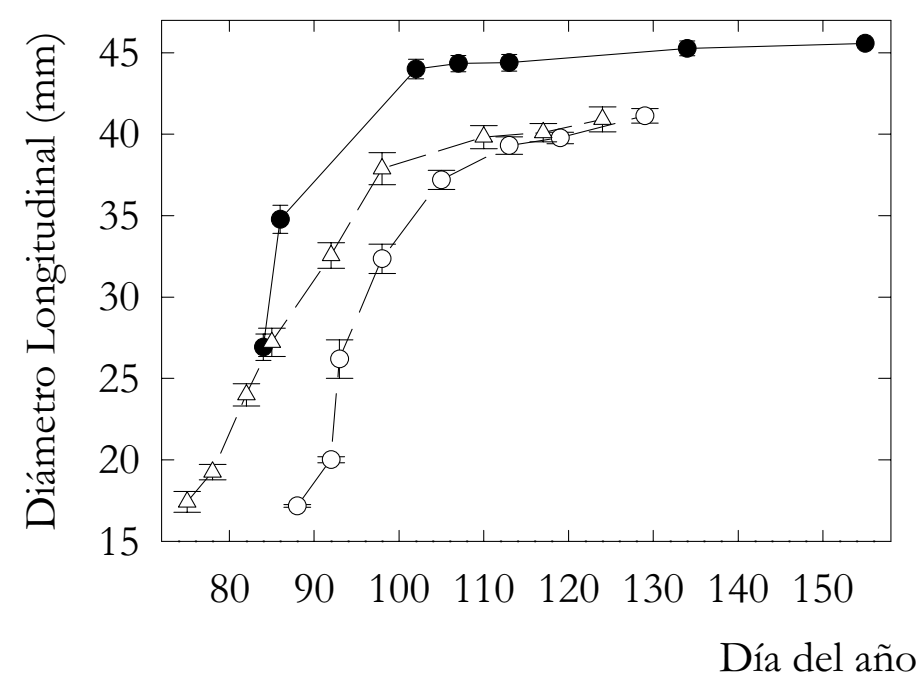

Figura 4.29. Evolución del crecimiento longitudinal del pericarpio durante los años 2002

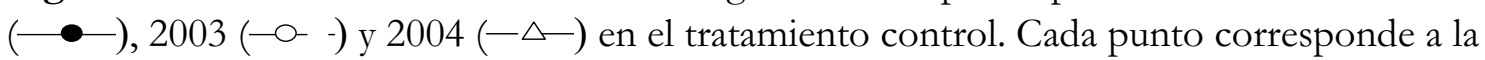
media de 3 repeticiones \pm ES. 
Las evoluciones de los parámetros morfológicos: diámetro longitudinal, ecuatorial y trasversal del fruto mostraron un patrón de crecimiento similar en todos los tratamientos de riego (Figura 4.30), no observándose diferencias por efecto de los mismos. Este hecho estaría justificado por la ausencia de déficit hídrico severo en los tratamientos deficitarios durante la fase III del almendro, tal como se reflejó en 2002 (Figura 4.5 y 4.13). Almendros adultos sometidos a RDC en condiciones edafoclimáticas similares tampoco presentaron diferencias en estos parámetros (Romero, 2002).

El peso seco del grano presentó una curva de tipo sigmoidal caracterizada por dos fases: una primera de baja tasa de crecimiento, y que transcurre durante la fase III, período en el que se alcanza el tamaño máximo del fruto y tiene lugar un importante crecimiento vegetativo (Figura 4.5), y una segunda, denominada fase IV, de elevada tasa de acumulación de materia seca (Figura 4.31). La fase IV se inició cuando el 50 y $65 \%$ del crecimiento vegetativo total había tenido lugar en 2002 y 2003, respectivamente (Figura 4.32 a y b), y tras acumularse 21827 y $22462{ }^{\circ} \mathrm{C}$ GDH desde la máxima floración en 2002 y 2003, respectivamente (Tabla 4.5). La figura 4.31 muestra la similitud de peso seco del grano en los distintos muestreos realizados durante 2003 en los 5 tratamientos de riego.

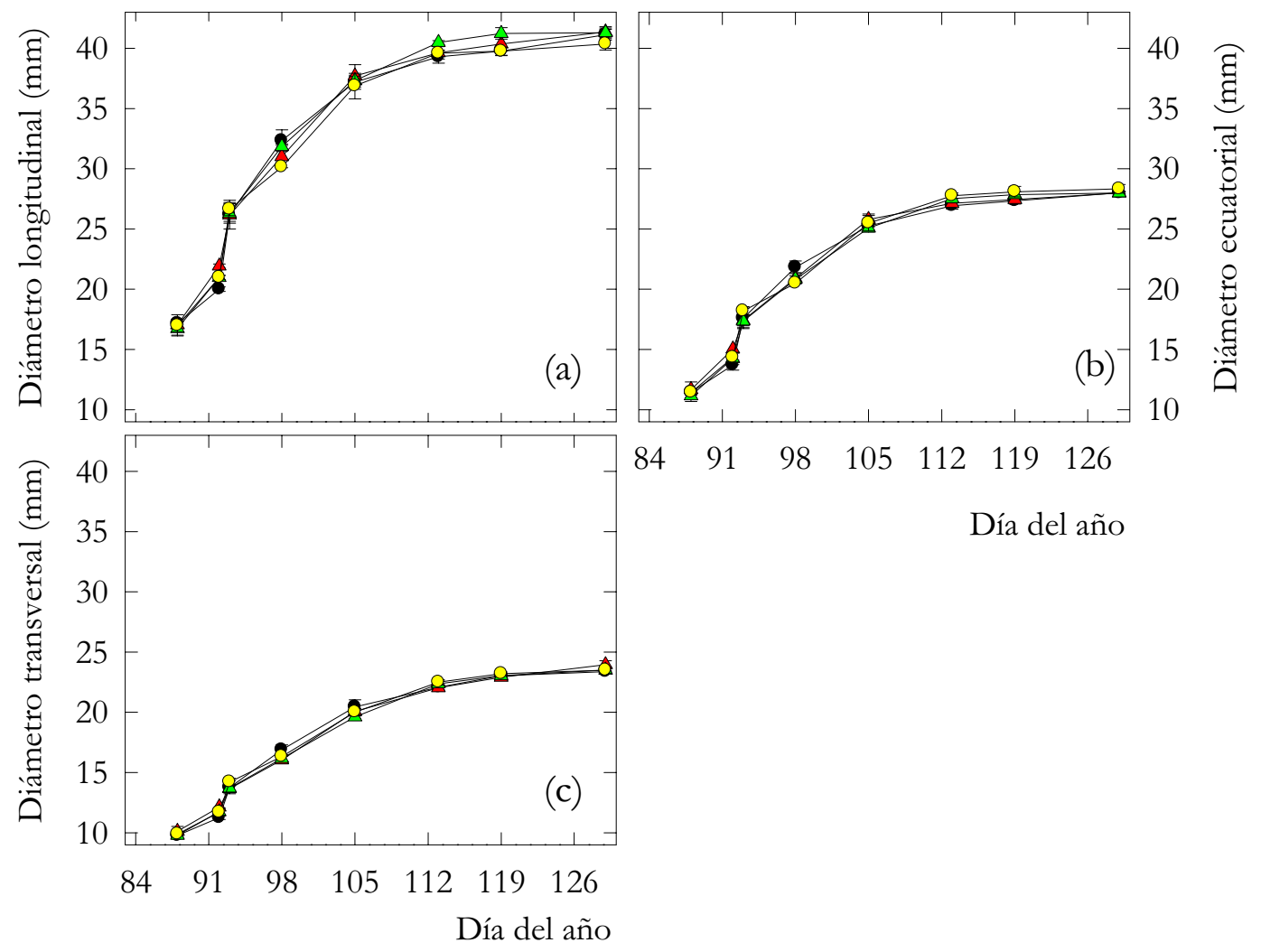

Figura 4.30. Evolución del diámetro longitudinal (a), ecuatorial (b) y trasversal (c) en $\mathrm{T}_{\text {CTL }}$ $(-\bullet), \mathrm{T}_{\mathrm{RD} 80}\left({ }^{-}-\cdot\right), \mathrm{T}_{\mathrm{RD} 60}\left({ }^{-\triangle-}\right)$ y $\mathrm{T}_{\mathrm{RDC} 40}(\cdots . \cdots)$ ) durante el 2003. Cada punto corresponde a la media de 3 repeticiones \pm ES. 


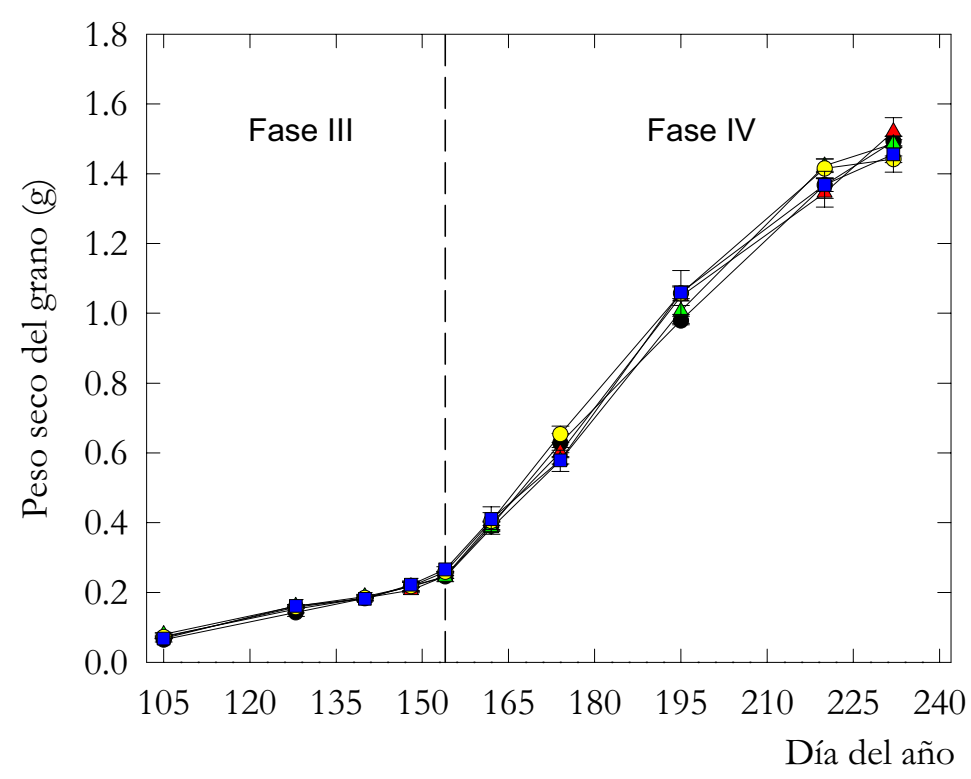

Figura 4.31. Evolución del peso seco del grano durante el 2003 en los cinco tratamientos de riego: $\mathrm{T}_{\mathrm{CTL}}(-\bullet), \mathrm{T}_{\mathrm{RD} 80}(-\boldsymbol{-}), \mathrm{T}_{\mathrm{RD} 60}\left({ }^{-\Delta-\cdot}\right), \mathrm{T}_{\mathrm{RDC} 40}(\cdots \cdots \cdots)$ y $\mathrm{T}_{\mathrm{RDC} 20}(--\cdot)$. Cada punto corresponde a la media de 3 repeticiones \pm ES.

\section{Producción}

Al tratarse de árboles jóvenes la producción de almendra experimentó un aumento notorio y constante en sus tres primeros años de cosecha (20022004). Así, y respecto al año anterior la producción se vio incrementada 6 veces en 2003 y 1.5 veces en 2004, siendo ésta una conducta general en el conjunto de los tratamientos (Tabla 4.6). En todos los años de ensayo los tratamientos más deficitarios $\left(\mathrm{T}_{\mathrm{RD} 60}, \mathrm{~T}_{\mathrm{RDC} 40} \mathrm{y} \mathrm{T}_{\mathrm{RDC} 20}\right)$ adelantaron la cosecha al menos 1 semana respecto a los más regados $\left(\mathrm{T}_{\mathrm{CTL}} \mathrm{y} \mathrm{T}_{\mathrm{RD} 80}\right)$.

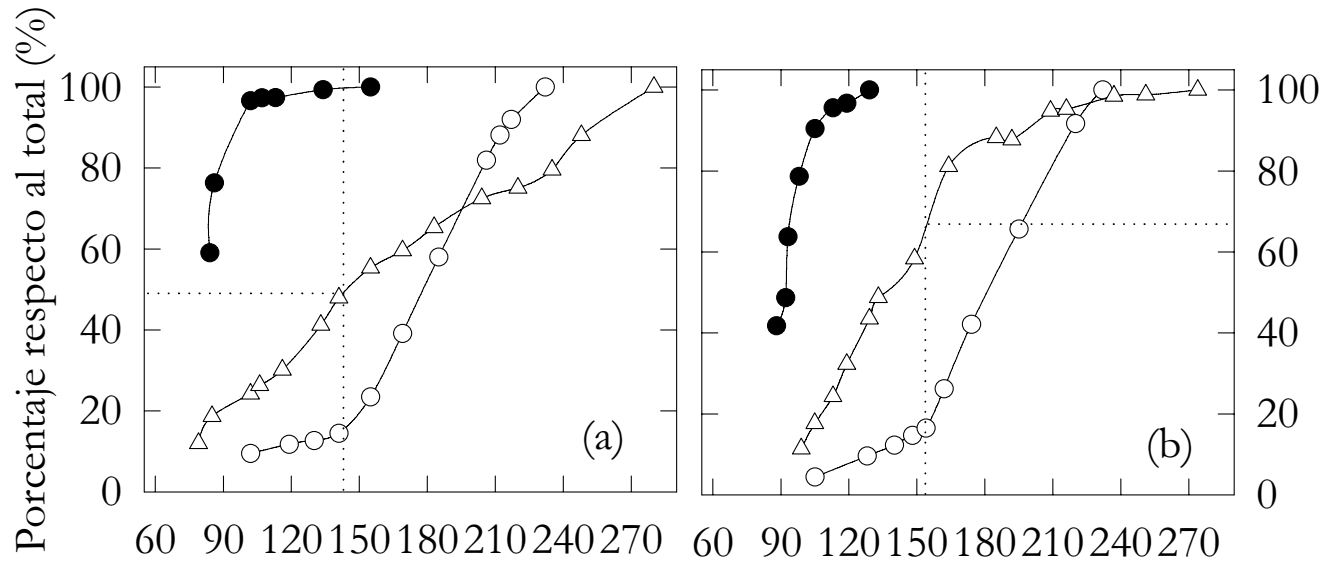

Día del año

Figura 4.32. Porcentaje respecto al total del crecimiento longitudinal $(-\bullet)$ y peso seco ( $-\cdots$ ) del fruto y longitud de brotes $(\cdots \Delta \cdots)$ en el tratamiento control. (a) 2002 y (b) 2003. 
En la cosecha de 2002, primera recolección de la plantación, a pesar de su escasa cuantía, se puso de manifiesto el efecto negativo del déficit hídrico sobre la producción. La importante reducción relativa de producción integraría los efectos del déficit hídrico tanto en el año en consideración como en el año previo, tal y como ha sido señalado en diversos trabajos (Goldhamer y Viveros, 2000; Esparza et al., 2001b; Girona et al., 2005; Goldhamer et al., 2006).

Tabla 4.6. Valores medios de los parámetros productivos para los distintos tratamientos durante el periodo experimental 2002-2004.

\begin{tabular}{|c|c|c|c|c|c|c|c|c|}
\hline Año & Trat & $\begin{array}{c}\text { Prod. } \\
\text { cáscara } \\
\left(\mathrm{kg} \mathrm{ha}^{-1}\right)\end{array}$ & $\begin{array}{c}\text { Prod. } \\
\text { grano } \\
\left(\mathrm{kg} \mathrm{ha}^{-1}\right)\end{array}$ & $\begin{array}{c}\mathrm{N}^{\mathbf{o}} \\
\text { frutos } \\
\text { árbol }^{-1} \\
\end{array}$ & $\begin{array}{c}\text { Pelonas } \\
(\%)\end{array}$ & $\begin{array}{c}\text { Dobles } \\
(\%)\end{array}$ & $\begin{array}{c}\text { Vacías } \\
(\%) \\
\end{array}$ & $\begin{array}{c}\text { Rto. } \\
\text { grano } \\
(\%) \\
\end{array}$ \\
\hline \multirow{5}{*}{2002} & $\mathbf{T}_{\mathrm{CTL}}$ & $27 \mathrm{a}$ & $68 \mathrm{a}$ & $178 \mathrm{a}$ & $2.51 \mathrm{a}$ & $0.27 \mathrm{a}$ & $0.01 \mathrm{a}$ & $29.92 \mathrm{a}$ \\
\hline & $\mathbf{T}_{\mathrm{RD} 80}$ & $103 \mathrm{~b}$ & $30 \mathrm{~b}$ & $78 \mathrm{~b}$ & $1.80 \mathrm{a}$ & $0.00 \mathrm{a}$ & $0.02 \mathrm{a}$ & $29.20 \mathrm{ab}$ \\
\hline & $\mathrm{T}_{\mathrm{RD} 60}$ & $154 \mathrm{~b}$ & $44 \mathrm{~b}$ & $117 \mathrm{~b}$ & $2.95 \mathrm{a}$ & $0.29 \mathrm{a}$ & $0.01 \mathrm{a}$ & $28.74 \mathrm{ab}$ \\
\hline & $\mathbf{T}_{\mathrm{RDC} 40}$ & $138 \mathrm{~b}$ & $39 \mathrm{~b}$ & $101 \mathrm{~b}$ & $1.03 \mathrm{a}$ & $0.07 \mathrm{a}$ & $0.02 \mathrm{a}$ & $28.75 \mathrm{~b}$ \\
\hline & $\mathbf{T}_{\mathrm{RDC} 20}$ & $244 \mathrm{a}$ & $72 \mathrm{a}$ & $192 \mathrm{a}$ & $1.54 \mathrm{a}$ & $0.13 \mathrm{a}$ & $0.01 \mathrm{a}$ & $29.38 \mathrm{ab}$ \\
\hline \multirow{5}{*}{2003} & $\mathbf{T}_{\mathrm{CTL}}$ & $1363.5 \mathrm{a}$ & $405.8 \mathrm{a}$ & $1184.7 \mathrm{a}$ & $0.83 \mathrm{ab}$ & $0.0 \mathrm{a}$ & $2.18 \mathrm{a}$ & $29.6 \mathrm{a}$ \\
\hline & $\mathbf{T}_{\mathrm{RD} 80}$ & $1128.7 \mathrm{a}$ & $327.1 \mathrm{a}$ & $940.5 \mathrm{a}$ & $1.99 \mathrm{~b}$ & $0.0 \mathrm{a}$ & $2.92 \mathrm{a}$ & $29.0 \mathrm{a}$ \\
\hline & $\mathbf{T}_{\mathrm{RD} 60}$ & $1183.4 \mathrm{a}$ & $349.6 \mathrm{a}$ & $984.4 \mathrm{a}$ & $0.07 \mathrm{a}$ & $0.0 \mathrm{a}$ & $1.60 \mathrm{a}$ & $29.3 \mathrm{a}$ \\
\hline & $\mathbf{T}_{\mathrm{RDC} 40}$ & $1282.3 \mathrm{a}$ & $386.2 \mathrm{a}$ & $1156.2 \mathrm{a}$ & $0.0 \mathrm{a}$ & $0.09 \mathrm{a}$ & $1.60 \mathrm{a}$ & $29.9 \mathrm{a}$ \\
\hline & $\mathbf{T}_{\mathrm{RDC} 20}$ & $1321.0 \mathrm{a}$ & $401.7 \mathrm{a}$ & $1215.8 \mathrm{a}$ & $0.19 \mathrm{a}$ & $0.0 \mathrm{a}$ & $1.80 \mathrm{a}$ & $30.0 \mathrm{a}$ \\
\hline \multirow{5}{*}{2004} & $\mathbf{T}_{\mathrm{CTL}}$ & $2164 \mathrm{a}$ & $655 \mathrm{a}$ & $1728 \mathrm{a}$ & $0.93 \mathrm{a}$ & $0.00 \mathrm{a}$ & $1.88 \mathrm{a}$ & $30.11 \mathrm{ab}$ \\
\hline & $\mathbf{T}_{\mathrm{RD} 80}$ & $2059 \mathrm{ab}$ & $601 \mathrm{ab}$ & $1655 \mathrm{ab}$ & $3.18 \mathrm{a}$ & $0.00 \mathrm{a}$ & $5.02 \mathrm{a}$ & $29.09 \mathrm{ab}$ \\
\hline & $\mathbf{T}_{\mathrm{RD} 60}$ & $1622 \mathrm{~b}$ & $464 \mathrm{~b}$ & $1212 \mathrm{~b}$ & $2.22 \mathrm{a}$ & $0.00 \mathrm{a}$ & $3.08 \mathrm{a}$ & $28.57 \mathrm{a}$ \\
\hline & $\mathbf{T}_{\mathrm{RDC} 40}$ & $1779 \mathrm{ab}$ & $532 \mathrm{ab}$ & $1415 \mathrm{ab}$ & $1.53 \mathrm{a}$ & $0.24 \mathrm{a}$ & $2.69 \mathrm{a}$ & $29.90 \mathrm{ab}$ \\
\hline & $\mathbf{T}_{\mathrm{RDC} 20}$ & $1989 \mathrm{ab}$ & $611 \mathrm{ab}$ & $1702 \mathrm{a}$ & $1.99 \mathrm{a}$ & $0.00 \mathrm{a}$ & $2.40 \mathrm{a}$ & $30.60 \mathrm{~b}$ \\
\hline
\end{tabular}

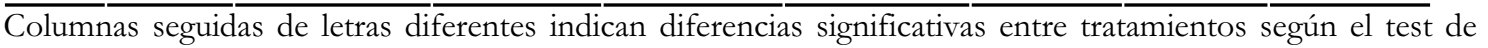
Tukey0.05.

La producción en grano respecto a $\mathrm{T}_{\mathrm{CTL}}$ se redujo un 56,35 y $43 \%$ en $T_{\mathrm{RD} 80}, \mathrm{~T}_{\mathrm{RD} 60}$ y $\mathrm{T}_{\mathrm{RDC} 40}$, respectivamente, sin que se diesen diferencias productivas entre tratamientos deficitarios (Tabla 4.6). El tratamiento $T_{\text {RDC20 }}$ 
con un ahorro de agua respecto a $\mathrm{T}_{\text {СТL }}$ del $56 \%$ en 2002 obtuvo una producción similar (Tabla 4.6). Este comportamiento diferencial de $\mathrm{T}_{\mathrm{RDC} 20}$ encuentra su explicación en el desarrollo vegetativo similar durante 2001 a $\mathrm{T}_{\text {СтL }}$ (Tabla 4.3). Durante este año los aportes hídricos en $\mathrm{T}_{\mathrm{RDC} 20}$ equivalieron al 100\% de la ETc, y por tanto, las posiciones fructíferas futuras no se vieron afectadas.

Aunque en 2003 y 2004 la producción fue similar en el conjunto de tratamientos, a excepción de $\mathrm{T}_{\mathrm{RD} 60}$ en 2004, se refleja una tendencia a la disminución de la producción por efecto del déficit. La perdida del $25 \%$ de producción en $\mathrm{T}_{\mathrm{RD} 60}$ durante 2004 se debió al menor número de frutos cosechados por árbol (Tabla 4.6), ya que el peso medio del grano fue similar al de $\mathrm{T}_{\text {CTL }}$ (Tabla 4.7).

Dado que el crecimiento vegetativo se ha confirmado como más sensible al estrés hídrico que el transporte de carbohidratos (Hsiao, 1973), la disminución experimentada por el tronco (Figura 4.20 y Tabla 4.3) y la superficie sombreada (Figura 4.22) en los tratamientos más deficitarios con respecto a $\mathrm{T}_{\mathrm{CTL}}$, supone un menor espacio para el asentamiento de los frutos en el árbol y, en definitiva, una menor carga productiva, tal y como ha sido presentado en otros estudios en almendros adultos sometidos a RDC (Goldhamer y Viveros, 2000; Esparza et al., 2001b; 2001a; Goldhamer et al., 2006).

Tabla 4.7. Valores medios del peso seco del grano en los cinco tratamientos de riego durante el período 2002-2004. Cada valor representa la media de 12 árboles por tratamiento.

\begin{tabular}{ccccc}
\hline & \multicolumn{4}{c}{ Peso seco del grano $\mathbf{( g )}$} \\
\hline Tratamiento & $\mathbf{2 0 0 2}$ & $\mathbf{2 0 0 3}$ & $\mathbf{2 0 0 4}$ & Media \\
\hline $\mathbf{T}_{\mathbf{C T L}}$ & $1.63 \mathrm{a}$ & $1.49 \mathrm{ab}$ & $1.64 \mathrm{a}$ & $1.59 \mathrm{a}$ \\
$\mathbf{T}_{\mathbf{R D} 80}$ & $1.60 \mathrm{a}$ & $1.53 \mathrm{a}$ & $1.68 \mathrm{a}$ & $1.60 \mathrm{a}$ \\
$\mathbf{T}_{\mathbf{R D 6 0}}$ & $1.63 \mathrm{a}$ & $1.49 \mathrm{ab}$ & $1.71 \mathrm{a}$ & $1.61 \mathrm{a}$ \\
$\mathbf{T}_{\mathbf{R D C 4 0}}$ & $1.65 \mathrm{a}$ & $1.44 \mathrm{~b}$ & $1.65 \mathrm{a}$ & $1.58 \mathrm{a}$ \\
$\mathbf{T}_{\mathbf{R D C 2 0}}$ & $1.57 \mathrm{a}$ & $1.45 \mathrm{ab}$ & $1.60 \mathrm{a}$ & $1.54 \mathrm{a}$
\end{tabular}

Columnas seguidas de letras diferentes indican diferencias significativas entre tratamientos según el test de Tukey0.05.

El peso seco del grano no se vio, generalmente, afectado por el tratamiento de riego (Tabla 4.7). Tan sólo en 2003, $\mathrm{T}_{\mathrm{RDC} 40}$ fue estadísticamente diferente a $\mathrm{T}_{\mathrm{RD} 80}$ debido principalmente al menor número de frutos en $\mathrm{T}_{\mathrm{RD} 80}$ (Tabla 4.6). El estrés hídrico moderado al que fue sometido $\mathrm{T}_{\mathrm{RDC} 20}$, tanto en 2002 como $2003\left(\Psi_{a} \geq-1 \mathrm{MPa}\right)$, no afectó a la acumulación de fotoasimilados 
en la semilla, lo que muestra el fuerte efecto sumidero que tiene el fruto durante este periodo de alta demanda evaporativa (junio-agosto).

A la recuperación del peso seco del grano en 2004 (Tabla 4.7), pudieron contribuir las importantes cantidades de lluvia $(500 \mathrm{~mm})$ acaecidas en el periodo invierno - primavera de 2003 y 2004 (Figura 4.24), al recargar el perfil hídrico del suelo. Girona et al. (2005) justificaron la reducción del peso seco del grano, en el tercer año de aplicación de RDC, al agotamiento progresivo del contenido de agua en el suelo debido a las escasas lluvias ocurridas durante el período invernal. Los mismos autores, a partir de tratamientos con riego al $20-50 \%$ de la ETc, durante la fase IV, observaron reducciones de producción entre el 5 y $9 \%$ e indicaron que el principal componente afectado fue el peso del grano (Girona y Marsal, 1995). Igualmente, Goldhamer y Smith (1995) Goldhamer y Viveros (2000) encontraron reducciones del peso del grano del orden del $10 \%$ en almendros en los que el déficit hídrico fue previo a la cosecha. Sin embargo, Romero et al. (2004a) no encontraron reducciones significativas en el peso seco del grano de almendros sometidos a estrés hídrico severo $\left(\Psi_{\mathrm{a}} \approx-2.4 \mathrm{MPa}\right)$ durante la fase $I V$, de lo que concluyen que la acumulación de fotoasimilados se mantuvo, a la vez que señalan la fuerte actividad de sumidero del fruto en este período, lo que a su vez es compartido por los anteriores autores.

Según nuestros resultados, la variedad 'Marta' presenta una escasa presencia de almendras pelonas, dobles y vacías, lo que en conjunción con su carácter productivo y autofértil le convierte en una variedad de gran interés. El tratamiento de riego no afectó al número de almendras pelonas, dobles ni vacías. Independientemente, de la estrecha relación encontrada entre el estrés hídrico aplicado en la fase IV del almendro y el porcentaje de pelonas (Goldhamer y Viveros, 2000; Romero et al., 2004a; Goldhamer et al., 2006).

El incremento anual de la sección del tronco da una idea del crecimiento vegetativo ocurrido en ese intervalo de tiempo; de esta forma la relación entre la producción y este incremento serviría para separar los recursos destinados al crecimiento vegetativo y al productivo (Ebel et al., 1995; González-Altozano y Castel, 1999). En 2003 y 2004, años de mayor relevancia productiva (Tabla 4.6), el reparto de recursos fue ligeramente favorable a la productividad, con valores de eficiencia productiva y de la relación kg $\Delta \mathrm{STT}^{-1}$ similares o incluso superiores a los del tratamiento control (Tabla 4.8).

La eficiencia de uso del agua de riego (EUA) aumentó con la reducción de los aportes hídricos, lo que es coincidente con lo indicado por otros autores (Torrecillas et al., 1989a; Hutmacher et al., 1994; Romero et al., 2004a). Así mismo, se observó un incremento lineal de EUA con la edad del árbol, lo que puede ser achacado al carácter juvenil del árbol. 
Tabla 4.8. Índices de eficiencia productiva y de uso del agua de riego (EUA) de almendros 'Marta' durante el período experimental.

\begin{tabular}{|c|c|c|c|c|c|c|}
\hline \multirow{2}{*}{ Índice } & \multirow{2}{*}{ Año } & \multicolumn{5}{|c|}{ Tratamiento de riego } \\
\hline & & $\mathbf{T}_{\mathrm{CTL}}$ & $\mathbf{T}_{\mathrm{RD} 80}$ & $\mathbf{T}_{\mathrm{RD} 60}$ & $\mathbf{T}_{\mathrm{RDC} 40}$ & $\mathrm{~T}_{\mathrm{RDC} 20}$ \\
\hline \multirow{3}{*}{$\begin{array}{c}\text { Eficiencia Productiva } \\
\text { (Produc./STT), kg/ } \\
\text { cm }^{2}\end{array}$} & 2002 & $0.047 \mathrm{~b}$ & $0.037 \mathrm{bc}$ & $0.029 \mathrm{c}$ & $0.039 \mathrm{bc}$ & $0.066 \mathrm{a}$ \\
\hline & 2003 & 0.558 a & $0.525 \mathrm{a}$ & $0.633 \mathrm{ab}$ & $0.729 \mathrm{~b}$ & $0.699 \mathrm{~b}$ \\
\hline & 2004 & $0.495 \mathrm{a}$ & $0.656 \mathrm{~b}$ & $0.534 \mathrm{a}$ & $0.573 \mathrm{ab}$ & $0.581 \mathrm{ab}$ \\
\hline \multirow{3}{*}{$\underset{\left.\mathrm{cm}^{2}\right)}{\text { Ratio } \mathrm{kg} / \Delta \mathrm{STT}(\mathrm{kg} /}$} & 2002 & $0.0056 \mathrm{~b}$ & $0.0047 \mathrm{~b}$ & $0.0033 \mathrm{~b}$ & $0.0051 \mathrm{~b}$ & $0.0082 \mathrm{a}$ \\
\hline & 2003 & $0.150 \mathrm{a}$ & $0.135 \mathrm{a}$ & $0.183 \mathrm{ab}$ & $0.222 \mathrm{~b}$ & $0.228 \mathrm{~b}$ \\
\hline & 2004 & $0.141 \mathrm{a}$ & $0.240 \mathrm{~b}$ & $0.155 \mathrm{a}$ & $0.181 \mathrm{a}$ & $0.154 \mathrm{a}$ \\
\hline \multirow{3}{*}{$\begin{array}{l}\text { EUA (Produc. } / \text { riego } \\
\text { +Lluvia), } \mathrm{kg} / \mathrm{m}^{3}\end{array}$} & 2002 & $0.049 \mathrm{~b}$ & $0.043 \mathrm{~b}$ & $0.034 \mathrm{~b}$ & $0.045 \mathrm{~b}$ & $0.081 \mathrm{a}$ \\
\hline & 2003 & $0.143 \mathrm{ab}$ & $0.134 \mathrm{a}$ & $0.150 \mathrm{bc}$ & $0.169 \mathrm{bc}$ & $0.183 \mathrm{c}$ \\
\hline & 2004 & $0.213 \mathrm{a}$ & $0.261 \mathrm{ab}$ & $0.270 \mathrm{~b}$ & $0.291 \mathrm{~b}$ & $0.365 \mathrm{c}$ \\
\hline
\end{tabular}

$\overline{\text { Filas seguidas de letras diferentes indican diferencias significativas entre tratamientos según el test }}$ de Tukey0.05.

\subsection{Conclusiones}

Bajo riego por goteo y adecuado suministro hídrico, almendros de 3 y 4 años de edad presentan la práctica totalidad de sus raíces en los $50 \mathrm{~cm}$ primeros de profundidad, así como un marcado carácter de crecimiento horizontal. Ambos aspectos son de gran interés con fines de diseño y manejo del riego.

La estrecha relación encontrada entre el índice de área foliar y la superficie sombreada, permite estimar el primero a partir de medidas sencillas de área sombreada.

La fase de llenado del grano (Fase IV), en almendros jóvenes 'Marta', se inicia tras acumular del orden de $27000{ }^{\circ} \mathrm{C}$ GDH. Este dato puede ser utilizado para marcar el inicio de la aplicación del déficit hídrico controlado en explotaciones en RDC

Los diferentes indicadores de estrés hídrico medidos tanto en suelo (potencial matricial y contenido de agua) como en planta (potencial hídrico y conductancia foliar) fueron sensibles al régimen de riego. Contenidos volumétricos de humedad del suelo del 40\%, medidos a $15 \mathrm{~cm}$ del emisor, correspondientes a valores de $\Psi_{\mathrm{a}}$ y $\Psi_{\mathrm{t}}$ de -0.55 y $1.0 \mathrm{MPa}$, son indicativos de condiciones no limitantes de agua en el suelo bajo las condiciones de ensayo. 
A partir de $\Psi_{\mathrm{a}}<-0.7 \mathrm{MPa}$ el almendro disminuye sus pérdidas de agua a través de una importante regulación estomática. Sin embargo, requiere un déficit hídrico mayor $\left(\Psi_{\mathrm{a}}<-1.1 \mathrm{MPa}\right)$ para desarrollar mecanismos de adaptación a la sequía del tipo ajuste osmótico.

El conjunto de variables controladas relativas al crecimiento y sus relaciones con la dotación hídrica e integral de estrés indican la alta sensibilidad de este proceso al déficit hídrico.

Aunque, tanto la producción como sus componentes se vieron poco o nada afectadas por el tratamiento de riego; es muy presumible que el menor tamaño de los árboles deficitarios, se corresponda con un número menor de posiciones fructíferas, afectando a producciones futuras. De ahí, la conveniencia de una programación óptima del riego en los primeros años de crecimiento y desarrollo de la plantación.

La práctica nula influencia del tratamiento de riego sobre el porcentaje de almendras pelonas, dobles y vacías, así como el carácter de la variedad 'Marta' a presentar bajísimos porcentajes de estas irregularidades productivas, la convierten en una variedad de gran interés para ser cultivada en riego deficitario controlado. 


\section{Relaciones hídricas y producción de almendros regados con agua salina}





\subsection{Introducción}

La escasez de agua en el sudeste español ha propiciado el empleo de tecnologías altamente eficientes de riego, pero también el uso de aguas subterráneas con contenidos medios-altos en sales solubles (Bolarín y Caro, 1995). El principio básico para la sostenibilidad del regadío cuando se emplean aguas salinas es mantener la concentración de sales en el suelo a un nivel relativamente constante y por debajo de un valor umbral específico de cada especie. La satisfacción de este requisito a partir de técnicas de programación de riego precisas es una práctica demostradamente rentable (Rhoades et al., 1992).

Sin embargo, la disponibilidad de agua en estas zonas sigue siendo escasa, de ahí que surja el planteamiento de cultivar con menos agua, y al ser posible, sin que suponga mermas importantes en la producción ni en la calidad de la cosecha. Los estudios realizados que abordan el efecto combinado del riego con agua salina y la reducción de los aportes hídricos sobre las relaciones hídricas, el crecimiento y producción del árbol son escasos. Por ello, se planteó este trabajo con el objetivo principal de determinar la respuesta del almendro al riego deficitario controlado con agua salina, al ser cada vez más frecuente que al problema de la escasez de recursos hídricos, en las regiones semiáridas, vaya unido el de la baja calidad agronómica de sus aguas.

\subsection{Materiales y métodos}

\section{Material vegetal, condiciones experimentales y tratamientos}

El ensayo se realizó durante los años 1999 - 2002 en una finca comercial de almendros (Prunus dulcis (Mill.) Webb), situada en Fuente-Álamo, Murcia $\left(37^{\circ} 46^{\prime} \mathrm{N}, 1^{\circ} 10^{\prime} \mathrm{E}\right)$. La plantación, inicialmente de secano, fue transformada a riego localizado en 1995 cuando los árboles tenían 9 años de edad, y desde entonces se riegan con agua de pozo de elevada salinidad. La variedad base de la finca es Colorada y en un $30 \%$ Peraleja como polinizador, ambas injertadas sobre patrón Franco de Garrigues. Los árboles dispuestos a un marco de plantación de $6 \times 6 \mathrm{~m}$, sombreaban al inicio del ensayo entre un $20-25 \%$ la superficie del suelo.

Durante el período experimental, el clima se caracterizó por una demanda evaporativa, ETo (Penman-Monteith), y lluvia media de 1350 y 225 $\mathrm{mm}$ respectivamente, con pequeñas desviaciones interanuales. El período de lluvias fue el usual de esta zona, ocurriendo durante los meses de primavera y otoño. El $67 \%$ de la lluvia acaecida en el año 2000 tuvo lugar el día 23 de 
octubre $(160 \mathrm{~mm})$ como consecuencia de un fenómeno de gota fría (Figura $5.1)$

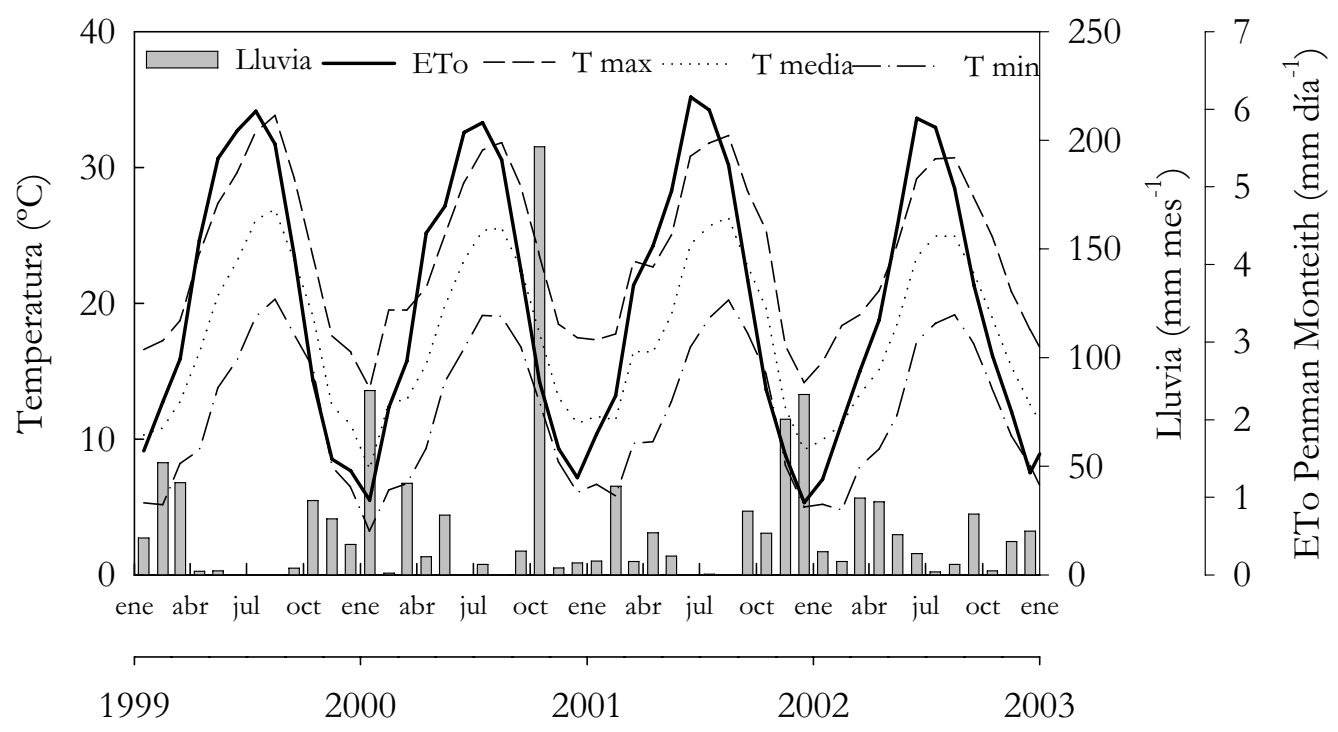

Figura 5.1. Evolución mensual de la temperatura máxima, mínima y media, evapotraspiración de referencia y lluvia durante el periodo experimental, 1999-2003.

El suelo de textura franco-arcillo-limosa presenta una capa petrocálcica a 120-140 cm de profundidad. Su contenido medio de agua útil, en los $90 \mathrm{~cm}$ primeros, fue de $170 \mathrm{~mm} \mathrm{~m}^{-1}$ y la densidad aparente osciló entre 1.35 y 1.55 $\mathrm{Mg} \mathrm{m}^{-3}$. Los niveles en potasio (55 $\left.\mathrm{ppm}\right)$ y materia orgánica $(1.37 \%)$ fueron bajos y alto su contenido en caliza $\left(10.2 \%\right.$ y sales solubles $\left(\mathrm{CE}_{\mathrm{e}} 6.2 \mathrm{dS} \mathrm{m}^{-1}\right)$. El agua de riego presentó valores medios de $\mathrm{CE}_{25^{\circ} \mathrm{C}}$ de $4.2 \mathrm{dS} \mathrm{m} \mathrm{m}^{-1} \mathrm{y}$ concentración de cloruros y sodio de 16.2 y $19.0 \mathrm{meq} \mathrm{L}^{-1}$, respectivamente. Las cantidades de elementos fertilizantes aplicados con el agua de riego fueron 75-30-40 kg ha ${ }^{-1}$ año ${ }^{-1}$ de $\mathrm{N}-\mathrm{P}_{2} \mathrm{O}_{5}-\mathrm{K}_{2} \mathrm{O}$. Se realizaron las labores de cultivo habituales de la zona, y se mantuvo el suelo libre de malas hierbas mediante pases de cultivador en la dirección de las calles y aplicaciones de herbicidas en la zona húmeda. No se podaron los árboles durante todo el período experimental.

Durante 1999 y 2000 el sistema de riego utilizado fue por microaspersión (3 emisores árbol ${ }^{-1}$, de $30 \mathrm{~L} \mathrm{~h}^{-1}$ ), que se cambió a riego por goteo en enero de 2001. Éste constó de dos laterales por hilera de árboles con 12 emisores árbol ${ }^{-1}$ de $8 \mathrm{~L} \mathrm{~h}^{-1}$ al objeto de mantener idéntico porcentaje de suelo mojado y evitar pérdidas de agua por deriva. El porcentaje de suelo humedecido fue muy similar en ambos sistemas de riego y estuvo en torno al $33 \%$, valor ligeramente superior al área sombreada por el cultivo.

Se ensayaron tres tratamientos de riego: un control, $\mathrm{T}_{\text {CTL }}$, regado al 125 $\%$ de la ETc, otro de riego deficitario controlado, $\mathrm{T}_{\mathrm{RDC}}$, al $100 \%$ del $\mathrm{T}_{\mathrm{CTL}}$ hasta alcanzar el tamaño exterior del fruto (mediados de abril), $70 \%$ hasta el 
inicio de la fase de acumulación rápida en materia seca del grano (finales de mayo), $30 \%$ hasta recolección (mediados de agosto) y $70 \%$ durante el resto de la estación de riego y un tercer tratamiento de secano, $\mathrm{T}_{\mathrm{SCO}}$, sin riego durante todo el año (Figura 5.2). El diseño estadístico fue de bloques al azar con tres repeticiones. Cada replica constó de tres hileras de árboles con seis árboles por hilera, de ellos se seleccionaron los 4 árboles centrales para la toma de medidas, considerándose el resto como árboles guarda (Figura 5.3). Por otro lado, y debido a la inexistencia de agua de buena calidad no se pudo plantear un tratamiento testigo con agua de baja salinidad, el que hubiese permitido un estudio más detallado de los efectos de las sales disueltas en el agua de riego y solución del suelo sobre el crecimiento y producción del almendro.

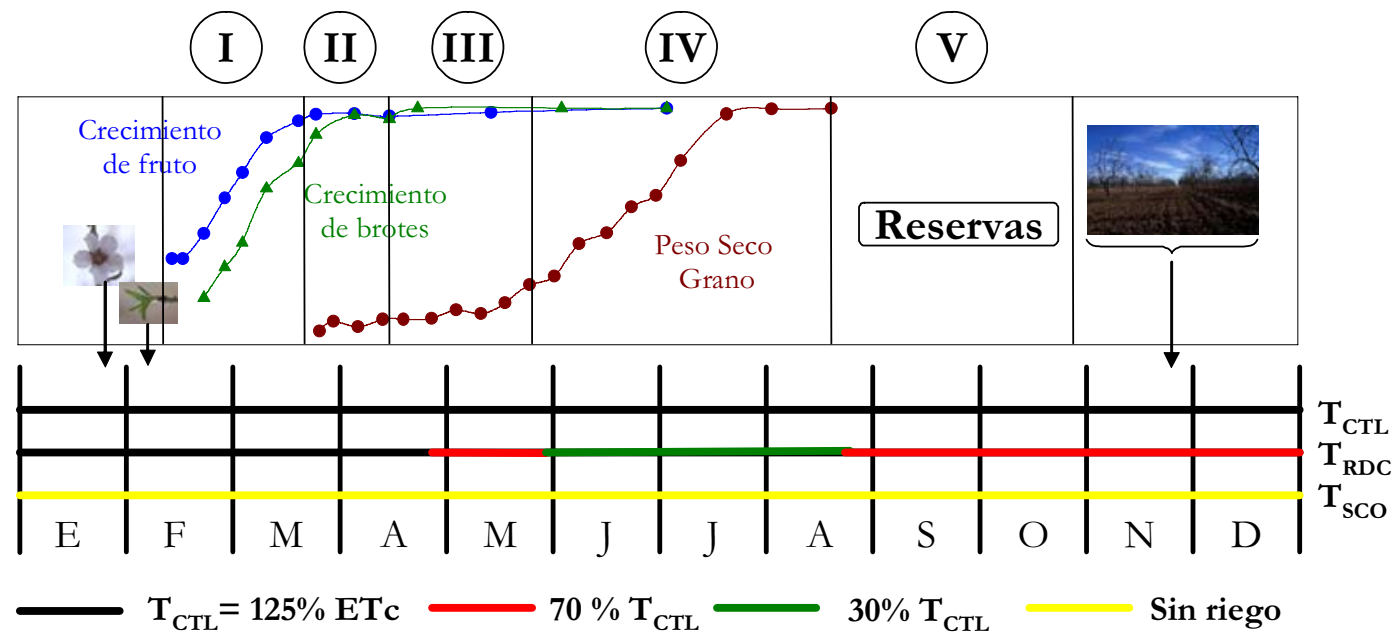

Figura 5.2. Régimen de riego, en los distintos tratamientos, de acuerdo a las fases del ciclo anual de almendros 'Colorada'.

La frecuencia de riego fue semanal en atención a las limitaciones impuestas por el agricultor-colaborador en los repartos del agua disponible y en orden a mantener una humedad adecuada en la profundidad radicular efectiva. Las dosis de riego, para la frecuencia fijada, se determinaron a partir de la evapotranspiración de referencia (ETo), según la ecuación de PenmanMonteith (Allen et al., 1998), proporcionada por el Servicio de Información Agraria de Murcia, SIAM (http://www.carm.es/cagr/cida/siam.htm), a partir de los datos registrados en la estación agroclimática vecina 'El Campillo' (CA91); los coeficientes de cultivo $\left(k_{c}\right)$ dados por Doorenbos y Pruitt (1977) y la estima de los requerimientos de lavado. Los volúmenes de riego calculados fueron ajustados en función del tamaño de copa (Fereres et al., 1982). Sin embargo, durante el 2002 y debido a una sequía severa no se pudieron aplicar las cantidades de agua programadas en la segunda mitad de la estación de riegos. La cantidad de agua aplicada se leyó semanalmente en contadores instalados en cada uno de los tratamientos. 


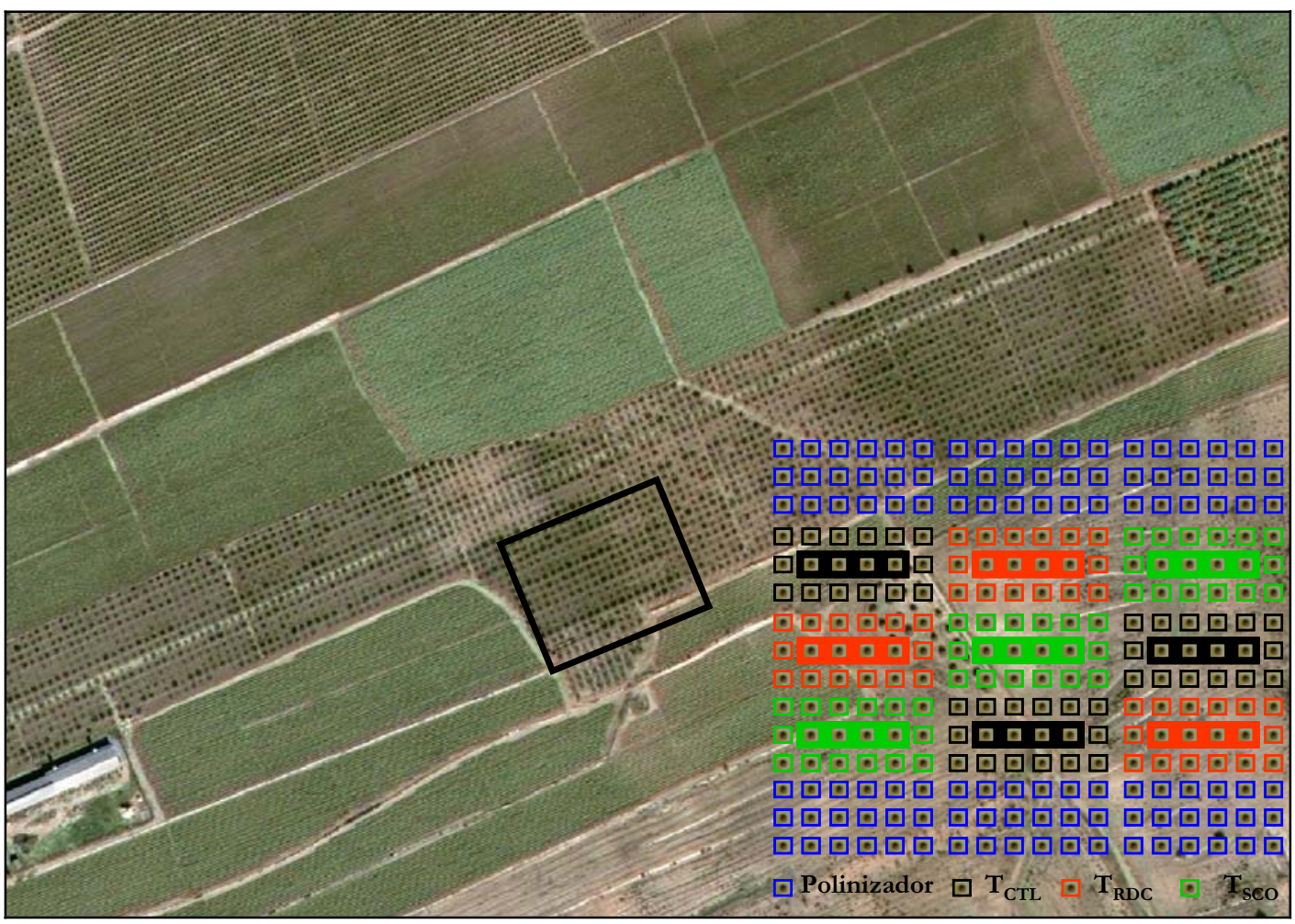

Figura 5.3. Vista aérea de la plantación comercial de almendros 'La Corverica'. El recuadro en negro señala la parcela experimental en la que se realizó el ensayo, de acuerdo con la distribución de tratamientos indicada.

\section{Medidas}

\section{Agua-suelo}

El potencial matricial del agua en el suelo $\left(\Psi_{\mathrm{m}}\right)$ se midió con tensiómetros y sensores de matriz granular (Watermarks) situados a 70 y 30 $\mathrm{cm}$ del emisor (microaspersión y goteo, respectivamente), en dos repeticiones por tratamiento y a las profundidades de 30,60 y $90 \mathrm{~cm}$. El contenido volumétrico de agua $\left(\theta_{\mathrm{v}}\right)$ se determinó con TDR (Moisture Point, Mod. MP917) en dos posiciones del volumen humedecido, próximo al emisor y en el frente húmedo, y en un árbol por repetición para cada tratamiento. En el tratamiento de secano, las sondas TDR se instalaron a idéntica distancia que en los tratamientos regados, pero en este caso respecto al emisor suprimido y en la zona perimetral de la proyección de la copa. La distribución de sales en el perfil de suelo humectado por los emisores se evaluó a partir de medidas de la concentración del ion cloruro, $\left[\mathrm{Cl}^{-}\right]_{\mathrm{e}}$ (Corning Chloride Analyzer, mod. 926) y de la conductividad eléctrica, $\mathrm{CE}_{\mathrm{e}}$, del extracto de saturación (Crison mod. 524). Las muestras se tomaron con idéntico criterio al de las medidas de contenido de humedad, próximas al emisor y en el frente húmedo, en capas de 
$30 \mathrm{~cm}$ hasta la profundidad de $120 \mathrm{~cm}$ y en 3 ubicaciones por tratamiento, una por repetición.

\section{Agua-planta}

Quincenalmente y en días típicos y soleados se controló el estado hídrico del árbol a partir de medidas de conductancia foliar $\left(\mathrm{g}_{\mathrm{I}}\right)$ y de potencial hídrico foliar antes del alba $\left(\Psi_{\mathrm{a}}\right)$ y a mediodía $\left(\Psi_{\mathrm{md}}\right)$, en 18 hojas adultas por tratamiento. Para ello, se utilizó un porómetro de estado estacionario (Licor Inc., mod. LI-1600) y una cámara de presión (Soil Moisture Equip. Corp, mod. 3000). En el año 2000 y con el período de déficit avanzado en $\mathrm{T}_{\mathrm{RDC}}$, día 19 de julio, se determinó el potencial hídrico foliar $\left(\Psi_{1}\right)$, el de hoja cubierta o potencial de tallo $\left(\Psi_{t}\right), g_{1}$ y las condiciones ambientales a intervalos de dos horas desde antes del alba hasta la puesta del sol. La evaluación diaria del estado hídrico del árbol fue intensificada en 2001, al objeto de caracterizar el funcionamiento hídrico del árbol al inicio (25 mayo) y mediados (26 julio) del período de déficit severo y tras mes y medio de la reanudación del riego al 70 $\% \mathrm{~T}_{\mathrm{CTL}}\left(25\right.$ octubre) en el $\mathrm{T}_{\mathrm{RDC}}$. En estas tres evaluaciones, se controló, además, el potencial osmótico foliar a saturación $\left(\Psi_{\mathrm{os}}\right)$, a partir de hojas situadas en los mismos 'spurs' que las utilizadas en las medidas de $\Psi_{\text {a }}$, y el potencial osmótico foliar actual $\left(\Psi_{\mathrm{o}}\right)$ en cada momento de medida de $\Psi_{1}$ con un osmómetro (Roebling, mod. 13 DR). El potencial de presión fue estimado como diferencia entre $\Psi_{1}$ y $\Psi_{\mathrm{o}}$. El déficit de presión de vapor (DPV) se determinó a partir de las lecturas obtenidas a partir de un sicrómetro de bulbo seco y húmedo, y la radiación fotosintéticamente activa (RFA) mediante el sensor de quantum del porómetro. En ambos años, las evoluciones diarias se realizaron el último día del intervalo entre riegos, al objeto de que el árbol reflejase la situación hídrica más desfavorable del período entre riegos.

\section{Contenido mineral en hoja}

A mediados de julio de 2000 y 2001, se tomaron muestras foliares de 150 hojas procedentes de los 'spur' para su análisis posterior. En el laboratorio se lavaron las hojas en una disolución al $0.3 \%$ de Teepol y enjuagaron con agua destilada, durante un período inferior a treinta segundos. Inmediatamente después, se secaron las muestras en estufa por corriente de aire a $70^{\circ} \mathrm{C}$ durante 24 horas, posteriormente se trituraron en un molinillo de aspas, quedando reducido a polvo finamente dividido y a continuación se desecaron a $105^{\circ} \mathrm{C}$ hasta peso constante (2 horas). Por último la muestra pulverizada se introdujo en frascos con cierre hermético para su conservación y posterior realización de las diferentes determinaciones (Grier, 1996). Así mismo y durante el 2001, se determinó, bimensualmente, el contenido foliar 
de cloruros, sodio y potasio en muestras de 150 hojas por repetición procedentes de 'spur'. La concentración de cloruros en hoja se valoró según el método propuesto por Gilliam (1971) utilizando un analizador de Cloruros (Corning, mod. 926), y las de sodio y potasio por espectrofotometría de absorción atómica (Espectrofotómetro Unicam, mod. 969 AA) de acuerdo a los métodos oficiales de análisis de la Unión Europea (1998).

La toma de muestras foliares en los meses en que se realizaron las tres evaluaciones diarias de control del estado hídrico de la planta coincidió con los días de las evoluciones, al objeto de utilizar los contenidos foliares en cloruro, sodio y potasio en el estudio de la contribución relativa de cada uno de estos solutos al potencial osmótico foliar medido a saturación. La contribución osmótica de los solutos analizados individualmente $\left(\Psi_{\mathrm{os}, \mathrm{i}}\right)$ se determinó a partir de la ecuación de Van’t Hoff:

$$
\Psi_{\text {os,i }}=-0.002479 \times \text { PSR } \times \text { C }
$$

donde $\Psi_{\mathrm{os}, \mathrm{i}}$ indica la contribución individual de los solutos $(\mathrm{MPa})$ al $\Psi_{\mathrm{os}}$ medido, PSR el peso seco relativo a saturación $\left(\mathrm{kg} \mathrm{m}^{-3}\right), \mathrm{C}$ la concentración molar de los solutos $\left(\mathrm{mol} \mathrm{kg}{ }^{-1}\right.$ ) y $0.002479 \mathrm{~m}^{3} \mathrm{MPa}^{-1}$ el valor RT a $25{ }^{\circ} \mathrm{C}$. Se asumió un comportamiento osmótico ideal de los solutos, es decir, una constante de ionización de uno (Alarcón et al., 1993).

\section{Crecimiento y desarrollo}

Para caracterizar la dinámica de crecimiento en longitud de los ramos y dado el escaso crecimiento observado en 1999, en 2000 y 2001 se seleccionaron y marcaron cuatro ramas de aproximadamente $1.5 \mathrm{~cm}$ de diámetro en cada una de las cuatro orientaciones, y en dos árboles representativos por parcela elemental. En ellas y con una frecuencia de 1 a 2 veces semana se midió la elongación apical y axilar de todas las brotaciones surgidas. Adicionalmente, y en un único brote del año por rama se midió con calibre digital (Crafstman, precisión $0.01 \mathrm{~mm}$ ) e idéntica frecuencia su diámetro basal.

El crecimiento de tronco se evalúo a partir de medidas periódicas del perímetro del tronco a una altura de aproximadamente $10 \mathrm{~cm}$ sobre la unión injerto-patrón y en 12 árboles por tratamiento. Adicionalmente, se midió, en idénticos árboles, el diámetro de la copa en dos direcciones perpendiculares (en la dirección de las filas y transversal a ella).

El área foliar total de árboles seleccionados se estimó a partir del producto peso seco foliar total por el área específica foliar. Para ello e inmediatamente después de la cosecha, se envolvió el árbol con una malla plástica de paso de luz inferior al tamaño mínimo de hoja. Las hojas caídas y 
recogidas en el fondo del envoltorio se retiraron periódicamente, hasta la recogida de la totalidad de las hojas presentes en el árbol, y se determinó su peso seco tras desecación en estufa ventilada a $65^{\circ} \mathrm{C}$. Previamente, y mediante un sistema de análisis de imagen DELTA-T se determinó el área foliar de una muestra de 150 hojas por repetición y tratamiento, y a continuación, su peso seco.

Para el estudio del patrón de crecimiento del fruto se midió, semanalmente, con calibre digital (Crafstman, precisión $0.01 \mathrm{~mm}$ ) la longitud y anchura de 100 frutos elegidos al azar en cuatro árboles por repetición, y, adicionalmente, se recogieron 60 frutos por tratamiento en los que se determinó el peso fresco y seco total y del grano. La cosecha se controló individualmente en cada uno de los cuatro árboles centrales de cada repetición, una vez eliminada la corteza y tras secado al aire durante 4 días. Tras ello y a partir de una muestra de 250 g por árbol se determinó el peso del grano y cáscara, rendimiento y porcentaje de semillas dobles, vacías y pelonas. El número de frutos por árbol se determinó dividiendo la producción total de cada árbol por el peso medio del fruto.

\subsection{Resultados y discusión}

\subsubsection{Relaciones hídricas}

\section{Agua - suelo}

Durante los años 2000 y 2001 y con una frecuencia semanal, se tomaron las lecturas de potencial hidráulico $\left(\Psi_{\mathrm{H}}\right)$, en cada una de las estaciones tensiométricas, momentos antes del inicio del riego. En el tratamiento $\mathrm{T}_{\mathrm{CTL}}$ y en el $\mathrm{T}_{\mathrm{RDC}}$ durante los períodos de riego al 100 y $70 \%$ del $\mathrm{T}_{\text {СтL }}$ las lecturas de $\Psi_{\mathrm{H}}$ se obtuvieron con tensiómetros, mientras que en $\mathrm{T}_{\mathrm{SCO}}$ y durante el período al $30 \%$ en $\mathrm{T}_{\mathrm{RDC}}$ se determinaron con sensores de matriz granular (Watermarks), al alcanzarse tensiones de agua en el suelo superiores a $80 \mathrm{kPa}$.

En la tabla 5.1 se recogen los valores medios de potencial matricial por períodos y profundidades para los tres tratamientos de riego. Estos períodos responden al tiempo de aplicación de los diferentes regímenes hídricos que definen al tratamiento $T_{\mathrm{RDC}}$. Los valores registrados de $\Psi_{\mathrm{m}}$ durante $2000 \mathrm{y}$ 2001 correspondieron, generalmente, al nivel máximo alcanzado de retención del agua por las partículas sólidas del suelo, durante cada uno de los intervalos de riego, y sus valores medios fueron muy similares en los dos años de registros, de ahí que la tabla 5.1 tan sólo refleje los correspondientes al 2000. 
A partir de los valores de $\Psi_{\mathrm{m}}$ correspondientes a las profundidades de 30, 60 y $90 \mathrm{~cm}$ (Tabla 5.1), perfil del suelo donde se encuentra la práctica totalidad del sistema radicular, se deduce la marcada influencia del régimen de riego en la disponibilidad del agua para el cultivo. Los valores medios prerriego de $\Psi_{\mathrm{m}}$ en el tratamiento control fueron medios-altos, relativamente estables y acordes con la programación realizada. Durante toda la estación de riego $\Psi_{\mathrm{m}}$ fue superior en $\mathrm{T}_{\mathrm{CTL}}$ que en $\mathrm{T}_{\mathrm{RDC}}$, a excepción del período febreromediados de mayo en el que se obtuvieron valores de $\Psi_{\mathrm{m}}$ parecidos en ambos tratamientos, como consecuencia de la mayor similitud entre los aportes hídricos y la menor demanda evaporativa de esta época del año. En el período de riego al $30 \%$ del $\mathrm{T}_{\mathrm{CTL}}$ los valores de $\Psi_{\mathrm{m}}$ en $\mathrm{T}_{\mathrm{RDC}}$ se mantuvieron por debajo del rango de medida del tensiómetro, niveles que posibilitan riesgos de estrés hídrico en planta (Pogue y Pooly, 1985). Esta situación unida a aplicaciones del $70 \%$ del $\mathrm{T}_{\text {СТL }}$ durante el período postcosecha no permitió la recuperación de $\Psi_{\mathrm{m}}$ a niveles similares a los del control, si bien, los valores alcanzados se podrían equiparar a condiciones de suministro hídrico adecuado, si se tiene en cuenta que la frecuencia de riego fue media (Taylor y Ashcroft, 1972) y bajo el supuesto de que no se hubiese tratado de un suelo salino $\left(\mathrm{CE}_{\mathrm{e}} \geq 4 \mathrm{dS} / \mathrm{m}\right)$. El $\mathrm{T}_{\mathrm{SCO}}$ presentó valores inferiores a $-80 \mathrm{kPa}$ en las tres profundidades de medida y durante casi todo el año, los que son indicativos del déficit hídrico severo (Taylor y Ashcroft, 1972; Pogue y Pooly, 1985) en el que tiene lugar el desarrollo de las distintas fases del ciclo anual del almendro bajo las condiciones de secano del Campo de Cartagena. De igual modo que con las lecturas tensiométricas, en la figura 5.4 se muestran los resultados de las medidas de contenido de humedad de 2000. Éstas se obtuvieron a partir de sondas TDR situadas a 50 y $100 \mathrm{~cm}$ del microaspersor. El período de medidas englobó dos etapas relevantes de la estrategia de riego seguida: i) acumulación rápida de materia seca del grano (Fase IV - meses de junio - agosto), y ii) período postcosecha (Fase V - desde la cosecha a las primeras caídas de hojas, Figura 5.2).

A pesar de la heterogeneidad del terreno, de la variabilidad tridimensional originada por el propio sistema de riego, los valores obtenidos siguieron una conducta esperable en todos los tratamientos de riego. Así el contenido relativo de humedad de $\mathrm{T}_{\mathrm{RDC}}$ y $\mathrm{T}_{\mathrm{SCO}}$ respecto a $\mathrm{T}_{\mathrm{CTL}}$, durante todo el período de mayor intensidad de déficit hídrico (fase IV del ciclo anual del almendro), se mantuvo por debajo del control, y como era de esperar éste fue sensiblemente inferior en $\mathrm{T}_{\mathrm{SCO}}$ que en $\mathrm{T}_{\mathrm{RDC}}$, presentando este último contenidos relativos medios en torno al $55 \%$ para el perfil de suelo de 0-120 $\mathrm{cm}$ (Figura 4.4). Sin embargo y al final de la estación de riegos, coincidiendo con la lluvia torrencial del 23 octubre $(160 \mathrm{~mm})$, se llegaron a igualar, en los tres tratamientos de riego, los contenidos de humedad en los $60 \mathrm{~cm}$ primeros 
de profundidad del punto de medida a $50 \mathrm{~cm}$ del emisor. En los siguientes 60 $\mathrm{cm}$ del perfil de suelo, que momentos antes de la lluvia se encontraban en $\mathrm{T}_{\mathrm{RDC}}$ y $\mathrm{T}_{\mathrm{SCO}}$ a niveles ligeramente inferiores a los de la mitad superior, el agua infiltrada fue insuficiente para llevar esta capa a idéntico contenido de humedad que en $\mathrm{T}_{\text {СТL }}$, observándose tan sólo un ligero incremento de humedad (Figura 5.4).

Tabla 5.1. Agua aplicada, lluvia y valores medios de potencial matricial previos al riego, durante los tres períodos de $\mathrm{T}_{\mathrm{RDC}}$ en 2000.

\begin{tabular}{|c|c|c|c|c|c|c|c|c|}
\hline \multirow[t]{3}{*}{ Trat. } & & Riego & Lluvia & \multirow[t]{2}{*}{ Año } & \multirow{2}{*}{$\begin{array}{l}\text { Prof. } \\
(\mathrm{cm})\end{array}$} & \multicolumn{3}{|c|}{$\Psi_{\mathrm{m}}$ prerriego $(\mathrm{kPa})$} \\
\hline & & \multicolumn{2}{|c|}{$(\mathrm{mm})$} & & & Fb $-1 / 2$ & $1 / 2$ My - & Sp - \\
\hline & 1999 & 424 & 190 & & 30 & -33 & -50 & -34 \\
\hline \multirow{3}{*}{$\mathrm{T}_{\text {CTL }}$} & 2000 & 480 & 385 & 2000 & 60 & -25 & -40 & -27 \\
\hline & 2001 & 465 & 285 & & 90 & -27 & -36 & -25 \\
\hline & 2002 & 205 & 180 & & & & & \\
\hline \multirow{4}{*}{$\mathrm{T}_{\mathrm{RDC}}$} & 1999 & 195 & 190 & & 30 & -39 & -92 & -52 \\
\hline & 2000 & 280 & 385 & 2000 & 60 & -29 & -85 & -45 \\
\hline & 2001 & 215 & 285 & & 90 & -40 & -88 & -52 \\
\hline & 2002 & 115 & 180 & & & & & \\
\hline \multirow{4}{*}{$\mathrm{T}_{\mathrm{sco}}$} & 1999 & 95 & 190 & & 30 & $-101^{*}$ & $-140^{*}$ & $-114^{*}$ \\
\hline & 2000 & 0 & 385 & 2000 & 60 & $-115^{*}$ & $-153^{*}$ & $-120^{*}$ \\
\hline & 2001 & 0 & 285 & & 90 & $-80^{*}$ & $-94.0 *$ & $-83.0^{*}$ \\
\hline & 2002 & 0 & 180 & & & & & \\
\hline
\end{tabular}

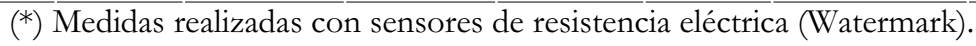

La pauta observada en las medidas realizadas en el frente húmedo del volumen humedecido por los emisores (sondas a $1 \mathrm{~m}$ del emisor) fue muy similar al registrado en la zona de elevado contenido de humedad (sondas a $0.5 \mathrm{~m}$ del emisor), si bien, se apreciaron algunas diferencias. Así y tras la reanudación del riego a dosis equivalentes al $70 \%$ del $\mathrm{T}_{\text {CTL }}$, fase $\mathrm{V}$ del almendro, se produjo una inmediata recuperación de los niveles de humedad de $\mathrm{T}_{\mathrm{RDC}}$ en los primeros $60 \mathrm{~cm}$ de profundidad del frente húmedo, mientras que en la zona de mayor contenido de humedad el incremento fue muy gradual, alcanzándose la recuperación tras la lluvia de octubre. En $\mathrm{T}_{\mathrm{SCO}}, \mathrm{y}$ 
contrariamente a lo observado en $\mathrm{T}_{\mathrm{RDC}}$, el nivel relativo de humedad alcanzado fue, generalmente, menor a 1 que a $0.5 \mathrm{~m}$ de distancia de la línea de plantas, lo que puede ser achacado a la variabilidad espacial del terreno y a la diferente distribución del sistema radicular. Aunque los incrementos de humedad en $T_{\text {RDC }}$ y $T_{\text {SCO }}$ para las capas de 60-90 y 90-120 cm de profundidad fueron más notorios en el punto de muestreo a $0.5 \mathrm{~m}$ que a $1 \mathrm{~m}$ del emisor, en ambas ubicaciones son indicativos del importante agotamiento del agua del suelo durante los meses de verano, ya que ni la reanudación del riego al $70 \%$ del $\mathrm{T}_{\mathrm{CTL}}$ ni la lluvia acaecida supusieron una recarga de agua importante para esta profundidad.

Durante el ciclo de cultivo y en la profundidad de máxima densidad radicular, primeros $90 \mathrm{~cm}$, el tratamiento control mantuvo contenidos volumétricos de humedad relativamente altos y próximos a su capacidad de campo $\left(\theta_{\mathrm{vCC}} \approx 30-35 \%\right)$, durante la mayor parte del intervalo entre riegos, valores concordantes con los de $\Psi_{\mathrm{m}}$ registrados (Tabla 5.1). Sin embargo, el contenido volumétrico de $\mathrm{T}_{\mathrm{SCO}}$, prácticamente constante durante las fases IV y $\mathrm{V}$, como consecuencia de la escasísima pluviometría ocurrida durante el verano y principios de otoño, se acercó a los correspondientes al punto de marchitez, lo que demuestra el importante nivel de agotamiento del agua en el suelo, capaz de afectar a los procesos de acumulación de materia elaborada en el grano, diferenciación floral y acumulación de reservas para el próximo ciclo (Girona y Marsal, 1995). En $\mathrm{T}_{\mathrm{RDC}}$ los valores de $\theta_{\mathrm{v}}$, en la generalidad del perfil, estuvieron entre los de $\mathrm{T}_{\mathrm{CTL}} \mathrm{y} \mathrm{T}_{\mathrm{SCO}}$, siendo más cercanos a este último.

$\mathrm{mm}$ sin escorrentía aparente, fue insuficiente para llevar a capacidad de campo las capas de suelo por debajo de los $60 \mathrm{~cm}$ de profundidad (Figura 5.4). Sin embargo, su ocurrencia mejoró las condiciones hídricas del suelo, a través del aumento de las componentes matricial y osmótica del agua en el suelo (Figuras 5.4, 5.5 y 5.6). 


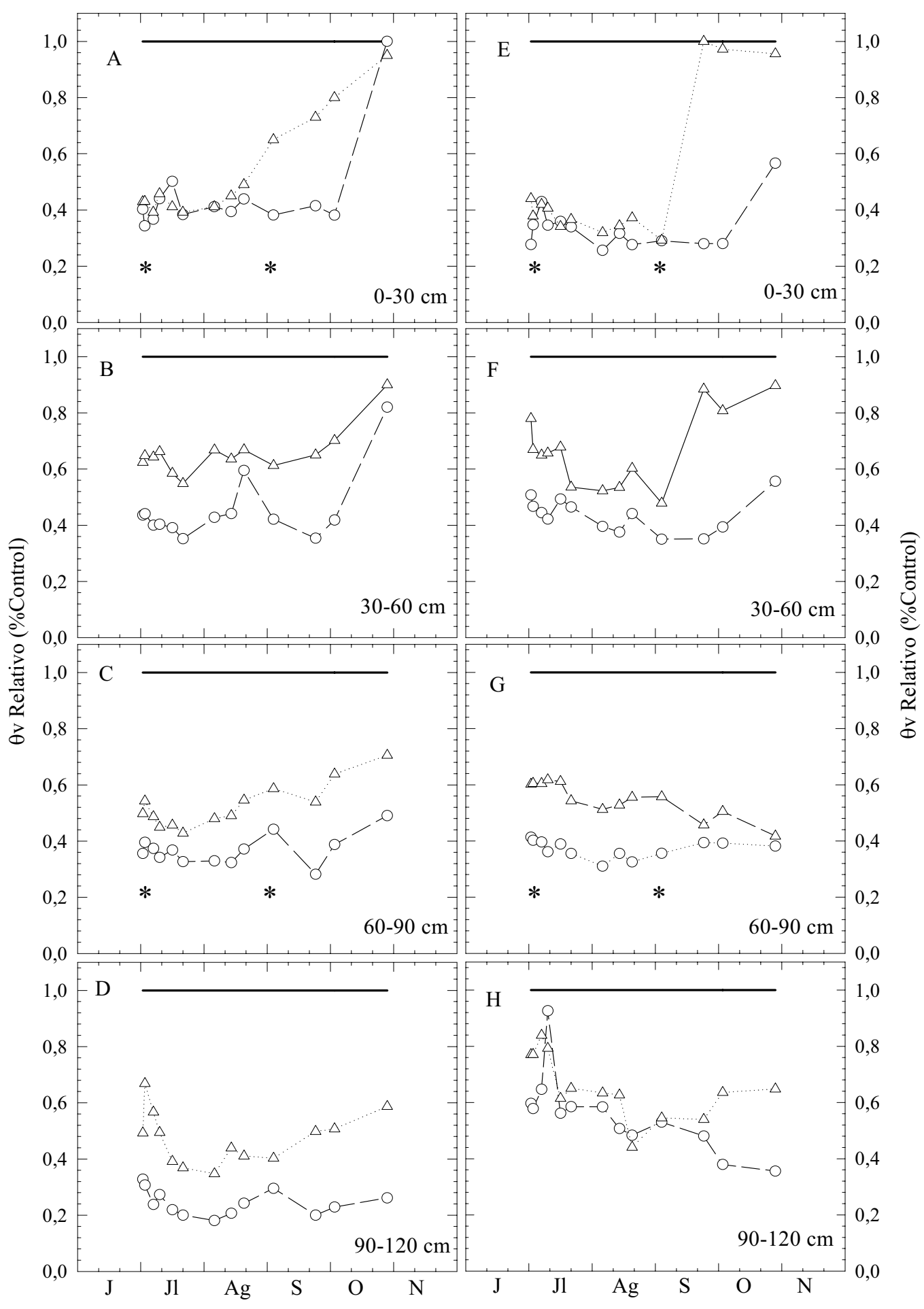

Figura 5.4. Evolución del contenido volumétrico de agua en el suelo relativo al control $\left(\theta_{\mathrm{VTi}} / \theta_{\mathrm{VTCt}}\right)$, para las profundidades de $0-30,30-60,60-90$ y $90-120 \mathrm{~cm}$. Los puntos representan el promedio de tres sondas de TDR situadas a $0.5 \mathrm{~m}(\mathrm{~A}, \mathrm{~B}, \mathrm{C}, \mathrm{D})$ y $1 \mathrm{~m}(\mathrm{E}, \mathrm{F}$, $\mathrm{G}, \mathrm{H})$ del emisor $\left(\mathrm{T}_{\mathrm{CTL}}(-), \mathrm{T}_{\mathrm{RDC}}(\cdots \Delta)\right.$ y $\left.\mathrm{T}_{\mathrm{SCO}}\left(-\mathrm{O}^{-}\right)\right)$. Los asteriscos indican el período de riego al $30 \%$ del $\mathrm{T}_{\mathrm{CTL}}$ en $\mathrm{T}_{\mathrm{RDC}} .2000$. 
El nivel de agotamiento del agua en el suelo en $\mathrm{T}_{\mathrm{RDC}}$ y $\mathrm{T}_{\mathrm{SCO}}$ quedó de manifiesto tras la lluvia de octubre de 2000, en el que una altura total de 160

\section{Salinidad}

La distribución de sales en el perfil del suelo de 0 a $120 \mathrm{~cm}$ de profundidad fue evaluada a partir de medidas de conductividad eléctrica, $\mathrm{CE}_{\mathrm{e}}$, y concentración de cloruros, $\left[\mathrm{Cl}^{-}\right]_{\mathrm{e}}$, en el extracto de saturación, en dos puntos característicos del volumen humedecido: frente húmedo y zona mojada (punto intermedio entre el emisor y el frente húmedo), y cuando $\mathrm{T}_{\mathrm{RDC}}$ llevaba dos meses regándose al $30 \%$ del $\mathrm{T}_{\text {CTL }}$. En $\mathrm{T}_{\mathrm{SCO}}$ la toma de muestras se realizó en un punto situado en la zona perimetral de proyección de la copa.

En la figura 5.5 se muestran los perfiles salinos de los tres tratamientos de riego correspondientes al año 2000. Y al igual que $\Psi_{\mathrm{m}}$ y $\theta_{\mathrm{vTi}} / \theta_{\text {vTctl }}$ los niveles de $\mathrm{CE}_{\mathrm{e}}, \mathrm{y}\left[\mathrm{Cl}^{-}\right]_{\mathrm{e}}$, se vieron afectados por el régimen de riego aplicado. Así en el frente húmedo y en la capa de mayor densidad radical, $60 \mathrm{~cm}$ primeros, se alcanzaron valores medios de $\mathrm{CE}_{\mathrm{e}}$ de 6.5 y $8.0 \mathrm{dS} \mathrm{m}^{-1}$, en los tratamientos $T_{\text {CTL }}$ y $T_{R D C}$, respectivamente, mientras que en la zona húmeda el contenido salino fue sensiblemente inferior al anterior $\left(4.4\right.$ y $\left.5.8 \mathrm{dS} \mathrm{m}^{-1}\right)$, todos propios de un suelo salino (Personal del Laboratorio de Salinidad de los E.U.A., 1982). La alta concentración salina observada en el $\mathrm{T}_{\mathrm{SCO}}\left(4.5 \mathrm{dS} \mathrm{m} \mathrm{m}^{-1}\right)$ puede ser atribuida a la historia previa del cultivo, ya que en los 5 años previos al inicio de los ensayos los árboles se regaron con aguas procedentes del mismo pozo, y a la baja pluviometría registrada tras la supresión del riego en $\mathrm{T}_{\mathrm{SCO}}$, interacción negativa que induce a mermas productivas, al agravar el problema de salinidad. Teniendo en cuenta que el umbral de tolerancia del almendro a la salinidad en la zona radicular se estima en una $\mathrm{CE}_{\mathrm{e}}$ de $1.5 \mathrm{dS} \mathrm{m} \mathrm{m}^{-1}$ (Maas, 1990) y que investigaciones adicionales cifran la disminución del rendimiento por incremento unitario de salinidad entre el 18 y $21 \%$ (Fulton et al., 1996), serían esperables producciones inferiores al $40 \%$ de la producción potencial de almendros adultos.

La distribución de cloruros mostró una pauta muy similar a la observada para la CE (Figura 5.5). Así, la concentración de este ion aumentó con la distancia al emisor, correspondiéndose con las menores fracciones de lavado típicas del frente húmedo, y con la profundidad en $\mathrm{T}_{\text {СТL }}$; mientras que en $\mathrm{T}_{\mathrm{RDC}}$ disminuyó a partir de los primeros $30 \mathrm{~cm}$, lo que apunta a un mayor lavado de sales en $\mathrm{T}_{\mathrm{CTL}}$, especialmente para la zona de mayor contenido de humedad. En esta zona y para la profundidad de $90 \mathrm{~cm}$, perfil de suelo donde se encuentra la generalidad de raíces finas en almendros en goteo (Catlin, 1996; Franco y Abrisqueta, 1997) la $\left[\mathrm{Cl}^{-}\right]_{\mathrm{e}}$ fue de 14.0 y $17.3 \mathrm{meq} \mathrm{\textrm {L } ^ { - 1 }}$ en $\mathrm{T}_{\text {CTL }} \mathrm{y}$ $\mathrm{T}_{\mathrm{RDC}}$, respectivamente, niveles muy altos y considerados de grado de restricción de uso severo, por entrañar un altísimo riesgo de toxicidad iónica 
en almendro (Fulton et al., 1996). Ambas concentraciones muestran la importante contribución del ion cloruro a la salinidad total de la solución del suelo.

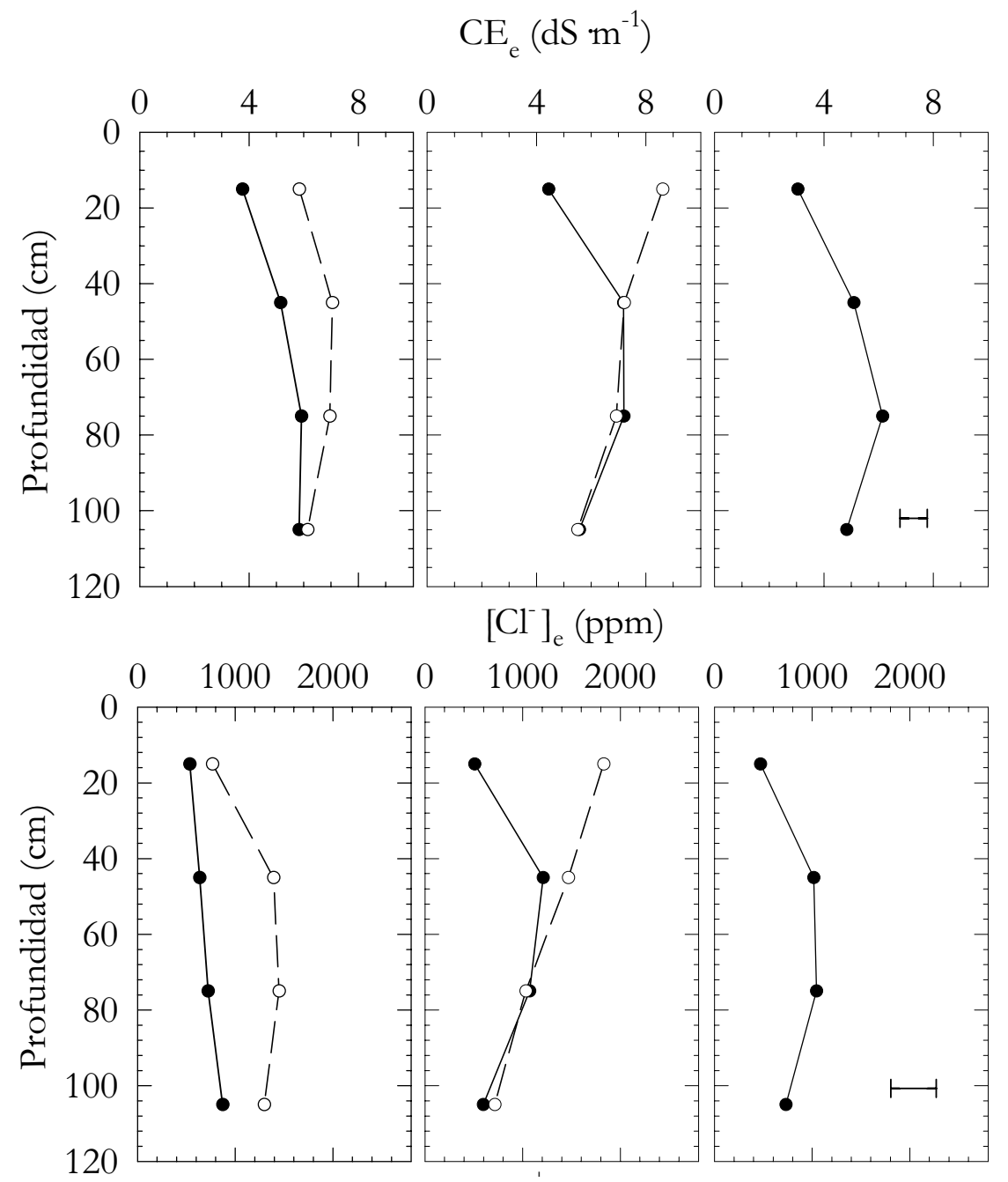

Figura 5.5. Perfiles de salinidad (CE) y concentración de cloruros $\left[\mathrm{Cl}^{-}\right]$en el extracto de saturación, a finales de agosto de 2000 , en la zona húmeda $(-\bullet)$ y frente húmedo $\left(-\begin{array}{c}- \\ -\end{array}\right.$ del círculo mojado por el emisor. La línea horizontal representa el ES medio del perfil.

La lluvia de octubre de 2000 redujo prácticamente a la mitad la $\mathrm{CE}_{\mathrm{e}}$ en los primeros $50 \mathrm{~cm}$ de profundidad y a la tercera parte la $\left[\mathrm{Cl}^{-}\right]_{\mathrm{e}}$, según el muestreo realizado en el frente húmedo de $\mathrm{T}_{\mathrm{RDC}}$, inmediatamente después de la lluvia y en comparación con los valores disponibles del mes de agosto (Figuras 5.5 y 5.6). Aunque la lluvia fue cuantiosa no fue suficiente para llevar a capacidad de campo el perfil de suelo por debajo de $10560 \mathrm{~cm}$ de profundidad (Figura 5.4), de ahí que parte de las sales presentes en las capas superiores de la zona radicular fuesen desplazadas a capas más profundas dentro de esta zona (Figura 5.6). El hecho de que la lluvia no encontrase el perfil muestreado a contenidos altos de humedad (frente húmedo), especialmente, en las capas más profundas pudo limitar el desplazamiento de 
las sales. Lixiviaciones mayores a las muestreadas podrían haber tenido lugar en la zona húmeda de este tratamiento y en $\mathrm{T}_{\mathrm{CTL}}$, $\mathrm{y}$ menores en $\mathrm{T}_{\mathrm{SCO}}$, en consideración a los contenidos de humedad del suelo en el momento en el que se produjo la lluvia (Ayers y Westcot, 1987). Bajo estas condiciones de cultivo y de acuerdo con los resultados obtenidos sería recomendable mantener un elevado contenido de agua en el suelo antes de la llegada de las lluvias, ya que generalmente van a ser insuficientes (Figura 5.1) para completar la lixiviación de las sales presentes.

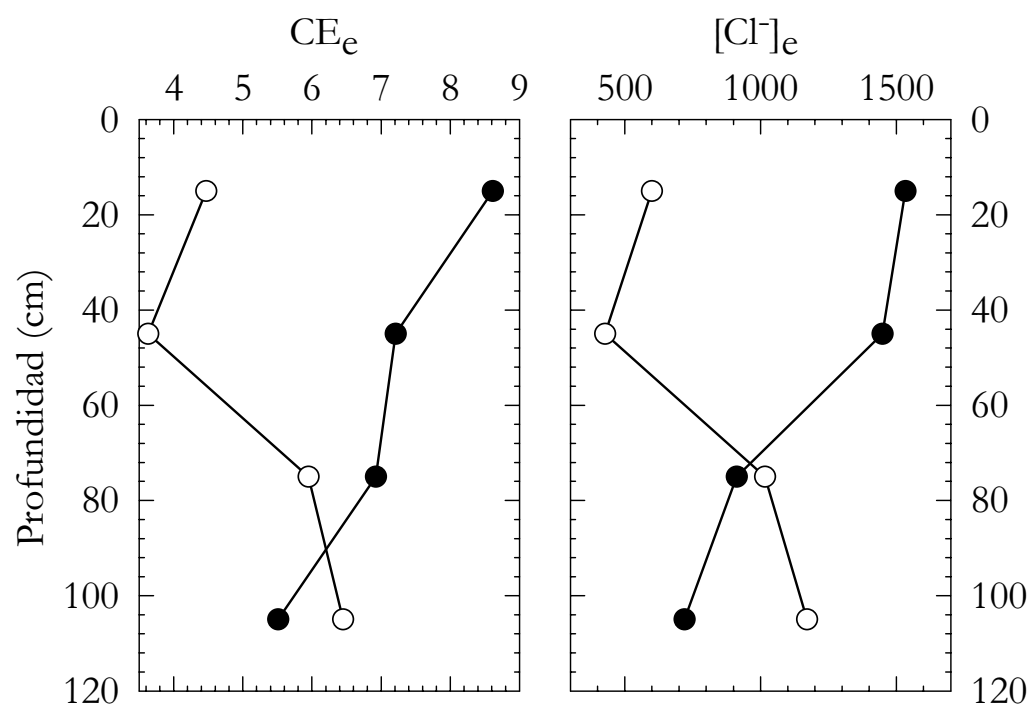

Figura 5.6. Perfiles de salinidad ( $\mathrm{CE}$ y $\left[\mathrm{Cl}^{-}\right]$en el extracto de saturación del suelo) en la capa de 0 a $1.20 \mathrm{~m}$ de profundidad para el tratamiento $\mathrm{T}_{\mathrm{RDC}}$, antes $\left(-{ }^{-}\right.$) y después $(-\mathrm{O}-$ ) de $160 \mathrm{~mm}$ de lluvia. Los valores corresponden al frente húmedo del volumen humectado.

\section{Agua-planta}

Durante el período experimental los parámetros hídricos foliares resultaron sensibles al déficit hídrico. En el tratamiento control el potencial hídrico foliar antes del alba $\left(\Psi_{a}\right)$ estuvo en torno a $-0.65 \mathrm{MPa}$, valores ligeramente inferiores a los obtenidos por Torrecillas et al. (1996); Goldhamer y Viveros (2000); Romero et al. (2004a); Girona et al. (2005), Nortes et al. (2005) en almendros regados con aguas de baja salinidad. Estos menores valores de $\Psi_{\text {a }}$ bajo condiciones de humedad adecuada (Figura 5.7 y Tabla 5.1) pueden ser atribuidos al efecto de la salinidad sobre el estado energético del agua en el suelo, ya que al disminuir la componente osmótica lo hace la disponibilidad del agua para la planta (Katerji et al., 2003). La pronunciada caída de $\Psi_{\mathrm{a}}$ a finales de agosto fue promovida por la supresión del riego durante la semana previa a la recolección; supresión que tuvo por objeto el endurecimiento del árbol de cara a disminuir los daños de descortezado de troncos por vibración mecánica. 
A excepción de los períodos de riego al $100 \%$ y precosecha al $70 \%$ del $\mathrm{T}_{\mathrm{CTL}}$ en $\mathrm{T}_{\mathrm{RDC}}$ y durante la generalidad de la estación en $\mathrm{T}_{\mathrm{SCO}}$, los valores de $\Psi_{\mathrm{a}}$ se mantuvieron por debajo de los del tratamiento control (Figura 5.7). Las diferencias de $\Psi_{a}$ respecto al control y para el período junio-septiembre fueron relativamente constantes para $\mathrm{T}_{\mathrm{RDC}}$, oscilando entre 0.2-0.3 MPa. Sin embargo, para $\mathrm{T}_{\mathrm{SCO}}$ se produjo un aumento gradual desde primeros de junio hasta finales de julio (0.4-1.1 MPa), para posteriormente mantenerse en torno a $0.75 \mathrm{MPa}$. Comportamiento que respondió, inicialmente, al aumento de la demanda evaporante (Figura 5.1) y disminución del agua útil del suelo (Tabla 5.1) y posteriormente a la disminución de la demanda climática y a la perdida de superficie foliar por defoliaciones y necrosis en hojas.

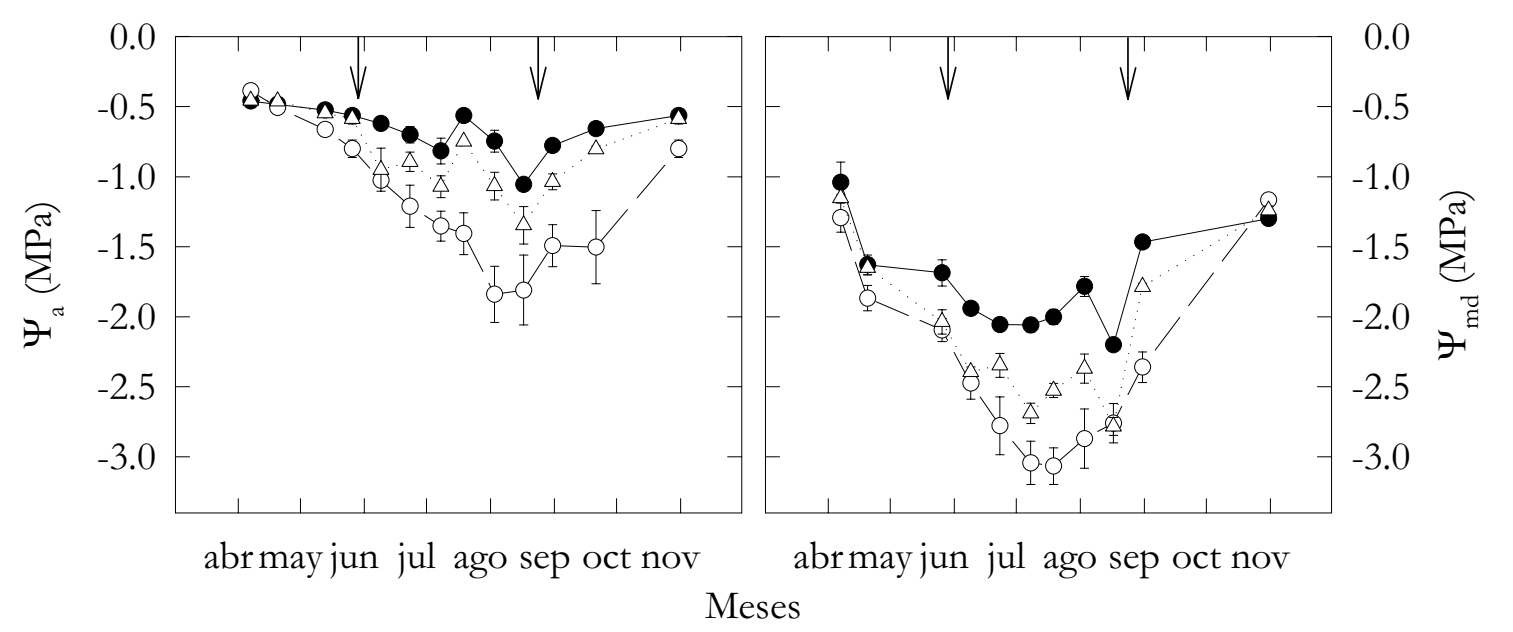

Figura 5.7. Evolución estacional del potencial hídrico foliar al alba $\left(\Psi_{2}\right)$ y a mediodía $\left(\Psi_{\mathrm{md}}\right)$ en 2000, para los tres tratamientos de riego: $\mathrm{T}_{\text {СTL }}(-\bullet), \mathrm{T}_{\mathrm{RDC}}(\cdots \Delta \cdots)$ y $\mathrm{T}_{\mathrm{SCO}}(-0-)$. Cada punto corresponde a la media de 3 repeticiones \pm ES. $\downarrow$ indica el cambio de riego en el tratamiento $\mathrm{T}_{\mathrm{RDC}}$.

Los valores de potencial hídrico foliar a mediodía $\left(\Psi_{\mathrm{md}}\right)$ fueron inferiores a $\Psi_{\mathrm{a}}$ y disminuyeron con el avance de la estación, alcanzándose niveles mínimos de $-2.0\left(\mathrm{~T}_{\mathrm{CTI}}\right),-2.6\left(\mathrm{~T}_{\mathrm{RDC}}\right)$ y $-3.1 \mathrm{MPa}\left(\mathrm{T}_{\mathrm{SCO}}\right)$ en julio, cuando la demanda evaporante fue mayor (DPV $\approx 3.5 \mathrm{kPa}$ ). Estos valores son similares e inclusive superiores a los encontrados por Hutmacher et al (1994) en almendros en riego por goteo, con agua de conductividad eléctrica media $1.54 \mathrm{dS} \mathrm{m}^{-1}$ y aportes hídricos equivalentes al 100 y $50 \%$ de la ETc estimada. Posteriormente y de forma paulatinamente, $\Psi_{\mathrm{md}}$ aumentó en los tres tratamientos de riego hasta alcanzar valores máximos de -1.2 MPa tras la lluvia de octubre, lo que indica que el agua infiltrada fue suficiente para que se igualasen los tres tratamientos, dando lugar a la recuperación de los valores de $\Psi_{\mathrm{md}}$ en ambos tratamientos deficitarios (Figura 5.7). Esta conducta de $\Psi_{\mathrm{md}}$, 
dependiente de la demanda evaporante ya fue indicada por Torrecillas et al. (1989b) en almendros en riego por goteo.

Aunque las diferencias de $\Psi_{1}$ en valor absoluto, respecto al control, fueron superiores en las medidas realizadas a mediodía que antes del amanecer (Figura 5.7), las mayores diferencias relativas encontradas al alba ( $\approx 2.5$ veces para el caso de $\mathrm{T}_{\mathrm{SCO}}$ ) hacen que $\Psi_{\mathrm{a}}$ sea considerado mejor indicador del estado hídrico del almendro que $\Psi_{\text {md }}$ y un buen estimador del potencial hídrico del suelo, ya que al alba se debiera haber equilibrado, o al menos en gran parte, con el potencial total del agua en el suelo (Jones, 2004; 2007). Ahora bien, y debido a la laboriosidad de las medidas, a la realización de éstas fuera de la jornada laboral habitual y a las dificultades para su automatización, se ha sugerido que podría ser más útil la estimación indirecta de un potencial umbral del agua en el suelo para la zona radicular de mayor actividad, a partir de medidas diurnas de potencial hídrico foliar y conductancia estomática (Jones, 2004). Hay que tener en cuenta que mientras $\Psi_{\mathrm{a}}$ es un buen indicador de la recuperación experimentada por la planta durante la noche y por tanto del grado de estrés con el que la planta inicia el día, $\Psi_{\text {md }}$ refleja la situación hídrica del cultivo en plena actividad del día, cuando la tasa de fotosíntesis y la demanda evaporante suelen ser máximas. De ahí la utilidad de ambos indicadores en la caracterización del estado hídrico del almendro y para ajustar los programas de riego previamente establecidos.

La conductancia foliar $\left(\mathrm{g}_{\mathrm{I}}\right)$ del $\mathrm{T}_{\mathrm{SCO}}$ presentó mayor variabilidad y fue significativamente inferior a la de los tratamientos regados, e igualmente la de $\mathrm{T}_{\mathrm{RDC}}$ con relación al control durante el período de déficit al $30 \%$ del $\mathrm{T}_{\mathrm{CTL}}$ (Figura 5.8). La reanudación del riego al $70 \%$ del $\mathrm{T}_{\text {CTL }}$ (finales de agosto) produjo la recuperación de $\mathrm{g}_{\mathrm{l}}$ en $\mathrm{T}_{\mathrm{RDC}}$, registrándose tasas similares a las del control en las medidas realizadas en septiembre. La lluvia caída en octubre, análogamente a $\Psi_{\mathrm{a}} \mathrm{y} \Psi_{\mathrm{md}}$, igualó los valores de $\mathrm{g}_{\mathrm{l}}$ en los tres tratamientos, si bien, tanto el número de hojas como su tamaño fueron claramente inferiores en $\mathrm{T}_{\mathrm{SCO}}$. Independientemente de esta realidad, estos datos corroboran la utilidad de $g_{1}$, indicada por Fereres et al. (1979), para evaluar la recuperación de las plantas después de un estrés hídrico, y muestran el papel regulador del estoma ante los cambios de humedad impuestos al suelo.

Los valores de $g_{1}$ en el tratamiento control fueron similares a los informados por Marsal et al. (1997) y Nortes et al. (2005) y superiores a los de Romero et al. (2004a) bajo condiciones climáticas parecidas y claramente inferiores a los obtenidos por Hutmacher et al. (1994) en California con aportes hídricos superiores $\left(\approx 10.000 \mathrm{~m}^{3} \mathrm{ha}^{-1}\right)$. En el tratamiento control, los valores máximos de $g_{1}$ tuvieron lugar durante el periodo de alta ET (julioseptiembre), mientras que en el de secano se obtuvieron valores mínimos del 
orden de la tercera parte de los de $\mathrm{T}_{\text {СТL }}\left(68 \mathrm{y} 96 \mathrm{mmol} \mathrm{m}^{2} \mathrm{~s}^{-1}\right)$. Los niveles de $\mathrm{g}_{\mathrm{l}}$ en $\mathrm{T}_{\mathrm{RDC}}$ se situaron en una zona intermedia entre los del tratamiento control y secano (Figura 5.8). Esta conducta es indicativa de como el estoma es capaz de regular las pérdidas de agua por transpiración en función del grado de su apertura y en respuesta a la disponibilidad hídrica del suelo (Turner et al., 1985; Girona et al., 1993a). En este sentido, algunos investigadores han constatado que condiciones de déficit hídrico ligero-moderado provocan una importante regulación estomática y un descenso en las tasas de intercambio gaseoso en plantas cultivadas en clima mediterráneo y desértico (Tenhunen et al., 1982; Pereira et al., 1986; Schulze, 1986; Sánchez-Blanco et al., 1991). Sin embargo, resulta difícil separar los efectos del déficit hídrico de otros factores que regulan el comportamiento estomático (Lynn y Carlson, 1990).

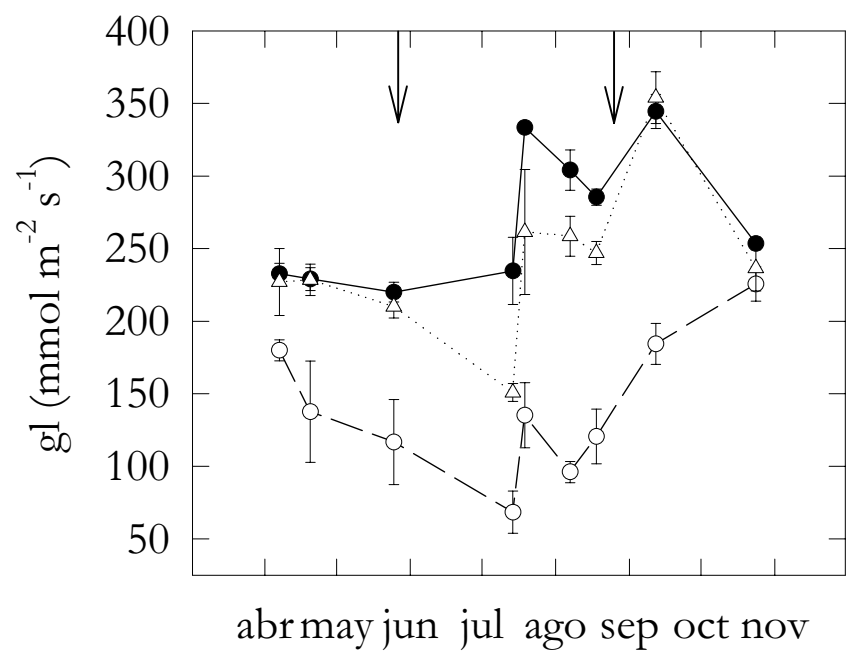

Meses

Figura 5.8. Evolución estacional de la conductancia foliar ( $\mathrm{g}_{\mathrm{i}}$ ) en el año 2000, en los 3 tratamientos de riego: $\mathrm{T}_{\mathrm{CTL}}(-\bullet), \mathrm{T}_{\mathrm{RDC}}(\cdots \Delta)$ y $\mathrm{T}_{\mathrm{SCO}}(-\mathrm{O}-\cdot)$. Cada punto corresponde a la media de 3 repeticiones \pm ES. $\downarrow$ indica el cambio de riego en el tratamiento $\mathrm{T}_{\mathrm{RDC}}$.

El aumento de gl con el avance de la estación hasta alcanzar valores máximos en los meses de mayor ET y su disminución al final de la misma (Figura 5.8) fue igualmente observado por Torrecillas et al. (1988a) en almendro, por (Aslam et al., 1977) en yuca, y por Pérez-Pastor (2001) en albaricoquero. Esta conducta del estoma puede explicar la tendencia a disminuir progresivamente los potenciales hídricos mínimos diarios (Figura 5.7). Por otro lado, la disminución de $g_{1}$ al final de la estación de riego puede estar asociada a procesos de origen ontogénico y a desequilibrios hormonales que tienen lugar en las hojas (Ruiz-Sánchez et al., 1988). Estos cambios también incluyen aumentos en el espesor de las paredes celulares, como revela el aumento estacional del peso específico foliar observado en $\mathrm{T}_{\text {СТL }}(0.0107 \mathrm{~g}$ $\mathrm{cm}^{-2}$ en abril y $0.0115 \mathrm{~g} \mathrm{~cm}^{-2}$ a finales de agosto de 2001). 


\section{Variaciones diurnas del potencial hídrico y conductancia foliar}

Las evoluciones diarias de $\Psi_{1}$ y $g_{1}$ (Figuras 5.9 y 5.10) recogen la situación hídrica de los tres tratamientos de riego en tres momentos característicos de la estrategia seguida en $\mathrm{T}_{\mathrm{RDC}}$. Las variaciones diarias de $\Psi_{1}$ mostraron un ritmo circadiano característico, con valores máximos al alba, mínimos a mediodía y una marcada recuperación desde el inicio del atardecer, lo que responde a la conducta típica de las plantas cultivadas (Torrecillas et al., 1988b; 1988a). El hecho de que en el mes de mayo se registrasen en $\mathrm{T}_{\mathrm{CTL}}$ potenciales hídricos foliares inferiores a los de julio, lo contrario a lo esperable en árboles bajo condiciones no limitantes de agua en el suelo, se debió a un fallo en el sistema de riego, lo que provocó un retraso de cuatro días en la aplicación de la dosis de riego. Además, es sobradamente conocida la estrecha dependencia del potencial hídrico foliar del almendro de la demanda evaporante del ambiente (Torrecillas et al., 1989b; Sánchez-Blanco et al., 1991; Romero y Botía, 2006). En este contexto, y a nivel diario, se encontró una buena correlación entre $\Psi_{1}$ y el déficit de presión de vapor (DPV). Los coeficientes de correlación $\Psi_{1}$ vs DPV en mayo, julio y octubre, bajo las condiciones del tratamiento control, fueron 0.89***; 0.96*** y 0.86***, respectivamente, valores similares a los encontrados en $\mathrm{T}_{\mathrm{RDC}}$ y $\mathrm{T}_{\mathrm{SCO}}$ en idénticas fechas. Las pendientes de las líneas de ajuste fueron similares en los tres tratamientos y en las tres fechas de medida. Sin embargo, la ordenada en el origen fue significativamente diferente, evidenciando las distintas condiciones de partida de los diferentes tratamientos de riego (Figura 5.11).

Por otro lado, el retraso en la aplicación del riego originó una disminución sustancial del contenido de agua en el suelo previo a la evolución de mayo, tal como quedó registrado en las lecturas tensiométricas antes del riego en $\mathrm{T}_{\text {СТL }}(-74,-67 \mathrm{y}-61 \mathrm{kPa}$ a 30,60 y $90 \mathrm{~cm}$, respectivamente), y en consecuencia una importante caída de $\Psi_{1}$ y g, particularmente en $g_{1}$ a partir de las 9:00h UT. De modo, que tanto los árboles control como los deficitarios mostraron la máxima apertura del estoma a primeras horas de la mañana, cuando la demanda evaporante fue menor, para disminuir a continuación con el aumento de la demanda. Esta pauta del estoma es similar a la observada por Torrecillas et al. (1988a) en almendros en riego deficitario y permite al árbol asimilar la máxima cantidad de $\mathrm{CO}_{2}$ mientras pierde la mínima cantidad de agua, manifestándose, por tanto, como un mecanismo conservador de agua.

La variación diaria del potencial hídrico foliar, en un día típico de julio cuando el $\mathrm{T}_{\mathrm{RDC}}$ llevaba aproximadamente mes y medio al $30 \%$ del $\mathrm{T}_{\mathrm{CTL}}$, fue considerable en los tres tratamientos de riego y contrastó con la de octubre que fue substancialmente inferior, estando los valores de esta última en concordancia con la menor demanda evaporante y conductancia foliar (Figura 
5.9). En $\mathrm{T}_{\mathrm{CTL}}, \Psi_{1}$ disminuyó de $-0.55 \mathrm{MPa}$ antes del alba a los $-2.1 \mathrm{MPa}$ a mediodía, en ambos años de medidas (Figuras 5.9 y 5.10).

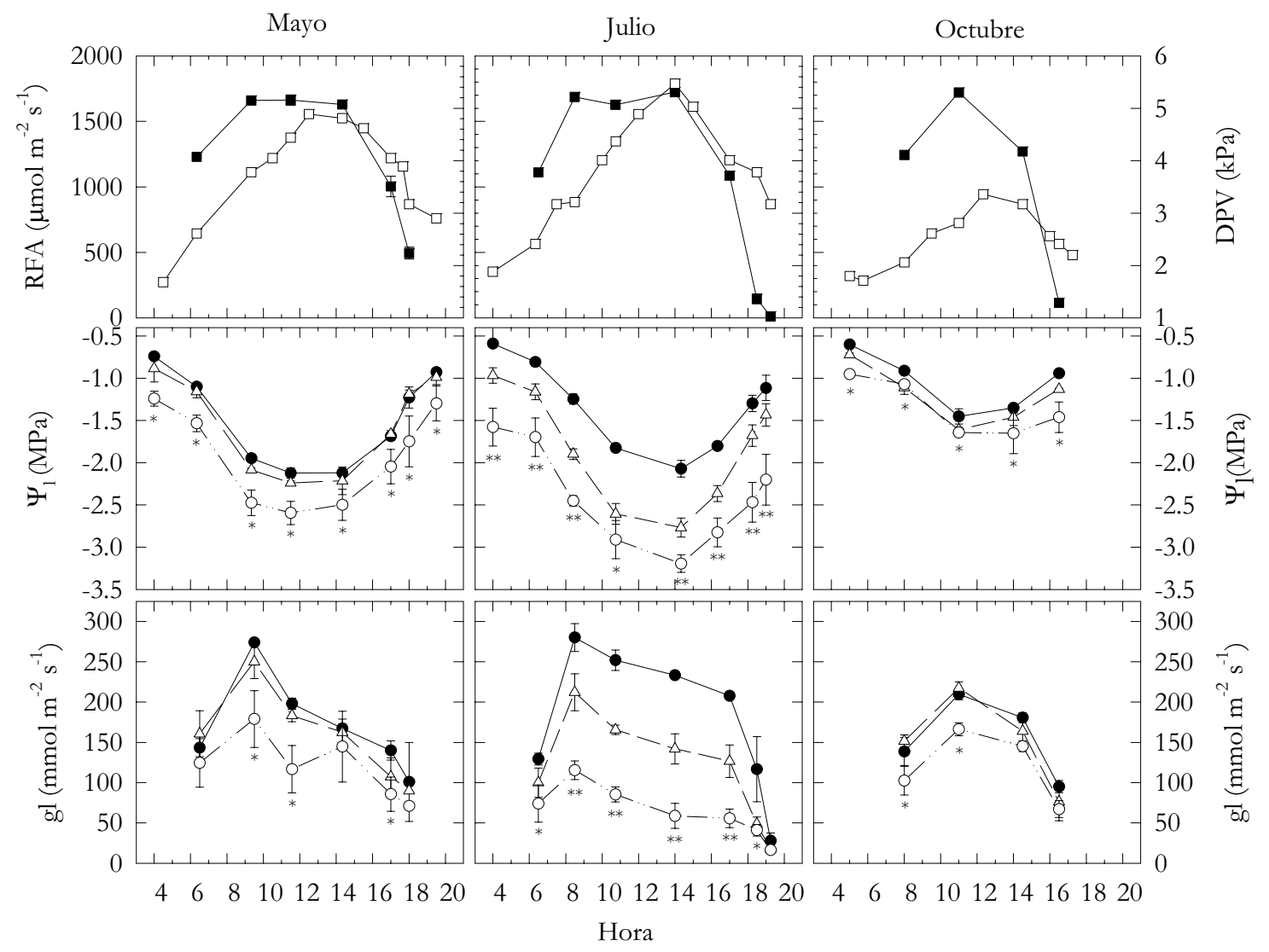

Figura 5.9. Evolución diaria de la radiación fotosintéticamente activa (RFA, - - ) déficit de presión de vapor (DPV, $-\square$ ), potencial hídrico $\left(\Psi_{1}\right)$ y conductancia foliar $\left(g_{1}\right)$ en los tres tratamientos de riego: $\mathrm{T}_{\mathrm{CTL}}\left(-{ }_{-}\right), \mathrm{T}_{\mathrm{RDC}}(\cdots \Delta \cdots)$ y $\mathrm{T}_{\mathrm{SCO}}\left(-\begin{array}{c}- \\ -)\end{array}\right.$ representa la media de tres repeticiones \pm ES. $*$ indica la existencia de diferencias significativas entre $\mathrm{T}_{\text {CTL }}$ y $\mathrm{T}_{\mathrm{SCO}}, \mathrm{y} * *$ entre todas las posibles comparaciones pareadas.

Los valores de $\Psi_{1}$ en los tratamientos de riego deficitario y secano fueron inferiores a los del control y cayeron en 2001 de -0.97 y $-1.58 \mathrm{MPa}$ de $\Psi_{\mathrm{a}}$ a -2.77 y $-3.19 \mathrm{MPa}$ de $\Psi_{\mathrm{md}}$ en $\mathrm{T}_{\mathrm{RDC}}$ y $\mathrm{T}_{\mathrm{SCO}}$, respectivamente. Las diferencias máximas absolutas respecto al control se dieron, por tanto, a mediodía con valores de $0.53 \mathrm{MPa}$ en 2000 y 0.67 en 2001 en $\mathrm{T}_{\mathrm{RDC}}$, mientras que en el $\mathrm{T}_{\mathrm{SCO}}$ fueron similares al alba y mediodía $(\approx 1.0 \mathrm{MPa})$, lo que se puede interpretar como una manifestación del déficit hídrico alcanzado en $\mathrm{T}_{\mathrm{SCO}}$, el que fue lo suficientemente severo para no permitir un mayor grado de recuperación de la planta durante la noche. La mayor adaptación de estos árboles a las condiciones de secano junto a su menor índice de área foliar explicarían las diferencias tan notables de potencial hídrico foliar al alba $\left(\Psi_{\mathrm{a}}\right)$ respecto a los valores obtenidos por Goldhamer et al. (2006) en almendros 'Nonpareil' en el período precosecha tras 1, 22 y 42 días de supresión del riego 
$\left(\Psi_{\mathrm{a}}=-0.53 ;-2.51 \mathrm{y}-4.0 \mathrm{MPa}\right.$, respectivamente). Estos mismos autores, $\mathrm{y}$ contrariamente a los resultados recogidos en la figura 5.9, obtuvieron, en idéntico mes, una mayor separación entre tratamientos en las medidas de $\Psi_{\text {a }}$ que $\Psi_{\text {md }}$, si bien, y al igual que en nuestras condiciones de cultivo $\Psi_{\text {a }}$ y $\Psi_{\text {md }}$ fueron significativamente diferentes (Figura 5.9).

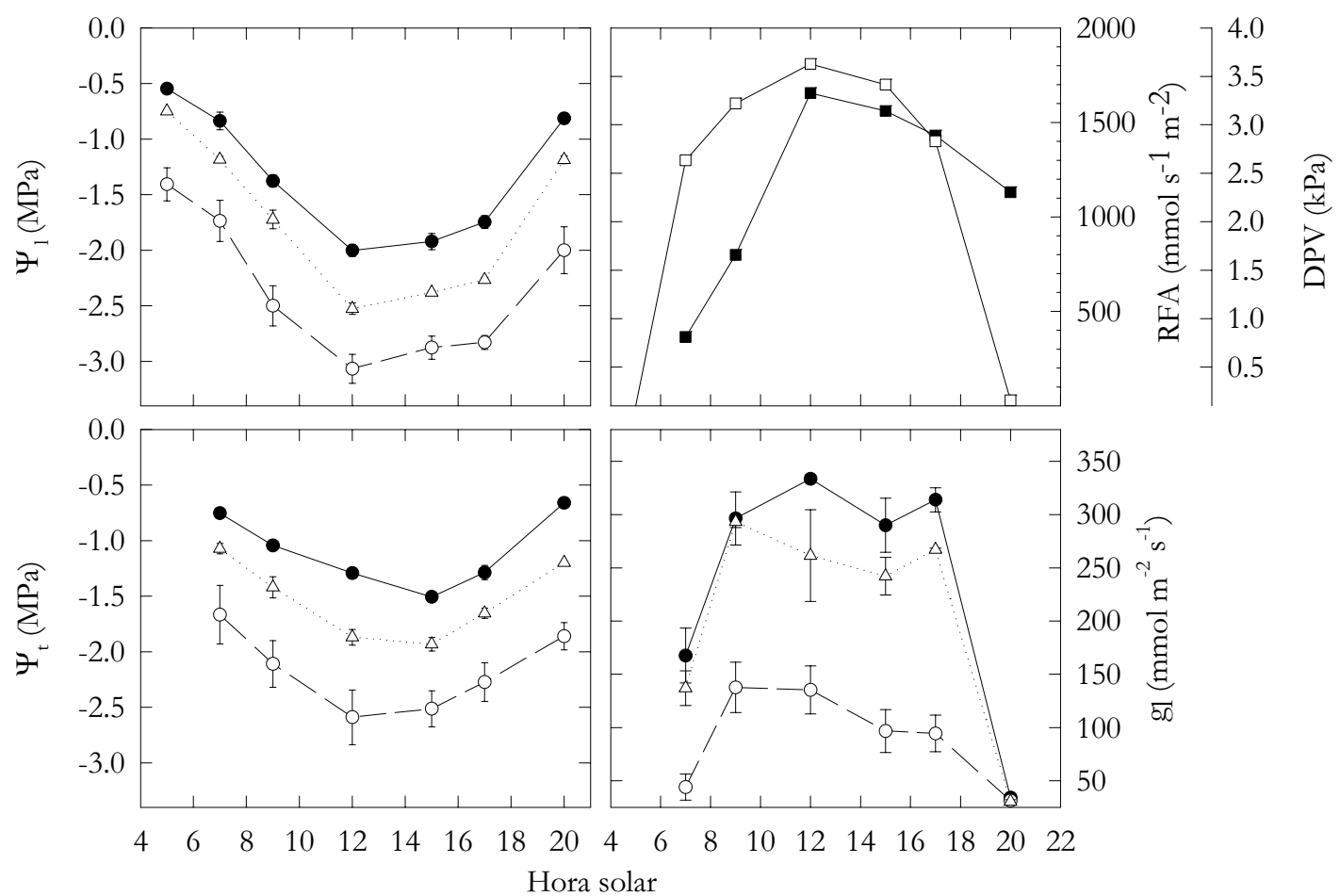

Figura 5.10. Evolución diaria de la radiación fotosintéticamente activa, RFA ( $\square-)$, déficit de presión de vapor, DPV, ( $\checkmark$ ) potencial hídrico foliar $\left(\Psi_{1}\right)$, de tallo $\left(\Psi_{t}\right)$ y conductancia foliar $\left(\mathrm{g}_{\mathrm{I}}\right)$, para los 3 tratamientos: $\mathrm{T}_{\mathrm{CTL}}(-\bullet), \mathrm{T}_{\mathrm{RDC}}(\cdots \Delta \cdots)$ y $\mathrm{T}_{\mathrm{SCO}}(-\mathrm{O}-), 19$ julio 2000. Cada punto corresponde a la media de 3 repeticiones \pm ES.

La evolución de $\Psi_{t}$, realizada en julio de 2000, mostró una pauta similar a la de $\Psi_{1}$ (Figura 5.10), con diferencias respecto al control sensiblemente mayores. Estos resultados corroboran la alta sensibilidad de $\Psi_{t}$ al régimen hídrico y su utilidad como indicador del estrés hídrico del árbol (Naor et al., 2001). A mediodía, los valores de $\Psi_{\mathrm{t}}$ en $\mathrm{T}_{\mathrm{CTL}}, \mathrm{T}_{\mathrm{RDC}}$ y $\mathrm{T}_{\mathrm{SCO}}$ superaban en 0.71 , 0.68 y $0.5 \mathrm{MPa}$, respectivamente a los de $\Psi_{\text {md }}$ (Figura 5.10).

Análogamente a $\Psi_{1}$, las máximas diferencias de $g_{1}$ entre tratamientos tuvieron lugar en la evolución de julio. En las horas centrales del día y en comparación con el control, $\mathrm{g}_{\mathrm{l}}$ fue significativamente inferior en $\mathrm{T}_{\mathrm{RDC}} \mathrm{y} \mathrm{T}_{\mathrm{SCO}}$, e igualmente en $\mathrm{T}_{\mathrm{SCO}}$ respecto a $\mathrm{T}_{\mathrm{RDC}}$. En 2001, los valores de $\mathrm{g}_{\mathrm{l}}$ en $\mathrm{T}_{\mathrm{CTL}} \mathrm{y}$ $\mathrm{T}_{\mathrm{RDC}}$ fueron 3.3 y 2.1 veces superiores a los registrados en $\mathrm{T}_{\mathrm{SCO}}$ (Figura 5.9), tendencia similar a la observada en 2000 pero con diferencias más 
pronunciadas (Figura 5.10). La conductancia foliar aumentó rápidamente en las primeras horas de la mañana, alcanzando en $\mathrm{T}_{\text {СтL }}$ un máximo en torno a $300 \mathrm{mmol} \mathrm{m} \mathrm{m}^{-1}$ a las 9:00 h UT y permaneciendo relativamente constante hasta las 17:30 en el tratamiento control. Sin embargo, en el resto de tratamientos se produjo un descenso gradual de $g_{1}$ (Figuras 5.9 y 5.10), similar a lo observado en la evolución de mayo, inclusive en $\mathrm{T}_{\text {СтL}}$, tras el fallo en el sistema de riego, y que supone un mecanismo claro de adaptación del árbol a la falta de agua, capaz de mejorar la eficiencia de absorción de $\mathrm{CO}_{2}$ con relación al agua perdida. A nivel diario, los máximos niveles de $\mathrm{g}_{1}$ coincidieron con los mínimos valores de $\Psi_{1}$ en $T_{\text {CTL }}$, especialmente en el 2000, no siendo así en $\mathrm{T}_{\mathrm{SCO}}$. Hay que señalar que mientras en el tratamiento control los potenciales matriciales prerriego $\left(\Psi_{\mathrm{m}}\right)$ se encontraban en torno a los $-40 \mathrm{kPa}$, en $\mathrm{T}_{\mathrm{SCO}}$ eran cuatro veces menores, los que corresponden a déficit hídrico severo (Schulbach y Schwankl, 1996).

Los niveles máximos de conductancia foliar en los tratamientos regados disminuyeron en octubre, especialmente en $\mathrm{T}_{\text {CTL }}$, quizás como consecuencia de los ya citados procesos de origen ontogénico y desequilibrios hormonales que tienen lugar en las hojas viejas. Sin embargo, los niveles, aunque por debajo de tratamientos regados, aumentaron en $\mathrm{T}_{\mathrm{SCO}}$, ya que tanto el área foliar total como la demanda evaporante disminuyeron substancialmente (Figura 5.1).

Dentro de esta misma línea, la figura 5.12 presenta los datos de $\mathrm{g}_{1}$ a mediodía, correspondientes al período de alta ET, en función de $\Psi_{\text {md }}$, para los tres tratamientos de riego, e ilustra su dependencia con la disminución de $\Psi_{\text {md. }}$. Esta relación, caracterizada por un alto coeficiente de correlación $(\mathrm{r}=$ $0.91^{* * *}$ ), indica que la conductancia disminuyó continuamente cuando lo hizo $\Psi_{\text {md }}$. Respuestas similares encontraron Landsberg et al. (1976) en manzano, Rawson (1979) en girasol, Castel y Fereres (1982) en almendro, etc., tanto bajo condiciones ambientales controladas como de campo. El gradual cierre estomático sobre un rango amplio de $\Psi_{\text {md }}$ puede contribuir al mantenimiento de un cierto nivel fotosintético durante largos períodos de déficit (Castel y Fereres, 1982).

Aunque bajo las condiciones de déficit hídrico ensayadas se produjo una importante regulación estomática, este déficit no fue lo suficiente alto para promover el cierre estomático, lo que indica que a valores de -3.0 y -2.5 $\mathrm{MPa}$ de $\Psi_{\text {md }}$ y $\Psi_{\mathrm{t}}$ respectivamente, se mantuviese un cierto grado de turgencia celular. La dispersión en los valores de gi para un mismo $\Psi_{\text {md }}$ (Figura 5.12) es típica de trabajos de campo (Castel y Fereres, 1982), habiéndose atribuido parte de esta dispersión a la respuesta del estoma a otros factores ambientales. 


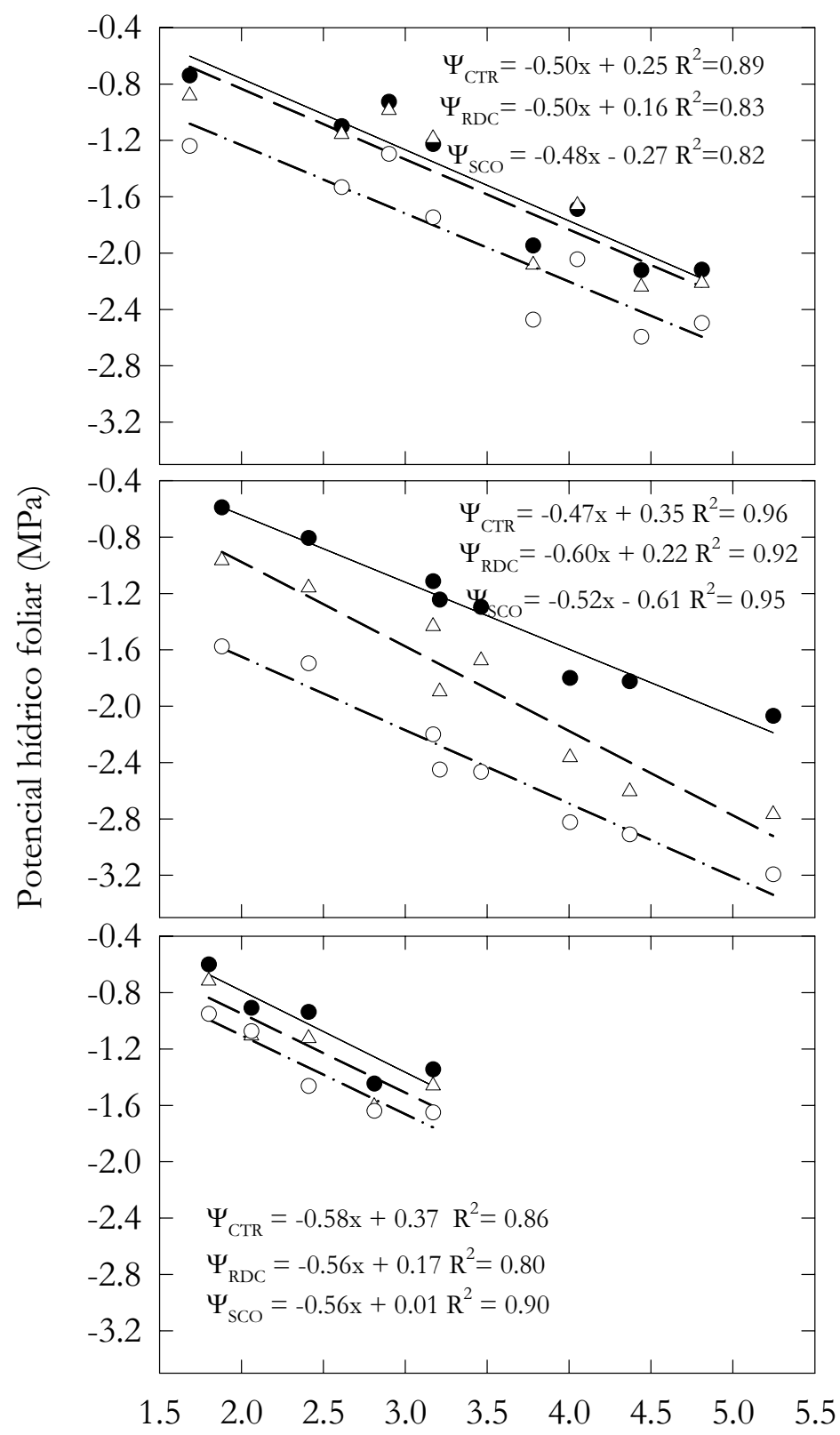

Déficit de presión de vapor $(\mathrm{kPa})$

Figura 5.11. Relaciones entre el potencial hídrico foliar y el déficit de presión de vapor obtenidas en las tres evoluciones diarias de 2001, para los 3 tratamientos $\mathrm{T}_{\mathrm{CTL}}(\bullet), \mathrm{T}_{\mathrm{RDC}}(\boldsymbol{\Delta})$ y $\mathrm{T}_{\mathrm{SCO}}(\mathrm{O})$.

Las estimas de las variaciones diurnas de la relación entre la conductancia foliar $\left(\mathrm{g}_{1}\right)$ y el potencial hídrico foliar $\left(\Psi_{1}\right)$ para cada tratamiento de riego se obtuvieron representando los datos horarios obtenidos en las evoluciones diarias a lo largo de la estación de riegos. Los resultados de estas aproximaciones se recogen en la figura 5.13, y muestran un claro fenómeno de histéresis para todos los tratamientos, lo que hace no unívoca la relación entre 
la conductancia foliar y potencial hídrico foliar. En las primeras horas del día $\mathrm{g}_{1}$ fue mayor, en todos los tratamientos, que al atardecer para un mismo $\Psi_{1}$. Sin embargo, los bucles de los tratamientos fueron tanto más cortos y aplanados cuanto mayor fue el déficit hídrico soportado, indicando una reducción de la apertura estomática y el aumento del papel jugado por el $\Psi_{1}$ en el control de la conducta estomática (Sánchez-Blanco et al., 1991).

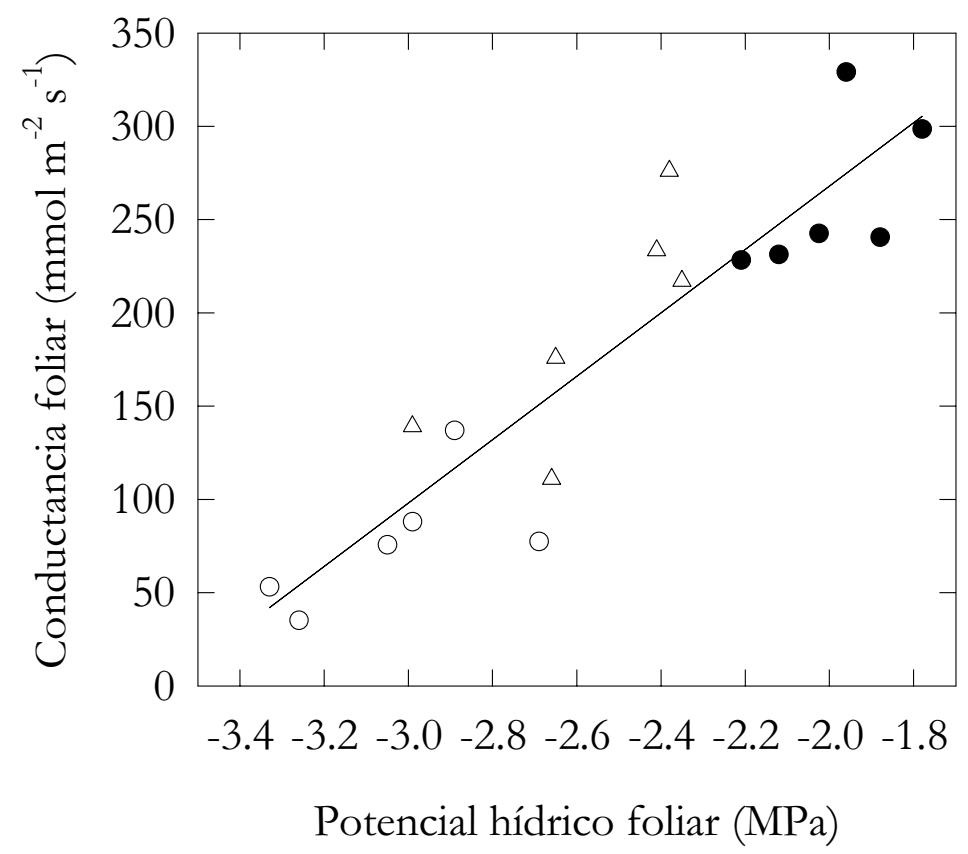

Figura 5.12. Conductancia foliar a mediodía $\left(\mathrm{g}_{\mathrm{l}}\right)$ en función del potencial hídrico foliar a mediodía $\left(\Psi_{\text {md }}\right.$ ), durante julio de 2000 y 2001, en los tratamientos $\mathrm{T}_{\mathrm{CTL}}(\bullet), \mathrm{T}_{\mathrm{RDC}}(\boldsymbol{\Delta})$ y $\mathrm{T}_{\mathrm{SCO}}$ (O). Cada punto representa la media de 3 medidas. La ecuación de la línea de ajuste viene dado por: $\mathrm{g}_{\mathrm{l}}\left(\mathrm{mmol} \mathrm{m}^{-2} \mathrm{~s}^{-1}\right)=607.8+169.9 \Psi_{\mathrm{md}}(\mathrm{MPa}) ; \mathrm{R}^{2}=0.83^{* * *}$. 


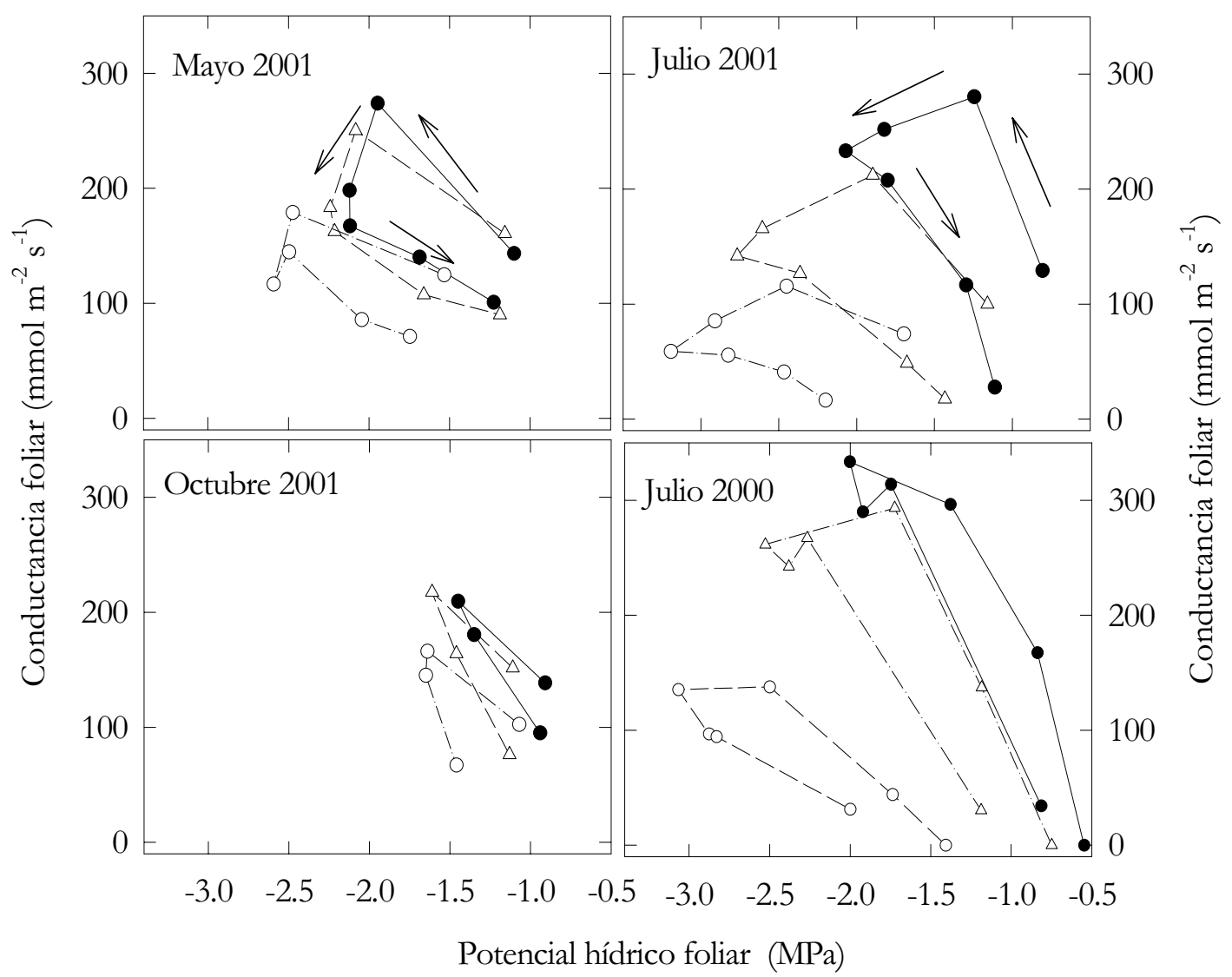

Figura 5.13. Variación diurna de la relación conductancia foliar $\left(\mathrm{g}_{1}\right)$ y potencial hídrico foliar $\left(\Psi_{1}\right)$ de almendros 'Colorada', en función del tratamientos de riego: $\mathrm{T}_{\mathrm{CTL}}(-\bullet), \mathrm{T}_{\mathrm{RDC}}$ $(\cdots \Delta \cdots)$ y $\mathrm{T}_{\mathrm{SCO}}(-\mathrm{O}-)$. Cada punto es la media de tres medidas por árbol en seis árboles por tratamiento. Las flechas indican el sentido horario de la evolución de los parámetros.

\section{Componentes del potencial hídrico foliar}

El estudio de las componentes del potencial hídrico foliar a partir de las muestras tomadas en las evoluciones de 2001 se muestra en la figura 5.14, y en la tabla 5.2 se recogen, junto al potencial osmótico a máxima saturación $\left(\Psi_{\mathrm{os}}\right)$ los potenciales osmótico y de presión actual a mediodía ( $\Psi_{\mathrm{o} \text { md }}$ y $\left.\Psi_{\mathrm{p} \mathrm{md}}\right)$.

En cada una de las evoluciones diarias el valor mínimo de $\Psi_{\mathrm{o}}$ ocurrió inmediatamente después de mediodía (Figura 5.14) como consecuencia de la concentración pasiva de solutos por deshidratación parcial. En la evolución de mayo, cuando los árboles controles estaban ligeramente estresados (Figura 5.9), las diferencias de potencial respecto a $T_{\text {СтL }}$ fueron mayores en $\Psi_{\text {o md }}$ que en $\Psi_{\text {md }}$, en ambos tratamientos deficitarios (Figuras 5.9 y 5.14, y Tabla 5.2), lo que explica la existencia de mayores $\Psi_{\text {pmd }}$ que en $\mathrm{T}_{\text {CTL }}$, quizás como consecuencia de una mejor adaptación al déficit hídrico y salino de $\mathrm{T}_{\mathrm{RDC}} \mathrm{y}$ $\mathrm{T}_{\mathrm{SCO}}$ tras dos años del inicio de los ensayos y después de un período de reducción lenta y gradual de la disponibilidad de agua en el suelo en el ciclo de 
crecimiento en curso. En julio, con los árboles de $\mathrm{T}_{\text {СТL }}$ adecuadamente regados y con diferencias de $\Psi_{\text {md }}$ y $g_{1}$ estadísticamente significativas entre todas las comparaciones posibles (Figura 5.9), $\Psi_{\text {md }}$ cayó alrededor de 0.79 $\left(\mathrm{T}_{\mathrm{RDC}}\right)$ y $1.09 \mathrm{MPa}\left(\mathrm{T}_{\mathrm{SCO}}\right)$ por debajo de $\mathrm{T}_{\mathrm{CTL}}$. Aproximadamente la totalidad de este cambio en $\mathrm{T}_{\mathrm{RDC}}$ y la mitad en $\mathrm{T}_{\mathrm{SCO}}$ tiene su explicación en la disminución de $\Psi_{\text {o md }}$ (Tabla 5.2). El hecho de que no se diese un ajuste osmótico adicional en $\mathrm{T}_{\mathrm{RDC}}$ e inclusive la pérdida de solutos en $\mathrm{T}_{\mathrm{SCO}}$ se corresponde con $\Psi_{\mathrm{p} \text { md }}$ similar y significativamente inferior a $\mathrm{T}_{\mathrm{CTL}}$ en $\mathrm{T}_{\mathrm{RDC}} \mathrm{y}$ $\mathrm{T}_{\mathrm{SCO}}$, respectivamente (Tabla 5.2), y a pesar de la reducción significativa de $\mathrm{g}_{\mathrm{l}}$ en ambos tratamientos. El aumento de $\Psi_{1}$ con la disminución de la demanda evaporante tuvo lugar en los tres tratamientos como queda reflejado en la evolución de octubre (Figura 5.9). Aportes de riego del $70 \%$ de $\mathrm{T}_{\text {СтL }}$ no originaron diferencias significativas de $\Psi_{1}$ respecto al control. Los mayores potenciales hídricos foliares y los menores potenciales osmóticos a mediodía alcanzados en octubre originaron los $\Psi_{\mathrm{p} \text { md }}$ más altos registrados durante todo el ciclo de crecimiento (Tabla 5.2).

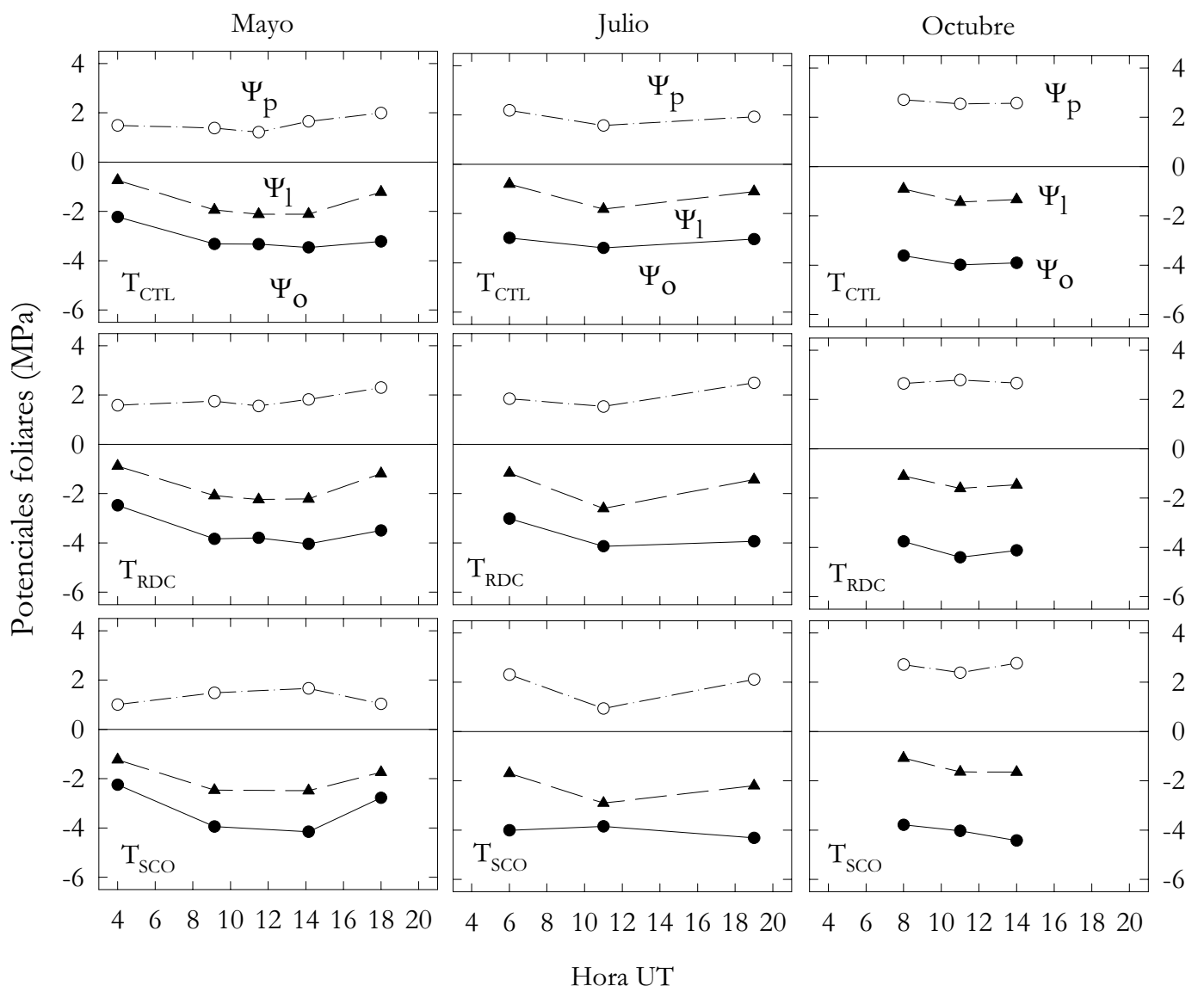

Figura 5.14. Evoluciones diarias del potencial hídrico foliar $(\smile)$ y de las componentes osmótica ( - - ) y de presión (- ) en mayo, julio y octubre de 2001, para los tres tratamientos de riego. 
Tabla 5.2. Valores de los componentes del potencial hídrico foliar en diferentes fechas y para los tres tratamientos de riego: potencial osmótico a máxima saturación $\left(\Psi_{\mathrm{os}}\right)$, potenciales osmótico y de presión actual a mediodía $\left(\Psi_{\mathrm{omd}}\right)$ y $\left(\Psi_{\mathrm{pmd}}\right) .2001$.

\begin{tabular}{lcccc}
\hline Fecha & Tratamiento & $\Psi_{\text {os }}$ & $\Psi_{\text {o md }}$ & $\Psi_{\mathrm{pmd}}$ \\
\cline { 2 - 5 } 25 Mayo & $\mathrm{T}_{\mathrm{CTL}}$ & $-1.6 \mathrm{a}$ & $-3.3 \mathrm{a}$ & $1.2 \mathrm{a}$ \\
& $\mathrm{T}_{\mathrm{RDC}}$ & $-1.8 \mathrm{~b}$ & $-3.8 \mathrm{~b}$ & $1.6 \mathrm{~b}$ \\
& $\mathrm{~T}_{\mathrm{SCO}}$ & $-2.7 \mathrm{c}$ & $-4.0 \mathrm{c}$ & $1.6 \mathrm{~b}$ \\
\cline { 2 - 5 } 26 Julio & $\mathrm{T}_{\mathrm{CTL}}$ & $-2.4 \mathrm{~b}$ & $-3.4 \mathrm{a}$ & $1.6 \mathrm{a}$ \\
& $\mathrm{T}_{\mathrm{RDC}}$ & $-2.5 \mathrm{~b}$ & $-4.1 \mathrm{~b}$ & $1.5 \mathrm{a}$ \\
& $\mathrm{T}_{\mathrm{SCO}}$ & $-2.1 \mathrm{a}$ & $-3.9 \mathrm{~b}$ & $0.9 \mathrm{~b}$ \\
\cline { 2 - 5 } & $\mathrm{T}_{\mathrm{CTL}}$ & $-2.5 \mathrm{a}$ & $-4.0 \mathrm{a}$ & $2.5 \mathrm{a}$ \\
& $\mathrm{T}_{\mathrm{RDC}}$ & $-2.9 \mathrm{a}$ & $-4.4 \mathrm{a}$ & $2.8 \mathrm{a}$ \\
& $\mathrm{T}_{\mathrm{SCO}}$ & $-2.5 \mathrm{a}$ & $-4.0 \mathrm{a}$ & $2.4 \mathrm{a}$
\end{tabular}

Los valores de cada fecha y columna seguidos de letras distintas son significativamente diferentes según el test de Tukeyo.05

Por otro lado y con relación al potencial osmótico a máxima saturación $\left(\Psi_{\text {os }}\right)$, a principios de ciclo, mayo, el tratamiento control presentó valores de 1.6 MPa (Tabla 5.2), niveles idénticos a los obtenidos por Torrecillas et al. (1996) en almendros 'Garrigues' y 'Ramillete' regados por goteo, con agua de buena calidad y volúmenes de riego correspondientes a sus máximas necesidades; mientras que los de $\mathrm{T}_{\mathrm{RDC}}\left(\Psi_{\mathrm{os}}=-1.8 \mathrm{MPa}\right.$; Tabla 5.2) coincidieron con los de los árboles a los que se les suprimió el riego durante 28 días, en el ensayo citado. Según estos autores, los $0.2 \mathrm{MPa}$ de reducción de $\Psi_{\text {os }}$ por estrés hídrico permanecieron constantes al aumentar la duración e intensidad del déficit hídrico, por lo que al igual que lo señalado por Castel y Fereres (1982) y Ruiz-Sánchez et al. (1993), concluyan que el almendro presenta una capacidad muy limitada para realizar ajuste osmótico por estrés hídrico. Esta conducta difiere claramente de la observada en los tratamientos $\mathrm{T}_{\mathrm{CTL}}$ y $\mathrm{T}_{\mathrm{RDC}}$ en los que $\Psi_{\mathrm{os}}$ disminuyó con el avance de la estación de crecimiento. Así y durante el período mayo - octubre, $\Psi_{\text {os }}$ cayó 0.9 y $1.1 \mathrm{MPa}$ en $\mathrm{T}_{\mathrm{CTL}}$ y $\mathrm{T}_{\mathrm{RDC}}$, respectivamente (Tabla 5.2). $\mathrm{Y}$ aunque parte de esta caída puede ser atribuida a una acumulación activa de solutos con la edad, característica de árboles caducifolios (Lakso et al., 1984), es difícilmente explicable en su totalidad al efecto de la edad de la hoja en $\mathrm{T}_{\text {CTL }} \mathrm{y}$ al de ésta en combinación con la restricción hídrica en $\mathrm{T}_{\mathrm{RDC}}$. Contrariamente a lo 
observado en $\mathrm{T}_{\text {CTL }}$ y $\mathrm{T}_{\mathrm{RDC}}, \Psi_{\text {os }}$ aumentó en $\mathrm{T}_{\mathrm{SCO}}$, especialmente de mayo a julio, coincidiendo con valores de $g_{1}$ extremadamente bajos (Tabla 5.2 y Figuras 5.9 y 5.10). Esto pudo deberse a que ya en mayo el potencial osmótico foliar se encontrase muy próximo al máximo nivel posible de acumulación de solutos y que un aumento en la intensidad de estrés hídrico por sequía osmótica ocasionase pérdidas de solutos invirtiendo el ajuste osmótico (Tyree y Jarvis, 1982).

A partir de lo anterior y de los resultados recogidos en la tabla 5.2, que suponen un importante ajuste osmótico para $\mathrm{T}_{\mathrm{SCO}} \mathrm{y}$ posteriormente en julio para $T_{C T L}$ y $T_{R D C}$, se considere como causa principal de la acumulación iónica $\mathrm{y}$ de los posibles solutos orgánicos la inducción por salinidad, tal como sugieren la alta $\mathrm{CE}_{\mathrm{e}}$ en la zona radicular (Figura 5.5) y las altas concentraciones de cloruros y sodio determinadas en hojas (Figura 5.16 y Tabla 5.4). Bañuls y Primo Millo (1992) encontraron $\Psi_{\mathrm{p}}$ en hojas de cítricos cultivados en suelos salinos similares a los obtenidos en suelos no salinos y que tanto el $\mathrm{Na}^{+}$como el $\mathrm{Cl}^{-}$acumulado contribuyen a los procesos de ajuste osmótico.

En general, $\Psi_{\mathrm{o}}$ disminuyó con la edad de las hojas y en respuesta al estrés hídrico y salino, permitiendo que $\Psi_{\mathrm{p} \text { md }}$ en los tratamientos regados permaneciera constante o incluso que aumentará, compensando así las reducciones de $\Psi_{1}$.

\subsubsection{Contenido mineral en hoja}

Teniendo en cuenta que el análisis químico de una muestra de hojas es el mejor método de diagnóstico del estado nutritivo de una plantación y de su utilidad para detectar toxicidades causadas por elementos como el cloro, sodio y boro; a mediados de julio de 2000 , momento incluido dentro del período en el que la generalidad de los elementos permanecen a concentraciones relativamente constantes en almendro (Uriu, 1978), se procedió a la toma de muestras para su posterior envío y análisis. Los resultados de las valoraciones realizadas por el laboratorio comercial para los tres tratamientos figuran en el tabla 5.3.

De los macroelementos determinados en hoja ( $\mathrm{N}, \mathrm{P}, \mathrm{K}, \mathrm{Ca}$ y $\mathrm{Mg})$, tan sólo el nitrógeno se encuentra por debajo del valor crítico considerado para almendro y aunque los contenidos son ligeramente inferiores en los árboles del tratamiento de secano, estos están dentro del rango de niveles adecuados. En cuanto a los microelementos $\mathrm{Fe}, \mathrm{Cu}, \mathrm{Zn}$ y Mn, solamente el $\mathrm{Zn}$ presenta niveles deficientes (Tabla 5.3). Sin embargo, los contenidos en sodio y cloruros son excesivos, lo que es indicativo de una elevada acumulación en hoja de estos iones específicos y por tanto de fitotoxicidad. 
Tabla 5.3. Resultados del análisis foliar en los tratamientos: $T_{\mathrm{CTL}}, \mathrm{T}_{\mathrm{RDC}}$ y $\mathrm{T}_{\mathrm{SCO}}$.

\begin{tabular}{llll}
\hline Parámetros & \multicolumn{3}{c}{ Tratamiento } \\
\hline & $\mathbf{T}_{\mathrm{CTL}}$ & $\mathbf{T}_{\mathrm{RDC}}$ & $\mathbf{T}_{\mathrm{SCO}}$ \\
\hline Nitrógeno total (\%) & 1.81 & 1.73 & 1.68 \\
Fósforo (\%) & 0.18 & 0.18 & 0.16 \\
Potasio (\%) & 1.38 & 1.33 & 1.00 \\
Calcio (\%) & 2.77 & 2.54 & 2.66 \\
Magnesio (\%) & 0.28 & 0.27 & 0.25 \\
Sodio (\%) & 0.43 & 0.50 & 0.81 \\
Cloruros (\%) & 0.75 & 0.77 & 0.81 \\
Hierro (ppm) & 75.20 & 61.90 & 81.60 \\
Cobre (ppm) & 5.23 & 4.33 & 3.53 \\
Zinc (ppm) & 13.92 & 13.19 & 7.93 \\
Manganeso (ppm) & 37.07 & 37.37 & 39.49 \\
Boro (ppm) & 22.77 & 22.32 & 19.68 \\
\hline
\end{tabular}

La deficiencia de nitrógeno detectada en hoja puede ser explicada por la interrelación entre la absorción de $\mathrm{NO}_{3}{ }^{-} \mathrm{y} \mathrm{Cl}^{-}$, que de ordinario se cita como antagónica (Fisarakis et al., 2001; Silveira et al., 2001), lo que aconsejaría un aporte mayor de $\mathrm{N}$ al recomendado bajo condiciones no salinas. La deficiencia de Zn, además de poder ser debida a alteraciones nutricionales inducidas por la salinidad, hay que considerar que puede estar condicionada por baja disponibilidad de $\mathrm{Zn}$ en la solución del suelo como consecuencia de su $\mathrm{pH}$ alcalino $(\mathrm{pH}=8.2)$ y bajo contenido en materia orgánica. En estas condiciones parece aconsejable recurrir al aporte de complejos orgánicos o a tratamientos vía foliar.

Los altos valores de $\mathrm{Cl}^{-}$y $\mathrm{Na}^{+}$detectados a partir del análisis foliar se corresponden con la sintomatología observada, necrosis en puntas y bordes de las hojas que aparecen como quemadas (Figura 5.15), y que además están en consonancia con los altos niveles de estos iones en suelo y agua de riego. Los niveles de $\mathrm{Cl}^{-}$y $\mathrm{Na}^{+}$encontrados en hoja son similares e inferiores, respectivamente, a los observados por Demiral (2005) en olivo, bajo nivel salino similar. 
A tenor de estos resultados y con el objetivo de realizar una comparación estadística de los niveles medios de $\mathrm{Cl}^{-}$entre tratamientos, se realizó un muestreo adicional a finales de julio de 2000 en hojas procedentes de 'spurs'. Simultáneamente, se recogió una muestra por repetición de la parte apical de brotes del año. En 2001, y con carácter bimensual, se determinó el contenido foliar en cloruros, sodio y potasio a partir de muestras de 150 hojas por repetición procedentes de 'spurs'. Los resultados de los muestreos de julio de 2000 se muestran en la tabla 5.4 y los de 2001 en la figura 5.16.
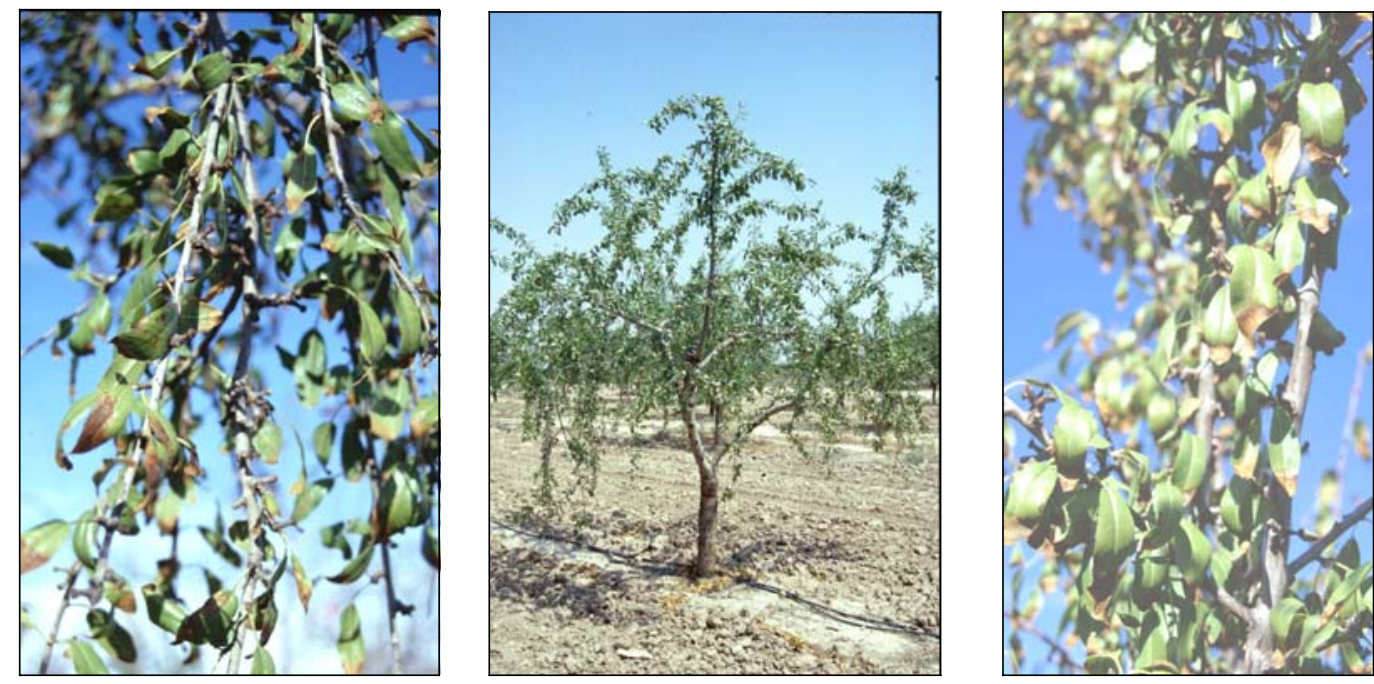

Figura 5.15. Detalle de necrosis en puntas de hojas por toxicidad de cloruros y sodio.

El hecho de que se diese una mayor concentración de cloruros en hojas en 2000 que en 2001 pudo deberse al lavado originado por las lluvias de octubre de 2000, de modo que el nuevo ciclo de cultivo se iniciase con un menor contenido salino en el suelo, y a un posible efecto de dilución como resultado del mayor desarrollo vegetativo del árbol en 2001 y por tanto de la masa foliar (Fernández et al., 1990; Jasso et al., 1999). Por otro lado, el que se observase una mayor concentración de cloruros en las hojas y brotes del tratamiento de secano pudo ser debido a la presencia de este ion en la madera (Fulton et al., 1996) como consecuencia de los cinco años previos en riego por goteo, a su mayor presencia en el suelo dada la escasez de las precipitaciones, y por tanto de lavado, lo que origina una mayor concentración de cloruro en el suelo a medida que pierde agua a través del proceso de evapotranspiración. La similitud entre las concentraciones de $\mathrm{Cl}^{-}$procedentes de la parte tierna de brotes de 2000 (Tabla 5.4) y de hojas de marzo de 2001 (Figura 5.16) sugieren edades parecidas, al ser el cloruro un ion que se acumula preferentemente en hojas viejas (Syvertsen et al., 1988) y especialmente cuando se dan condiciones de contenidos elevados en suelo (Brown y Uriu, 1996).

En 2001, como era esperable, la concentración $\mathrm{Cl}^{-}$en hoja aumentó con el avance del ciclo de crecimiento (Figura 5.16), alcanzándose en julio niveles 
superiores en $\mathrm{T}_{\mathrm{RDC}} \mathrm{y} \mathrm{T}_{\mathrm{SCO}} \mathrm{y}$ en septiembre en el $\mathrm{T}_{\mathrm{CTL}}$ a los considerados como críticos (Brown y Uriu, 1996).
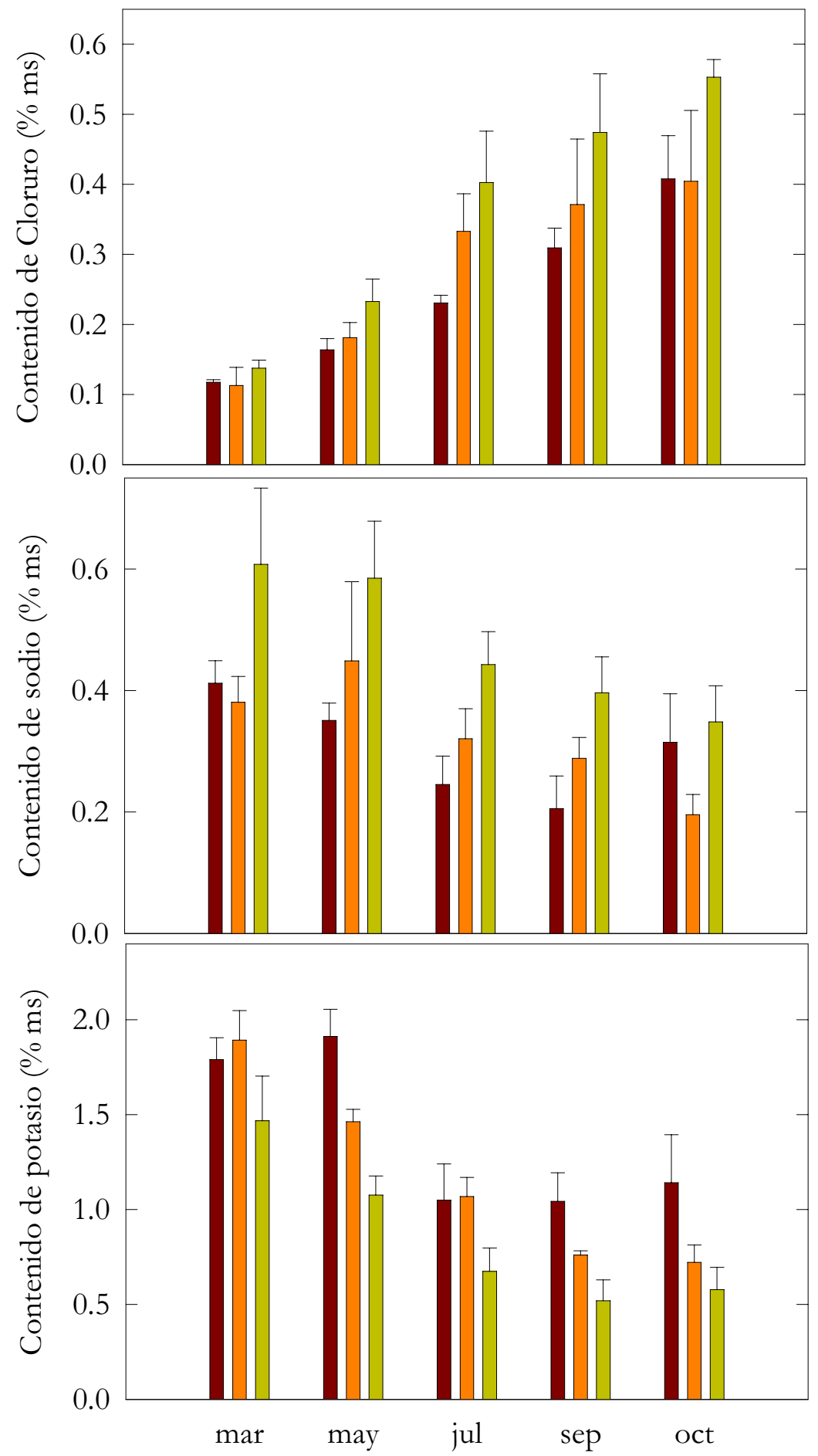

Figura 5.16. Efecto del régimen de riego sobre el contenido y evolución en hoja de cloruros, sodio y potasio a lo largo del ciclo de cultivo de 2001, para los tres tratamientos de riego: $\mathrm{T}_{\mathrm{CTL}}(\square), \mathrm{T}_{\mathrm{RDC}}(\square)$ y $\mathrm{T}_{\mathrm{SCO}}(\square)$. Las barras representan $\mathrm{ES}$. 
A finales de verano los síntomas de fitotoxicidad por $\mathrm{Cl}^{-}$fueron evidentes en los 3 tratamientos, siendo más acentuados en $\mathrm{T}_{\mathrm{SCO}}$. Aunque no se dieron diferencias significativas entre los dos tratamientos de riego, excepto en el mes de julio, se observó una tendencia de mayor acumulación de $\mathrm{Cl}^{-}$en el $\mathrm{T}_{\mathrm{RDC}}$. El incremento de la [Cl] en hoja a lo largo de la estación de riego, como ya fue comentado, puede ser atribuible a los altos niveles de este ion en el suelo (Figura 5.5), consecuencia de la utilización continuada de un agua de riego clasificada de restricción de uso severo (Uriu, 1978). Las determinaciones de cloruros en el grano del fruto evidenciaron la práctica ausencia de este ion en la pepita de la almendra, con valores similares en todos los tratamientos (1-5 $\left.\mathrm{mg} \mathrm{Cl}^{-} \mathrm{L}^{-1}\right)$, lo que demuestra que no es un órgano de acumulación de cloruros en el árbol.

Tabla 5.4. Concentración de cloruro en hojas y brotes del año en base a materia seca. Julio de 2000 .

\begin{tabular}{|c|c|c|}
\hline Tratamiento & Hojas & Brotes \\
\hline & \multicolumn{2}{|c|}{ (\% ms) } \\
\hline $\mathbf{T}_{\mathrm{CTL}}$ & $0.54 \mathrm{ab}$ & $0.12 \mathrm{a}$ \\
\hline $\mathbf{T}_{\mathrm{RDC}}$ & $0.72 \mathrm{~b}$ & $0.11 \mathrm{a}$ \\
\hline $\mathbf{T}_{\text {sco }}$ & $0.75 \mathrm{~b}$ & $0.19 \mathrm{~b}$ \\
\hline
\end{tabular}

Contrariamente a lo esperable el contenido foliar en $\mathrm{Na}^{+}$disminuyó con el avance de la estación (Figura 5.16). Según Brown y Uriu (1996), bajo altos contenidos de cloruros (Figura 5.5) y sodio en el suelo (PSI $=24 \%$ ), los iones $\mathrm{Cl}^{-}$y Na${ }^{+}$tienden a entrar en la planta en cantidades proporcionales a su concentración en el medio radicular. A partir de ahí, se translocan rápidamente vía corriente de transpiración del xilema hacia las hojas, acumulándose en éstas con el tiempo y la edad de las mismas (Tester y Davenport, 2003).

Una vez en las hojas, salvo la existencia de glándulas salinas, la única vía de salida es a través del floema, bien hacía la raíz para su exclusión al medio, o bien hacia otros órganos sumidero. Aunque la movilidad del $\mathrm{Na}^{+}$se presupone altamente unidireccional, existen datos que apoyan una relativamente alta movilidad de $\mathrm{Na}^{+}$en el floema (Tester y Davenport, 2003). Sin embargo, existe poca información al respecto y hay algunos argumentos en contra, como son la baja concentración de $\mathrm{Na}^{+}$en el fruto de tomate dónde el transporte es mayoritariamente floemático, pero se supone que este mecanismo de retranslocación puede tener una fuerte influencia en el control de los niveles foliares de $\mathrm{Na}^{+}$, minimizando o retrasando así el efecto tóxico, 
como se ha sugerido en arroz y tomate (Matsushita y Matoh, 1991; PérezAlfocea et al., 2000).

La dinámica del ion potasio fue coincidente con la descrita por otros autores (Brown y Uriu, 1996); valores altos al inicio de la estación, seguidos de una caída constante durante la fase IV y estabilización de los niveles a partir del momento en el que la almendra está prácticamente hecha (Figura 5.16). Así y con independencia del tratamiento de riego aplicado, los cationes $\mathrm{K}^{+} \mathrm{y}$ $\mathrm{Na}^{+}$disminuyeron notablemente a partir de mediados de mayo, coincidiendo con el inicio de la fase IV, mientras que el ión $\mathrm{Cl}^{-}$se acumuló paulatinamente en las hojas analizadas con el avance de la estación de riego. Una posible explicación a este hecho sería la mayor movilidad del $\mathrm{K}^{+}$y $\mathrm{Na}^{+}$hacia los nuevos sumideros en crecimiento activo, los que tienen una alta demanda de floema procedente de las hojas fotosintéticamente activas. Un argumento a favor de que este mecanismo pueda estar afectando a ambos cationes simultáneamente es el hecho de que dentro de cada muestreo se mantenga una relación inversa entre los contenidos de $\mathrm{Na}^{+}$y $\mathrm{K}^{+}$cuando se comparan los tres tratamientos. Por lo tanto, sería presumible que ambos cationes fueran movilizados hacia los frutos o semillas en particular, las cuales, en condiciones normales presentan un 0.5-0.7 \% de potasio y entre $40-132 \mathrm{mg}$ de sodio por $\mathrm{kg}$ de muestra (Saura et al., 1988; Sánchez Bel et al., 2001), estos últimos valores podrían sufrir un incremento en condiciones de riego con aguas salinas. Otro argumento a favor de estas hipótesis es que el $\mathrm{Cl}^{-}$no sigue esta misma evolución debido a su baja movilidad en el floema en comparación con los otros dos cationes, tal y como se ha observado en tomate (Pérez-Alfocea et al., 2000).

La tabla 5.5 muestra la contribución relativa de los cationes $\mathrm{Na}^{+}$y $\mathrm{K}^{+}$y del anión $\mathrm{Cl}^{-}$al $\Psi_{\text {os }}$ medido en tres fechas señalas de la estrategia de RDC. De forma global, se aprecia una mayor contribución de estos solutos al $\Psi_{\text {os }}$ a finales de la fase III del ciclo de cultivo del almendro, que cuando las fases IV y $\mathrm{V}$ ya están avanzadas, finales de julio y octubre, respectivamente. Esta merma en la contribución relativa con el avance de la estación fue acompañada de la disminución de $\Psi_{\text {os }}$ en $T_{\text {CTL }}$ y $T_{\text {RDC }}$ (Tabla 5.2). La contribución media de $\mathrm{Na}^{+}+\mathrm{Cl}^{-}$al $\Psi_{\text {os }}$ osciló entre el $16 \%$, tratamientos regados, y el $22 \%$ del secano, valores similares a los encontrados en melocotonero bajo condiciones salinas por Massai et al. (2004). La contribución porcentual del $\mathrm{K}^{+}$a $\Psi_{\text {os }}$ fue menor en los tratamientos deficitarios que en el control (65-30\%, 47-16\%, 22-15\%, mayo-octubre, en $\mathrm{T}_{\mathrm{CTL}}, \mathrm{T}_{\mathrm{RDC}} \mathrm{y} \mathrm{T}_{\mathrm{SCO}}$, respectivamente) y en los tres tratamientos disminuyó con el progreso de la estación de riego. 
Aunque la acumulación masiva de $\mathrm{Na}^{+}$y $\mathrm{Cl}^{-}$permite el mantenimiento de la turgencia foliar y por tanto de los intercambios gaseosos no se la puede considerar como una estrategia sostenible a largo plazo en almendro por sus efectos dominantes de fitotoxicidad (Figura 5.15). El aumento del contenido de $\mathrm{Na}^{+}$y $\mathrm{Cl}^{-}$en hoja con la edad y la menor presencia de $\mathrm{K}^{+}$(dificultad para mantener la selectividad del $\mathrm{K}^{+}$) son características propias de plantas sensibles a la salinidad (Downton y Millhouse, 1983).

Tabla 5.5. Contribución de los solutos $\mathrm{Na}^{+}, \mathrm{K}^{+}$y $\mathrm{Cl}^{-}$en $\mathrm{MPa}$ al potencial osmótico foliar a saturación $\left(\Psi_{\mathrm{os}}\right)$, en tres momentos representativos del manejo del riego en RDC. 2001

\begin{tabular}{ccccc}
\hline Tratamientos & $\mathbf{N a}^{+}(\mathbf{M P a})$ & $\left.\mathbf{K}^{+} \mathbf{( M P a}\right)$ & $\mathbf{C l}^{-}(\mathbf{M P a})$ & $\mathbf{\Sigma} \mathbf{( M P a})$ \\
\hline $\mathrm{T}_{\mathrm{CTL}}$ & -0.20 & -1.07 & -0.09 & $\mathbf{- 1 . 3 5}$ \\
$\mathrm{T}_{\mathrm{RDC}}$ & -0.26 & -0.84 & -0.10 & $\mathbf{- 1 . 2 0}$ \\
$\mathrm{T}_{\mathrm{SCO}}$ & -0.33 & -0.60 & -0.13 & $\mathbf{- 1 . 0 6}$ \\
\hline & & \multicolumn{3}{c}{ Julio } \\
$\mathrm{T}_{\mathrm{CTL}}$ & -0.15 & -0.64 & -0.14 & $\mathbf{- 0 . 9 4}$ \\
$\mathrm{T}_{\mathrm{RDC}}$ & -0.20 & -0.66 & -0.21 & $\mathbf{- 1 . 0 7}$ \\
$\mathrm{T}_{\mathrm{SCO}}$ & -0.27 & -0.41 & -0.25 & $\mathbf{- 0 . 9 3}$ \\
\hline & & \multicolumn{2}{c}{ Octubre } & -1.20 \\
$\mathrm{~T}_{\mathrm{CTL}}$ & -0.20 & -0.74 & -0.26 & $\mathbf{- 0 . 8 5}$ \\
$\mathrm{T}_{\mathrm{RDC}}$ & -0.13 & -0.46 & -0.26 & $\mathbf{- 0 . 9 6}$ \\
$\mathrm{T}_{\mathrm{SCO}}$ & -0.23 & -0.37 & -0.36 &
\end{tabular}




\subsubsection{Crecimiento vegetativo}

\section{Brotes}

Los datos correspondientes al crecimiento de los ramos durante los años 2000 y 2001 se muestran en la figura 5.17. El crecimiento de brotes, dependiendo del año, se inicio a mediados-finales de febrero y finalizó a primeros-mediados de abril. El patrón de crecimiento en longitud de los brotes, mejor definido en 2001 que en 2000, respondió a una función sigmoidal, tipo Gompertz $\left(\mathrm{R}^{2}=0.993\right)$.

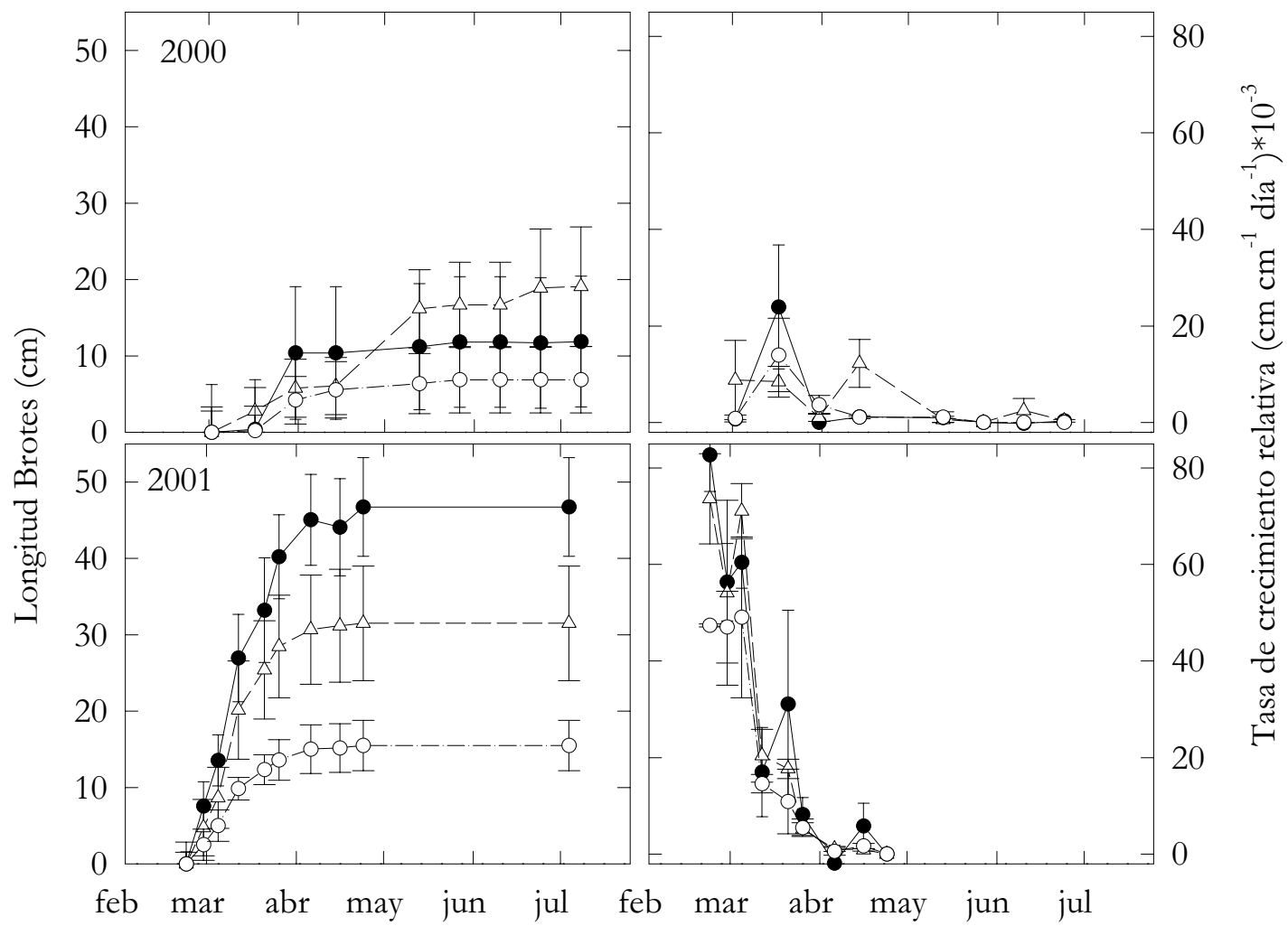

Meses

Figura 5.17. Dinámica del crecimiento de brotes en longitud y tasa de crecimiento relativa en 2000 y 2001, para los tres tratamientos $\mathrm{T}_{\mathrm{CTL}}(-\bullet), \mathrm{T}_{\mathrm{RDC}}(\cdots \Delta \cdot \cdots)$ y $\mathrm{T}_{\mathrm{SCO}}(-0-)$. Cada punto corresponde a la media de 3 repeticiones \pm ES.

En 2000, un año altamente productivo, apenas si hubo crecimiento de ramos, de ahí que no se observase relación entre la cantidad de agua aplicada y el crecimiento de ramos. Contrariamente, en 2001, con una producción de aproximadamente la mitad, el crecimiento total, aunque escaso, fue muy superior al de 2000 (Figura 5.17) registrándose diferencias significativas de crecimiento entre $\mathrm{T}_{\text {CTL }}$ y $\mathrm{T}_{\mathrm{SCO}}$, pero no entre ambos tratamientos regados (Figura 5.17). Esta última observación es coincidente con lo informado por 
Girona et al. (1993a) a partir de la aplicación durante tres años de un tratamiento de riego deficitario en almendro.

Aunque, los valores de velocidad de crecimiento relativo en longitud (Figura 5.17) fueron similares a los obtenidos por Romero et al. (2004a) en almendros regados con agua de buena calidad y de edad y condiciones de clima similares, éstos se tradujeron en menor longitud total, ya que el período de crecimiento fue del orden de la tercera parte del observado por estos autores. De igual modo que la longitud total, al analizar la evolución del diámetro de la base del brote del año y velocidad de crecimiento relativo del mismo (Figura 5.18) sus valores fueron inferiores a los señalados por Romero et al. (2004a).

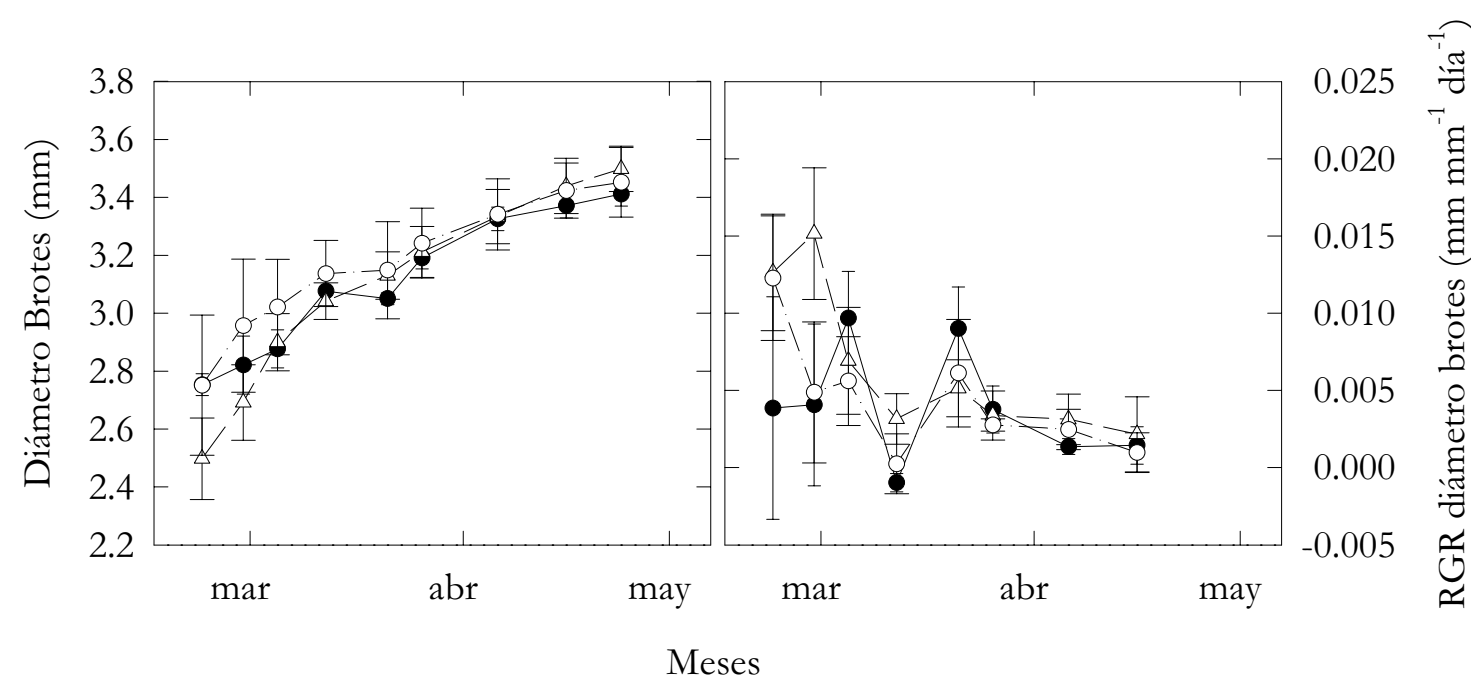

Figura 5.18. Evolución del diámetro de brotes y tasa de crecimiento relativa durante el 2001, para los tres tratamientos $\mathrm{T}_{\mathrm{CTL}}(-\bullet), \mathrm{T}_{\mathrm{RDC}}(\cdots \Delta)$ y $\mathrm{T}_{\mathrm{SCO}}(-0 \cdot)$. Cada punto corresponde a la media de 3 repeticiones \pm ES.

\section{Tronco}

El diámetro de tronco al inicio del ensayo, medido al final de la cosecha de 1999, fue similar en los tres tratamientos de riego. Sin embargo y en idéntica fecha de 2001 las diferencias entre los tratamientos regados y el de secano fueron significativas $(\mathrm{P}<0,05)$, indicando el menor crecimiento habido en $\mathrm{T}_{\mathrm{SCO}}$ (Figura 5.19). La respuesta al riego medida a partir de la tasa de crecimiento en sección transversal de tronco durante el período 1999-2001 fue proporcional al volumen de agua recibido (riego más lluvia), siendo los valores medios de todo el período de 3.92; 2.39 y 0.83 × $10^{-2} \mathrm{~cm}^{2}$ día $^{-1}$ para $T_{C T L}, T_{R D C}$ y $\mathrm{T}_{\mathrm{SCO}}$, respectivamente, valores muy bajos e inferiores a los registrados por Romero et al. (2004a) en árboles de edad similar y por Nortes et al. (2005) para almendros de diámetro de tronco de partida similar, aunque más jóvenes. 


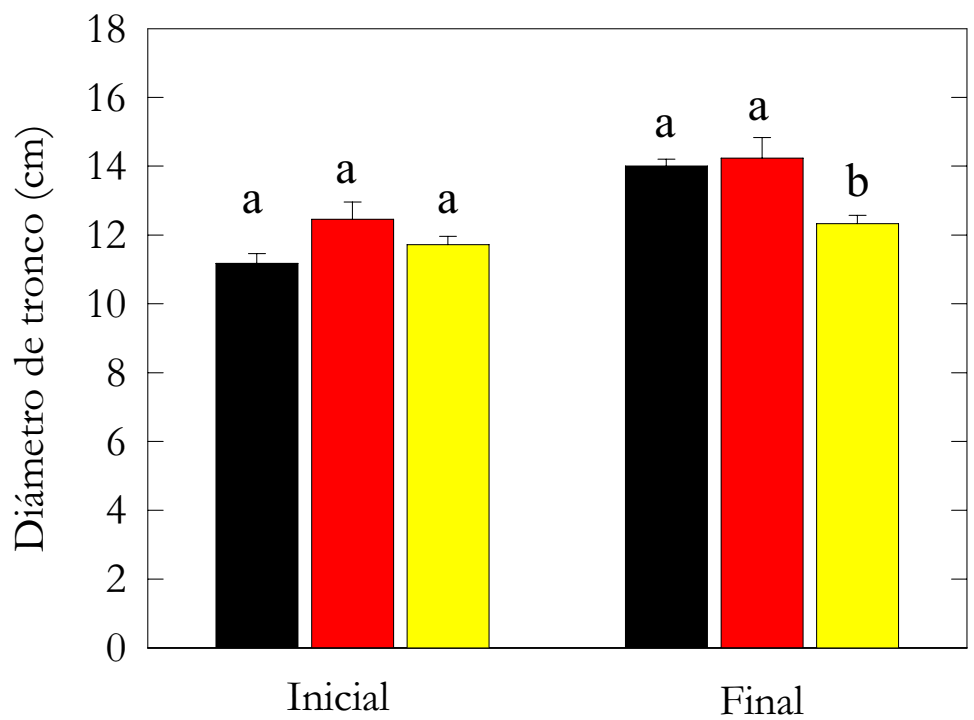

Figura 5.19. Diámetro de tronco al final de las campañas 1999 y 2001, para los tratamientos $\mathrm{T}_{\mathrm{CTL}}(\square), \mathrm{T}_{\mathrm{RDC}}(\square)$ y $\mathrm{T}_{\mathrm{SCO}}(\square)$. Cada punto corresponde a la media de 3 repeticiones \pm ES.

\section{Hojas}

A finales de abril las hojas de los 'spurs' de los distintos tratamientos alcanzan su tamaño y peso final tal como indican los muestreos mensuales realizados durante el período abril-agosto y el de recogida total en diciembre (Tabla 5.6). El área y peso específico foliar fue similar en los dos tratamientos regados, $\mathrm{T}_{\mathrm{CTL}}$ y $\mathrm{T}_{\mathrm{RDC}}$, independientemente del importante ahorro de agua que supuso $\mathrm{T}_{\mathrm{RDC}}$ y contrariamente a lo observado por Torrecillas et al. (1989a) y Romero et al. (2004a). Sin embargo, $\mathrm{T}_{\mathrm{SCO}}$ redujo significativamente el área foliar sin afectar al peso específico. Aunque el índice de área foliar (IAF) fue muy bajo en los tres tratamientos (IAF: $0.25 ; 0.17$ y 0.055 en $\mathrm{T}_{\text {СтL }}, \mathrm{T}_{\mathrm{RDC}} \mathrm{y}$ $\mathrm{T}_{\mathrm{SCO}}$, respectivamente), se dieron claras diferencias entre ellos (Tabla 5.6).

La menor longitud de brotes y área foliar, unido a la mayor caída de hojas en el $\mathrm{T}_{\mathrm{SCO}}$ redujeron el IAF a la cuarta parte del $\mathrm{T}_{\mathrm{CTL}}$, según determinaciones realizadas tras la cosecha. Estos resultados contrastan con los presentados por Romero et al. (2004a) en almendros regados para satisfacer sus máximas necesidades hídricas, los que tuvieron un IAF de 10.2, a pesar de su menor tamaño de hoja. La estrecha correlación lineal observada entre el agua recibida por cada tratamiento (riego+lluvia) y el IAF $\left(\mathrm{R}^{2}=0.99\right)$, distintamente a lo observado para el área foliar unitaria, evidencia la capacidad integradora de este parámetro del conjunto de efectos derivados del déficit hídrico y toxicidad iónica sobre el crecimiento vegetativo del árbol. Los bajos IAF podrían haber contribuido al mantenimiento observado de la turgencia foliar (Tabla 5.2) a lo largo del ciclo y reflejar un mecanismo de tolerancia al estrés; ya que pequeños ratios brotes/raíz suponen una reducción de las 
pérdidas de agua vía transpiración y pueden reflejar un tipo de mecanismo de tolerancia de la planta al déficit hídrico (Gardner et al., 1990). Además, hay que señalar que la salinidad del suelo es otra propiedad química importante que influye en el ratio brotes/raíz. Según Shalhevet et al. (1995) el efecto depresivo de la salinidad sobre el crecimiento radicular es menos severo que sobre el crecimiento de los ramos.

Tabla 5.6. Valores medios del área foliar unitaria y total del árbol, peso específico e índice de área foliar (IAF) de los 3 tratamientos, de acuerdo al total de hojas presentes en el árbol tras la cosecha de 2000.

\begin{tabular}{ccccc}
\hline Trat. & $\begin{array}{c}\text { Área foliar } \\
\left(\mathbf{c m}^{2}\right)\end{array}$ & $\begin{array}{c}\text { Peso específico } \\
\text { foliar }\left(\mathbf{g} / \mathbf{c m}^{2}\right)\end{array}$ & $\begin{array}{c}\text { Área foliar } \\
\text { total } \\
\left(\mathbf{m}^{2} / \text { árbol }\right)\end{array}$ & IAF \\
\hline $\mathbf{T}_{\mathrm{CTL}}$ & $8.66 \mathrm{a}$ & $0.0147 \mathrm{a}$ & $8.93 \mathrm{a}$ & $0.25 \mathrm{a}$ \\
$\mathbf{T}_{\mathrm{RDC}}$ & $8.02 \mathrm{a}$ & $0.0155 \mathrm{a}$ & $6.16 \mathrm{~b}$ & $0.17 \mathrm{~b}$ \\
$\mathbf{T}_{\mathrm{SCO}}$ & $5.91 \mathrm{~b}$ & $0.0144 \mathrm{a}$ & $1.97 \mathrm{c}$ & $0.055 \mathrm{c}$ \\
\hline
\end{tabular}

Los valores de cada columna seguidos de letras distintas son significativamente diferentes según el test de Tukey 0.05

Aunque la generalidad de los parámetros evaluados para caracterizar el crecimiento vegetativo del árbol no se vieron afectados significativamente por el tratamiento de riego deficitario controlado, similarmente a lo observado por Franco et al. (2000) en almendros en riego deficitario y con agua de similar calidad, no es menos cierto que éstos mostraron una tendencia a registrar valores menores que en el tratamiento control. Esta tendencia que es acorde con la gran sensibilidad mostrada por este proceso al déficit hídrico (Hsiao, 1973) hace suponer que una mayor duración del período de ensayo podría dar lugar a diferencias entre ambos tratamientos regados. Esta hipótesis estaría en consonancia con la mayor reducción de las tasas de crecimiento de brotes, observada por Hutmacher et al. (1994) en almendros bajo riego deficitario, después de cinco años de aplicación de estas estrategias de riego deficitario.

Por otro lado, y si se tiene en cuenta que durante los cuatro años de estudio no se precisaron prácticas de poda, ya que el objeto fue mantener el desarrollo vegetativo generado para garantizar las máximas posiciones fructíferas para las campañas siguientes, así como las notables diferencias de crecimiento entre los árboles del ensayo y los datos informados por Romero et al. (2004a) y por Nortes et al. (Nortes et al., 2005) para condiciones de cultivo similares, a excepción de la calidad del agua; se hacen presumibles los efectos de la alta salinidad del suelo y agua de riego en el crecimiento y desarrollo de una planta clasificada como sensible a la salinidad (Maas, 1986). Sin embargo, y por tratarse de un proceso de interacción entre dos variables, salinidad y 
agua en el suelo, resulta difícil cuantificar la contribución de cada una de ellas a la respuesta observada en el cultivo (Bresler y Hoffman, 1986).

\section{Crecimiento y desarrollo del fruto}

En los cuatro años de estudio la máxima floración tuvo lugar en la primera quincena de febrero, con un desfase máximo interanual de quince días, de modo que a primeros-mediados de marzo los frutos marcados tenían un diámetro longitud y ecuatorial de aproximadamente $13 \mathrm{~mm}$ y $9.5 \mathrm{~mm}$, respectivamente (Figura 5.20), y un mes más tarde alcanzaban, prácticamente, el tamaño final del fruto, lo que muestra el carácter temprano de esta variedad (Felipe, 2000). Los brotes, al igual que el fruto concluyeron prácticamente su crecimiento a mediados de abril (Figura 5.15), con lo que el estrés hídrico aplicado en $\mathrm{T}_{\mathrm{RDC}}$ no coincidió con el período de crecimiento exterior del fruto ni con el de los brotes en longitud. En la figura 5.2 puede observarse que la aplicación de la reducción del riego en un $30 \%$ de $\mathrm{T}_{\text {CTL }}$ se inició tras completarse ambos crecimientos y que un mes más tarde (finales de mayo) con el comienzo de la acumulación rápida en materia seca del grano se redujo en un $70 \%$, al ser considerado el período comprendido entre este momento y la recolección poco sensible al déficit hídrico (Goldhamer y Shackel, 1989; Girona y Marsal, 1995).

La dinámica de crecimiento del fruto, evaluada en base a la longitud de su pericarpio, tanto medido de forma longitudinal, como ecuatorial, se ajustó a una curva de tipo sigmoidal, con una fase inicial exponencial muy corta, seguida de otra lineal en la que el diámetro aumentó a una tasa constante, para a continuación ralentizar su crecimiento de forma exponencial hasta alcanzar el tamaño final del fruto (Figura 5.20). El patrón de crecimiento en peso seco del grano fue doble sigmoidal, mostrando claramente el inicio de la fase IV o de llenado rápido del grano, lo que resulta de gran interés en la aplicación de estrategias de RDC (Figura 5.20). En ningún momento del período de crecimiento exterior del fruto se dieron diferencias significativas de diámetro de fruto entre tratamientos, independientemente de que se alcanzase un tamaño final u otro según los años. Sin embargo, al analizar la evolución del peso seco de la semilla se observó cómo en $\mathrm{T}_{\mathrm{SCO}}$ tenía lugar una temprana disminución de la velocidad de crecimiento en 2001 y un adelanto de la cosecha de aproximadamente de tres semanas en 2000 respecto a los dos tratamientos regados, tal como muestra la clara estabilización de su peso seco (Figura 5.20) y la manifestación del logro de las condiciones adecuadas para proceder a la cosecha. Ambas situaciones resultaron en un menor peso del grano cosechado (Figura 5.20, y Tabla 5.8). 


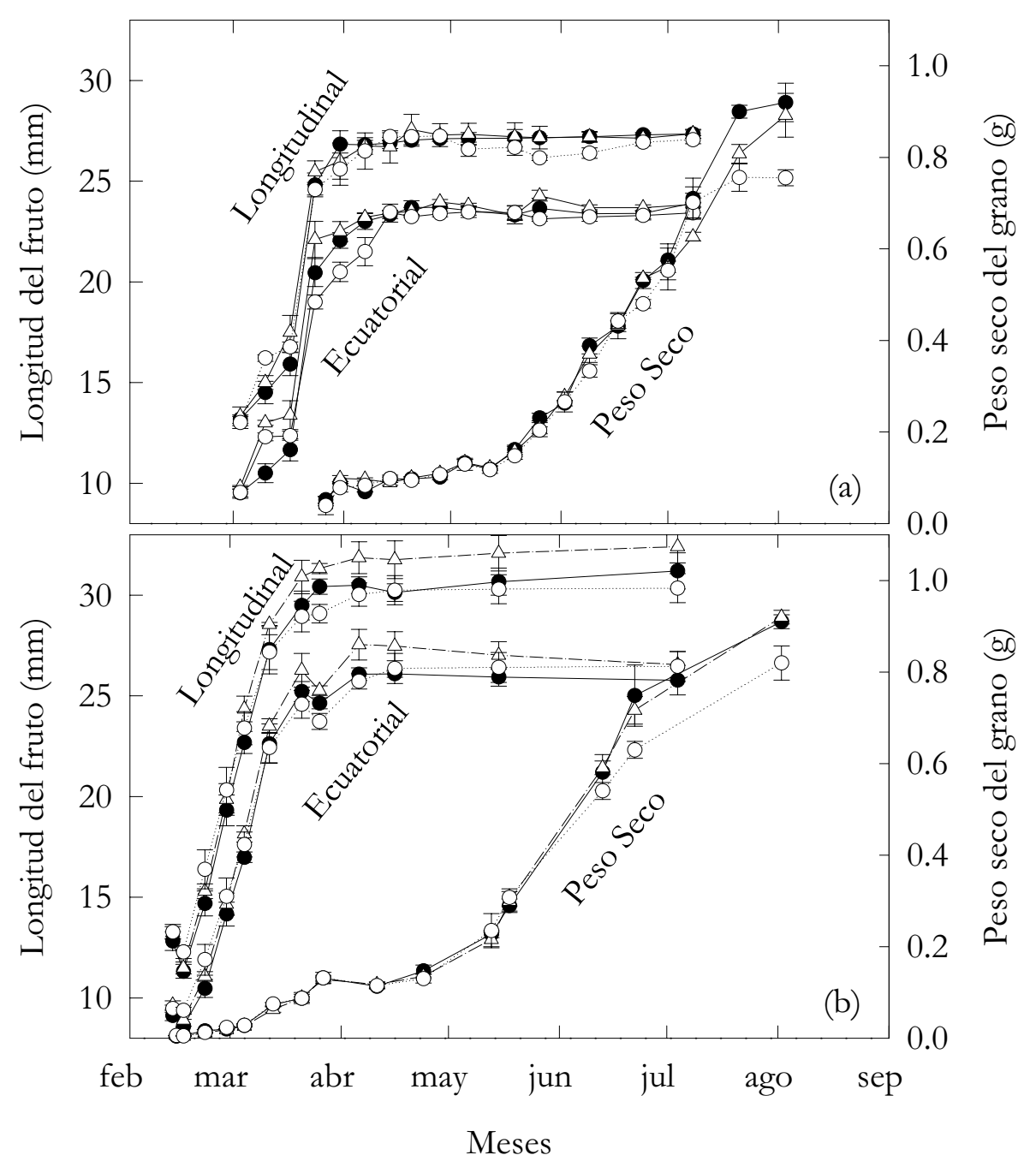

Figura 5.20. Evolución del diámetro longitudinal y ecuatorial de los frutos y en peso seco del grano, para los tres tratamientos $\mathrm{T}_{\mathrm{CTL}}(-\bullet), \mathrm{T}_{\mathrm{RDC}}(\cdots \Delta \cdots)$ y $\mathrm{T}_{\mathrm{SCO}}(-0-)$, durante los años 2000 (a) y 2001 (b). Cada punto corresponde a la media de 3 repeticiones \pm ES.

$\mathrm{T}_{\mathrm{RDC}}$, con diferencias de $\Psi_{\mathrm{a}}$ respecto al control durante todo el período junio-septiembre de 0.2-0.3 $\mathrm{MPa}$, no afectó al peso de la semilla y por tanto al transporte de fotoasimilados al fruto, contrariamente a lo indicado por otros autores tras reducir substancialmente el riego en los dos meses previos a la cosecha (Goldhamer, 1996; Girona et al., 1997). Este hecho diferencial puede derivar de que las comparaciones de medias en este ensayo son con relación a un tratamiento control regado con agua de elevada salinidad y por tanto los efectos derivados de la salinidad podrían haber mitigado los derivados del aporte hídrico diferencial. Sin embargo, disminuciones máximas de $\Psi_{a}$ de 1.1 $\mathrm{MPa}$ respecto al control, generadas por $\mathrm{T}_{\mathrm{SCO}}$, causaron reducciones medias en el peso de la semilla entre el 9 y $12 \%$, reducciones similares a las observadas por (Goldhamer y Shackel, 1989; Goldhamer y Viveros, 2000; Girona et al., 2005) tras suprimir el riego durante los meses de junio y julio. Estos resultados 
indican que incluso bajo estrés hídrico muy severo $\left(\Psi_{\mathrm{a}}<-1.84 \mathrm{MPa}\right.$ en $\left.\mathrm{T}_{\mathrm{SCO}}\right)$ la acumulación de fotoasimilados en la semilla se vio poco alterada, lo que indica la fuerte actividad sumidero que presenta el fruto y la semilla en este período (Romero, 2002). A tenor de los resultados y de acuerdo con Girona y Marsal (1995), se podría decir que no parece recomendable la supresión del riego durante la fase de llenado del grano (Figura 5.9 y Tabla 5.8).

\subsubsection{Producción y componentes}

En las tablas 5.7 y 5.8 se recoge la producción total, componentes de la misma y eficiencia de uso del agua para cada uno de los cuatro años de estudio. En 1999 no se registraron diferencias significativas entre tratamientos ni en la producción total ni en sus componentes, a excepción del peso seco del grano que se vio negativamente afectado por el tratamiento de secano. La ausencia de diferencias entre los tratamientos regados y el de secano pudo deberse a la historia previa de la plantación, caracterizada por un manejo del riego idéntico en toda la plantación, así como por el hecho de que la aplicación de los tratamientos de riego se iniciase el 1 de mayo, cuando ya se había alcanzado el tamaño definitivo del fruto. La reducción del peso del grano como consecuencia de la supresión del riego en $\mathrm{T}_{\mathrm{SCO}}$, durante los meses previos a la cosecha, es consistente con lo indicado por Goldhamer y Shackel (1989) e implica una pérdida de calidad de la almendra.

En las dos cosechas siguientes 2000 y 2001 los efectos de los tratamientos de riego sobre la producción fueron muy estables estadísticamente, independientemente de las producciones alcanzadas. $\mathrm{T}_{\text {CTL }} \mathrm{y}$ $\mathrm{T}_{\mathrm{RDC}}$, sin diferencias significativas entre ellos tanto a nivel de producción como de sus componentes, triplicaron la producción del $\mathrm{T}_{\mathrm{SCO}}$. El tratamiento de secano disminuyó tanto la producción total como el rendimiento en grano y peso seco de éste al aire, y aumentó el número de almendras vacías y pelonas (Tabla 5.8). Los bajos rendimientos cosechados en 2001 pudieron deberse a una polinización defectuosa como consecuencia de los fuertes vientos y lluvias acaecidas durante la floración.

En 2002, un año anómalo en cuanto a la disponibilidad de agua de riego, no se pudo llevar a cabo la aplicación del riego de acuerdo a las estrategias de riego diseñadas, especialmente a partir de junio, momento en el que el agricultor dio prioridad a los cultivos hortícolas de su explotación por encontrarse con frutos en desarrollo y ante la necesidad de asegurar su producción. Sin embargo y a pesar de la práctica supresión del riego a partir de junio (Tabla 5.1), fue el año más productivo del período de estudio (Tabla 5.7), en parte por las buenas condiciones climáticas durante la polinización, la baja producción de 2001 y posiblemente y no menos importante porque el manejo del riego durante los tres años anteriores contribuyó al mantenimiento 
de la capacidad productiva de los árboles. La figura 5.17 muestra el desigual crecimiento de brotes de 2000 y 2001, siendo el de éste último año muy superior al anterior. Es presumible que las buenas producciones relativas de 2002 derivasen del mayor crecimiento de brotes de 2001 al asegurar un buen número de posiciones fructíferas para 2002, además de las condiciones de medio ya indicadas. Estos resultados reafirman el hecho sobradamente conocido de que la producción del almendro es el resultado de un ciclo de desarrollo de 2 años y que los posibles efectos de la reducción o privación de agua en el año en curso pueden no verse reflejados en la cosecha del año y si tener una marcada influencia en la cosecha del año siguiente (Girona y Marsal, 1995).

Tabla 5.7. Producción total y rendimiento en grano y aparente del agua (EUA, kg de almendra cáscara por $\mathrm{m}^{3}$ de agua de riego más lluvia).

\begin{tabular}{|c|c|c|c|c|}
\hline Año & Trat. & $\begin{array}{c}\text { Producción en grano } \\
\left(\mathrm{kg} \mathrm{ha}^{-1}\right)\end{array}$ & Rendimiento (\%) & $\operatorname{EUA}\left(\mathrm{kg} \mathrm{m}^{-3}\right)$ \\
\hline \multirow{3}{*}{1999} & $\mathrm{~T}_{\text {CTL }}$ & $522 \mathrm{a}$ & $33.8 \mathrm{a}$ & $0.25 \mathrm{~b}$ \\
\hline & $\mathrm{T}_{\mathrm{RDC}}$ & $611 \mathrm{a}$ & $33.0 \mathrm{a}$ & $0.48 \mathrm{a}$ \\
\hline & $\mathrm{T}_{\text {sco }}$ & $482 \mathrm{a}$ & $34.4 \mathrm{a}$ & $0.49 \mathrm{a}$ \\
\hline \multirow{3}{*}{2000} & $\mathrm{~T}_{\text {CTL }}$ & $898 \mathrm{a}$ & $37.8 \mathrm{a}$ & $0.33 \mathrm{~b}$ \\
\hline & $\mathrm{T}_{\mathrm{RDC}}$ & $928 \mathrm{a}$ & $38.1 \mathrm{a}$ & $0.47 \mathrm{a}$ \\
\hline & $\mathrm{T}_{\text {sco }}$ & $310 \mathrm{~b}$ & $33.5 \mathrm{~b}$ & $0.39 \mathrm{ab}$ \\
\hline \multirow{3}{*}{2001} & $\mathrm{~T}_{\text {CTL }}$ & 516 a & $33.1 \mathrm{a}$ & $0.22 \mathrm{a}$ \\
\hline & $\mathrm{T}_{\mathrm{RDC}}$ & $420 \mathrm{a}$ & $32.3 \mathrm{ab}$ & $0.31 \mathrm{a}$ \\
\hline & $\mathrm{T}_{\text {sco }}$ & $171 \mathrm{~b}$ & $30.5 \mathrm{~b}$ & $0.24 \mathrm{a}$ \\
\hline \multirow{3}{*}{2002} & $\mathrm{~T}_{\mathrm{CTL}}$ & $1163 \mathrm{a}$ & $39.0 \mathrm{a}$ & $0.77 \mathrm{~b}$ \\
\hline & $\mathrm{T}_{\mathrm{RDC}}$ & $1215 \mathrm{a}$ & $37.3 \mathrm{a}$ & $1.10 \mathrm{a}$ \\
\hline & $\mathrm{T}_{\mathrm{sco}}$ & $533 \mathrm{~b}$ & $34.3 \mathrm{a}$ & $0.86 \mathrm{~b}$ \\
\hline
\end{tabular}

Los valores de cada columna y año seguidos de letras distintas son significativamente diferentes según el test de Tukey 0.05

El peso medio de grano de los tratamientos regados se redujo en $12 \%$ con relación al de los años anteriores, siendo éste muy similar al obtenido en idénticos años en $\mathrm{T}_{\mathrm{SCO}}$. De igual modo, se observó una reducción del $9 \%$ en $\mathrm{T}_{\mathrm{SCO}}$ respecto a 2000 y 2001. Ambas reducciones en el peso medio de grano 
inducen a pensar en un efecto combinado de la supresión del riego durante los meses previos a la cosecha y a la mayor carga productiva de 2002, igual tendencia fue observada por (Romero, 2002) en los años más productivos. El mayor número de frutos presentes en el árbol, unido a las escasas reservas de asimilados del árbol, pudo originar una importante competencia por los asimilados fotosintetizados por las hojas en el año en curso, fuente principal de la materia seca que se acumula en el grano (Girona y Marsal, 1995), afectando a la calidad del mismo.

En cuanto al análisis de las componentes de la producción es de destacar que el $\mathrm{T}_{\mathrm{RDC}}$ no afectó a ninguna de las componentes controladas y que tan sólo en uno de los cuatro años de estudio el número de almendras dobles y vacías se vio disminuido y aumentado, respectivamente, por efecto de $\mathrm{T}_{\mathrm{SCO}}$. Sin embargo, el número de pelonas mostró una clara tendencia al aumento con la supresión del riego, registrándose diferencias significativas en tres de los cuatro años de estudio (Tabla 5.8), lo que supone una merma de calidad del producto cosechado.

Tabla 5.8. Componentes de la producción durante el período experimental 1999-2002.

\begin{tabular}{|c|c|c|c|c|c|}
\hline \multirow[t]{2}{*}{ Año } & \multirow{2}{*}{ Trat. } & \multirow{2}{*}{$\begin{array}{c}\text { Peso seco del grano } \\
\text { (g) }\end{array}$} & Dobles & Vacías & Pelonas \\
\hline & & & \multicolumn{3}{|c|}{$(\%)$} \\
\hline \multirow[t]{3}{*}{1999} & $\mathrm{~T}_{\text {CTL }}$ & $0.97 \mathrm{a}$ & $17.3 \mathrm{a}$ & $0.90 \mathrm{a}$ & $1.33 \mathrm{a}$ \\
\hline & $\mathrm{T}_{\mathrm{RDC}}$ & $0.98 \mathrm{a}$ & $17.8 \mathrm{a}$ & $3.91 \mathrm{a}$ & $2.26 \mathrm{a}$ \\
\hline & $\mathrm{T}_{\mathrm{sco}}$ & $0.90 \mathrm{~b}$ & $16.2 \mathrm{a}$ & $2.18 \mathrm{a}$ & $4.26 \mathrm{a}$ \\
\hline \multirow[t]{3}{*}{2000} & $\mathrm{~T}_{\text {CTL }}$ & $0.99 \mathrm{a}$ & $21.3 \mathrm{a}$ & $1.97 \mathrm{a}$ & $1.39 \mathrm{a}$ \\
\hline & $\mathrm{T}_{\mathbf{R D C}}$ & $0.98 \mathrm{a}$ & $17.9 \mathrm{a}$ & $1.82 \mathrm{a}$ & $2.13 \mathrm{a}$ \\
\hline & $\mathrm{T}_{\mathrm{sco}}$ & $0.83 \mathrm{~b}$ & $10.5 \mathrm{~b}$ & $4.81 \mathrm{~b}$ & $5.71 \mathrm{~b}$ \\
\hline \multirow[t]{3}{*}{2001} & $\mathrm{~T}_{\mathrm{CTL}}$ & $1.00 \mathrm{a}$ & $8.15 \mathrm{a}$ & $1.27 \mathrm{a}$ & $0.86 \mathrm{a}$ \\
\hline & $\mathrm{T}_{\mathbf{R D C}}$ & $1.07 \mathrm{a}$ & $7.97 \mathrm{a}$ & $2.26 \mathrm{a}$ & $3.95 \mathrm{a}$ \\
\hline & $\mathrm{T}_{\mathrm{sco}}$ & $0.85 \mathrm{~b}$ & $11.6 \mathrm{a}$ & $3.77 \mathrm{a}$ & $15.4 \mathrm{~b}$ \\
\hline \multirow[t]{3}{*}{2002} & $\mathrm{~T}_{\mathrm{CTL}}$ & $0.87 \mathrm{a}$ & $9.69 \mathrm{a}$ & $1.39 \mathrm{a}$ & $2.52 \mathrm{a}$ \\
\hline & $\mathrm{T}_{\mathrm{RDC}}$ & $0.88 \mathrm{a}$ & $11.16 \mathrm{a}$ & $2.83 \mathrm{a}$ & $5.59 \mathrm{a}$ \\
\hline & $\mathrm{T}_{\mathrm{sCo}}$ & $0.78 \mathrm{a}$ & $15.1 \mathrm{a}$ & $2.23 \mathrm{a}$ & $28.11 \mathrm{~b}$ \\
\hline
\end{tabular}

Los valores de cada columna y año seguidos de letras distintas son significativamente diferentes según el test de Tukey0.05 
La producción media obtenida en $\mathrm{T}_{\mathrm{RDC}}$ fue del orden del $56 \%$ a la lograda por Girona et al. (2005) con 'Ferragnes' bajo riego deficitario controlado, agua de buena calidad y aportes hídricos (riego+lluvia) 1.5 superiores a los de $\mathrm{T}_{\mathrm{RDC}}$. Bajo condiciones climáticas similares, distancia entre fincas aproximadamente $15 \mathrm{~km}$, y para almendros 'Cartagenera' con idéntico diámetro de tronco a los del ensayo, Romero (2002) obtuvo un $30 \%$ más de producción a partir de un tratamiento de $\mathrm{RDC}$ regado con agua de $\mathrm{CE}_{25^{\circ} \mathrm{C}}=$ $1.3 \mathrm{dS} \mathrm{m}^{-1}$ y que recibió volúmenes de riego equivalentes 2.2 veces a los de $\mathrm{T}_{\mathrm{RDC}}$. Contrariamente, y para dotaciones hídricas, calidad del agua $\mathrm{y}$ condiciones de clima y desarrollo del árbol similares a las de $\mathrm{T}_{\mathrm{RDC}}$, Franco et al. (2000) obtuvieron rendimientos del orden del $25 \%$ inferiores a los $\mathrm{T}_{\mathrm{RDC}}$ en los cultivares 'Cartagenera' y 'Ramillete' y similares en 'Atocha'. Estos resultados coincidentes, en cierta medida, con los informados por Franco et al. (2000), corroboran el efecto negativo de la salinidad del agua de riego sobre la producción potencial del almendro. Sin embargo, los rendimientos obtenidos, en ambos tratamientos regados, fueron superiores a los esperados para la salinidad presente en el agua y suelo. Cabría pensar en la buena adaptación relativa de esta variedad autóctona al estrés hídrico (déficit hídrico más estrés osmótico), lo que le permitiría utilizar más eficazmente el agua disponible.

En la generalidad del período de estudio el tratamiento de riego deficitario controlado mejoró substancialmente la eficiencia de uso del agua (Tabla 5.7), sin que se diesen mermas de producción ni de calidad de la almendra cosechada (Tablas 5.7 y 5.8). Bajo el supuesto que $\mathrm{T}_{\mathrm{RDC}}$ presentase idénticos caracteres de estabilidad y sostenibilidad que $\mathrm{T}_{\text {CTL }}$, su validación hubiese requerido una mayor duración de los ensayos, su mayor eficiencia le convertiría en una estrategia de riego de gran interés bajo las condiciones de cultivo de la zona.

\subsection{Conclusiones}

Bajo las condiciones de ensayo se ha puesto de manifiesto la efectividad de las lluvias en el lavado de las sales del suelo; así como la importante cantidad de lluvia necesaria para reducir el contenido salino del mismo en la profundidad radicular. Por ello, sería recomendable mantener un elevado contenido de agua en el suelo en épocas de baja demanda evaporante y de alta probabilidad de lluvias, ya que éstas generalmente van a ser insuficientes para completar la lixiviación de las sales presentes.

Durante el período experimental los valores de potencial matricial, contenido de agua en el suelo, potencial hídrico foliar y de tallo y conductancia foliar fueron indicativos de diferencias consistentes en el estado hídrico del suelo y la planta en los distintos tratamientos. 
En el período menos crítico, fase de llenado del grano (junio-agosto), y por lo tanto más aconsejable para el ahorro de agua, diferencias en el estado hídrico de los árboles respecto al control entre $0.2-0.3 \mathrm{MPa}$ en $\Psi_{\text {a }}$ y 0.5-0.6 $\mathrm{MPa}$ en $\Psi_{\mathrm{md}}$, equivalentes a un ahorro de agua del $50 \%$, no afectaron a la producción ni a sus componentes. Sin embargo, se observó una tendencia general de reducción del crecimiento vegetativo en los árboles RDC respecto a los del tratamiento control.

En condiciones de secano árido, las evoluciones de las diferencias en $\Psi_{\text {a }}$ y $\Psi_{\text {md }}$ respecto al control son muy similares. Valores de $0.5 \mathrm{MPa}$ desde primeros de junio y su aumentó gradualmente hasta finales de julio (1.1 MPa), para posteriormente mantenerse en torno a $0.75 \mathrm{MPa}$, disminuyen el crecimiento y producción total. Ésta última, como consecuencia del menor número de frutos, disminución del rendimiento y peso seco del grano y aumento del número de pelonas; características que conllevan la depreciación del valor comercial de la almendra. El estrés hídrico generado con $\mathrm{T}_{\mathrm{SCO}}$ puede catalogarse de severo.

Independientemente de que las mayores diferencias de $\Psi_{1}$, en valor absoluto y entre tratamientos, se registrasen en las medidas realizadas a mediodía; $\Psi_{\mathrm{a}}$ se considera mejor indicador del estado hídrico del almendro que $\Psi_{\text {md }}$ debido a que las mayores diferencias relativas tienen lugar en las medidas realizadas antes del alba. De igual modo, $\Psi_{\mathrm{t}}$ a mediodía se ha revelado como un indicador más útil que $\Psi_{\mathrm{md}}$ con fines de diagnóstico del estado hídrico del almendro. A mediodía y en días típicos de verano, los valores de $\Psi_{\mathrm{t}}$ superaban en $0.5-0.7 \mathrm{MPa}$ a los de $\Psi_{\mathrm{md}}$, dependiendo del tratamiento de riego.

La disminución del $\Psi_{\text {o }}$ en respuesta a la mayor edad de las hojas e incremento del estrés hídrico y salino, permitió que $\Psi_{\mathrm{p}}$ en los tratamientos regados permaneciera constante o incluso que aumentará, compensando así las reducciones de $\Psi_{1}$. Así mismo, el aumento del contenido en cloruros en hojas con el avance de la estación de riegos presentó una alta correlación con la disminución del $\Psi_{\mathrm{o}}$ en los tratamientos regados. De modo que, tanto el $\mathrm{Na}^{+}$como $\mathrm{Cl}^{-}$acumulado en hojas contribuyen a los procesos de ajuste osmótico de almendros cultivados en suelos salinos.

La débil correlación existente entre $\Psi_{\mathrm{o}}$ y $\left[\mathrm{Cl}^{-}\right]$en hojas de los árboles de secano pudo deberse a que ya en mayo el potencial osmótico foliar se encontrase muy próximo al máximo nivel posible de acumulación de solutos y que un aumento en la intensidad de estrés hídrico por sequía osmótica ocasionase pérdidas de solutos invirtiendo el ajuste osmótico. 
Los resultados del ensayo demuestran, claramente, el efecto negativo del riego con agua salina sobre el desarrollo y producción del almendro. Sin embargo, los rendimientos obtenidos, en ambos tratamientos regados, fueron superiores a los esperados para la salinidad presente en el agua y suelo. Cabría pensar en la buena adaptación de esta variedad autóctona al estrés hídrico y salino, lo que le permitiría utilizar más eficazmente el agua disponible. Con reducciones de agua de riego del $50 \%$ de las teóricamente necesarias se consiguieron producciones similares al control. Sin embargo, un mayor período experimental hubiese sido deseado para evaluar los efectos que distintos niveles salinos en planta pueden generar a más largo plazo.

A modo de resumen se puede concluir que las relaciones hídricas del almendro se ven negativamente afectadas por la sequía y la salinidad. Y que los mecanismos desarrollados por el almendro para afrontar los periodos de sequía en condiciones de alta salinidad se basan en: (i) la disminución del potencial hídrico foliar, al objeto de generar un mayor gradiente de potencial hídrico entre el suelo y la hoja, y de este modo favorecer la absorción de agua, (ii) una temprana regulación estomática, desde las primeras horas del día, permitiéndole una mayor eficiencia en la absorción de $\mathrm{CO}_{2}$ respecto a las pérdidas de agua, (iii) el desarrollo de ajuste osmótico durante la mayor parte de la estación de crecimiento, lo que permite mantener la turgencia celular y compensar las disminuciones de $\Psi_{1}$ y (iv) la disminución del LAI, lo que supone una contribución adicional al mantenimiento de la turgencia, ya que al disminuir el ratio brotes/raíz se reduce la tasa transpirativa para idéntica demanda evaporante. 



\section{Estudio de la sensibilidad de indicadores biológicos en la caracterización del estado hídrico del árbol}





\subsection{Introducción}

El conocimiento del estado hídrico del cultivo y su respuesta fisiológica, tanto a distintas dotaciones hídricas como a los cambios rápidos de disponibilidad de agua en el suelo, es clave para una programación eficiente del riego, especialmente cuando se aplican estrategias de riego deficitario controlado.

A nivel de explotación comercial, los métodos más utilizados de programación del riego son los basados en balances hídricos simulados y en el estado energético del agua en el suelo. Los métodos basados en medidas directas o indirectas del estado hídrico de la planta y de su respuesta fisiológica al régimen hídrico contrastan claramente con los anteriores (Jones, 2004; 2007), al integrar ésta las condiciones del entorno, clima y suelo a la vez.

Aunque son muchos los trabajos de investigación que demuestran la utilidad de los indicadores del estado hídrico de la planta: potencial hídrico foliar al alba $\left(\Psi_{2}\right)$ y potencial de hoja cubierta a mediodía, que estima el potencial hídrico de tallo $\left(\Psi_{t}\right)$, para determinar el estado hídrico del árbol y con fines de programación de riegos (McCutchan y Shackel, 1992; Shackel et al., 1997; Naor et al., 2001), la realidad es que han tenido una escasa aplicación a nivel de finca comercial. En parte debido al inconveniente de tener que realizar las medidas de $\Psi_{a}$ antes del amanecer o por la necesidad de cubrir las hojas 2 o 3 horas antes de las medidas de $\Psi_{t}$, requiriendo ambos de varios viajes a las fincas y de mano de obra capacitada.

Los avances tecnológicos recientes permiten utilizar indicadores alternativos a $\Psi_{\text {a }}$ y $\Psi_{\mathrm{t}}$ para evaluar el estado hídrico del árbol, tales como los derivados del registro automático de las variaciones continuas de diámetro de tronco. La máxima contracción diaria (MCD) y la tasa de crecimiento diaria de tronco (TCD), ésta última principalmente en árboles jóvenes, son los dos parámetros que mayor interés están suscitado con fines de programación de riegos debido a su respuesta a los cambios de humedad en el suelo (Goldhamer et al., 2000; Cohen et al., 2001; Moriana y Fereres, 2002; Remorini y Massai, 2003; Ortuño et al., 2004; Nortes et al., 2005) y por su relación con los parámetros discretos anteriormente citados (Goldhamer et al., 2000; Naor y Cohen, 2003; Intrigliolo y Castel, 2004). Sin embargo, antes de ser utilizados en la programación del riego es conveniente estudiar su sensibilidad y variabilidad a los cambios de contenido de humedad bajo las condiciones de cultivo que se pretenden.

Actualmente varios grupos de investigación trabajan con este tipo de biosensores en agricultura, y los esfuerzos están dirigidos al control y 
optimización del riego. La idea fundamental consiste en utilizar a la planta como sensor de sus propias necesidades. Sin embargo, la aplicación práctica de dichos sensores no es sencilla y su puesta a punto requiere de la utilización de sensores de clima, suelo y planta que proporcionen la información necesaria para el establecimiento de valores umbrales o consigna (Baille, 1992). Además, los protocolos de riego propuestos (Intrigliolo y Castel, 2006; Moreno et al., 2006; Ortuño et al., 2006b; García-Orellana et al., 2007; Vélez et al., 2007) son muy específicos de la especie, edad y estado fenológico.

Por todo ello, se plantearon dos ensayos: uno con almendros jóvenes no productivos y otro al inicio de su entrada en producción. El propósito principal de ambos ensayos fue determinar y comparar la sensibilidad de distintos indicadores de estrés hídrico en planta a los cambios de disponibilidad de agua en el suelo.

\subsection{Materiales y métodos}

\section{Material vegetal y condiciones experimentales}

Los ensayos se realizaron durante el periodo 2002-2004 en la parcela experimental de almendros 'Marta' descrita en el Capitulo IV y cuya secuencia de crecimiento y desarrollo aparente se recoge en la (Figura 6.1).

Las evoluciones de valores de las variables climáticas: temperatura, pluviometría y evapotranspiración de referencia reinantes durante el periodo de estudio aparecen representadas en la figura 6.2. 

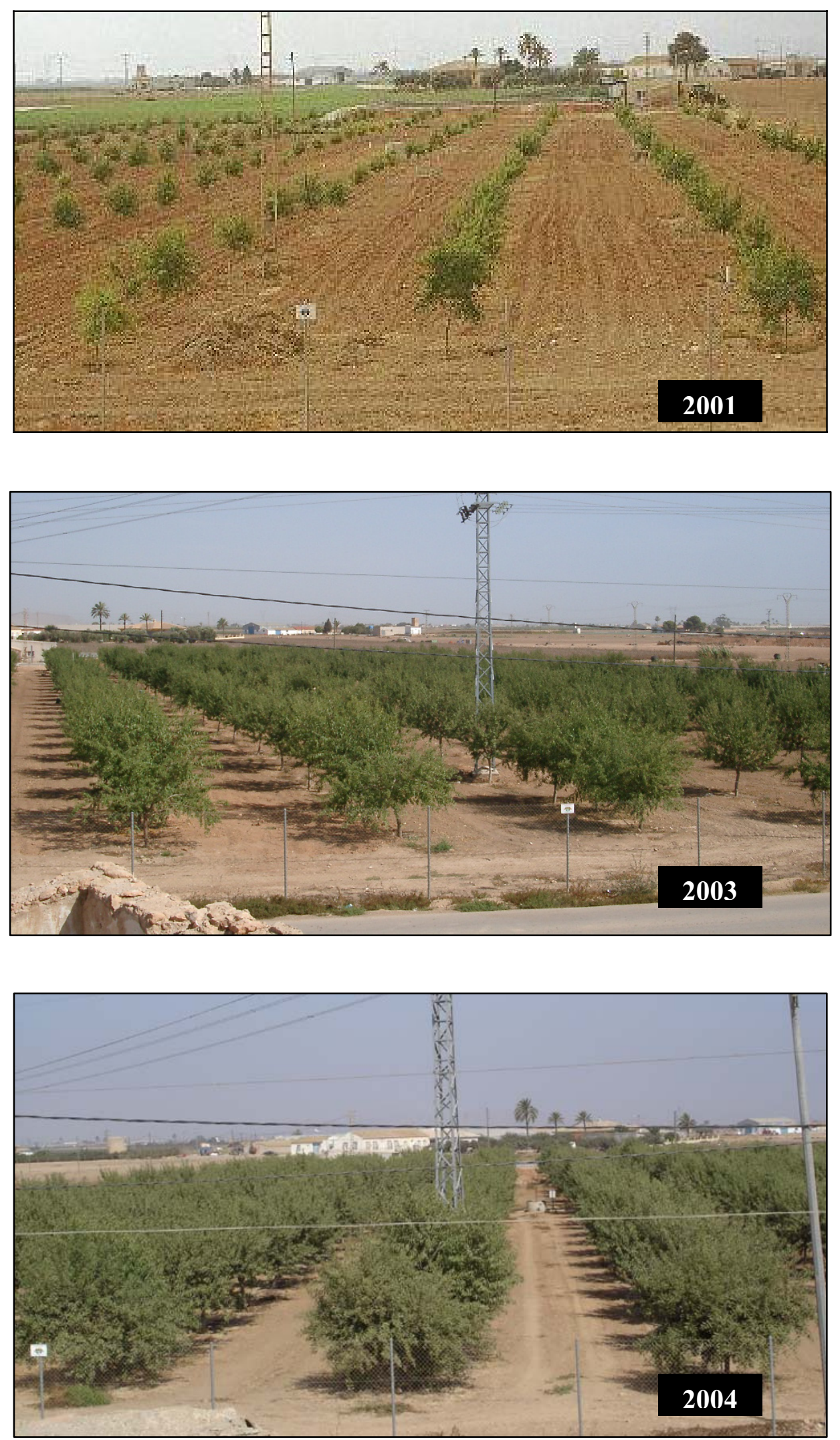

Figura 6.1. Vista general y evolución de la parcela experimental de almendros (ETSIAUPCT) durante el periodo de estudio. 


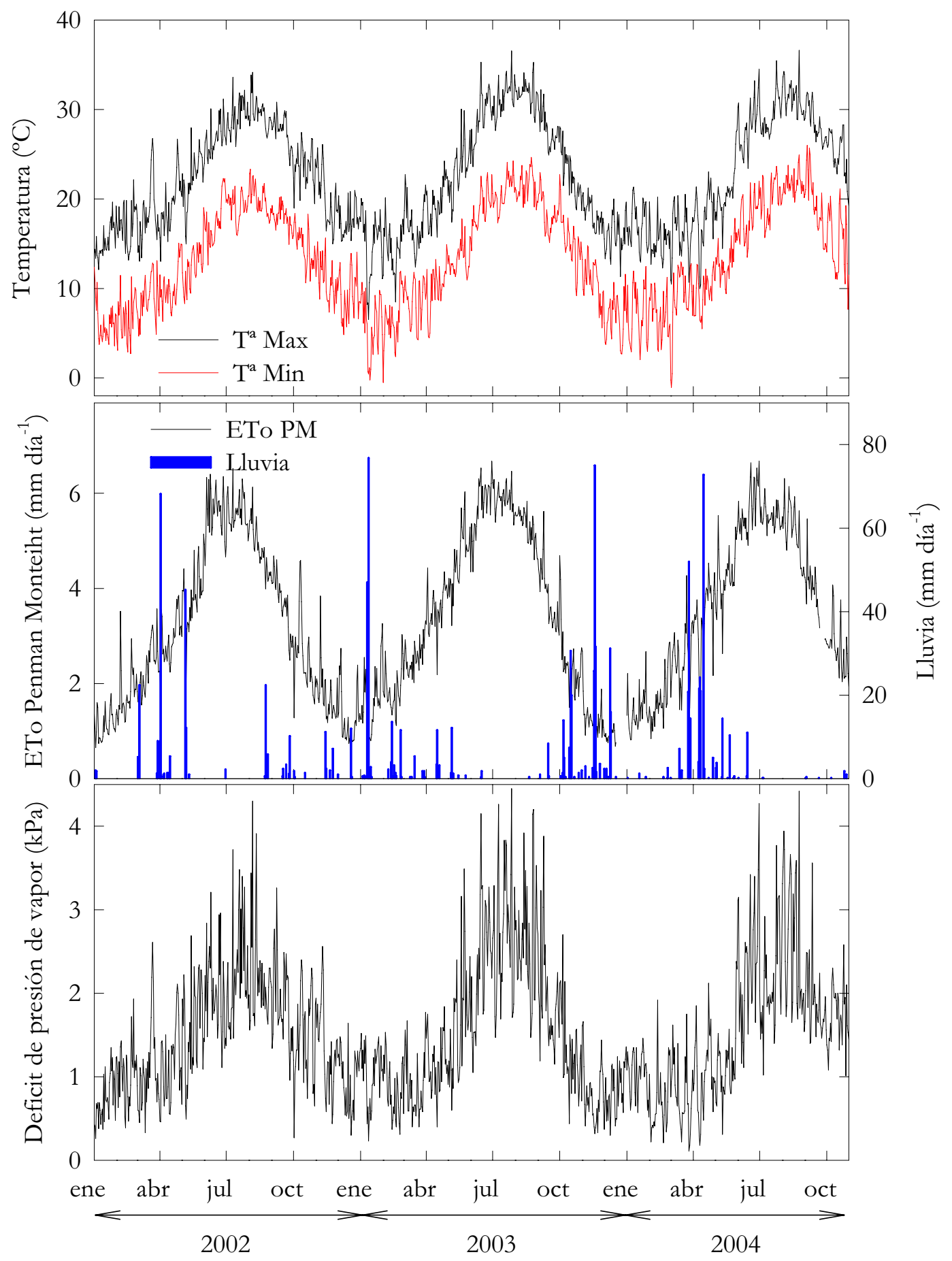

Figura 6.2. Valores diarios de temperatura máxima y mínima, pluviometría, evapotranspiración de referencia de Penman Monteith, déficit de presión de vapor máximo en la parcela experimental durante 2002-2004. 


\section{Medidas}

\section{Agua-Planta}

Se evaluó, con cámara de presión (Soil Moisture Equip. Corp, model 3000), el potencial hídrico foliar al alba $\left(\Psi_{a}\right)$ y mediodía $\left(\Psi_{\mathrm{md}}\right)$ y potencial de tallo a mediodía $\left(\Psi_{t}\right)$, y con porómetro (LICOR modelo LI 1600) la conductancia foliar $\left(\mathrm{g}_{\mathrm{j}}\right)$, en 12 hojas adultas por tratamiento. Para la medida del potencial de tallo, se envolvieron las hojas con plástico negro y papel aluminio 2 horas antes de cada medida (capítulo III).

Las fluctuaciones de diámetro de tronco se midieron con dendrómetros LVDT "Linear Variable Differential Transformer" (Solartron modelo DF \pm 2.5 ; $\mathrm{UK}$ ) de forma continua, con una precisión de $\pm 1 \mu \mathrm{m}$ y un recorrido máximo de $5 \mathrm{~mm}$. Para su colocación en el tronco del árbol se utilizaron portasensores formados por dos piezas de aluminio unidas por dos varillas de material invar (aleación de hierro y níquel con un coeficiente de dilatación por temperatura de $\left.1.7 \times 10^{-6}{ }^{\circ} \mathrm{C}^{-1}\right)$. Los sensores fueron colocados a $40 \mathrm{~cm}$ del suelo, en la cara Norte del tronco (6 sensores por tratamiento), las medidas se realizaban cada 10 minutos y fueron registradas con equipos MicroIsis con comunicación GSM RS-485, colocados en la misma parcela experimental (capítulo III). Al inicio del ensayo el diámetro medio de tronco fue de unos $6 \mathrm{~cm}$.

\subsection{Almendros jóvenes no productivos}

\subsubsection{Tratamientos de riego}

Durante el 2002, con árboles en su segundo año de plantación, se ensayaron 3 tratamientos de riego $\mathrm{T}_{\mathrm{CTL}}, \mathrm{T}_{\mathrm{RD} 60} \mathrm{y} \mathrm{T}_{\mathrm{RDC} 40}$ descritos en el capítulo IV. Los volúmenes de agua aplicados a cada uno de los tratamientos fueron de 3167,1524 y $1437 \mathrm{~m}^{3}$ ha $^{-1}$ año ${ }^{-1}$.

\subsubsection{Resultados y discusión}

Los valores del potencial mátrico del agua en el suelo $\left(\Psi_{\mathrm{m}}\right)$ fueron similares en los tres tratamientos de riego hasta mediados de abril. A partir de ese momento se produjo un cambio de pauta, caracterizado en: i) $T_{R D 60}$ por una pronunciada disminución de $\Psi_{\mathrm{m}}$ hasta mediados de mayo y por su mantenimiento prácticamente constante durante el resto de la estación de riego, y ii) $\mathrm{T}_{\mathrm{RDC} 40}$ por valores ligeramente inferiores a los de $\mathrm{T}_{\text {СTL }}$ hasta primeros de junio y por lecturas fuera de rango, en las tres profundidades, durante el periodo de riego al $40 \%$. $\mathrm{T}_{\text {CTL }}$ mantuvo valores medios de -12, -18 y $-23 \mathrm{kPa}$ a 30, 60 y $90 \mathrm{~cm}$ de profundidad respectivamente. Tras la restitución 
del riego al $100 \%$ en $\mathrm{T}_{\mathrm{RDC} 40}$ se alcanzaron valores similares a $\mathrm{T}_{\mathrm{CTL}}$ con una demora de 10, 21 y 45 días para las profundidades de 30, 60 y $90 \mathrm{~cm}$, respectivamente.

En la figura 6.3 se muestra la evolución a lo largo de la estación de riego de los valores medios de $\Psi_{\text {a }}, \Psi_{\text {md }}$ y $\Psi_{\mathrm{t}}$. Los valores de $\Psi_{\text {a }}$ en $\mathrm{T}_{\text {CTL }}$ durante todo el periodo rondaron los $-0.4 \mathrm{MPa}$, niveles similares a los obtenidos por Torrecillas et al. (1996) y Marsal et al. (1997) en almendros bien regados. A partir de mediados de junio en $T_{\mathrm{RD} 60}$ y de julio en $T_{\mathrm{RDC} 40}, \Psi_{\mathrm{a}}$ fue significativamente diferente al control, manteniéndose las diferencias prácticamente constantes hasta finales de septiembre $(\approx 0.13$ y $0.29 \mathrm{MPa}$ respecto al control para $\mathrm{T}_{\mathrm{RD} 60}$ y $\mathrm{T}_{\mathrm{RDC} 40}$, respectivamente). De igual modo, claras diferencias en $\Psi_{\mathrm{a}}$ fueron registradas entre ambos tratamientos deficitarios durante el periodo de mediados de julio a finales de septiembre. La conducta de $\Psi_{\mathrm{t}}$ fue similar a la descrita para $\Psi_{\mathrm{a}}$, aunque con una ligera disminución de los valores relativos al control (Figura 6.3 a). Esta similitud, entre ambos parámetros muestra el interés de $\Psi_{\mathrm{t}}$ a mediodía como indicador del déficit hídrico en almendros jóvenes y, concuerda con la alta sensibilidad de $\Psi_{\mathrm{t}}$ al déficit hídrico observada por Naor et al. (2001) en árboles frutales.

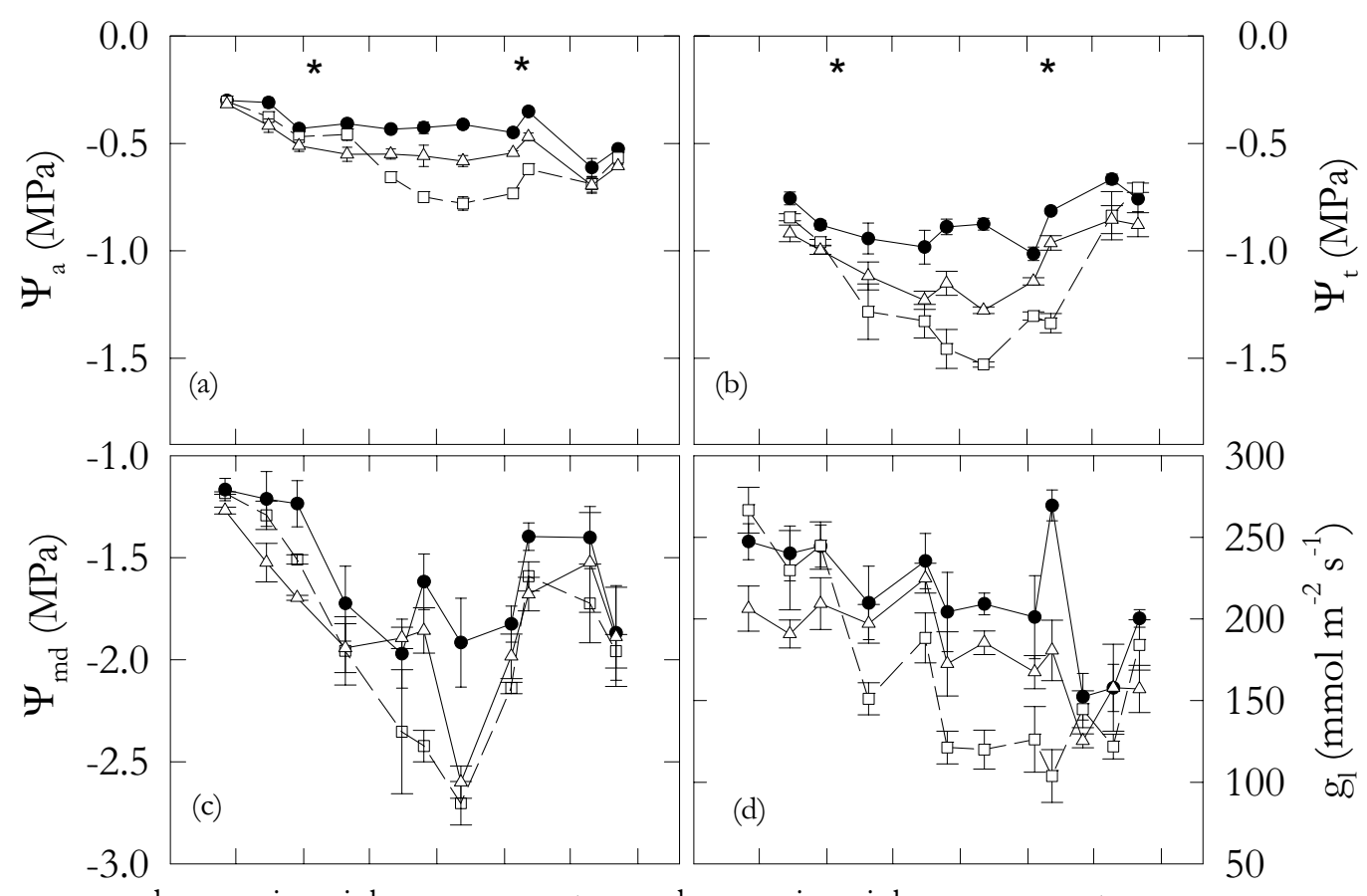

abr may jun jul ago sep oct novabr may jun jul ago sep oct nov

Meses

Figura 6.3. Evolución del potencial hídrico foliar al alba $\left(\Psi_{\text {a }}\right)$, mediodía $\left(\Psi_{\mathrm{md}}\right)$, tallo $\left(\Psi_{\mathrm{t}}\right)$ y conductancia foliar $\left(g_{1}\right)$ en los tres tratamientos de riego, $T_{\text {CTL }}(\longrightarrow), T_{\text {RDC60 }}(-\triangle--)$ y $\mathrm{T}_{\mathrm{RDC} 40}(-\square-\cdot)$. Los puntos corresponden a la media de tres repeticiones \pm ES. Los asteriscos indican el comienzo y final del periodo al $40 \%$ de la ETc en $\mathrm{T}_{\mathrm{RDC} 40}$. 
Los valores de $\Psi_{\mathrm{t}}$ en el tratamiento $\mathrm{T}_{\mathrm{CTL}}$ variaron de -0.66 a $-1.01 \mathrm{MPa}$, niveles similares a los obtenidos por Fereres y Goldhamer (2003) en almendros en condiciones no limitantes de agua en el suelo. Tras la reducción del riego al $40 \%$ en $\mathrm{T}_{\mathrm{RDC} 40}, \Psi_{\mathrm{t}}$ fue más precoz que $\Psi_{\mathrm{a}}$ en detectar diferencias significativas respecto al control (Figuras $6.3 \mathrm{a} \mathrm{y} \mathrm{b).} \mathrm{Por} \mathrm{otro} \mathrm{lado,} \mathrm{las} \mathrm{mayores}$ oscilaciones de $\Psi_{\text {md }}$ encontradas entre tratamientos y dentro del mismo tratamiento no dieron lugar a diferencias significativas claras, excepto durante el mes de agosto. En este mes los valores de $\Psi_{\text {md }}$ descendieron a -1.92, -2.6 y 2.7 MPa en $\mathrm{T}_{\text {CTL }}, \mathrm{T}_{\mathrm{RD} 60}$ y $\mathrm{T}_{\mathrm{RDC} 40}$, respectivamente (Figura $6.3 \mathrm{c}$ ). No se dieron diferencias significativas de $\Psi_{\text {md }}$ entre ambos tratamientos deficitarios.

La conductancia foliar $\left(\mathrm{g}_{\mathrm{I}}\right)$ presentó valores medios de 215 y $180 \mathrm{mmol}$ $\mathrm{m}^{-2} \mathrm{~s}^{-1}$ para $\mathrm{T}_{\text {CTL }}$ y $\mathrm{T}_{\mathrm{RD} 60}$ a lo largo de la campaña de riego y de $136 \mathrm{mmol} \mathrm{m}^{-2}$ $\mathrm{s}^{-1}$ para $\mathrm{T}_{\mathrm{RDC} 40}$ durante el periodo de déficit (Figura $6.3 \mathrm{~d}$ ). Aunque los valores relativos al control fueron muy similares a los de $\Psi_{\mathrm{a}}$ y $\Psi_{\mathrm{t}}$ (Figura 6.3 a y b) tan solo se dieron diferencias significativas entre $\mathrm{T}_{\mathrm{CTL}}$ y $\mathrm{T}_{\mathrm{RDC} 40}$ durante el periodo finales de julio-mediados de septiembre, como consecuencia de la mayor variabilidad de las medidas.

Para ilustrar los datos obtenidos a partir de los sensores LVDT se muestra la media de las fluctuaciones del diámetro de tronco por tratamiento y mes, caracterizado este último por un período de 6 días (Figura 6.4). Se observa com22o la actividad del cambium comienza a finales de febrero, coincidiendo con la máxima floración y la emergencia de nuevos brotes y hojas. La expansión cambial continúa hasta finales de octubre, con un crecimiento relativamente constante hasta últimos de agosto, reducción gradual en septiembre y mínimo crecimiento en octubre, coincidiendo con los primeros síntomas de senescencia de las hojas (Figura 6.4). 


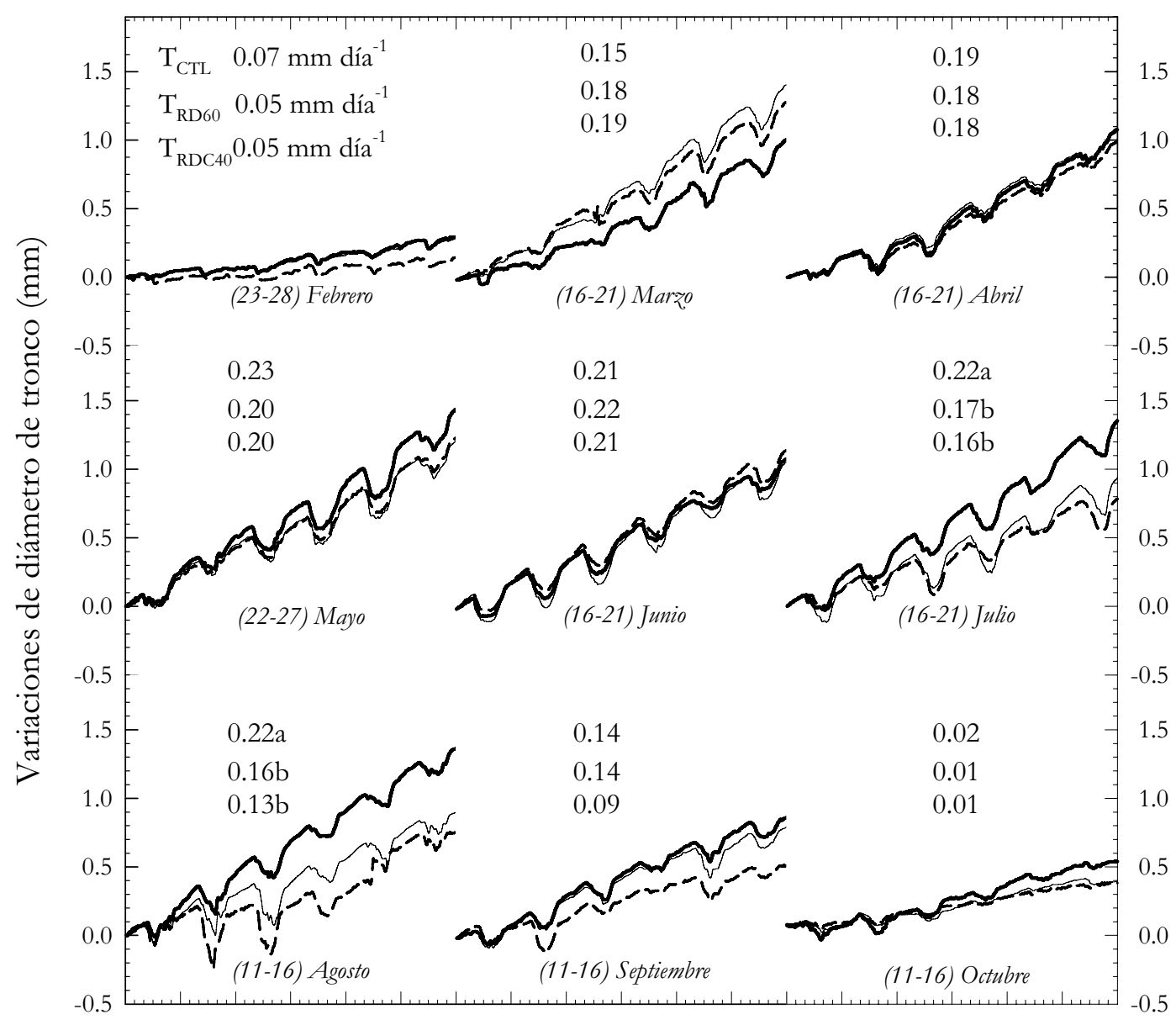

Figura 6.4. Fluctuaciones medias del diámetro de tronco durante la estación de crecimiento para los tres tratamientos de riego: $\mathrm{T}_{\mathrm{CTL}}(-), \mathrm{T}_{\mathrm{RD} 60}(\quad)$ y $\mathrm{T}_{\mathrm{RDC} 40}(--)$. Cada mes está caracterizado por un periodo de seis días. Las columnas numéricas representan la media mensual de crecimiento diario para los diferentes tratamientos. Los valores seguidos de letras distintas son estadísticamente diferentes según el test de Tukey $_{0.05}$.

El crecimiento diario (TCD) de los distintos tratamientos de riego fue prácticamente idéntico durante el periodo marzo-junio, con valores medios mensuales en torno a $0.2 \mathrm{~mm} \mathrm{día}^{-1}$ (Figura 6.4). Una clara reducción de los valores de TCD como consecuencia del régimen de riego fue observada en julio y agosto en $\mathrm{T}_{\mathrm{RD} 60}$, extendiéndose hasta septiembre en $\mathrm{T}_{\mathrm{RDC} 40}$. Durante este periodo de alta demanda evaporativa, los valores de TCD relativos al control fueron muy similares a los de $\Psi_{\text {a }}$ y $\Psi_{\mathrm{t}}$ (Figura 6.5), con diferencias estadísticamente significativas entre los tratamientos control y deficitarios para la generalidad de los días. Sin embargo, no se observaron diferencias significativas entre los tratamientos deficitarios, a excepción de determinados días del mes de septiembre, cuando el $\mathrm{T}_{\mathrm{RD} 60}$ mantuvo un crecimiento similar al $\mathrm{T}_{\mathrm{CTL}}$. 


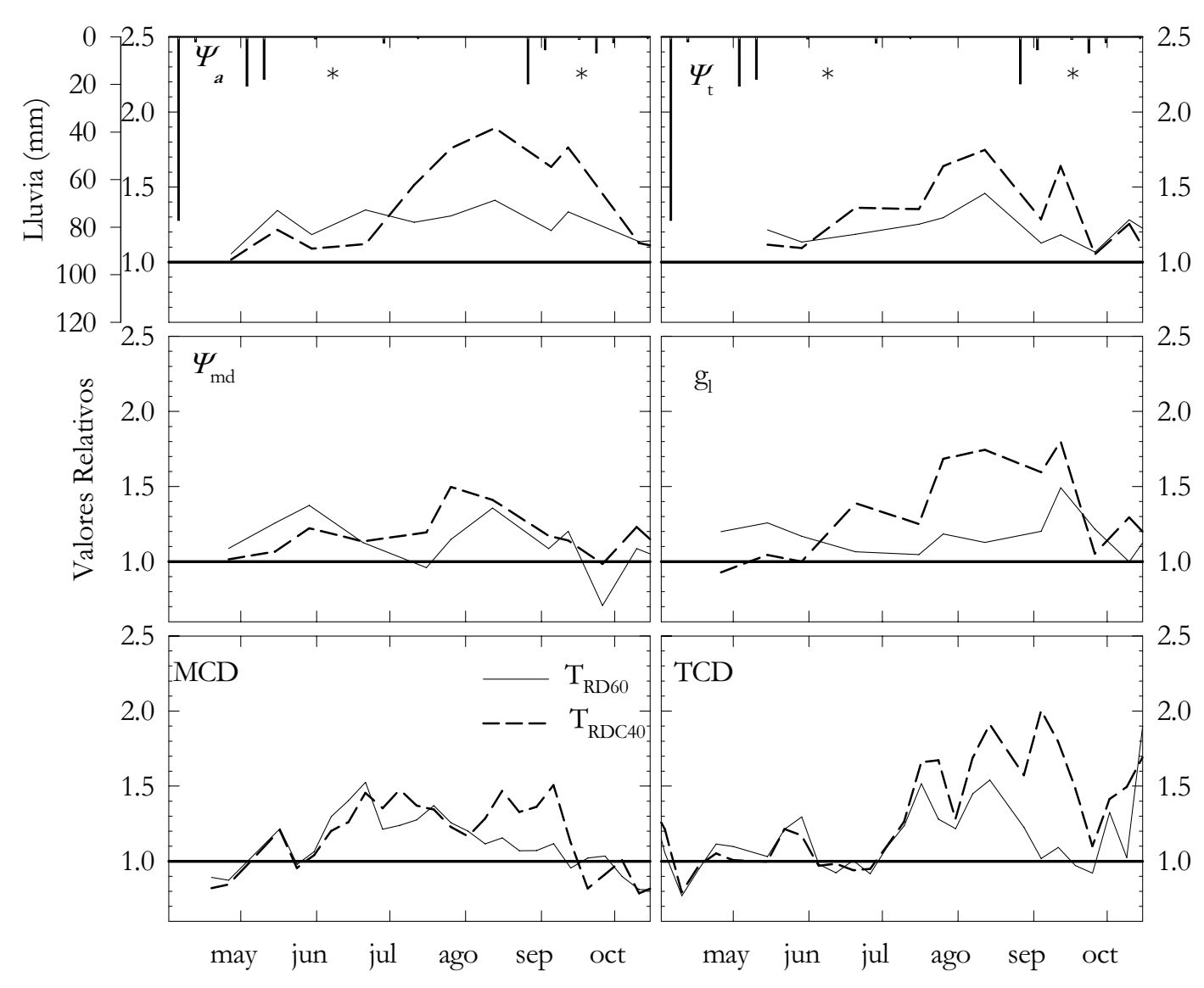

Figura 6.5. Evolución relativa de los parámetros: Potencial hídrico foliar al alba, mediodía y tallo a mediodía, $\Psi_{a}$ y $\Psi_{\text {md }}, \Psi_{t}\left(T_{n} / T_{\text {CTL }}\right)$, conductancia foliar, $g_{1}\left(T_{\text {CTL }} / T_{n}\right)$, máxima contracción diaria, MCD $\left(\mathrm{T}_{\mathrm{n}} / \mathrm{T}_{\text {СТL }}\right)$ y crecimiento diario a partir de los máximos diámetros, TCD $\left(\mathrm{T}_{\mathrm{CTL}} / \mathrm{T}_{\mathrm{n}}\right)$. Los asteriscos indican el inicio y final del periodo al $40 \%$ de la ETc en $\mathrm{T}_{\mathrm{RDC} 40}$.

El crecimiento total del tronco fue mayor en el tratamiento control que en los deficitarios. Los valores medios del incremento anual del diámetro de tronco en base a los sensores LVDT fueron de 41.6; 37.0 y $33.2 \mathrm{~mm}$ para $\mathrm{T}_{\mathrm{CTL}}, \mathrm{T}_{\mathrm{RD} 60}$ y $\mathrm{T}_{\mathrm{RDC} 40}$ respectivamente, lo que supuso una reducción de diámetro del 11 y $20 \%$ para $\mathrm{T}_{\mathrm{RD} 60}$ y $\mathrm{T}_{\mathrm{RDC} 40}$, respectivamente (Figura 6.6).

La evolución de la MCD mostró un aumento progresivo de sus valores desde principios de marzo hasta mediados de junio, una relativa estabilización durante los meses de verano y disminución de los mismos a partir de septiembre (Figura 6.7). El aumento progresivo de la MCD fue coincidente con el crecimiento en longitud de los brotes (aumento del área foliar) e incremento de la temperatura y de la transpiración en esta época del año. Ginestar y Castel (1996) en mandarinos jóvenes y Huguet et al. (1992) en manzanos encontraron un efecto similar. Además, tanto MCD como $\Psi_{t}$ estuvieron bien correlacionada con la ETo, para el tratamiento control, con 
coeficientes de correlación de $0.69^{* * *}$ y $0.91^{* * *}$, respectivamente, alcanzando los valores más altos con la mayor demanda climática (Figura 6.7 y 6.8).

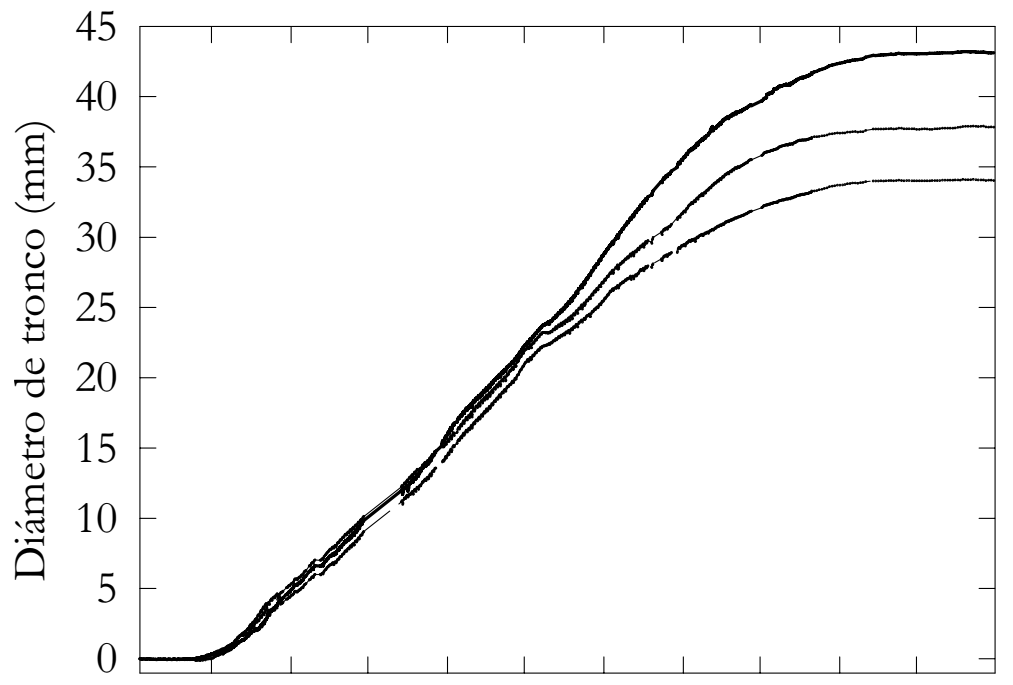

feb mar abr may jun jul ago sep oct nov dic

Figura 6.6. Evolución anual del diámetro de tronco en los distintos tratamientos de riego, $\mathrm{T}_{\mathrm{CTL}}(-), \mathrm{T}_{\mathrm{RD} 60}(-)$ y $\mathrm{T}_{\mathrm{RDC} 40}(--)$.

Durante el periodo junio-agosto, la conducta observada en los dos tratamientos deficitarios fue la de presentar valores superiores de MCD que el control (Figura 6.7), aunque las diferencias no fueron significativas en la generalidad de los días. La alta variabilidad de las determinaciones pudo ser la causa de ello, así y durante el periodo de crecimiento los coeficientes de variación oscilaron entre 10 y $35 \%$ para los tres tratamientos, valores similares a los encontrados por Ginestar y Castel (1996).

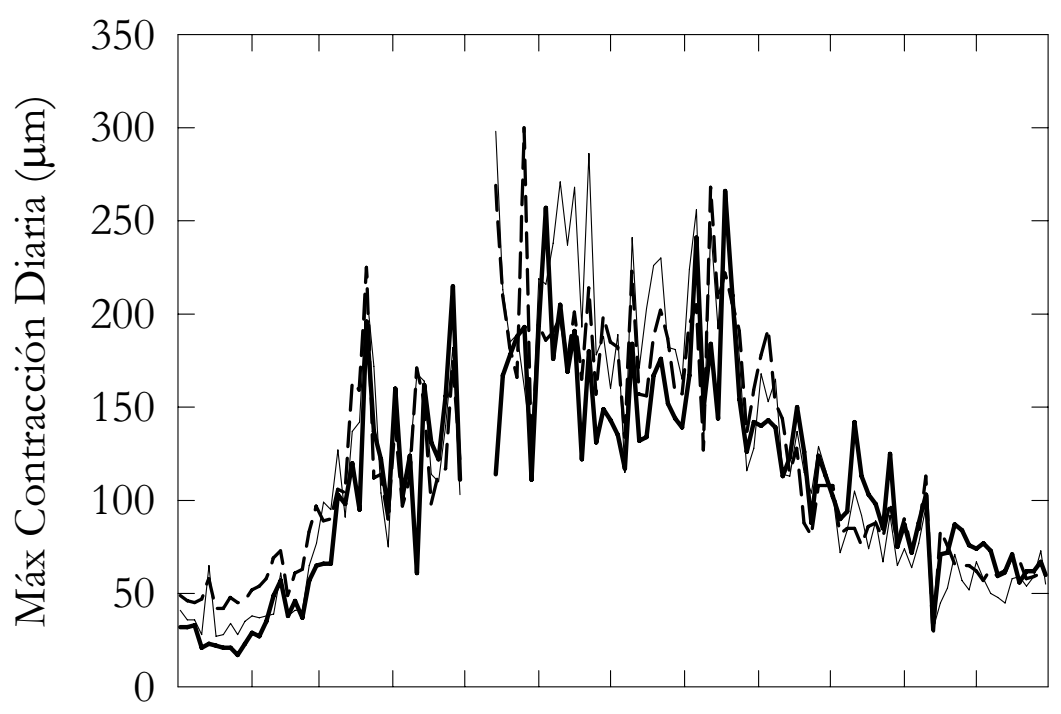

ene febmar abrmay jun jul ago sep oct nov dic

Figura 6.7.- Evolución de la máxima contracción diaria para los diferentes tratamientos de riego, $\mathrm{T}_{\mathrm{CTL}}(-), \mathrm{T}_{\mathrm{RD} 60}(\longrightarrow)$ y $\mathrm{T}_{\mathrm{RDC} 40}(--)$. 
El análisis de las evoluciones de TCD y MCD mostró una pauta más claramente relacionada con el desarrollo del estrés hídrico para TCD que para MCD. El cambio de tendencia al aumento de la relación $\left(\mathrm{T}_{\mathrm{CTL}} / \mathrm{T}_{\mathrm{n}}\right)$ de TCD en los tratamientos deficitarios coincidió con valores de $\Psi_{\mathrm{a}}$ y $\Psi_{\mathrm{t}}$ en torno a -0.55 y $-1.2 \mathrm{MPa}$ respectivamente (Figura 6.3 y 6.5). Estos valores de potencial hídrico fueron significativamente diferentes a los del control $(\approx-0.4$ y -0.93 $\mathrm{MPa} \Psi_{\mathrm{a}}$ y $\Psi_{\mathrm{t}}$; Figura 6.3).

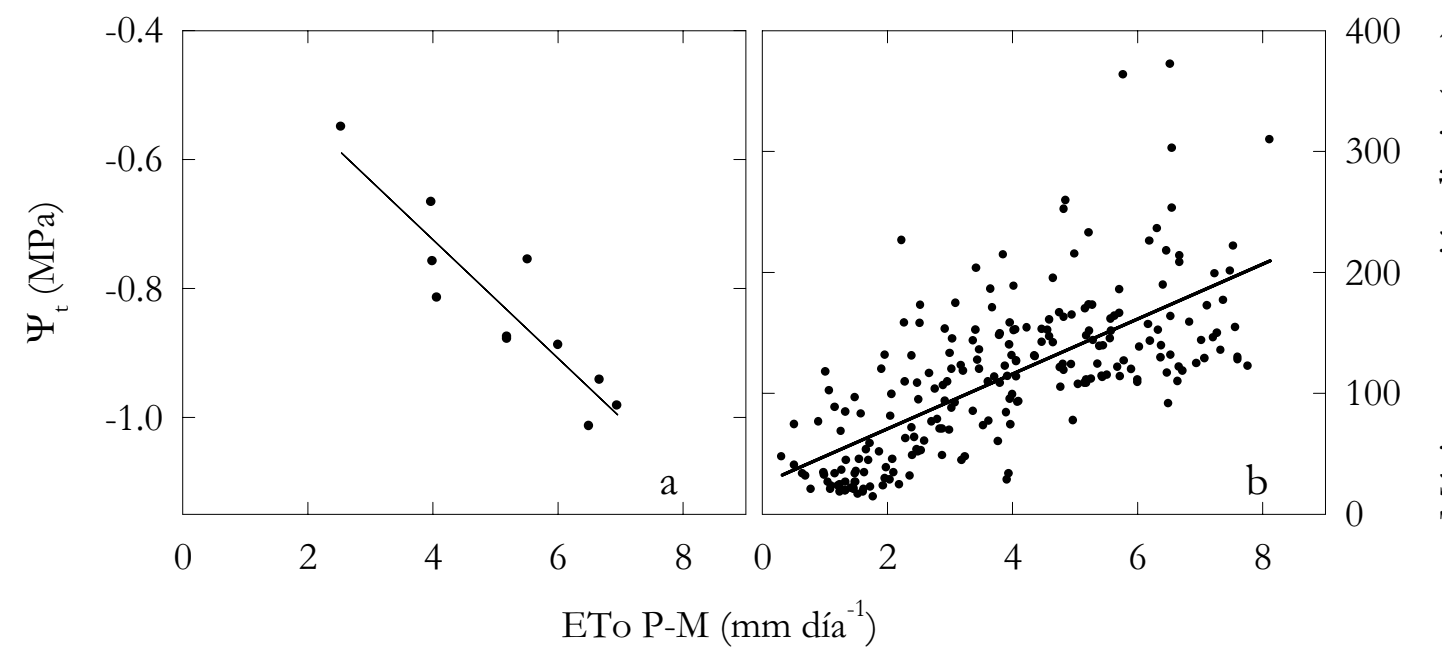

Figura 6.8.- Relaciones del potencial de tallo a mediodía $\left(\Psi_{t}\right)$ y máxima contracción diaria (MCD) y la evapotranspiración de referencia Penman Monteith (ETo) para el tratamiento control. $\Psi_{\mathrm{t}}=-0.091$ ETo $-0.35\left(\mathrm{R}^{2}=0.827, \mathrm{P}<0.05\right) ; \mathrm{MCD}_{\mathrm{TCTL}}=25.2+22.7$ ETo $\left(\mathrm{R}^{2}=\right.$ $0.479, \mathrm{P}<0.05)$.

\subsubsection{Conclusiones}

Tanto el potencial hídrico foliar al alba, como el potencial hídrico de tallo a mediodía respondieron claramente a la disminución del potencial matricial del suelo, demostrando su alta sensibilidad al régimen de riego. Por tanto, ambos parámetros pueden ser utilizados como herramientas fiables para cuantificar el déficit hídrico y como ayuda a la toma de decisiones en el manejo del riego.

La alta correlación existente entre el potencial hídrico de tallo a mediodía y la demanda evaporante exige que ésta sea tenida en cuenta en el establecimiento de los valores umbrales de riego $\Psi_{\mathrm{t}}$.

El potencial hídrico foliar a mediodía, conductancia foliar y máxima contracción diaria, fueron los parámetros que mayor variabilidad presentaron en sus medidas. Este hecho fue, posiblemente, la causa de la inexistencia de diferencias nítidas entre tratamientos.

La máxima contracción diaria fue función de la demanda evaporante y del estrés hídrico, pero la posible influencia por otros factores relativos al 
crecimiento hace de ella un indicador menos potente de cara a diferenciar niveles moderados de estrés entre tratamientos.

El crecimiento diario de tronco, determinado a partir de los máximos diámetros, fue más indicativo del nivel de estrés que la máxima contracción diaria. Al disminuir el estado energético del agua del suelo y de la planta $\left(\Psi_{\mathrm{a}} \leq\right.$ $-0.55 \mathrm{MPa}$ y $\Psi_{\mathrm{t}} \leq-1.2 \mathrm{MPa}$ ), por efecto del déficit hídrico, las tasas de crecimiento de los tratamientos deficitarios fueron sensiblemente inferiores a las del control. Por ello, debe de ser considerado como un índice de estrés útil para la programación del riego en almendros jóvenes, especialmente, durante los periodos de altas tasas de crecimiento del tronco.

\subsection{Almendros jóvenes al inicio de su entrada en producción}

\subsubsection{Tratamientos de riego}

Durante el 2003, se aplicaron cuatro tratamientos de riego: $\mathrm{T}_{\mathrm{CTL}}, \mathrm{T}_{\mathrm{RD} 80}$, $\mathrm{T}_{\mathrm{RD} 60}$ y $\mathrm{T}_{\mathrm{RDC} 20}$, los que han sido descritos en el capítulo IV. Durante la época de máxima demanda evaporante y coincidiendo con el periodo de déficit hídrico ya avanzado en $\mathrm{T}_{\mathrm{RDC} 20}$, los tres tratamientos deficitarios se sometieron a un ciclo de recuperación durante una semana (días 190-196), en el que recibieron idéntica dotación hídrica que el $\mathrm{T}_{\mathrm{CTL}}$. Los volúmenes de agua aplicados durante toda la estación de riego fueron: 4610, 3405, 2662 y $2079 \mathrm{~m}^{3}$ ha $^{-1}$ año ${ }^{-1}$ para $T_{C T L}, T_{R D 80}, T_{R D 60}$ y $T_{R D C 20}$, respectivamente.

\subsubsection{Resultados y discusión}

\section{Potencial hídrico de tallo y conductancia foliar}

El potencial de tallo fue sensible al déficit hídrico, detectando diferencias entre tratamientos desde el inicio de la aplicación de los mismos (Figura 6.9). Durante toda la campaña de riegos, los valores de $\Psi_{t}$ en $T_{\text {CTL }}$ fueron muy estables, si se exceptúan los días 188 y 190 en los que debido a una avería en el cabezal de riego $\Psi_{\mathrm{t}}$ disminuyó a valores de $-1.4 \mathrm{MPa}$ (Figura 6.9). Estos valores con ligeras fluctuaciones en torno a $-1.0 \mathrm{MPa}$, son típicos de condiciones no limitantes de agua en el suelo (Shackel et al., 1997; Goldhamer y Fereres, 2004). En $T_{\mathrm{RD} 80}, \Psi_{\mathrm{t}}$ osciló entre valores iguales e inferiores a los del control lo que demuestra el carácter ligero del déficit hídrico aplicado. Sin embargo en $\mathrm{T}_{\mathrm{RD} 60}$, con riego al $60 \%$ de la ETc, los valores de $\Psi_{t}$ fueron inferiores a los de $T_{\text {CTL }}$ y $T_{R D 80}$ prácticamente durante todo el periodo de riego. $\mathrm{T}_{\mathrm{RD} 60}$ alcanzó valores inferiores a $-1.25 \mathrm{MPa}$ durante los meses de junio, julio y agosto, con un mínimo de $-1.5 \mathrm{MPa}$, a mediados de agosto. Estos niveles pueden ser calificados de estrés moderado (Shackel et al., 1997). El tratamiento $T_{\mathrm{RDC} 20}$ presentó valores similares al $\mathrm{T}_{\mathrm{CTL}}$ en el periodo 
de riego al $100 \%$ ETc, mientras que durante el período de riego al $20 \%$ ETc el rango de diferencias respecto al control fue de 0.6 - 1.2 MPa. Estas diferencias fueron significativas desde la primera medida realizada tras la reducción del riego (día 176) e indicadoras del estrés severo aplicado (Figura 6.9). $\mathrm{T}_{\mathrm{RDC} 20}$ mantuvo, durante todo el periodo de déficit, valores de $\Psi_{\mathrm{t}}$ inferiores al resto de tratamientos. En $\mathrm{T}_{\mathrm{RD} 60} \mathrm{y} \mathrm{T}_{\mathrm{RDC} 20}$ las máximas diferencias de $\Psi_{\mathrm{t}}$ respecto al control fueron 1.5 y 4 veces superiores a las de $\mathrm{T}_{\mathrm{RD} 80}$, respectivamente, lo que demuestra el gradiente de estrés para los distintos tratamientos de riego ensayados.

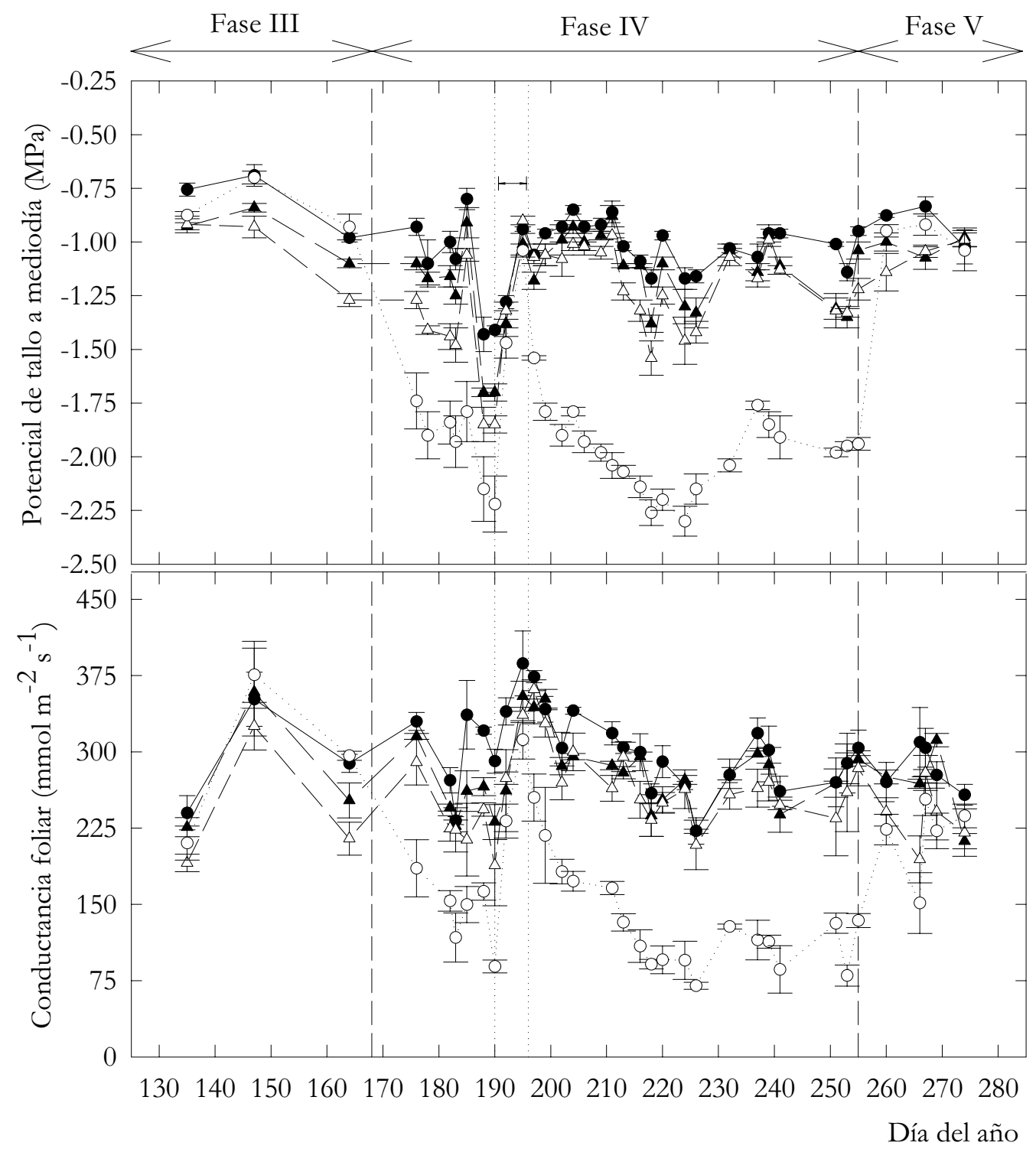

Figura 6.9. Evolución estacional del potencial de tallo $\left(\Psi_{t}\right)$ y conductancia foliar a mediodía $\left(\mathrm{g}_{1}\right)$, en los cuatro tratamientos de riego $\mathrm{T}_{\mathrm{CTL}}(-\bullet), \mathrm{T}_{\mathrm{RD} 80}(-\mathbf{-}-), \mathrm{T}_{\mathrm{RD} 60}$ $(-\wedge--)$ y $\mathrm{T}_{\mathrm{RDC} 20}(\cdots \cdots)$. Cada punto corresponde a la media de 3 repeticiones \pm ES. Las líneas de trazo discontinuo indican el inicio y fin del periodo de riego al $20 \%$ ETc en $\mathrm{T}_{\mathrm{RDC} 20}$, y las de puntos la semana de recuperación al $120 \%$ de la ETc en todos los tratamientos. 
Tras la reparación de la avería del cabezal de riego (día 189), todos los tratamientos se regaron al $120 \%$ de la ETc durante una semana (días 190196). $\mathrm{Y}$ aunque, $\Psi_{\mathrm{t}}$ también disminuyó en $\mathrm{T}_{\mathrm{CTL}}$ durante los dos días sin riego, siempre mantuvo valores claramente superiores al resto de los tratamientos. Los tratamientos de riego deficitario constante, $\mathrm{T}_{\mathrm{RD} 80}$ y $\mathrm{T}_{\mathrm{RD} 60}$, alcanzaron valores similares a $\mathrm{T}_{\text {CTL }}$ tras dos días de riego al $120 \% \mathrm{ETc}$, mientras que $\mathrm{T}_{\mathrm{RDC20}}$ necesitó cuatro días para igualar sus valores a $\mathrm{T}_{\mathrm{CTL}}$ (Figura 6.9). Este comportamiento fue análogo al observado tras la reanudación del riego al 100 \% de la ETc (día 255) una vez finalizado el período al $20 \%$ (Figura 6.9). Resultados similares fueron observados en almendro por Goldhamer y Fereres (2001), en melocotonero por Goldhamer, et al. (1999), y en peral por Naor y Cohen (2003). Por lo tanto, $\Psi$ t fue más rápido en la detección de condiciones de disminución del estado hídrico del árbol que de recuperación del mismo, tanto cuando se parte de condiciones no limitantes de agua en el suelo o de déficit hídrico moderado-severo (día 197, déficit, y día 190, recuperación Figura 6.9).

La conductancia foliar tuvo un comportamiento similar al potencial de tallo, con valores medios estacionales entre 225 y $300 \mathrm{mmol} \mathrm{m}^{-2} \mathrm{~s}^{-1} \mathrm{y}$, generalmente, sin diferencias significativas entre $T_{C T L}, T_{R D 80}$ y $T_{R D 60}$. En $T_{R D C 20}$ los niveles de $g_{1}$ fueron similares a los del control, excepto en el periodo de reducción del riego al $20 \%$, disminuyendo a valores medios de $100 \mathrm{mmol} \mathrm{m}^{-2}$ $\mathrm{s}^{-1}$ (Figura 6.9). Las únicas diferencias significativas observadas en $\mathrm{T}_{\mathrm{RD} 60}$ con respecto al control tuvieron lugar en días aislados. Este hecho junto a lo observado en $\mathrm{T}_{\mathrm{RDC} 20}$ demuestra, que son necesarios altos déficit hídricos para conseguir una clara regulación estomática en esta especie (Romero et al., 2004b).

Al objeto de completar el estudio de la influencia de los tratamientos de riego en los distintos parámetros estudiados, el día 224, cuando el tratamiento $\mathrm{T}_{\mathrm{RDC} 20}$ se venía regando al $20 \%$ de la ETc durante 2 meses, se realizó un seguimiento diario con medidas cada 2 horas del potencial de tallo y la conductancia foliar.

La evolución diaria del potencial de tallo mostró, en todos los tratamientos, valores máximos antes del alba y mínimos ligeramente después del mediodía, sobre las 15:00 horas UT coincidiendo con el mínimo diámetro de tronco registrado con sensores LVDT (Figura 6.10). El nivel de recuperación de $\Psi_{\mathrm{t}}$ a última hora de la tarde fue evidente en los tratamientos más regados, mientras que en $T_{\mathrm{RDC} 20}$, las diferencias de $\Psi_{\mathrm{t}}$ respecto a primeras horas de la mañana triplicaban a las de $\mathrm{T}_{\mathrm{CTL}}, \mathrm{T}_{\mathrm{RD} 80}$ y $\mathrm{T}_{\mathrm{RD} 60}(0.77 \mathrm{MPa}$ frente a $0.22 \mathrm{MPa}$ ). Esta ausencia de recuperación a lo largo del atardecer y durante la noche se tradujo en diferencias respecto al control de 0.59 y $1.13 \mathrm{MPa}$, al alba y mediodía, respectivamente, las que son acordes con el nivel de déficit 
aplicado. La caída de $\Psi_{\mathrm{t}}$ en los tratamientos de déficit hídrico fue proporcional a la reducción de riego aplicada. Las máximas diferencias absolutas respecto al control tuvieron lugar a las 15:00 horas y fueron de 0.3, 0.49 y $1.31 \mathrm{MPa}$ para $\mathrm{T}_{\mathrm{RD} 80}, \mathrm{~T}_{\mathrm{RD} 60}$ y $\mathrm{T}_{\mathrm{RDC} 20}$, respectivamente.

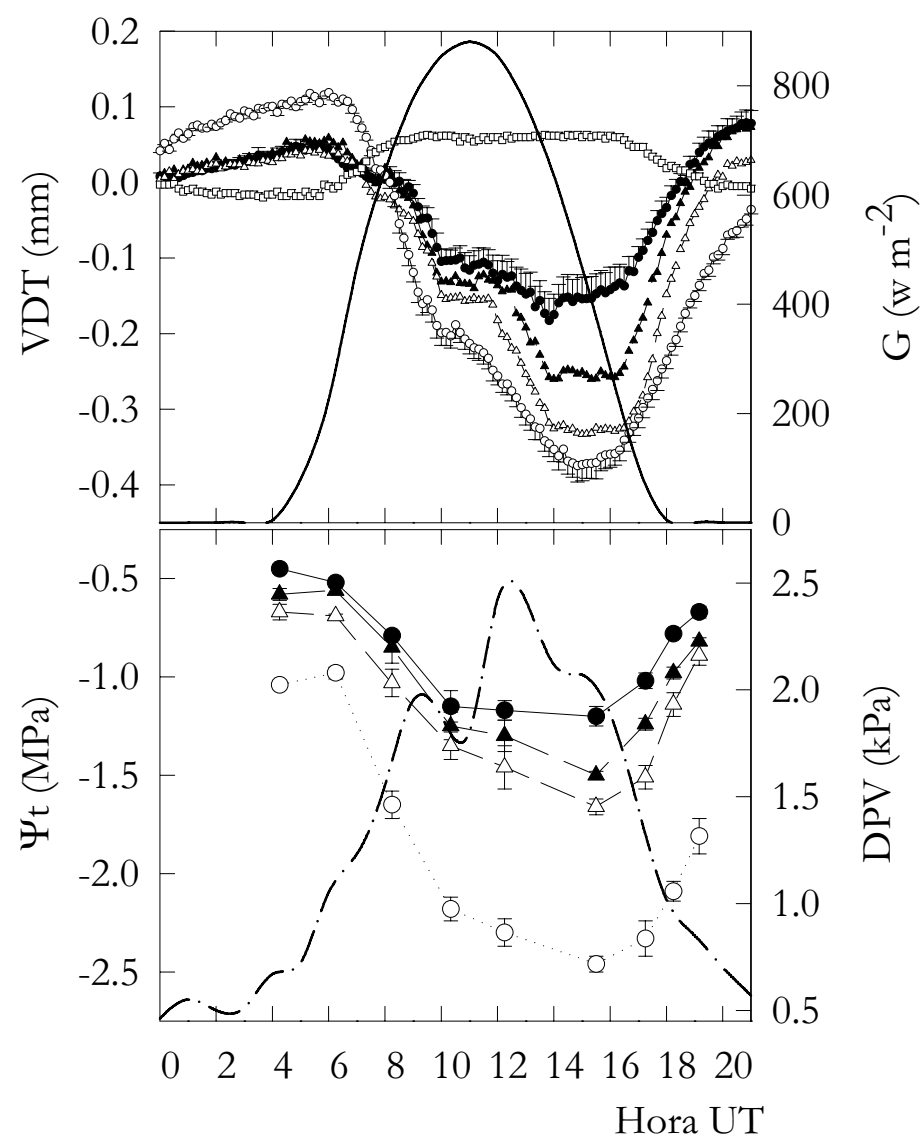

Figura 6.10. Evolución de las variaciones de diámetro de tronco (VDT), radiación global $(\mathrm{G})$, déficit de presión de vapor (DPV) y potencial hídrico de tallo a mediodía $\left(\Psi_{t}\right)$ en los cuatro tratamientos de riego $\mathrm{T}_{\mathrm{CTL}}(-\bullet), \mathrm{T}_{\mathrm{RD} 80}(-\boldsymbol{-}-), \mathrm{T}_{\mathrm{RD} 60}\left(--_{--}\right)$y $\mathrm{T}_{\mathrm{RDC} 20}(\cdots \cdots) \mathrm{y}$ en un tronco muerto ( $\quad)$, durante el día 224.

Los máximos niveles de conductancia foliar $\left(\mathrm{g}_{\mathrm{f}}\right)$ fueron alcanzados en torno a las 8:00 horas en todos los tratamientos, permaneciendo prácticamente constantes hasta las 17:00 en $\mathrm{T}_{\mathrm{CTL}}, \mathrm{T}_{\mathrm{RD} 80}$ y $\mathrm{T}_{\mathrm{RD} 60}$, mientras que en $\mathrm{T}_{\mathrm{RDC} 20}$ se produjo un descenso gradual de $\mathrm{g}_{\mathrm{l}}$ en las horas centrales del día, coincidiendo con la mayor demanda evaporativa (datos no mostrados).

La Figura 6.11 relaciona el diámetro de tronco con el potencial hídrico de tallo y muestra el grado de histéresis existente entre ambas variables en un día de alta demanda evaporante y para un determinado diámetro. Así, para un mismo potencial de tallo le corresponden dos diámetros según se considere que se ha llegado a ese diámetro a través de un proceso de pérdida de agua (mañana-primeras horas de la tarde) o de ganancia de agua durante la tarde- 
noche. Para un mismo $\Psi_{\mathrm{t}}$ el diámetro de tronco fue menor por la tarde que por la mañana, acentuándose el nivel de histéresis con el aumento del déficit hídrico soportado por los distintos tratamientos. Así mismo, el desfase entre ambos parámetros aumentó con la intensidad del estrés hídrico, indicando la mayor duración de un flujo de agua positivo desde el reservorio del tronco hacia el xilema. Este fenómeno es considerado como un mecanismo de adaptación a situaciones limitantes de agua en el suelo (Molz y Klepper, 1973; Brough et al., 1986; Gènard et al., 2001; Doltra et al., 2007), ya que permite el mantenimiento de los procesos transpirativos durante un periodo de tiempo mayor. Los bucles correspondientes a los tratamientos $\mathrm{T}_{\text {CTL }}$ y $\mathrm{T}_{\mathrm{RD} 60}$ muestran como el crecimiento en diámetro de tronco tiene lugar durante las últimas horas del día y la noche.

\section{Variaciones de diámetro de tronco}

Las variaciones del diámetro de tronco registradas a partir de los sensores LVDT reflejaron el régimen hídrico de cada uno de los tratamientos ensayados. El crecimiento acumulado (CA) en diámetro de tronco, evaluado a partir de los máximos diámetros (MXTD), fue de 27, 25, 21 y $22.5 \mathrm{~mm}$ en $\mathrm{T}_{\mathrm{CTL}}, \mathrm{T}_{\mathrm{RD} 80}, \mathrm{~T}_{\mathrm{RD} 60}$ y $\mathrm{T}_{\mathrm{RDC} 20}$, respectivamente (Figura 6.12). Las tasas medias diarias de crecimiento de tronco (TCD) en $\mathrm{T}_{\mathrm{CTL}}, \mathrm{T}_{\mathrm{RD} 80}$ y $\mathrm{T}_{\mathrm{RD} 60}$, fueron prácticamente constantes $\left(0.13,0.12\right.$ y $\left.0.09 \mathrm{~mm} \mathrm{día}^{-1}\right)$ durante todo el ciclo de crecimiento, tal como era de esperar en árboles jóvenes ( $4^{\circ}$ año de injerto). Sin embargo, en $\mathrm{T}_{\mathrm{RDC} 20}$ con valores iniciales similares a $\mathrm{T}_{\mathrm{CTL}}$ se produjo una drástica disminución con la reducción del riego al $20 \%\left(0.03 \mathrm{~mm}\right.$ día $\left.^{-1}\right)$, lo que demuestra la sensibilidad de este parámetro al déficit hídrico (Moriana y Fereres, 2002; Naor et al., 2006; Ortuño et al., 2006a; Ortuño et al., 2006b; García-Orellana et al., 2007). En esta misma línea, y tras la restitución del riego al $100 \%$ (día 255), $\mathrm{T}_{\mathrm{RDC} 20}$ experimentó TCD superiores a las de $\mathrm{T}_{\mathrm{CTL}}$, situando su dinámica de crecimiento por encima de $\mathrm{T}_{\mathrm{RD} 60}$ (Figura 6.12). Esta pronta respuesta de TCD al aumento de los aportes hídricos fue igualmente observada por Moriana y Fereres (2002), en olivos jóvenes. 


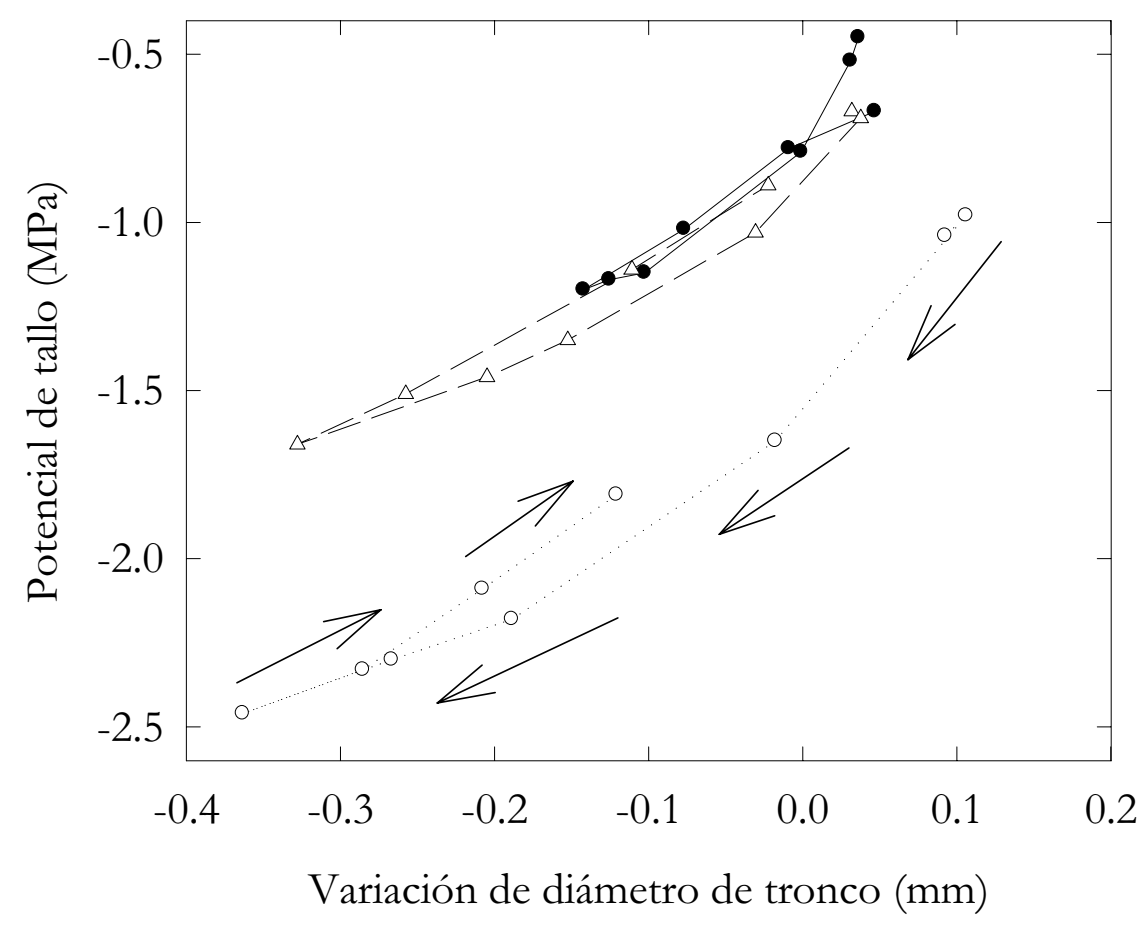

Figura 6.11. Relación a lo largo de una jornada (día 224) entre el potencial hídrico de tallo y las variaciones de diámetro de tronco, para los tratamientos de riego $\mathrm{T}_{\mathrm{CTL}}(-\bullet-), \mathrm{T}_{\mathrm{RD} 60}$ $(-\triangle--)$ y $\mathrm{T}_{\mathrm{RDC} 20}(\cdots \cdots)$. Las flechas indican el sentido horario de la relación entre ambos parámetros.

La máxima contracción diaria de diámetro de tronco (MCD) aumentó progresivamente, desde mediados de marzo (plena floración) hasta mediadosfinales de julio, coincidiendo con el aumento de la demanda evaporante y el crecimiento de los brotes (Figura 6.3 y 6.13). A partir de julio, mes en el que se alcanzaron los máximos valores de $\mathrm{MCD}$, se invierte la tendencia hasta experimentar mínimos valores a mediados de octubre. MCD se vio afectada por el tratamiento de riego. Así y a partir de primeros de mayo $\mathrm{T}_{\mathrm{RD} 80}$ y $\mathrm{T}_{\mathrm{RD} 60}$, con MCD similares, presentaron valores superiores a $\mathrm{T}_{\mathrm{CTL}}$. Durante el periodo de riego al $20 \%$ ETc, la MCD de $\mathrm{T}_{\mathrm{RDC} 20}$ fue mayor que la de $\mathrm{T}_{\mathrm{CTL}}, \mathrm{T}_{\mathrm{RD} 80} \mathrm{y}$ $\mathrm{T}_{\mathrm{RD} 60}$, con valores medios de $465 \mu \mathrm{m}$ frente a las $222,300,309 \mu \mathrm{m}$ del $\mathrm{T}_{\mathrm{CTL}}$, $\mathrm{T}_{\mathrm{RD} 80}$ y $\mathrm{T}_{\mathrm{RD} 60}$, respectivamente. Estas $\mathrm{MCD}$ son muy similares a las observadas por Goldhamer y Fereres (2001) y Fereres y Goldhamer (Fereres y Goldhamer, 2003) en almendros de 4 y 6 años, respectivamente. El incremento de la MCD en los árboles control, en el transcurso de un año (2002-2003) y para el período junio-agosto fue del $39 \%$, de acuerdo con los datos recogidos en Nortes et al. (2005). Durante 2004 no se observó incremento alguno de la MCD en los estos mismos árboles, a pesar del notable crecimiento vegetativo observado. 


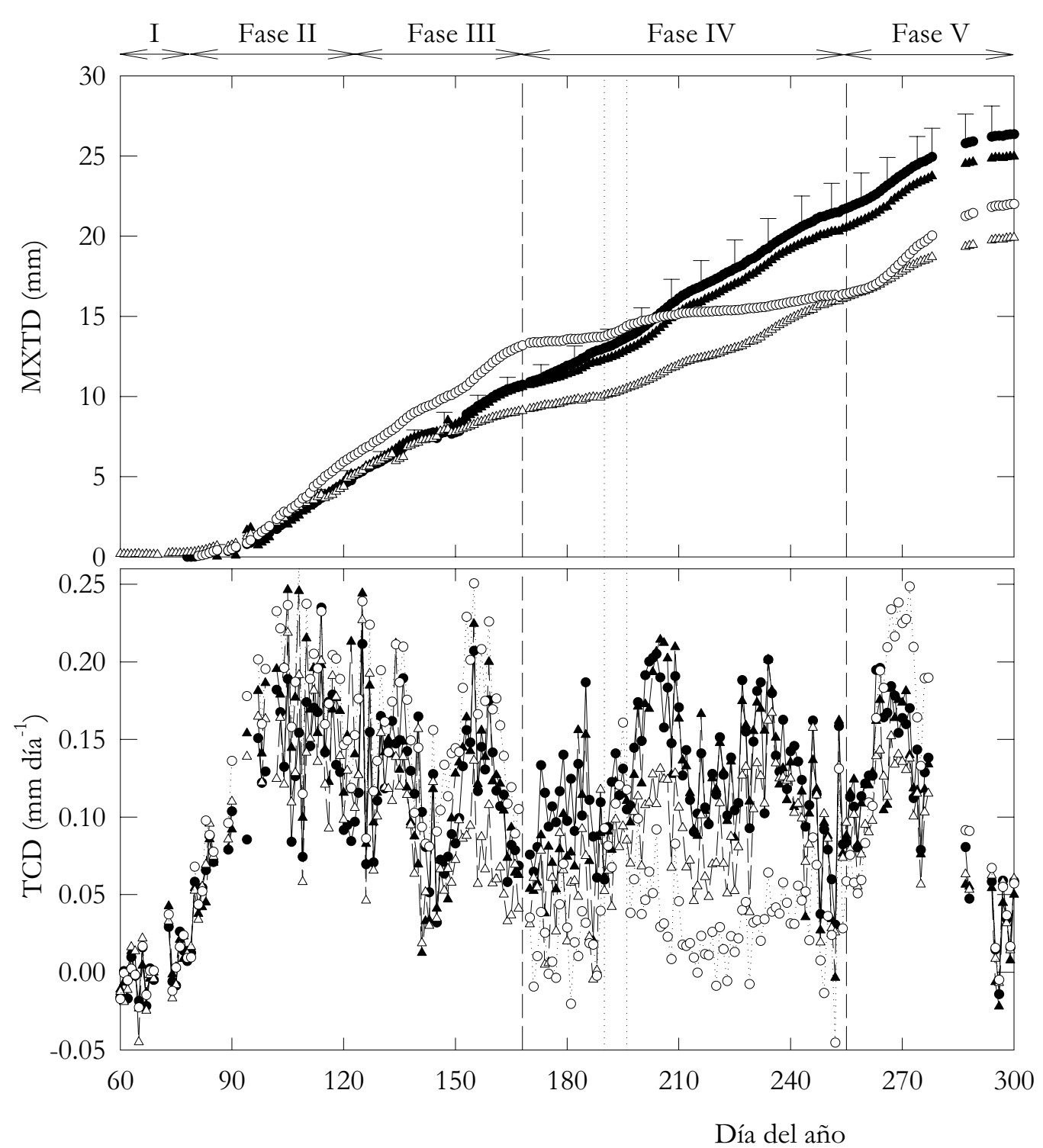

Figura 6.12. Evolución estacional del diámetro máximo (MXTD) y de la tasa de crecimiento diaria de tronco $(\mathrm{TCD})$, en los tratamientos $\mathrm{T}_{\mathrm{CTL}}(-\bullet), \mathrm{T}_{\mathrm{RD} 80}(-\mathbf{-}-), \mathrm{T}_{\mathrm{RD} 60}$ $(-\triangle--)$ y $\left.\mathrm{T}_{\mathrm{RDC} 20}(-)^{-}\right)$. Cada punto corresponde a la media de 6 sensores LVDT \pm ES. La línea de trazo discontinuo indica el inicio y fin del periodo al $20 \%$ ETc en $\mathrm{T}_{\mathrm{RDC} 20}$, y la de puntos la semana de riego al $120 \%$ de la ETc en todos los tratamientos.

Durante el período de recuperación, días 190-196, los tratamientos deficitarios igualaron la TCD y MCD, en el mismo día de cambio de riego a las del control. Análogo comportamiento fue observado en $\mathrm{T}_{\mathrm{RDC} 20}$ tras la reanudación del riego al $100 \%$ de la ETc, día 255 (Figuras 6.12 y 6.13) (tiempos de riego para el periodo 190-196 de 12:00 a 14:40 y de 23:00 a 1:40 y para el día 255 de 23:00 a 1:50), evidenciando una recuperación más rápida que $\Psi_{\mathrm{t}}$. En este último tratamiento, el mayor tiempo requerido por $\Psi_{\mathrm{t}}$ para su recuperación es consecuente con el déficit hídrico severo alcanzado $\left(\Psi_{\mathrm{t}}\right.$ se mantuvo entre -2.0 y $-2.2 \mathrm{MPa}$, Figura 6.9). Esta demora para igualar sus niveles a los $\mathrm{T}_{\text {CTL }}$ fue acompañada de una importante regulación estomática 
(Figura 6.9), la que permaneció un tiempo después de que se hubiese igualado $\Psi_{\mathrm{t}}$.

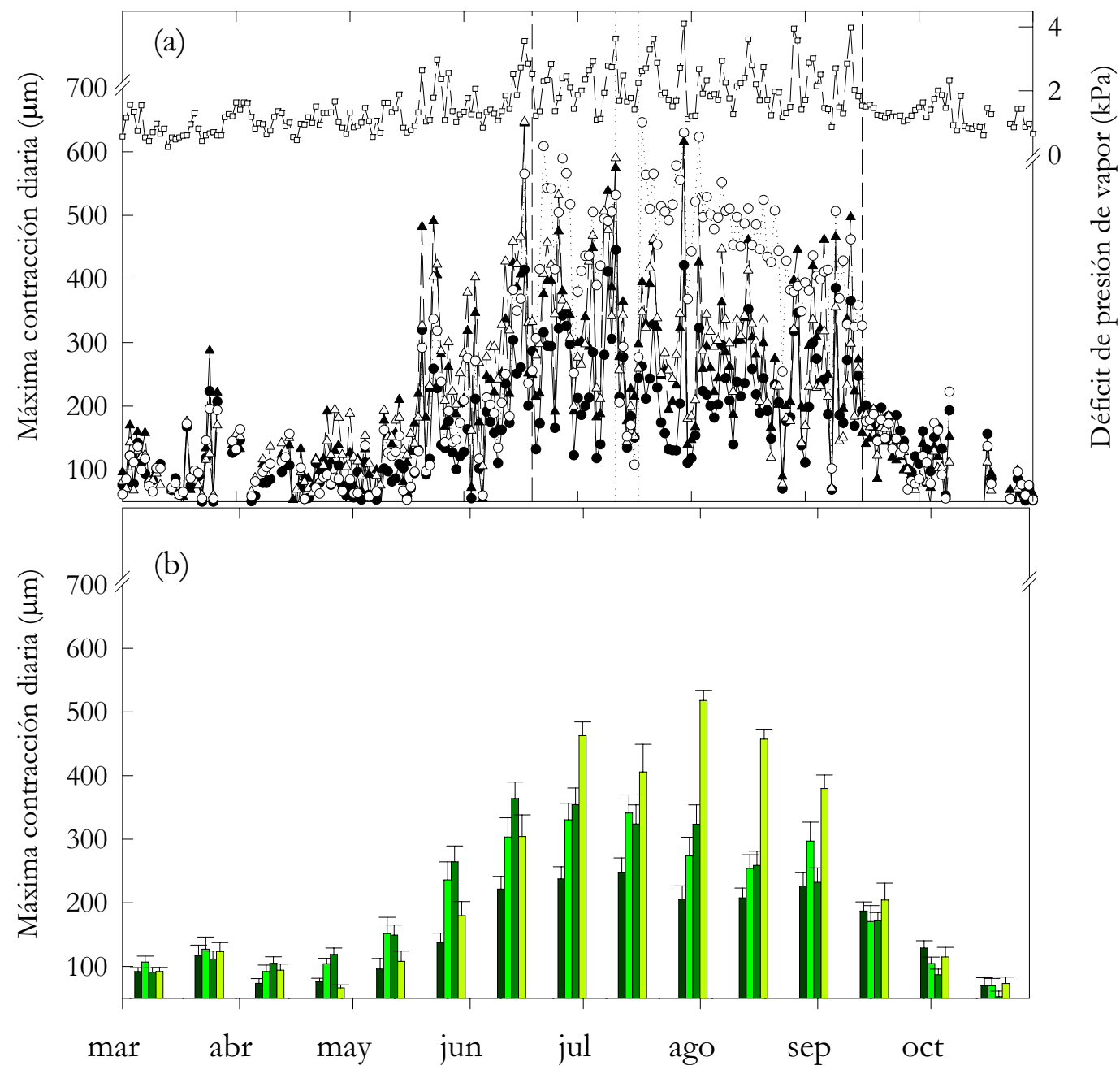

Figura 6.13. Evolución estacional de la máxima contracción diaria (MCD) y déficit de presión de vapor máximo diario (DPV) (a) y máxima contracción diaria quincenal, en $\mathrm{T}_{\mathrm{CTL}}$

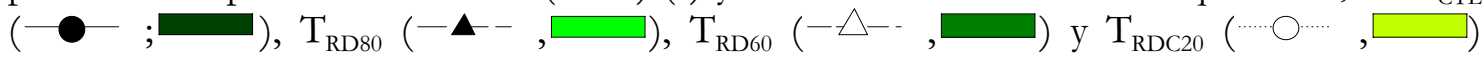
(b). Cada punto corresponde a la media de 6 sensores LVDT \pm ES. La línea de trazo discontinuo indica el inicio y fin del periodo al $20 \%$ ETc en $T_{\mathrm{RDC} 20}$, y la de puntos la semana de riego al $120 \%$ de la ETc.

Este desfase entre $\Psi_{\mathrm{t}} \mathrm{y} \mathrm{g}_{\mathrm{l}}$ ha sido observado en otras especies leñosas: en naranjo (Fereres et al., 1979) y en limonero (Domingo, 1994), bajo estrés hídrico severo. Este retraso relativo en la recuperación de $g_{1}$ puede ser atribuido a la acción del ácido abscísico producido en las raíces durante el período de déficit (Davies y Zhang, 1991). En cualquier caso este hecho puede considerarse como un mecanismo de seguridad que permite al árbol alcanzar la recuperación de la turgencia celular más rápidamente (Mansfield y Davies, 1981). 
El estudio comparativo del grado de sensibilidad al déficit hídrico de los distintos indicadores controlados se realizó de acuerdo a Goldhamer y Fereres (2001). Para ello, se determinó el ratio "intensidad de señal/ruido"; donde la intensidad de señal viene dada por el valor de la variable relativo al de árboles bajo condiciones no limitantes de agua en el suelo, y el ruido, por el coeficiente de variación de la variable medida. En la tabla 6.1 se recogen los valores medios de señal y ruido, durante la fase de rápida acumulación de materia seca del grano (junio-agosto), para los distintos tratamientos de riego ensayados. Los mayores valores de señal correspondieron a TCD, seguidos de los de MCD y a continuación $\Psi_{\mathrm{t}}$ y $\mathrm{g}_{\mathrm{l}}$. Sin embargo, los coeficientes de variación medios aumentaron en la secuencia $\Psi_{\mathrm{t}}, \mathrm{g}_{1}, \mathrm{MCD}$ y TCD; con valores del 7, 20, 21 y $40 \%$ respectivamente. El comportamiento fue similar al indicado por Intrigliolo y Castel (2004), en ciruelo; Nortes et al. (2005) y Goldhamer y Fereres (2001), en almendro. De modo, que el orden de mayor a menor sensibilidad fue: $\Psi_{\mathrm{t}}>\mathrm{MDC}>\mathrm{g}_{\mathrm{l}}>\mathrm{TCD}$, orden que concuerda con el observado por Intrigliolo y Castel (2004) en ciruelo y que difiere del encontrado por Goldhamer y Fereres (2001), en almendro; probablemente debido a que el sistema de riego empleado por éstos últimos autores fue diferente y el porcentaje de suelo mojado superior al $25 \%$ de nuestro ensayo.

Tabla 6.1. Valores medios del ratio 'Señal/Ruido' para los diferentes índices de estrés evaluados. Junio - mediados de septiembre de 2003.

\begin{tabular}{llcccc}
\hline & & $\mathbf{g}_{1}$ & $\Psi_{\mathbf{t}}$ & $\mathbf{M C D}$ & $\mathbf{T C D}$ \\
\hline \multirow{2}{*}{$\mathbf{T}_{\text {RD80 }}$} & Señal (S) & 0.92 & 1.11 & 1.31 & 1.05 \\
& Ruido (R) & 0.15 & 0.08 & 0.2 & 0.23 \\
& Ratio (S/R) & $\mathbf{6 . 1 3}$ & $\mathbf{1 3 . 8 8}$ & $\mathbf{6 . 5 5}$ & $\mathbf{4 . 5 7}$ \\
\cline { 2 - 6 } & Señal (S) & 0.87 & 1.2 & 1.46 & 1.63 \\
$\mathbf{T}_{\text {RD60 }}$ & Ruido (R) & 0.18 & 0.08 & 0.27 & 0.48 \\
& Ratio (S/R) & $\mathbf{4 . 8 3}$ & $\mathbf{1 5 . 0 0}$ & $\mathbf{5 . 4 1}$ & $\mathbf{3 . 4 0}$ \\
\cline { 2 - 6 } & Señal (S) & 0.5 & 1.83 & 1.95 & 3.39 \\
$\mathbf{T}_{\text {RDC20 }}$ & Ruido (R) & 0.27 & 0.07 & 0.18 & 0.45 \\
& Ratio (S/R) & $\mathbf{1 . 8 5}$ & $\mathbf{2 6 . 1 4}$ & $\mathbf{1 0 . 8 3}$ & $\mathbf{7 . 5 3}$ \\
\hline
\end{tabular}




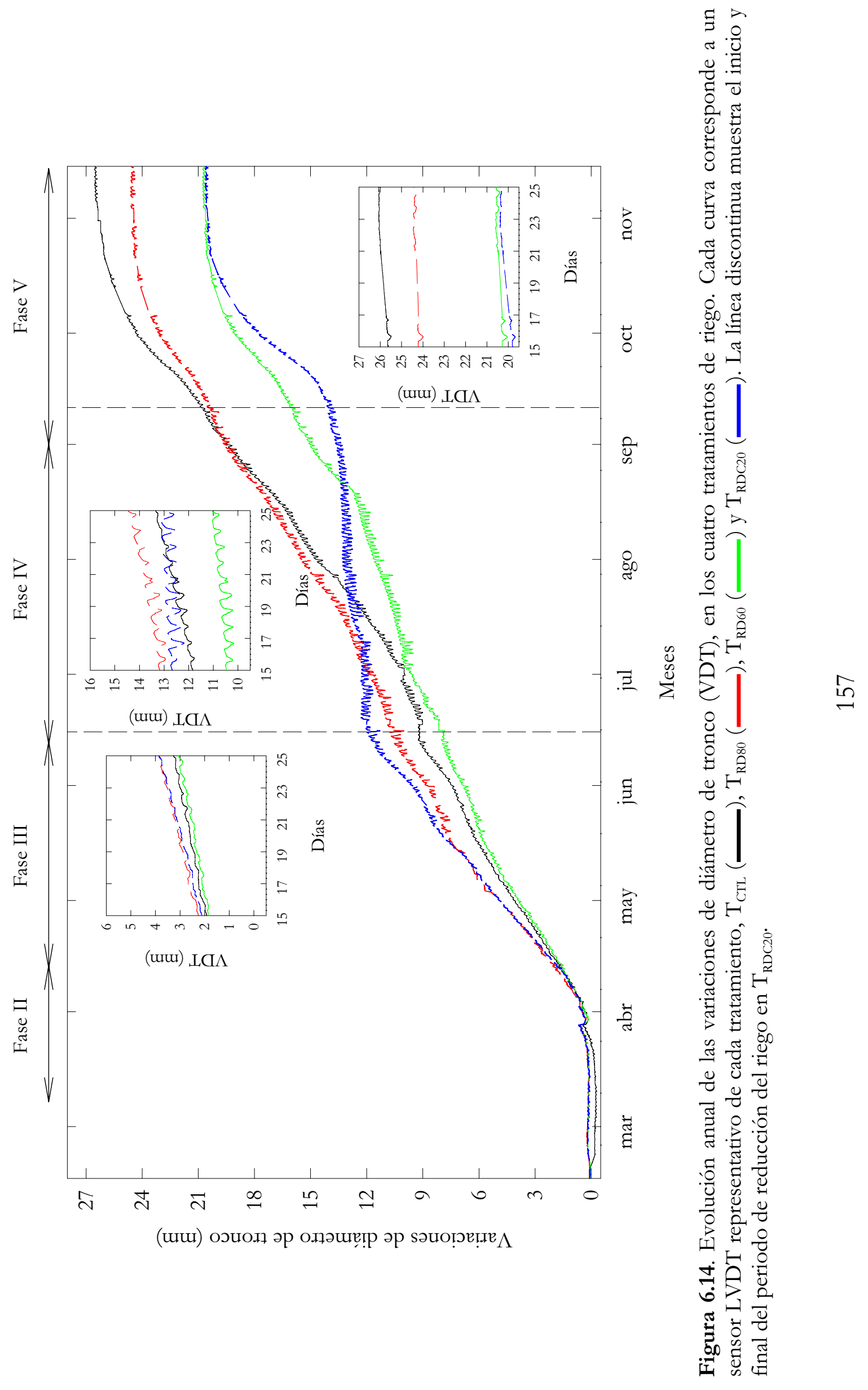




\section{Relaciones entre los diferentes indicadores de estrés hídrico}

A fin de determinar la utilidad de TCD y MCD para ser empleados como indicadores para la programación del riego, se obtuvieron diferentes relaciones con otros parámetros clásicos, del estado energético del agua en la planta, potencial al alba $\left(\Psi_{a}\right)$, potencial de tallo a mediodía $\left(\Psi_{t}\right)$ y potencial de presión de hojas cubierta $\left(\Psi_{\mathrm{pt}}\right)$ y sin cubrir $\left(\Psi_{\mathrm{p}}\right)$.

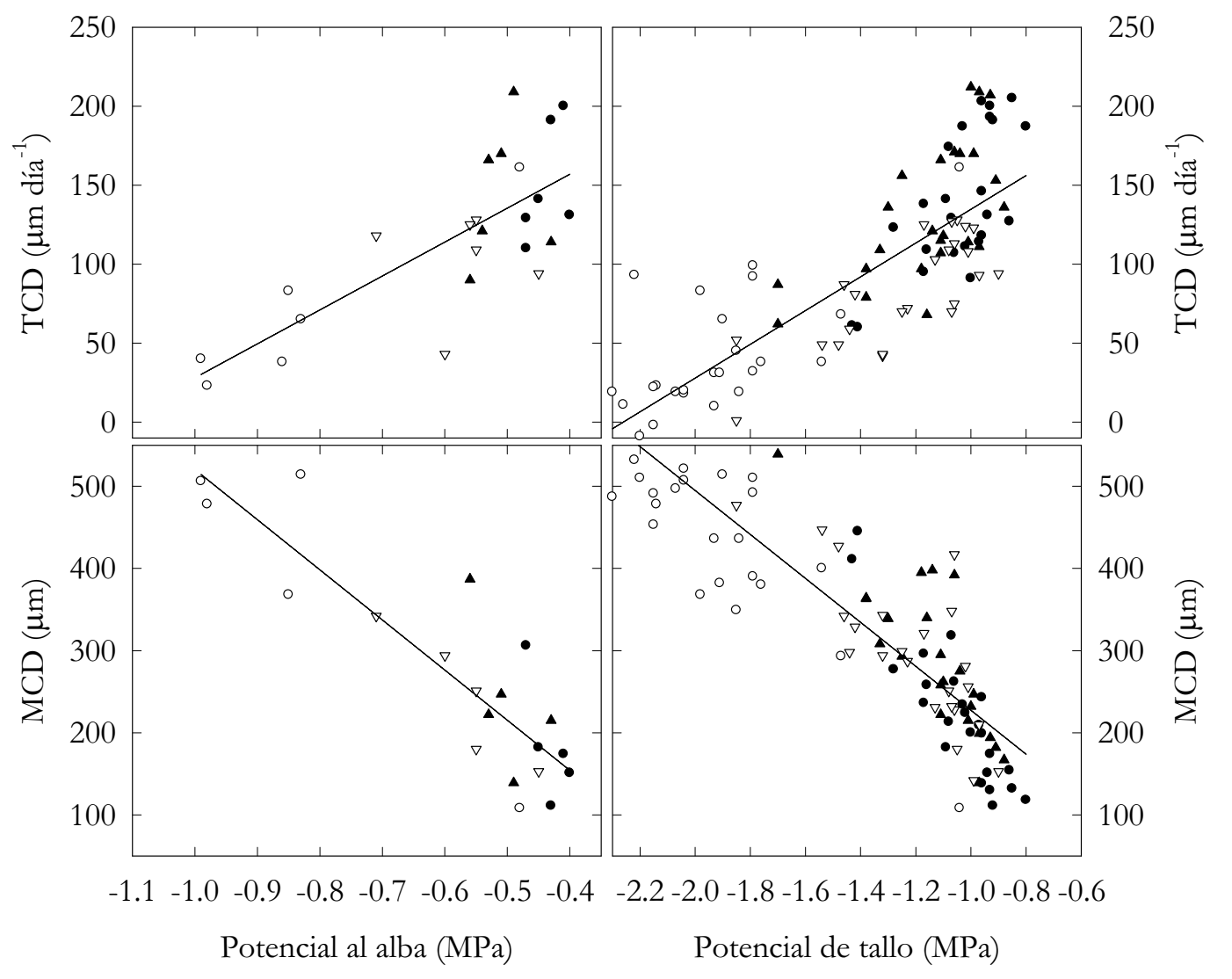

Figura 6.15. Relaciones entre TCD y MCD y el potencial hídrico foliar al alba $\left(\Psi_{\mathrm{a}}\right)$ y el de tallo a mediodía $\left(\Psi_{t}\right)$, durante el periodo experimental., para los 4 tratamientos de riego: $\mathrm{T}_{\mathrm{CTL}}(\bullet), \mathrm{T}_{\mathrm{RD} 80}(\boldsymbol{\bullet}), \mathrm{T}_{\mathrm{RD} 60}(\nabla)$ y $\mathrm{T}_{\mathrm{RDC} 20}(\mathrm{O})$.

El crecimiento diario (TCD), determinado a partir de los máximos diámetros, y la máxima contracción diaria (MCD) mostraron correlaciones altamente significativas tanto con el potencial al alba como con el de tallo a mediodía (Figura 6.15 y Tabla 6.2). Sin embargo, los valores de MCD fueron mejor explicados por $\Psi_{\mathrm{a}}$ y $\Psi_{\mathrm{t}}$ que los de TCD. Esta misma pauta fue observada en las relaciones con el potencial de presión a mediodía, tanto en hojas sin cubrir como en hojas cubiertas (Figura 6.16 y Tabla 6.2). 
Tabla 6.2 Valores de los parámetros de las relaciones máxima contracción diaria (MDC, $\mu \mathrm{m})$ y crecimiento diario de tronco (TCD, $\mu \mathrm{m} \mathrm{día}{ }^{-1}$ ) versus potencial hídrico foliar al alba $\left(\Psi_{\mathrm{a}}\right)$, de tallo a mediodía $\left(\Psi_{\mathrm{t}}\right)$ y de presión en hojas expuestas y cubiertas $\left(\Psi_{\mathrm{p}}, \Psi_{\mathrm{p} t}\right)$, en MPa.

\begin{tabular}{cccc}
\hline $\begin{array}{c}\text { Relación } \\
\left(\mathrm{y}=\mathrm{y}_{0}+\mathrm{m} \mathbf{x}\right)\end{array}$ & $\mathrm{m}$ & $\mathrm{y}_{\mathbf{0}}$ & $\mathbf{R}^{2}$ \\
\hline $\mathbf{M C D} v \boldsymbol{s} \Psi_{\mathrm{a}}$ & -610 & -90 & $0.78^{* * *}$ \\
$\mathbf{T C D} v \boldsymbol{s} \Psi_{\mathrm{a}}$ & 214 & 242 & $0.57^{* *}$ \\
$\mathbf{M C D} v \boldsymbol{s} \Psi_{\mathrm{t}}$ & -270 & -41 & $0.75^{* * *}$ \\
$\mathbf{T C D} v \boldsymbol{s} \Psi_{\mathrm{t}}$ & 106 & 241 & $0.63^{* *}$ \\
$\mathbf{M C D} v \boldsymbol{s} \Psi_{\mathrm{pt}}$ & -423 & 923 & $0.65^{* *}$ \\
$\mathbf{M C D} v \boldsymbol{s} \Psi_{\mathrm{p}}$ & 417 & 818 & $0.72^{* * *}$ \\
\hline
\end{tabular}

Puesto que ambos parámetros (MCD y TCD) mostraron relaciones muy similares, a nivel estacional, frente al estado energético del agua en la planta; adicionalmente, se obtuvo la relación de MCD y TCD frente a la demanda climática (Figura 6.17), a fin de determinar el parámetro de mayor utilidad como herramienta para la programación del riego. La relación MCD vs ETo-PM, de tipo potencial, fue altamente significativa para todos los tratamientos de riego ensayados. Distinto comportamiento fue observado en TCD (datos no mostrados), presentando coeficientes de determinación no significativos para todos los tratamientos. Este comportamiento diferente pudo ser debido a la disminución de las tasas de crecimiento, consecuencia de la aplicación del déficit hídrico y por la competencia entre órganos por los fotoasimilados y nutrición hídrica. Todo ello hace que, en árboles en producción, MCD sea más adecuada con fines de programación del riego que TCD. Resultados similares para MCD y TCD fueron obtenidos en almendro por Goldhamer y Fereres (2004) y en ciruelo Japonés por Intringliolo y Castel (2004; 2005b).

Además, y con el objeto de validar la idoneidad del empleo de MCD como indicador de estrés hídrico, se realizó el análisis de regresión entre MCD y $\Psi_{t}$ durante toda la estación de riego (Figura 6.18 y Tabla 6.3), ya que $\Psi_{\mathrm{t}}$ es considerado por muchos autores como un indicador de referencia del estado hídrico de la planta (McCutchan y Shackel, 1992; Naor et al., 1995; 2001; 2003; 2004; 2006; Shackel et al., 1997). La relación entre estos parámetros fue significativa, con coeficientes de determinación altos en los tratamientos $\mathrm{T}_{\mathrm{CTL}}$ y $\mathrm{T}_{\mathrm{RD} 80}\left(\mathrm{R}^{2}=0.7^{* * *}\right.$ y $\left.0.68^{* * *}\right)$, y sensiblemente inferiores en los tratamientos más deficitarios $\mathrm{T}_{\mathrm{RD} 60}$ y $\mathrm{T}_{\mathrm{RDC} 20}\left(\mathrm{R}^{2}=0.59^{* *}\right.$ y $\left.0.3^{* *}\right)$. Estos valores indican la 
bondad de MCD como herramienta de evaluación de los primeros síntomas de déficit hídrico y mientras éstos permanezcan dentro del intervalo déficit ligero-moderado.
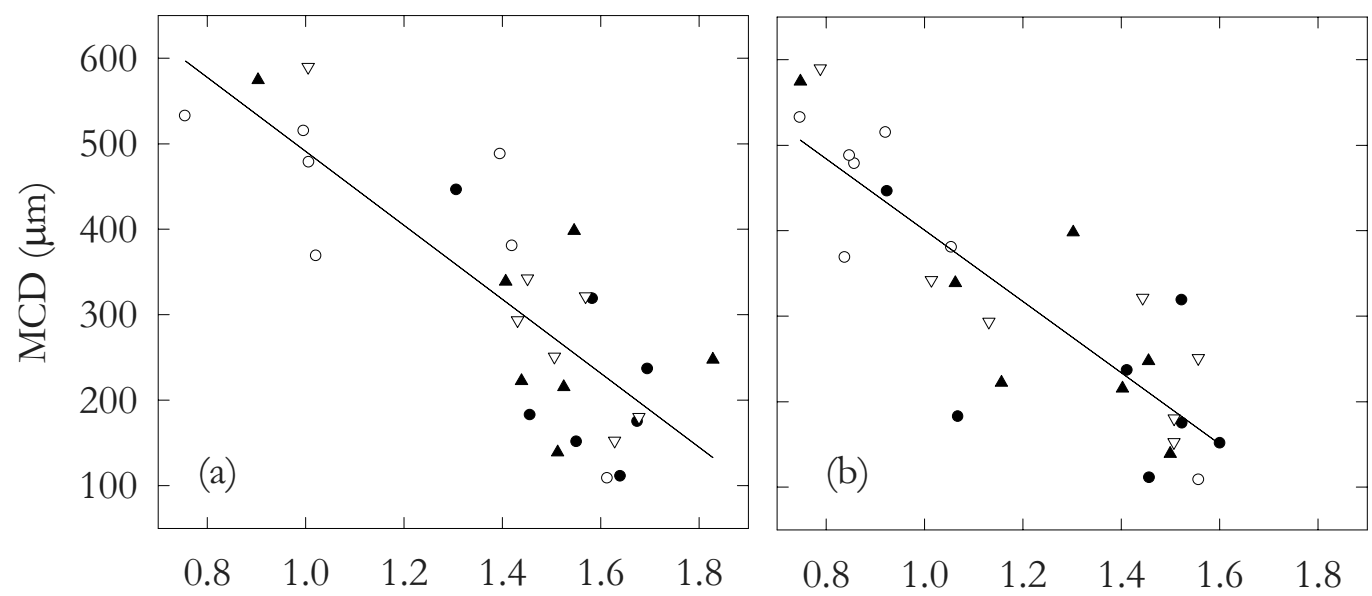

Potencial de presión $(\mathrm{MPa})$

Figura 6.16. Relaciones entre MCD y el potencial de presión a mediodía: (a) hojas cubiertas $\left(\Psi_{\mathrm{pt}}\right)$ y (b) sin cubrir $\left(\Psi_{\mathrm{p}}\right)$, durante el periodo experimental y para los 4 tratamientos de riego $\mathrm{T}_{\mathrm{CTL}}(\bullet), \mathrm{T}_{\mathrm{RD} 80}(\mathbf{\bullet}), \mathrm{T}_{\mathrm{RD} 60}(\nabla)$ y $\mathrm{T}_{\mathrm{RDC} 20}(\mathrm{O})$.

A conclusiones similares llegaron Fereres y Goldhamer (2003) en trabajos con almendros adultos, Intrigliolo y Castel (2004) en ciruelo, Moreno et al (2006) en olivo y Ortuño et al (2006b) y García-Orellana et al. (2007) en limonero. La baja relación observada en $\mathrm{T}_{\mathrm{RDC} 20}$, tratamiento de déficit hídrico severo, pudo ser debida a un importante agotamiento de las reservas del árbol. Este agotamiento limitaría la capacidad de contracción de los tejidos elásticos del tronco (Gènard et al., 2001), afectando a la relación MCD vs $\Psi_{\mathrm{t}}$. De ahí, que a partir de un valor de $-1.8 \mathrm{MPa}$ de $\Psi_{\mathrm{t}}$ las disminuciones de $\Psi_{\mathrm{t}}$ no se traduzcan en aumentos proporcionales de MCD. 


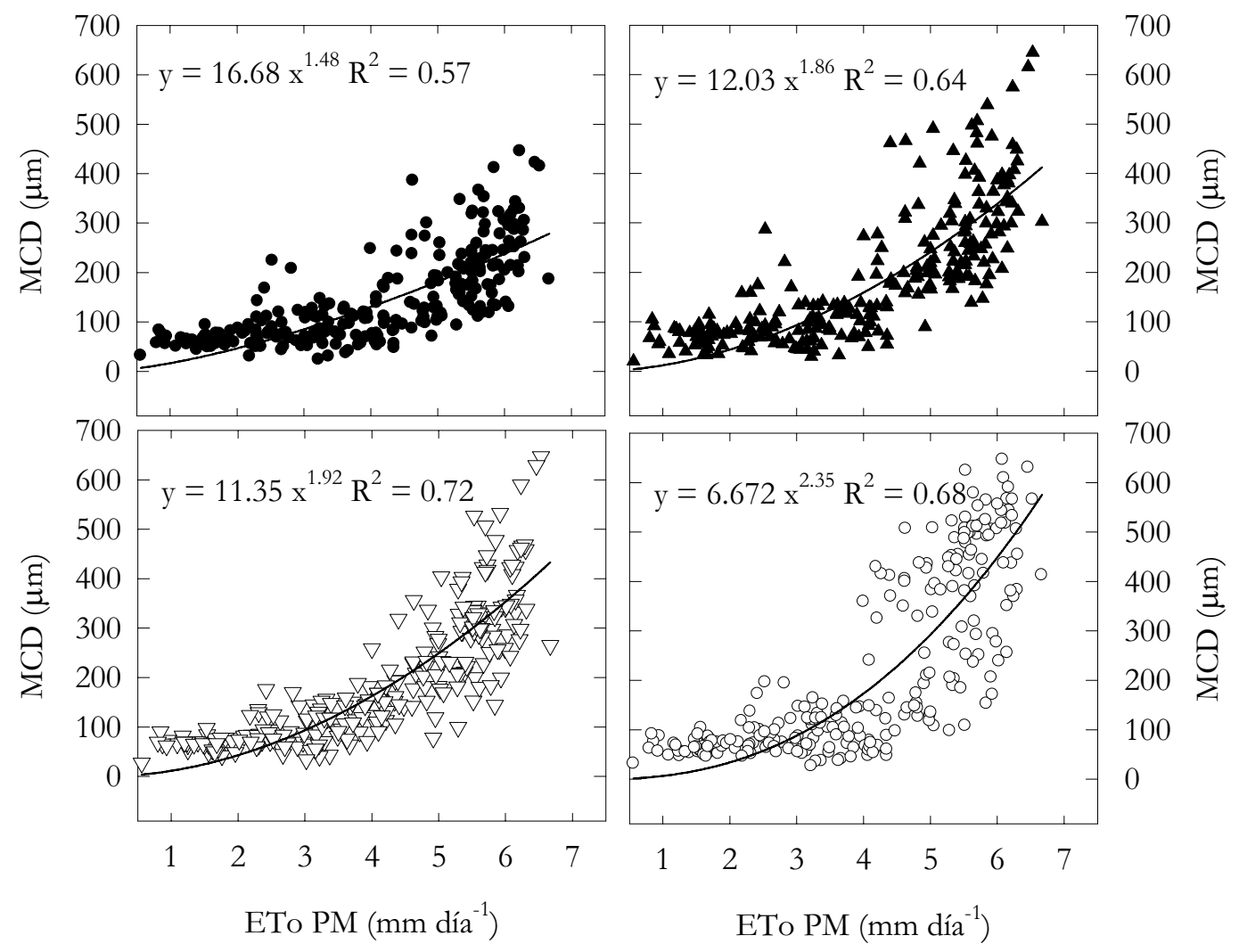

Figura 6.17. Relación entre la evapotranspiración de referencia Penman Monteith (ETo PM) y la máxima contracción diaria de tronco (MCD) durante el periodo experimental, para los 4 tratamientos de riego, $\mathrm{T}_{\mathrm{CTL}}(\bullet), \mathrm{T}_{\mathrm{RD} 80}(\boldsymbol{\bullet}), \mathrm{T}_{\mathrm{RD} 60}(\nabla)$ y $\mathrm{T}_{\mathrm{RDC} 20}(O)$.

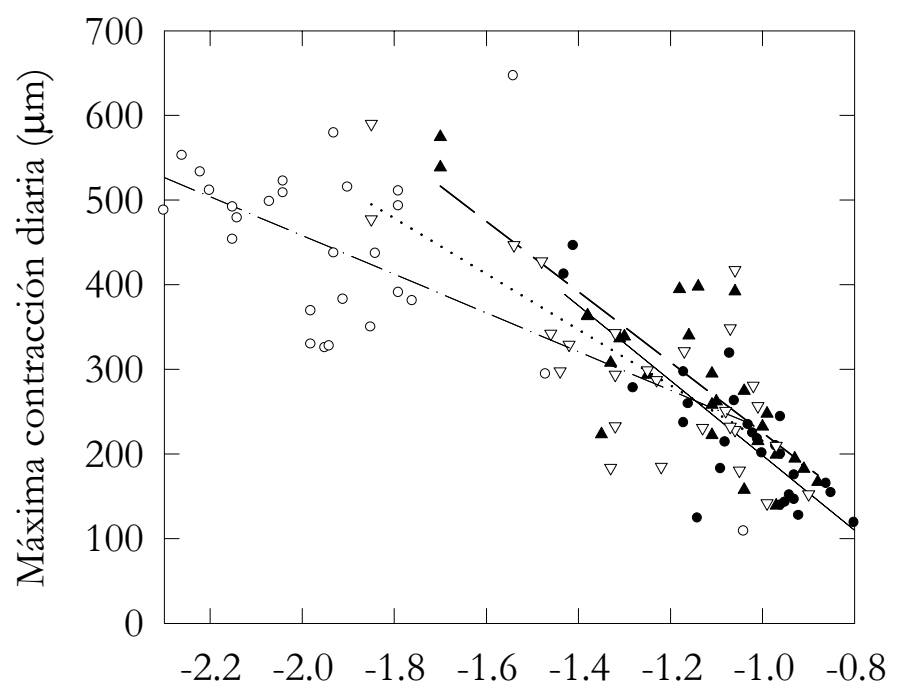

Potencial de tallo $(\mathrm{MPa})$

Figura 6.18. Relación entre la máxima contracción diaria de tronco (MCD) y el potencial de tallo a mediodía $\left(\Psi_{t}\right)$ durante el periodo experimental, para los 4 tratamientos de riego, $\mathrm{T}_{\mathrm{CTL}}(\bullet), \mathrm{T}_{\mathrm{RD} 80}(\bullet), \mathrm{T}_{\mathrm{RD} 60}(\nabla)$ y $\mathrm{T}_{\mathrm{RDC} 20}(\mathrm{O})$. 
La Figura 6.19, muestra el análisis estacional de las regresiones de $\Psi_{\mathrm{t}} \mathrm{y}$ MCD sobre DPV para los distintos tratamientos ensayados. MCD vs DPV mostró en todos los tratamientos coeficientes de determinación altos y superiores a los de $\Psi_{\mathrm{t}}$ (Tabla 6.4), lo que indica que MCD tiene una mayor dependencia de DPV que $\Psi_{\mathrm{t}}$. Al ser ambos parámetros, MCD y DPV, fácilmente automatizables, es factible establecer protocolos de manejo de riego, en función del periodo fenológico, a partir de las relaciones MCD vs DPV.

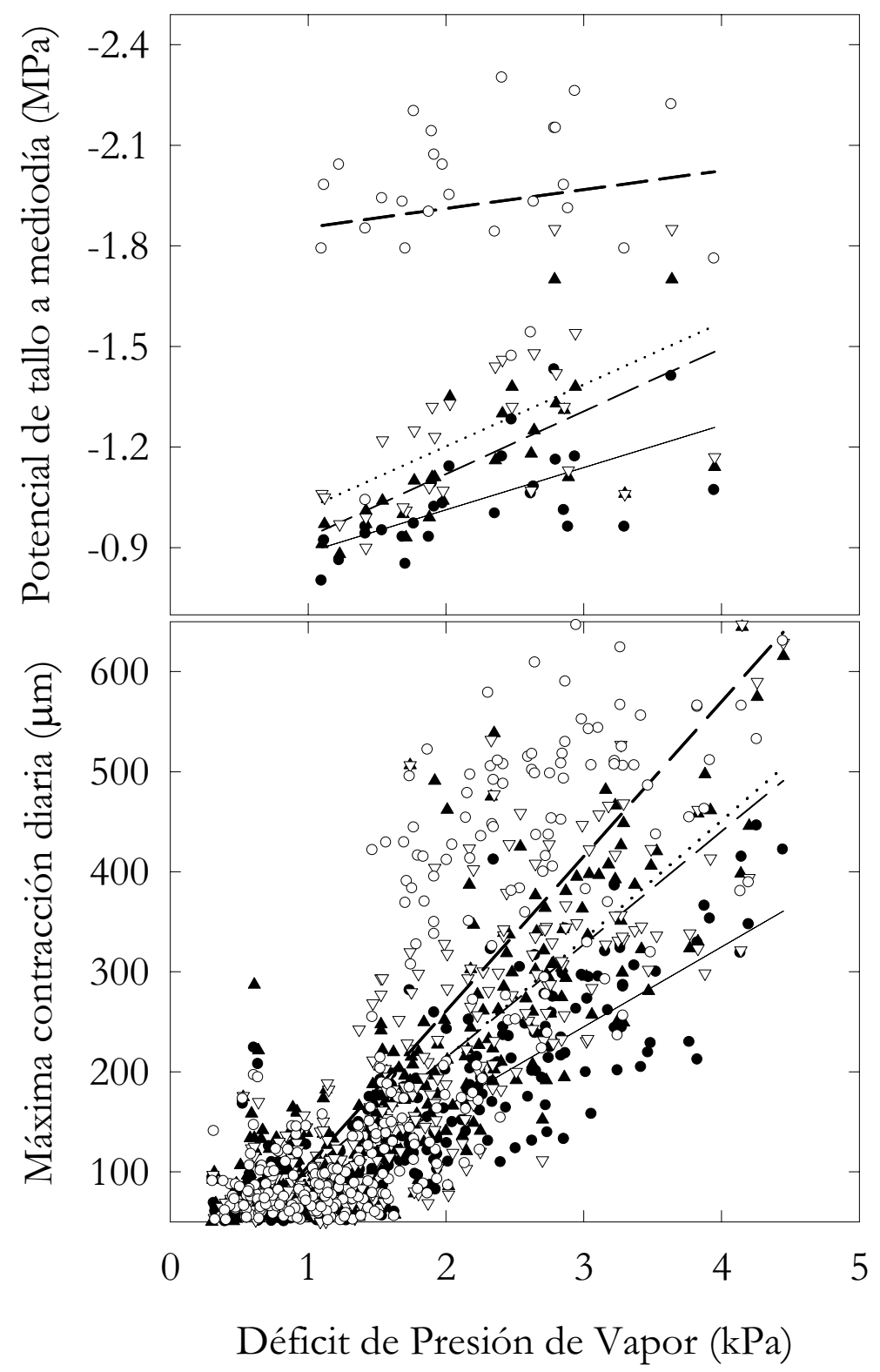

Figura 6.19. Relaciones entre el déficit de presión de vapor máximo diario (DPV) y el potencial de tallo a mediodía $\left(\Psi_{t}\right)$ (a) y la máxima contracción diaria (MCD) (b) para los distintos tratamientos de riego, $\mathrm{T}_{\mathrm{CTL}}(\bullet), \mathrm{T}_{\mathrm{RD} 80}(\boldsymbol{\bullet}), \mathrm{T}_{\mathrm{RD} 60}(\nabla)$ y $\mathrm{T}_{\mathrm{RDC} 20}(\mathrm{O})$. 
Tabla 6.3. Relaciones estacionales entre la máxima contracción diaria (MDC, $\mu \mathrm{m}$ ) y el potencial tallo $\left(\Psi_{\mathrm{t}}, \mathrm{MPa}\right)$, para los cuatro tratamientos de riego.

\begin{tabular}{cccc}
\hline $\begin{array}{c}\text { Tratamiento } \\
\left(\mathrm{y}=\mathrm{y}_{0}+\mathrm{m} \mathrm{x}\right)\end{array}$ & $\mathbf{m}$ & $\mathrm{y}_{0}$ & $\mathbf{R}^{2}$ \\
\hline $\mathbf{M C D}_{\mathrm{TCTL}} \boldsymbol{v s} \Psi_{\mathrm{t}}$ & -441 & -243 & $0.696^{* * *}$ \\
$\mathbf{M C D}_{\mathrm{TRD} 80} \boldsymbol{v s} \Psi_{\mathrm{t}}$ & -416 & -191 & $0.687^{* * *}$ \\
$\mathbf{M C D}_{\mathrm{TRD60}} \boldsymbol{v s} \Psi_{\mathrm{t}}$ & -328 & -113 & $0.586^{* *}$ \\
$\mathbf{M C D}_{\text {TRDC20 }} \boldsymbol{v s} \Psi_{\mathrm{t}}$ & -228 & 0.6 & $0.307^{* *}$ \\
\hline
\end{tabular}

La Figura 6.20 recoge el análisis de regresión lineal MCD vs DPV a nivel mensual, para los tratamientos $\mathrm{T}_{\mathrm{CTL}} \mathrm{y} \mathrm{T}_{\mathrm{RD} 80}$, a fin de reducir los posibles errores debidos a los cambios que experimenta MCD a lo largo de la estación y que suelen depender principalmente del periodo fenológico y de la competencia existente entre distintos órganos. Fereres y Goldhamer (2003) e Intrigliolo y Castel (2004), en almendro y ciruelo respectivamente, mejoraron substancialmente la relación MCD vs DPV al delimitar la componente estacional.

Tabla 6.4. Relaciones entre el potencial de tallo $\left(\Psi_{\mathrm{t}}, \mathrm{MPa}\right)$ y la máxima contracción diaria $(\mathrm{MDC}, \mu \mathrm{m})$ frente al déficit de presión de vapor máximo a mediodía (DPV, $\mathrm{kPa}$ ), para los cuatro tratamientos de riego.

\begin{tabular}{|c|c|c|c|}
\hline $\begin{array}{c}\text { Relación } \\
\left(\mathrm{y}=\mathrm{y}_{0}+\mathrm{m} \mathrm{x}\right)\end{array}$ & $\mathrm{m}$ & $\mathrm{y}_{0}$ & $\overline{\mathbf{R}^{2}}$ \\
\hline$\Psi_{\mathrm{t}} v s \operatorname{DPV}\left(\mathrm{T}_{\mathrm{CTL}}\right)$ & -0.12 & -0.76 & $0.38^{* * *}$ \\
\hline$\Psi_{\mathrm{t}}$ vs DPV $\left(\mathrm{T}_{\mathrm{RD} 80}\right)$ & -0.19 & -0.74 & $0.44^{* * *}$ \\
\hline$\Psi_{\mathrm{t}} v s \mathrm{DPV}\left(\mathrm{T}_{\mathrm{RD} 60}\right)$ & -0.18 & -0.83 & $0.32^{* *}$ \\
\hline$\Psi_{\mathrm{t}} v s \mathrm{DPV}\left(\mathrm{T}_{\mathrm{RDC} 20}\right)$ & -0.05 & -1.79 & $0.02^{\mathrm{n} . \mathrm{s}}$ \\
\hline MCD vs DPV ( $\left.\mathrm{T}_{\mathrm{CTL}}\right)$ & 79 & 5 & $0.73^{* * *}$ \\
\hline $\mathrm{MCD}$ vs $\mathrm{DPV}\left(\mathrm{T}_{\mathrm{RD} 80}\right)$ & 113 & -12 & $0.71^{* * *}$ \\
\hline $\mathrm{MCD}$ vs $\mathrm{DPV}\left(\mathrm{T}_{\mathrm{RD} 60}\right)$ & 118 & -24 & $0.71^{* * *}$ \\
\hline $\mathrm{MCD}$ vs $\mathrm{DPV}\left(\mathrm{T}_{\mathrm{RDC} 20}\right)$ & 154 & -49 & $0.69^{* * *}$ \\
\hline
\end{tabular}




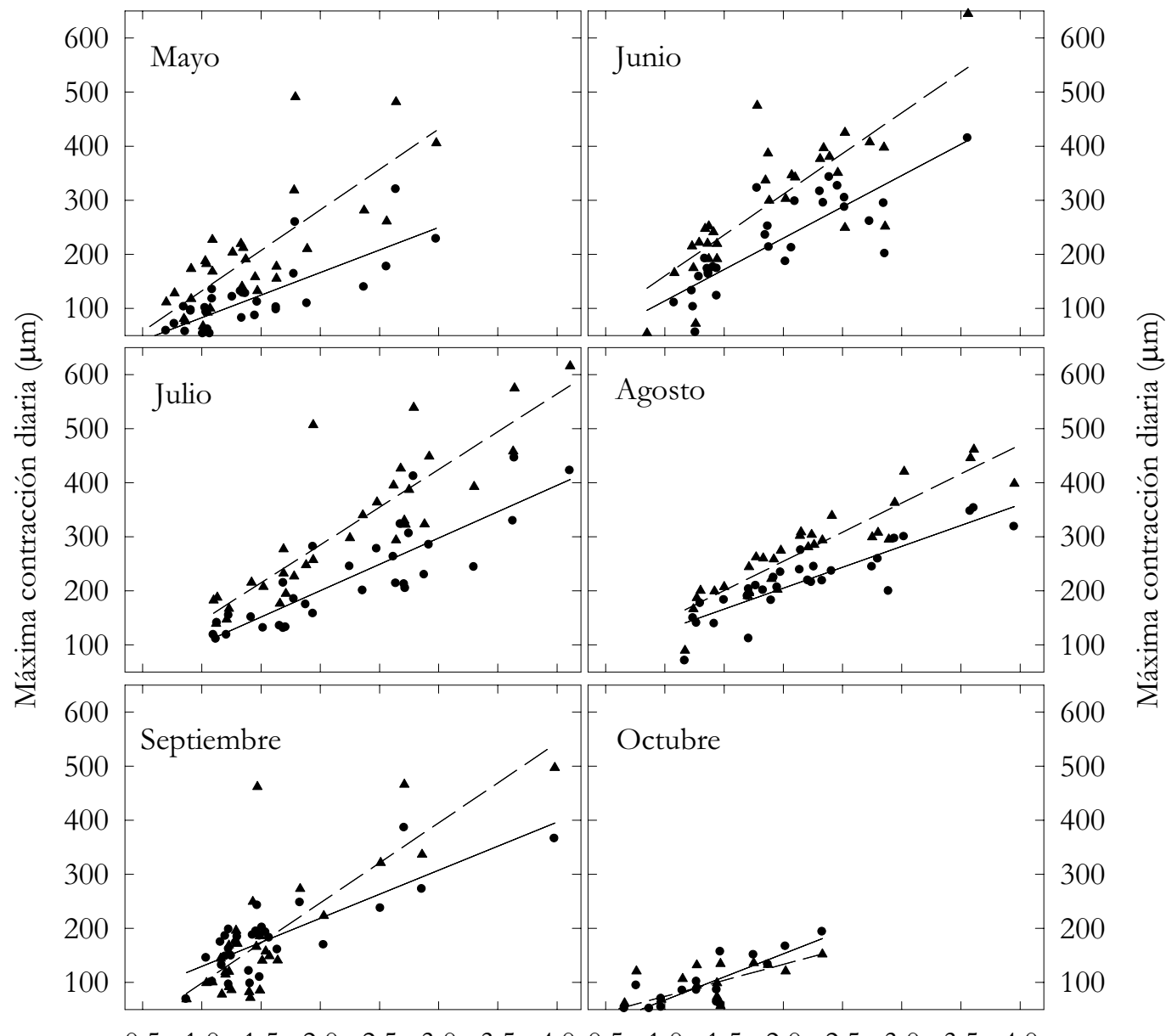

$\begin{array}{llllllllllllllll}0.5 & 1.0 & 1.5 & 2.0 & 2.5 & 3.0 & 3.5 & 4.0 & 0.5 & 1.0 & 1.5 & 2.0 & 2.5 & 3.0 & 3.5 & 4.0\end{array}$

Déficit de presión de vapor $(\mathrm{kPa})$

Figura 6.20. Relaciones mensuales entre la máxima contracción diaria de tronco (MCD) y el déficit de vapor máximo diario (DPV) para los tratamientos de riego $\mathrm{T}_{\mathrm{CTL}}(\bullet)$ y $\mathrm{T}_{\mathrm{RD} 80}$ $(\Delta)$.

El manejo del riego vendría dado en función de la máxima contracción diaria de referencia $\left(\mathrm{MCD}_{\text {ref }}\right)$, que sería la obtenida a partir de la relación en cada uno de los periodos seleccionados entre MCD y DPV durante el 2003 para los tratamientos $\mathrm{T}_{\mathrm{CTL}}$ y $\mathrm{T}_{\mathrm{RD} 80}$ (Figura 6.20 y Tabla 6.5), delimitando como límite superior el valor correspondiente a $\mathrm{T}_{\mathrm{RD} 80}$ y límite inferior el de $\mathrm{T}_{\mathrm{CTL}}$, a fin de evitar exceso de aportes hídricos, como altos déficit hídricos. De este modo y a partir de esta información, se regará a fin de mantener en función del DPV actual, el valor de MCD comprendido entre las correlaciones anteriores, aumentando o disminuyendo un porcentaje determinado del volumen de riego programado. 
Tabla 6.5. Relaciones mensuales entre la máxima contracción diaria de tronco (MCD) y el déficit de vapor máximo diario (DPV) para los tratamientos de riego $\mathrm{T}_{\mathrm{CTL}}(\bullet)$ y $\mathrm{T}_{\mathrm{RD} 80}(\mathbf{\bullet})$

\begin{tabular}{ccccc}
\hline $\mathbf{y}=\mathbf{m x}+\mathbf{b}$ & $\mathbf{M C D}_{\text {ref }}$ & $\mathbf{m}$ & $\mathbf{y}_{\mathbf{0}}$ & $\mathbf{R}^{2}$ \\
\hline \multirow{2}{*}{ Mayo } & $\mathbf{T}_{\mathrm{CTL}}$ & $83^{* * *}$ & $-0.3^{* * *}$ & 0.63 \\
& $\mathbf{T}_{\mathrm{RD} 80}$ & 149 & -17 & 0.64 \\
\hline Junio & $\mathbf{T}_{\mathrm{CTL}}$ & $116^{* *}$ & $-19^{* *} \mathrm{a}$ & 0.71 \\
& $\mathbf{T}_{\mathrm{RD} 80}$ & 150 & 9.1 & 0.65 \\
\hline \multirow{2}{*}{ Julio } & $\mathbf{T}_{\mathrm{CTL}}$ & $97^{* *}$ & 5 & 0.73 \\
\hline Agosto & $\mathbf{T}_{\mathrm{RD} 80}$ & 139 & 5 & 0.76 \\
\hline \multirow{2}{*}{ Septiembre } & $\mathbf{T}_{\mathrm{CTL}}$ & $77^{* *}$ & 49 & 0.77 \\
& $\mathbf{T}_{\mathrm{RD} 80}$ & $107 \mathrm{a}$ & 38 & 0.84 \\
\hline Octubre & $\mathbf{T}_{\mathrm{CTL}}$ & $88^{* * *}$ & $41^{* * *}$ & 0.66 \\
& $\mathbf{T}_{\mathrm{RD} 80}$ & 148 & -49 & 0.63 \\
\hline & $\mathbf{T}_{\mathrm{CTL}}$ & 85 & $-17^{* *}$ & 0.72 \\
\hline
\end{tabular}

\subsubsection{Conclusiones}

El potencial hídrico de tallo a mediodía, la máxima contracción y la tasa de crecimiento diaria de tronco fueron sensibles a los cambios de contenido de humedad del suelo como consecuencia del régimen hídrico, por lo que pueden ser considerados como herramientas útiles para el manejo del riego de almendros en crecimiento.

En respuesta a los distintos niveles de déficit hídrico ensayados, los árboles desarrollaron mecanismos de evitación basados en la regulación estomática que resultó favorecida por los aumentos de la resistencia al flujo de agua a través de la planta, y por posibles emisiones de señales químicas desde las raíces.

Tras el estrés, la persistente regulación estomática favoreció la rápida rehidratación de los tejidos foliares, por lo que los parámetros derivados de las fluctuaciones de diámetro de tronco, máxima contracción y tasa de crecimiento diaria detectaron más rápidamente condiciones de suministro 
hídrico adecuado que el potencial hídrico de tallo. Mientras que fueron igualmente válidos para la detección de agotamientos de agua en suelo como consecuencia de la reducción de las dosis de riego.

El orden de mayor a menor sensibilidad para los tres indicadores estudiados fue $\Psi_{t}>$ MDC $>$ TCD, como consecuencia de la menor variabilidad de las medidas de potencial hídrico de tallo a mediodía. Sin embargo, la rápida detección de los cambios de humedad por MCD y TCD en conjunción con su seguimiento en tiempo real les convierte en útiles herramientas para el manejo y automatización del riego.

La estrecha relación observada a nivel estacional y mensual entre la máxima contracción diaria (MCD) y el déficit de presión de vapor (DPV), podría ser utilizada como herramienta de programación automática del riego. 
Bibliografía 

Abrisqueta, J.M., Hernansáez, A. y Franco, J.A. 1994. Root dynamics of young almond trees under different drip-irrigation rates. Journal of Horticultural Science (69):237-242.

Alarcón, J.J., Sánchez Blanco, M.J., Bolarín, M.C. y Torrecillas, A. 1993. Water relations and osmotic adjustment in lycopersicon-esculentum and l-pennellii during short-term salt exposure and recovery. Physiologia Plantarum (89):441-447.

Allen, RG., Pereira, LS., Raes, D., y Smith, M. 1998. Crop evapotranspiration. Guidelines for computing crop water requirements. FAO, Rome: FAO - irrigation and drainage paper 56.

Allen, R.G. y Fisher, D.K. 1990. Low-cost electronic weighing lysimeters. Transactions of the Asae (33):1823-1833.

Ameglio, T., Archer, P., Cohen, M., Valancogne, C., Daudet, F.A., Dayau, S. y Cruiziat, P. 1998. Significance and limits in the use of predawn leaf water potential for tree irrigation. Plant and Soil (207):155-167.

Aslam, M., Lowe, S.B. y Hunt, L.A. 1977. Effect of leaf age on photosynthesis and transpiration of cassava (manibot-esculenta). Canadian Journal of Botany-Revue Canadienne de Botanique (55):2288-2295.

Assaf, R., Levin, I. y Bravdo, B.A. 1989. Optimization of water for fruit-trees by a computerized irrigation system. Agronomie (9):451-456.

Aussenac, G. y Valette, J.C. 1982. Summer water status of cedrus-atlantica manetti, quercus-ilex and quercus-pubescens willd and of some pinetrees on the Mont-Ventoux. Annales des Sciences Forestieres (39):41-62.

Ayers, RS y Westcot, DW. 1987. La calidad del agua en la agricultura. Roma: Food and Agriculture Organization of the United Nations.

Baille, A. 1992. Water status monitoring in greenhouse crops. Acta Horticulturae (304):15-27.

Banuls, J. y Primomillo, E. 1992. Effects of chloride and sodium on gasexchange parameters and water relations of citrus plants. Physiologia Plantarum (86):115-123. 
Besset, J., Gènard M., Girard T., Serra, V. y Bussi, C. 2001. Effect of water stress applied during the final stage of rapid growth on peach trees $(\mathrm{cv}$. Big-Top). Scientia Horticulturae (91):289-303.

Boland, A.M., Mitchell, P.D., Jerie, P.H. y Goodwin, I. 1993. The effect of regulated deficit irrigation on tree water-use and growth of peach. Journal of Horticultural Science (68):261-274.

Bolarín, M.C. y Caro, M. 1995. Aguas de riego. En: Álvarez-Cobelas, M y Cabrera, F. (ed.) La calidad de las aguas continentales españolas: estado actual e investigación. Logroño: Geoforma Ediciones.

Breda, N.J.J. 2003. Ground-based measurements of leaf area index: a review of methods, instruments and current controversies. Journal of Experimental Botany (54):2403-2417.

Bresler, E. y Hoffman, G.J. 1986. Irrigation management for soil-salinity control - theories and tests. Soil Science Society of America Journal (50):1552-1559.

Brough, D.W., Jones, H.G. y Grace, J. 1986. Diurnal changes in water-content of the stems of apple-trees, as influenced by irrigation. Plant Cell and Environment (9):1-7.

Brown, D.S. 1953. The effects of irrigation on flower bud development and fruiting in the apricot. Proceedings of the American Society for Horticultural Science (61):119-124.

Brown, P.H. y Uriu, K. 1996. Nutrition deficiencies and toxicities: diagnosis and correcting imbalances. En: Micke WC. (ed.). Almond production manual. University of California: Division of Agriculture and Natural Resouces. p 179-188.

Brun, C.A., Raese, J.T. y Stahly, E.A. 1985. Seasonal response of anjou pear trees to different irrigation regimes .2. Mineral-composition of fruit and leaves, fruit disorders, and fruit-set. Journal of the American Society for Horticultural Science (110):835-840.

Campbell, C.S., Campbell, G.S., Cobos, D.R. y Teare, B. 2006. Performance of a new, low-cost soil moisture, temperature, and electrical conductivity sensor. HortScience (41):1024.

Campbell, G.S. 1988. Soil water potential measurement - An overview. Irrigation Science (9):265-273. 
Campbell, G.S. y Gardner, W.H. 1971. Psychrometric measurement of soil water potential - temperature and bulk density effects. Soil Science Society of America Proceedings (35):8-\&.

Caspari, H.W., Behboudian, M.H. y Chalmers, D.J. 1994. Water-use, growth, and fruit yield of Hosui Asian pears under deficit irrigation. Journal of the American Society for Horticultural Science (119):383-388.

Castel, J.R. y Fereres, E. 1982. Responses of young almond trees to two drought periods in the field. Journal of Horticultural Science (57):175187.

Catlin, P.B. 1996. Root systems and root physiology. En: Micke, WC. (ed.). Almond production manual. University of California: Division of Agricultural and Natural Resources. p 107-112.

Chalmers, D.J., Burge, G., Jerie, P.H. y Mitchell, P.D. 1986. The mechanism of regulation of Bartlett pear fruit and vegetative growth by irrigation withholding and regulated deficit irrigation. Journal of the American Society for Horticultural Science (111):904-907.

Chalmers, D.J., Mitchell, P.D. y Van Heek, L.A.G. 1981. Control of peach tree growth and productivity by regulated water supply, tree density, and summer prunning. Journal of the American Society for Horticultural Science (106):307-312.

Chanzy, A., Bertuzzi, P., Bruckler, L., y Gaudu, J.C. 1997. Mesure de la teneur en eau et du potentiel hydrique dans le sol. En: L'eau dans l'espace rural: production végétale et qualité de l'eau. Riou, C., Bonhomme, R., Chassin, P., Neveu, A. y Papy, F. (ed.). Paris: INRA editions. p 143152.

Chen, J.M. y Black, T.A. 1992. Defining leaf-area index for non-flat leaves. Plant Cell and Environment (15):421-429.

Chone, X., van Leeuwen, C., Dubourdieu, D. y Gaudillere, J.P. 2001. Stem water potential is a sensitive indicator of grapevine water status. Annals of Botany (87):477-483.

Christen, P. 1969. Seasonal changes and distribution of nutritional elements in Thompson Seedless grapevines. American Journal of Enology and Viticulture (20):176-\&.

Cochard, H. 1992. Vulnerability of several conifers to air-embolism. Tree Physiology (11):73-83. 
Cochard, H. 2006. Cavitation in trees. Comptes Rendus Physique (7):10181026.

Cohen, M., Goldhamer, D.A., Fereres, E., Girona, J. y Mata, M. 2001. Assessment of peach tree responses to irrigation water deficits by continuous monitoring of trunk diameter changes. Journal of Horticultural Science \& Biotechnology (76):55-60.

Cruiziat, P., Cochard, H. y Améglio, T. 2002. Hydraulic architecture of trees: main concepts and results. Annals of Forest Sciences (59):723-752.

Daudet, F.A. y Vachaud, G. 1977. Neutronic measure of water stock in soil applications to determination of water-balance. Annales Agronomiques (28):503-519.

Davies, W.J. y Zhang, J. 1991. Root signals and the regulation of growth and development of plants in drying soil. Annual Review of Plant Physiology (42):55-76.

Dejong, T.M., Doyle, J.F. y Day, K.R. 1987. Seasonal patterns of reproductive and vegetative sink activity in early and late maturing peach (PrunusPersica) cultivars. Physiologia Plantarum (71):83-88.

Dejong, T.M. y Grossman, Y.L. 1994. A supply and demand approach to modeling annual reproductive and vegetative growth of deciduous fruit trees. HortScience (29):1435-1442.

Del Amor, F., Torrecillas, A., Ruiz-Sánchez, M.C. y Gómez, J. 1987. Respuesta del almendro al riego de alta frecuencia. Fruticultura Profesional (11):77-87.

Demiral, M.A. 2005. Comparative response of two olive (Olea europeae L.) caultivars to salinity. Turkish Journal of Agriculture and Forestry (29):267-274.

Dodd, I.C. 2005. Root-to-shoot signalling: Assessing the roles of 'up' in the up and down world of long-distance signalling in planta. Plant and Soil (274):251-270.

Doltra, J., Oncins, J.A., Bonany, J. y Cohen, M. 2007. Evaluation of plantbased water status indicators in mature apple trees under field conditions. Irrigation Science (25):351-359. 
Domingo, R. 1994. Respuesta del limonero Fino al riego deficitario controlado. Aspectos fisiológicos. Tesis Doctoral. Universidad de Murcia. 237 p.

Domingo, R., Nortes, P.A., Egea, G., Torres, R. y Pérez-Pastor, A. 2005. Utilización de sensores en planta para la programación del riego y uso eficiente del agua en la agricultura. Vida Rural (217):42-46.

Domingo, R., Ruiz-Sánchez, M.C., Nortes, P.A., Torrecillas, A. y PérezPastor, A. 2001. Respuesta productiva de albaricoqueros 'Búlida' al riego deficitario. ITEA (97):123-133.

Domingo, R., Ruiz-Sánchez, M.C., Sánchez-Blanco, M.J. y Torrecillas, A. 1996. Water relations, growth and yield of Fino lemon trees under regulated deficit irrgation. Irrigation Science (16):115-123.

Doorenbos, J. y Pruitt, WO. 1977. Crop water requirements. Roma: FAO.

Doorenbos, J y Pruitt, WO. 1986. Las necesidades de agua de los cultivos. Roma.

Downton, W.J.S. y Millhouse, J. 1983. Turgor maintenance during salt stress prevents loss of variable fluorescence in grapevine leaves. Plant Science Letters (31):1-7.

Dry, P.R. y Loveys, B.R. 1999. Grapevine shoot growth and stomatal conductance are reduced when part of the root system is dried. Vitis (38):151-156.

Dry, P.R., Loveys, B.R. y During, H. 2000. Partial drying of the rootzone of grape. I. Transient changes in shoot growth and gas exchange. Vitis (39):3-7.

Dry, P. R., Loveys, B. R., Düring, H. y Botting, D. G. 1996. Effects of partial rootzone drying on grapevine vigour, yield compositions of fruit and use of water. En: Stockley, C. S., Sas, A. N., Johnstone, R. S. y Lee, T. H. Proc. 9th Aust. Wine Ind. Techn. Conf. Adelaide, Australia,: 128131

Du Plessis, H.M. 1988. Irrigation scheduling of citrus. En: Goren, R. y Mendel, K., (ed.). Proceedings of the Sixth International Citrus Congres. Tel Aviv. Israel: p 731-739. 
Ebel, R.C., Proebsting, E.L. y Evans, R.G. 1995. Deficit irrigation to control vegetative growth in apple and monitoring fruit-growth to schedule irrigation. HortScience (30):1229-1232.

El-Sharkawi, H.M. y El-Monayeri, M. 1976. Response of olive and almond orchards to partial irrigation under dry-farming practices in semi-arid regions. 3. Plant-soil water relations in almond during growing season. Plant and Soil (44):113-128.

Eldredge, E.P., Shock, C.C. y Stieber, T.D. 1993. Calibration of granular matrix sensors for irrigation management. Agronomy Journal (85):1228-1232.

Elfving, D.C., Hall, A.E. y Kaufmann, M.R. 1972. Interpreting leaf water potential measurements with a model of soil-plant-atmosphere continuum. Physiologia Plantarum (27):161-\&.

Esparza, G., Dejong, T.M. y Weinbaum, S.A. 2001a. Effects of irrigation deprivation during the harvest period on nonstructural carbohydrate and nitrogen contents of dormant, mature almond trees. Tree Physiology (21):1081-1086.

Esparza, G., Dejong, T.M., Weinbaum, S.A. y Klein, I. 2001b. Effects of irrigation deprivation during the harvest period on yield determinants in mature almond trees. Tree Physiology (21):1073-1079.

Evett, S.R. y Steiner, J.L. 1995. Precision of neutron scattering and capacitance type soil water content gauges from field calibration. Soil Science Society of America Journal (59):961-968.

Evreinoff, V.A. 1952. Quelque observations biologiques sur l'amandier. International Botanic Applied (359):442-459.

Farquhar, G.D. y Sharkey, T.D. 1982. Stomatal conductance and photosynthesis. Annual Review of Plant Physiology and Plant Molecular Biology (33):317-345.

Felipe, A.J. 1999. El cultivo del almendro. SECH Boletín Informativo, XII, $\mathrm{N}^{\mathrm{o}} 1$.

Felipe, AJ. 2000. El almendro. I. El material vegetal. Editorial Mira.

Fereres, E., Aldrich, T.M., Schulbach, H. y Martinich, D.A. 1981a. Responses of young almond trees to late season drought. California Agriculture (35):11-12. 
Fereres, E., Cruz-Romero, G., Hoffman, G.J. y Rawlins, S.L. 1979. Recovery of orange trees following severe water stress. Journal of Applied Ecology (16):833-842.

Fereres, E. y Goldhamer, D.A. 1990. Deciduous fruit and nut trees. En: Sewart, BA y Nielsen, DR, (ed.). Irrigation of agricultural crops. Madison, WI: American Society of Agronomy. p 987-1017.

Fereres, E. y Goldhamer, D.A. 2000. Avances recientes en la programación de los riegos. Ingeniería del Agua (7):47-54.

Fereres, E. y Goldhamer, D.A. 2003. Suitability of stem diameter variations and water potential as indicators for irrigation scheduling of almond trees. Journal of Horticultural Science \& Biotechnology (78):139-144.

Fereres, E., Martinich, D.A., Aldrich, T.M., Castel, J.R., Holzapfel, E. y Schulbach, H. 1982. Drip irrigation saves money in young almond orchard. California Agriculture (36):12-13.

Fereres, E., Pruitt, W.O., Beutel, J.A., Henderson, D.W., Holzapfel, E., Sculbach, H., y Uriu, K. 1981b. Evapotranspiration and drip irrigation scheduling. En: Fereres E, (ed.). Drip irrigation management. Davis, CA: Univ. of CA. Div. of Agric. Sci. p 8.

Fernández, I.J., Lawrence, G.B. y Richards, K.J. 1990. Characteristics of foliar chemistry in a commercial spruce-fir stand of northern New-England, USA. Plant and Soil (125):288-292.

Fernández, J.E., Moreno, F., Martín-Aranda, J. y Fereres, E. 1992. Olive-tree root dynamics under different soil water regimes. Agricultura Mediterránea (122):225-235.

Fernández, J.E., Palomo, M.J., Díaz-Espejo, A., Clothier, B.E., Green, S.R., Girón, I.F. y Moreno, F. 2001. Heat-pulse measurements of sap flow in olives for automating irrigation: tests, root flow and diagnostics of water stress. Agricultural Water Management (51):99-123.

Fisarakis, I., Chartzoulakis, K. y Stavrakas, D. 2001. Response of Sultana vines ( $V$-vinifera $L$.) on six rootstocks to $\mathrm{NaCl}$ salinity exposure and recovery. Agricultural Water Management (51):13-27.

Fleckinger, J. 1945. Notations phénologiques et représentation graphiques du développment des bourgeons de poiriers. En: CR. Congrès de Paris de l'Association française pour l'avancement des Sciences. Bibliographical 
reference in "Fruticultura de Coutanceau". 1971. Barcelona: Oikos-tau: p 118.

Franco, J.A. y Abrisqueta, J.M. 1997. A comparison between minirhizotron and soil coring methods of estimating root distribution in young almond trees under trickle irrigation. Journal of Horticultural Science (72):797-805.

Franco, J.A., Abrisqueta, J.M., Hernansáez, A. y Moreno, F. 2000. Water balance in a young almond orchard under drip irrigation with water of low quality. Agricultural Water Management (43):75-98.

Fulton, A., Buchner, R., Olson, B., Schwankl, L.J., Gilles, C., Bertagna, N., Walton, J. y Shackel, K.A. 2001. Rapid equilibration of leaf and stem water potential under field conditions in almonds, walnuts and prunes. HortTechnology (11):609-615.

Fulton, A.E., Oster, J.D., y Hanson, B.R. 1996. Salinity management. En: Micke WC, (ed.). Almond production manual. University of California: Division of Agricultural and Natural Resources. p 29-40.

García-Orellana, Y., Ruiz-Sánchez, M.C., Alarcón, J., Conejero, W., Ortuño, M.F., Nicolás, E. y Torrecillas, A. 2007. Preliminary assessment of the feasibility of using maximum daily trunk shrinkage for irrigation scheduling in lemon trees. Agricultural Water Management (89):167171.

Gardner, C.M.K., Dean, T.J. y Cooper, J.D. 1998. Soil water content measurement with a high-frequency capacitance sensor. Journal of Agricultural Engineering Research (71):395-403.

Gardner, FP., Pearce, RB. y Mitchell, RL. 1990. Physiology of crops plants.

Gardner, W.H. 1986. Water content. En: Klute A, (ed.). Methods of soil analysis, Part 1. Madison, USA: ASA-SSSA. p 493-544.

Garnier, E. y Berger, A. 1985. Testing water potential in apple trees as an indicator of water stress. Journal of Horticultural Science (60):47-56.

Gaudu, J.C., Mathieu, J.M., Fumanal, J.C., Bruckler, L., Chanzy, A., Bertuzzi, P., Stengel, P. y Guennelon, R. 1993. Mesure de l'humidité des sols par une méthode capacitive: analyse des facteurs influençant de la mesure. Agronomie (13):57-73. 
Gebre, G.M. y Kuhns, M.R. 1993. Effects of water-stress preconditioning on gas-exchange and water relations of Populus-Deltoides clones. Canadian Journal of Forest Research-Revue Canadienne de Recherche Forestiere (23):1291-1297.

Gènard, M., Fishman, S., Vercambre, G., Huguet, J.G., Bussi, C., Besset, J. y Habib, R. 2001. A biophysical analysis of stem and root diameter variations in woody plants. Plant Physiology (126):188-202.

Germana, C. 1997. Experiences on the response of almond plants (Amygdalus communis L.) to water stress. Acta Horticulturae (449):497-503.

Gilliam, J.W. 1971. Rapid measurement of chlorine in plant materials. Soil Science Society of America Proceedings (35):512-\&.

Ginestar, C. y Castel, J.R. 1996. Utilización de dendrómetros como indicador de estrés hídrico en mandarinos jóvenes regados por goteo. Riegos y Drenajes XXI (89):40-46.

Giorio, P. y Giorio, G. 2003. Sap flow of several olive trees estimated with the heat-pulse technique by continuous monitoring of a single gauge. Environmental and Experimental Botany (49):9-20.

Girona, J. 1992. Estrategias de riego deficitario en el cultivo del almendro. Fruticultura Profesional (47):38-45.

Girona, J. 2006. La respuesta del cultivo del almendro al riego. Vida Rural (234):12-16.

Girona, J., Marsal, J., Cohen, M., Mata, M. y Miravete, C. 1993a. Physiological, growth and yield responses of almonds (Prunus dulcis L.) to different irrigation regimes. Acta Horticulturae (335):389-398.

Girona, J., Marsal, J., Mata, M., Arbonés, A. y Dejong, T.M. 2004. A comparison of the combined effect of water stress and crop load on fruit growth during different phenological stages in young peach trees. Journal of Horticultural Science \& Biotechnology (79):308-315.

Girona, J., Marsal, J., Mata, M., Arbonés, A. y Miravete, C. 1997. Evaluation of almond (Prunus amygdalus L.) seasonal sensitivity to water stress. Physiological and yield responses. Acta Horticulturae (449):489-496.

Girona, J., Mata, M., del Campo, J., Arbonés, A., Bartra, E. y Marsal, J. 2006. The use of midday leaf water potential for scheduling deficit irrigation in vineyards. Irrigation Science (24):115-127. 
Girona, J., Mata, M., Goldhamer, D.A., Johnson, R.S. y Dejong, T.M. 1993b. Patterns of soil and tree water status and leaf functioning during regulated deficit irrigation scheduling in peach. Journal of the American Society for Horticultural Science (118):580-586.

Girona, J. y Marsal, J. 1995. Estrategias de RDC en almendro. En: Riego Deficitario Controlado. Zapata M. y Segura P., (ed.). España: Mundi Prensa. p 97-118.

Girona, J., Mata, M. y Marsal, J. 2005. Regulated deficit irrigation during the kernel-filling period and optimal irrigation rates in almond. Agricultural Water Management (75):152-167.

Goldhamer, D.A. 1996. Irrigation Scheduling. En: Almond production manual.. Micke WC, (ed.). University of California. Division of agriculture and natural resources. p 171-178.

Goldhamer, D.A. y Fereres, E. 2001. Irrigation scheduling protocols using continuously recorded trunk diameter measurements. Irrigation Science (20):115-125.

Goldhamer, D.A. y Fereres, E. 2004. Irrigation scheduling of almond trees with trunk diameter sensors. Irrigation Science (23):11-19.

Goldhamer, D.A., Fereres, E., Cohen, M., Girona, J. y Mata, M. 2000. Comparison of continuous and discrete plant-based monitoring for detecting tree water deficits and barriers to grower adoption for irrigation management. Acta Horticulturae (537):431-445.

Goldhamer, D.A., Fereres, E., Mata, M., Girona, J. y Cohen, M. 1999. Sensitivity of continuous and discrete plant and soil water stress monitoring in peach trees subjected to deficit irrigation. Journal of the American Society for Horticultural Science (124):437-444.

Goldhamer, D.A., Salinas, M., Crisosto, C., Day, K.R., Soler, M. y Moriana, A. 2002. Effects of regulated deficit irrigation and partial root zone drying on late harvest peach tree performance. Acta Horticulturae (592):343350.

Goldhamer, D. A. and Shackel, K. A. 1989. Irrigation cutoff and drought irrigation strategy effects on almond. En: 17th Annual Almond Research Conference. Modesto,: 35-37 
Goldhamer, D.A. y Smith, T.E. 1995. Single-season drought irrigation strategies influence almond production. California Agriculture (49):1922.

Goldhamer, D.A. y Viveros, M. 2000. Effects of preharvest irrigation cutoff durations and postharvest water deprivation on almond tree performance. Irrigation Science (19):125-131.

Goldhamer, D.A., Viveros, M. y Salinas, M. 2006. Regulated deficit irrigation in almonds: effects of variations in applied water and stress timing on yield and yield components. Irrigation Science (24):101-114.

González-Altozano, P. y Castel, J.R. 1999. Regulated deficit irrigation in 'Clementina de Nules' citrus trees. I. Yield and fruit quality effects. Journal of Horticultural Science \& Biotechnology (74):706-713.

Goode, J.E. y Higgs, K.H. 1973. Water, osmotic and pressure potential relationships in apple leaves. Journal of Horticultural Science (48):203215.

Gowing, D.J.G., Davies, W.J. y Jones, H.G. 1990. A positive root-sourced signal as an indicator of soil drying in apple, Malus $\times$ Domestica-Borkh. Journal of Experimental Botany (41):1535-1540.

Granier, A. 1985. Une nouvelle methode pour la mesure des flux de seve dans le tronc des arbres. Annales des Sciences Forestieres (42):193-200.

Grasselly, C. y Crossa-Raynaud, P. 1984. El almendro. Madrid: Ediciones Mundi-Prensa.

Green, S.R. y Clothier, B.E. 1988. Water-use of kiwifruit, vines and appletrees by the heat-pulse technique. Journal of Experimental Botany (39):115-123.

Hatfield, J.L. 1990. Methods of estimating evapotranspiration. En: Irrigation of agricultural crops. Steward, BA. y Nielsen, DR., (ed.). Madison, USA: ASA-CSSA-SSSA. p 435-474.

Henson, I.E., Alagarswamy, G., Bidinger, F.R. y Mahalakshmi, V. 1982. Stomatal responses of pearl-millet (Pennisetum-Americanum L Leeke) to leaf water status and environmental-factors in the field. Plant Cell and Environment (5):65-74. 
Hilgeman, R.H. y Sharp, F.O. 1970. Response of valencia orange trees to 4 soil water schedules during 20 years. Journal of the American Society for Horticultural Science (95):739-\&.

Hilhorst, M.A. y Dirksen, C. 1994. Dielectric water content sensors: time domain versus frequency domain. En: Proceedings of the Symposium on TDR in Environmental Infrastructure and Mining Applications. Evanston, Illinois, USA: p 23-33.

Hillel, D. 1990. Role of irrigation in agricultural systems. En: Irrigation of agricultural crops. Stewart, BA. y Nielsen, DR., (ed.). Agronomy. Wisconsin, USA: p 5-31.

Hsiao, T.C. 1973. Plant responses to water stress. Annual Review of Plant Physiology (24):519-570.

Hsiao, T.C. 1990. Measurements of plant water status. En: Irrigation of Agricultural Crops. Steward, BA. y Nielsen, DR., (ed.). Madison,Wis.: American Society of Agronomy. p 243-279.

Huber, B. 1932. Beobachtung und Messung pflanzicher Saftstrome. Berichte der Deutschen botanischen Gesellschaft (50):89-109.

Hueso, J.J. 2005. Riego deficitario controlado en níspero japonés. Tesis Dosctoral. Universidad de Almería.

Huguet, J.G., Li, S.H., Lorendeau, J.Y. y Pelloux, G. 1992. Specific micromorphometric reactions of fruit-trees to water-stress and irrigation scheduling automation. Journal of Horticultural Science (67):631-640.

Hutmacher, R.B., Nightingale, H.I., Rolston, D.E., Biggar, J.W., Dale, F., Vail, S.S. y Peters, D. 1994. Growth and yield responses of almond (PrunusAmygdalus) to trickle irrigation. Irrigation Science (14):117-126.

Idso, S.B., Jackson, R.D., Pinter, P.J., Reginato, R.J. y Hatfield, J.L. 1981. Normalizing the stress-degree-day parameter for environmental variability. Agricultural Meteorology (24):45-55.

Intrigliolo, D.S. y Castel, J.R. 2004. Continuous measurement of plant and soil water status for irrigation scheduling in plum. Irrigation Science (23):93-102. 
Intrigliolo, D.S. y Castel, J.R. 2005a. Effects of regulated deficit irrigation on growth and yield of young Japanese plum trees. Journal of Horticultural Science \& Biotechnology (80):177-182.

Intrigliolo, D.S. y Castel, J.R. 2005b. Usefulness of diurnal trunk shrinkage as a water indicator in plum trees. Tree Physiology (26):303-311.

Intrigliolo, D.S. y Castel, J.R. 2006. Performance of various water stress indicators for prediction of fruit size response to deficit irrigation in plum. Agricultural Water Management (83):173-180.

Intrigliolo, D.S., Pérez, D. y Castel, J.R. 2005. Water relations of field grown drip irrigated "Tempranillo" grapevines in Requena, Spain. Acta Horticulturae (689):317-323.

Irvine, J. y Grace, J. 1997. Continuous measurement of water tensions in the xylem of trees based on the elastic properties of wood. Planta (202):455-461.

Irving, D.E. y Drost, J.H. 1987. Effects of water deficit on vegetative growth, fruit-growth and fruit-quality in Cox orange pippin apple. Journal of Horticultural Science (62):427-432.

Itier, B. 1996. Applicability and limitations of irrigation scheduling methods and techniques. En: Irrigation Scheduling: from theory to practice. Rome, Italy: FAO.

Jackson, R.D. 1982. Canopy temperature and crop water stress. Advances in Irrigation (1):43-85.

Jasso, C., Vera, J. y Núñez, R. 1999. Dinámica de nutrientes en hojas de melocotonero cultivado en condiciones de salinidad y riego localizado. Fruticultura Profesional (101):43-57.

Jones, H. 2004. Irrigation scheduling:advantages and pitfalls of plant-based methods. Journal of Experimental Botany (55):2427-2436.

Jones, H. 2007. Monitoring plant and soil water status: established and novel revisited and their relevance to studies of drought tolerance. Journal of Experimental Botany (58):119-130.

Jones, H.G. 1983. Estimation of an effective soil-water potential at the root surface of transpiring plants. Plant Cell and Environment (6):671-674. 
Jones, H.G. 1990. Physiological aspects of the control of water status in horticultural crops. HortScience (25):19-26.

Jones, H.G. y Sutherland, R.A. 1991. Stomatal control of xylem embolism. Plant Cell and Environment (14):607-612.

Katerji, N., Schoch, P.G., Rimgoto, P. y Lhotel, J.C. 1990. Diagnosis via stem microvariations of water-stress periods in greenhouse-grown eggplants. Agronomie (10):541-549.

Katerji, N., van Hoorn, J.W., Hamdy, A. y Mastrorilli, M. 2003. Salinity effect on crop development and yield, analysis of salt tolerance according to several classification methods. Agricultural Water Management (62):3766.

Kilili, A.W., Behboudian, M.H. y Mills, T.M. 1996. Water relations, photosynthesis, growth, and yield of 'Braeburn' apples under reduced irrigation applied at different stages of the growing season. Gartenbauwissenschaft (61):267-273.

Klein, I., Esparza, G., Weinbaum, S.A. y Dejong, T.M. 2001. Effects of irrigation deprivation during the harvest period on leaf persistence and function in mature almond trees. Tree Physiology (21):1063-1072.

Klepper, B., Browing, U.D. y Taylor, H.M. 1971. Stem diameter in relation to plant water status. Plant Physiology (48):683-685.

Knipling, E.B. 1967. Effect of leaf aging on water deficit-water potential relationships of dogwood leaves growing in 2 environments. Physiologia Plantarum (20):65-\&.

Kozlowski, T.T. 1966. Expansion and contraction as indices of water stress in tree seedlings. Plant Physiology. 5-\&.

Kozlowski, T.T. 1967. Diurnal variations in stem diameters of small trees. Botanical Gazette (128):60-\&.

Kozlowski, T.T. 1968. Diurnal changes in diameters of fruits and tree stems of montmorency cherry. Journal of Horticultural Science \& Biotechnology (43):1-\&.

Kozlowsky, T.T. y Winget, C.H. 1964. Diurnal and seasonal variation in radii of tree stems. Ecology (45):149-155. 
Kramer, P.J. 1983. Problems in water relations of plants and cells. International Review of Cytology-A Survey of Cell Biology (85):253286.

Kramer, P.J. 1988. Changing concepts regarding plant water relations. Plant Cell and Environment (11):565-568.

Lakso, A.N., Geyer, A.S. y Carpenter, S.G. 1984. Seasonal osmotic relations in apple leaves of different ages. Journal of the American Society for Horticultural Science (109):544-547.

Lampinen, B., Shackel, K.A., Southwick, S., Olson, B., Yeager, J. y Goldhamer, D.A. 1995. Sensitivity of yield and fruit quality of French prune to water deprivation at different fruit growth stages. Journal of the American Society for Horticultural Science (120):139-147.

Lampinen, B., Shackel, K.A., Southwick, S. y Olson, W. 2001. Deficit irrigation strategies using midday stem water potential in prune. Irrigation Science (20):47-54.

Landsberg, J.J., Blanchard, T.W. y Warrit, B. 1976. Studies on movement of water through apple-trees. Journal of Experimental Botany (27):579596.

León, A., DelAmor, F., Torrecillas, A. y Ruiz-Sánchez, M.C. 1985. Drip irrigation in young almond trees. Fruits (40):659-663.

Leverenz, J., Deans, J.D., Ford, E.D., Jarvis, P.G., Milne, R. y Whitehead, D. 1982. Systematic spatial variation of stomatal conductance in a sitka spruce plantation. Journal of Applied Ecology (19):835-851.

Li, S.H., Bussi, C., Hugard, J. y Clanet, H. 1989a. Critical period of flower bud induction in peach-trees Associated with shoot length and bud position. Gartenbauwissenschaft (54):49-53.

Li, S.H., Huguet, J.G., Schoch, P.G. y Orlando, P. 1989b. Response of peachtree growth and cropping to soil-water deficit at various phenological stages of fruit-development. Journal of Horticultural Science (64):541552.

López-Ritas, J. 1972. El almendro y su cultivo. Ministerio de Agricultura. 313 pp. 
Lösch, R. 1979. Stomatal responses to changes in air humidity. En: Structure, funtion and ecology of stomata. Sen, DN., Chawan, DD., y Bansal, RP., (ed.). p 189-216.

Loveys, B., Stoll, M., y Davies, F.S. 2004. Physiological approaches to enhance water use efficiency in agriculture:exploiting plant signalling in novel irrigation practice. En: Water Use Efficiency in Plant Biology. Bacon, MA., (ed.). Oxford, UK: Blackwell Publishing Ltd. p 113-138.

Lynn, B.H. y Carlson, T.N. 1990. A stomatal-resistance model illustrating plant vs external control of transpiration. Agricultural and Forest Meteorology (52):5-43.

MAPA. Anuario de estadística agroalimentaria 2004 www.mapa.es

Maas, E.V. 1986. Salt tolerance of plants. International Jurnal of Applied Agricultural Research (1):12-26.

Maas, E.V. 1990. Crop salt tolerance. En: Agricultural salinity assessment and management. Tangi, KK., (ed.). New York: American society of civil engineers. p 287-290.

Mansfield, T.A. y Davies, W.J. 1981. Stomata and stomatal mechanisms. En: The physiology and biochemistry of drought resistance in plants. Paleg, LG. y Aspinall, D., (ed.). New York: p 315-346.

Marsal, J., Girona, J. y Mata, M. 1997. Leaf water relation parameters in almond compared to hazelnut trees during a deficit irrigation period. Journal of the American Society for Horticultural Science (122):582587.

Martín de Santa Olalla, M. y De Juan Valero, J. 1993. Agronomía del riego.

Martin, G.C. y Kester, D. 1978. Almond growth and development. En: Almond orchard management. Micke, W. y Kester, D., (ed.). California: División of Agricultural Science. University of California. p 46-51.

Massai, R., Remorini, D. y Tattini, M. 2004. Gas exchange, water relations and osmotic adjustment in two scion/rootstock combinations of Prunus under various salinity concentrations. Plant and Soil (259):153-162.

Mastrorilli, M., Katerji, N., Rana, G. y Ben Nouna, B. 1998. Daily actual evapotranspiration measured with TDR technique in Mediterranean conditions. Agricultural and Forest Meteorology (90):81-89. 
Matsushita, N. y Matoh, T. 1991. Characterization of $\mathrm{Na}^{+}$exclusion mechanisms of salt-tolerant reed plants in comparison with saltsensitive rice plants. Physiologia Plantarum (83):170-176.

McCutchan, H. y Shackel, K.A. 1992. Stem water potential as a sensitive indicator of water stress in prune trees. Journal of the American Society for Horticultural Science (117):607-611.

Métodos oficiales de análisis de la Unión Europea. 1998. Diario oficial de la C.E. Madrid.

Mitchell, P.D. y Chalmers, D.J. 1982. The effect of reduced water supply on peach tree growth and yields. Journal of the American Society for Horticultural Science (107):853-856.

Mitchell, P.D., Vandenende, B., Jerie, P.H. y Chalmers, D.J. 1989. Responses of Bartlett pear to withholding irrigation, regulated deficit irrigation, and tree spacing. Journal of the American Society for Horticultural Science (114):15-19.

Molz, F.J. y Klepper, B. 1973. Mechanism of water-stress-induced stem deformation. Agronomy Journal (65):304-306.

Molz, F.J., Klepper, B. y Browning, V.D. 1973. Radial diffusion of free-energy in stem phloem - experimental study. Agronomy Journal (65):219-222.

Monteith, J.L. 1965. Evaporation and the environment. En: Proceedings of the 19th Symposium, Society of Experimental Biology. London: Cambridge University Press. p 205-234.

Monteith, JL. 1973. Principles of environmental physics. En: Contemporary Biology. Arnold, E. (ed.). 241 p.

Moran, M.S., Clarke, T.R., Inoue, Y. y Vidal, A. 1994. Estimating crop waterdeficit using the relation between surface-air temperature and spectral vegetation index. Remote Sensing of Environment (49):246-263.

Moreno, F., Conejero, W., Martín-Palomo, M.J., Girón, I.F. y Torrecillas, A. 2006. Maximum daily trunk shrinkage reference values for irrigation scheduling in olive trees. Agricultural Water Management (84):290-294.

Moriana, A. y Fereres, E. 2002. Plant indicators for scheduling irrigation of young olive trees. Irrigation Science (21):83-90. 
Morris, J.R. y Cawthon, D.L. 1982. Effect of irrigation, fruit load, and potassium fertilization on yield, quality, and petiole analysis of concord (Vitis-Labrusca L) grapes. American Journal of Enology and Viticulture (33):145-148.

Mpelasoka, B.S., Behboudian, M.H. y Mills, T.M. 2001. Water relations, photosynthesis, growth, yield and fruit size of 'Braeburn' apple: Responses to deficit irrigation and to crop load. Journal of Horticultural Science \& Biotechnology (76):150-156.

Myers, B.J. 1988. Water stress integral-a link between short-term stress and long-term growth. Tree Physiology (4):315-323.

Nanos, G.D., Kazantzis, L., Kefalas, P., Petrakis, C. y Stavroulakis, G.G. 2002. Irrigation and harvest time affect almond kernel quality and composition. Scientia Horticulturae (96):249-256.

Naor, A. 2004. The interactions of soil- and stem-water potentials with crop level, fruit size and stomatal conductance of field-grown 'Black Amber' Japanese plum. Journal of Horticultural Science \& Biotechnology (79):273-280.

Naor, A. y Cohen, S. 2003. Sensitivity and variability of maximum trunk shrinkage, midday stem water potential, and transpiration rate in response to withholding irrigation from field-grown apple trees. HortScience (38):547-551.

Naor, A., Gal, Y. y Peres, M. 2006. The inherent variability of water stress indicators in apple, nectarine and pear orchards, and the validity of a leaf-selection procedure for water potential measurements. Irrigation Science (24):129-135.

Naor, A., Hupert, H., Greenblat, Y., Peres, M., Kaufman, A. y Klein, I. 2001. The response of nectarine fruit size and midday stem water potential to irrigation levelin stage III and crop load. Journal of the American Society for Horticultural Science (126):140-143.

Naor, A., Klein, I. y Doron, I. 1995. Stem water potential and apple fruit size. Journal of the American Society for Horticultural Science (120):577582.

Naor, A., Klein, I., Doron, I., Gal, Y., Ben-David, Z. y Bravdo, B. 1997. The effect of irrigation and crop load on stem water potential and apple fruit size. Journal of Horticultural Science (72):765-771. 
Nicolás, E., Torrecillas, A., Dell'Amico, J. y Alarcón, J. 2005. The effect of short-term flooding on the sap flow, gas exchange and hydraulic conductivity of young apricot trees. Trees-Structure and Function (19):51-57.

Nortes, P.A., Pérez-Pastor, A., Egea, G., Conejero, W. y Domingo, R. 2005. Comparison of changes in stem diameter and water potential values for detecting water stress in young almond trees. Agricultural Water Management (77):296-307.

Nortes, P.A., Pérez-Pastor, A., Méndez, J. y Domingo, R. 2002. Respuesta del almendro al riego deficitario con agua salina. XXI Congreso Nacional de Riegos.

Olien, M.E. y Flore, J.A. 1990. Effect of a rapid water-stress and a slow waterstress on the growth of redhaven peach-trees. Fruit Varieties Journal (44):4-11.

Ortuño, M.F., Alarcón, J.J., Nicolás, E. y Torrecillas, A. 2004. Interpreting trunk diameter changes in young lemon trees under deficit irrigation. Plant Science (167):275-280.

Ortuño, M.F., García-Orellana, Y., Conejero, W., Ruiz-Sánchez, M.C., Alarcón, J.J. y Torrecillas, A. 2006a. Stem and leaf water potentials, gas exchange, sap flow, and trunk diameter fluctuations for detecting water stress in lemon trees. Trees-Structure and Function (20):1-8.

Ortuño, M.F., García-Orellana, Y., Conejero, W., Ruiz-Sánchez, M.C., Mounzer, O., Alarcón, J.J. y Torrecillas, A. 2006b. Relationships between climatic variables and sap flow, stem water potential and maximum daily trunk shrinkage in lemon trees. Plant and Soil (279):229-242.

Parchomchuck, P., Tan, C.S. y Berard, R.G. 1997. Practical use of time domain reflectometry for monitoring soil water content in microirrigated orchards. Hort'Technology (7):17-22.

Passioura, J.B. 1988. Water transport in and to roots. Annual Review of Plant Physiology and Plant Molecular Biology (39):245-265.

Penman, H.L. 1948. Natural evaporation from open water, bare soil and grass. Proceedings of the Royal Society of London, Series A (193):120-148.

Pereira, J.S., Tenhunen, J.D., Lange, O.L., Beyschlag, W., Meyer, A. y David, M.M. 1986. Seasonal and diurnal patterns in leaf gas-exchange of 
Eucalyptus-Globulus trees growing in Portugal. Canadian Journal of Forest Research-Revue Canadienne de Recherche Forestiere (16):177184.

Peretz, J., Evans, R.G. y Proebsting, E.L. 1984. Leaf water potentials for management of high-frequency irrigation on apples. Transactions of the Asae (27):437-442.

Pérez-Alfocea, F., Balibrea, M.E., Alarcón, J.J. y Bolarín, M.C. 2000. Composition of xylem and phloem exudates in relation to the salttolerance of domestic and wild tomato species. Journal of Plant Physiology (156):367-374.

Pérez-Pastor, A. 2001. Estudio agronómico y fisiológico del albaricoquero en condiciones de infradotación hídrica. Tesis Doctoral. Universidad Politécnica de Cartagena. 225 p.

Pérez-Pastor, A., Ruiz-Sánchez, M.C., Domingo, R. y Torrecillas, A. 2004. Growth and phenological stages of 'Builida' apricot trees in south-east Spain. Agronomie (24):93-100.

Phene, C.J., Hoffman, G.J. y Rawlins, S.L. 1971. Measuring soil Matric potential in situ by sensing heat dissipation within a porous body 1 . Theory and sensor construction. Soil Science Society of America Proceedings (35):27-\&.

Pittinelli, E., Sorge, M., Lena, B. y Trabucco, A. 1998. On the use of time domain reflectometry (TDR) method for soil water content evaluation. Irrigazione e Drenaggio (45):35-41.

Pogue, W.R. y Pooly, S.G. 1985. Tensiometric management of soil water. En: Proc.Third Int.Drip and Trickle Irrig.Cong, (ed.). Drip trickle irrigation in action. Michigan, USA: American Society of Agricultural Engineers. p $761-766$.

Pospisilova, J. y Santrucek, J. 1994. Stomatal patchiness. Biologia Plantarum (36):481-510.

Prichard, T. L., Asai, W., Verdegaal, P., Micke, W, and Fuson, K. 1992. Effects of water supply and irrigation strategies on almonds. En: Proc. 20th Annual Almond Research Conference. Sacramento,: 60-63

Rawson, H.M. 1979. Vertical wilting and photosynthesis, transpiration, and water-use efficiency of sunflower leaves. Australian Journal of Plant Physiology (6):109-120. 
Rebour, H. 1971. Frutales mediterráneos. Madrid.

Remorini, D. y Massai, R. 2003. Comparison of water status indicators for young peach trees. Irrigation Science (22):39-46.

Rhoades, JD., Kandiah A. y Mashali, AM. 1992. The use of saline waters for crops production. Roma.

Richardson, E.A., Seeley, S.D., Walker, D.R., Anderson, J.L. y Ashcroft, G.L. 1976. Pheno-climatography model for deciduous plants. Bulletin of the American Meteorological Society (57):1409.

Romero, P. 2002. Respuesta del almendro (cv. Cartagenera) al riego deficitario controlado en condiciones de riego subterráneo. Tesis Doctoral. Universidad de Murcia. 288 p.

Romero, P. y Botía, P. 2006. Daily and seasonal patterns of leaf water relations and gas exchange of regulated deficit-irrigated almond trees under semiarid conditions. Environmental and Experimental Botany (56):158-173.

Romero, P., Botía, P. y García, F. 2004a. Effects of regulated deficit irrigation under subsurface drip irrigation conditions on vegetative development and yield of mature almond trees. Plant and Soil (260):169-181.

Romero, P., Botía P. y García, F. 2004b. Effects of regulated deficit irrigation under subsurface drip irrigation conditions on water relations of mature almond trees. Plant and Soil (260):155-168.

Ruiz-Sánchez, M.C., Domingo, R., Savé, R., Biel, C. y Torrecillas, A. 1997. Effects of water stress and rewatering on leaf water relations of lemon plants. Biologia Plantarum (39):623-631.

Ruiz-Sánchez, M.C., Egea, J., Galego, R. y Torrecillas, A. 1999. Floral biology of 'Bulida' apricot trees subjected to postharvest drought stress. Annals of Applied Biology (135):523-528.

Ruiz-Sánchez, M.C., Plana, V., Ortuño, M.F., Tapia, L.M. y Abrisqueta, J.M. 2005. Spatial root distribution of apricot trees in different soil tillage practices. Plant and Soil (272):211-221.

Ruiz-Sánchez, M.C., Sánchez-Blanco, M.J., Planes, J., Alarcón, J. y Torrecillas, A. 1993. Seasonal changes in leaf water potential components in two almond cultivars. Journal of Horticultural Science (120):347-351. 
Ruiz-Sánchez, M.C., Torrecillas, A., DelAmor, F., León, A. y Abrisqueta, J.M. 1988. Leaf water potential and leaf conductance during the growingseason in almond trees under different irrigation regimes. Biologia Plantarum (30):327-332.

Sánchez Bel, P., Madrid, R., Sánchez, A., Valverde, M. y Romojaro, F. 2001. La calidad de la almendra española. I. Cuadernos de fitopatología (67):15-21.

Sánchez-Blanco, M.J., Ruiz-Sánchez, M.C., Planes, J. y Torrecillas, A. 1991. Water relations of two almond cultivars under anomalous rainfall in non-irrigated culture. Journal of Horticultural Science (66):403-408.

Saura, F., Cañellas, J. y Soler, L. 1988. La almendra. Composición, variedades, desarrollo y maduración. Ed INIA, Madrid.

Scholander, P.F., Hammel, H.T., Bradstreet, E.D. y Hemingsen, E.A. 1965. Sap pressure in vascular plants. Science (148):339-346.

Schulbach, H. y Schwankl, L.J. 1996. Measuring soil moisture. En: Almond production manual. University of California: Division of Agricultural and Natural Resources. p 167-170.

Schulze, E.D. 1986. Carbon-dioxide and water-vapor exchange in response to drought in the atmosphere and in the soil. Annual Review of Plant Physiology and Plant Molecular Biology (37):247-274.

Schulze, E.D. y Hall, A.E. 1982. Stomatal responses, water lossand $\mathrm{CO}_{2}$ assimilation rates of plants in contrasting environments . En: Lange, OL., Nobel, PS., Osmond, CB. y Ziegler, H., (ed.). Encyclopedia plant phisiology. Springer Verlag Berlin Heidelberg New York: p 181-230.

Shackel, K.A., Ahmadi, H., Biasi, W., Buchner, R., Goldhamer, D.A., Gurusinghe, S.H., Hasey, J., Kester, D., Krueger, B., Lampinen, B., McGourty, G., Micke, W., Mitcham, E., Olson, B., Pelletrau, K., Philips, H., Ramos, D., Schwankl, L.J., Sibbet, S., Snyder, R., Southwick, S., Stevenson, M., Thorpe, M., Weinbaum, S. y Yeager, J. 1997. Plant water status as an index of irrigation need in deciduous fruit trees. HortTechnology (7):23-29.

Shackel, K.A., Gurusinghe, S.H., Kester, D. y Micke, W. 1998. Water stress responses of almond [Prunus dulcis (Mill.) Webb.] trees under field conditions . Acta Horticulturae (470):390-316. 
Shackel, K.A., Lampinen, B., Sibbet, S. y Olson, W. 2000. The relation of midday stem water potential to the growth and physiology of fruit trees under water limited conditions. Acta Horticulturae (537):425-430.

Shalhevet, J., Huck, M.G. y Schroeder, B.P. 1995. Root and shoot growthresponses to salinity in maize and soybean. Agronomy Journal (87):512516.

Shinn, J.D., Timian, D.A., Morey, R.M., Mitchell, G., Antle, C.L. y Hull, R. 1998. Development of a CPT deployed probe for in situ measurement of volumetric soil moisture content and electrical resistivity. Field Analytical Chemistry and Technology (2):103-109.

Silveira, J.A.G., Melo, A.R.B., Viegas, R.A. y Oliveira, J.T.A. 2001. Salinityinduced effects on nitrogen assimilation related to growth in cowpea plants. Environmental and Experimental Botany (46):171-179.

Simonneau, T., Habib, R., Goutouly, J.P. y Huguet, J.G. 1993. Diurnal changes in stem diameter depend upon variations in water content: direct evidence in peach trees. Journal of Experimental Botany (44):615-621.

Slatyer, RO. 1967. Plant water relationships. London and New York: Academic Press.

Snyder, R.L. y Spano, D. 1994. Using surface renewal measurements to estimate crop evapotranspiration. Proceedings of the Third Congress of the European Society for Agronomy410-411.

Syvertsen, J.P., Lloyd, J. y Kriedemann, P.E. 1988. Salinity and drought stress effects on foliar ion concentration, water relations, and photosynthetic characteristics of orchard citrus. Australian Journal of Agricultural Research (39):619-627.

Tabuenca, M.C. y Herrero, J. 1966. Influencia de la temperatura en la época de floración de los frutales. An Aula Dei (8):115-153.

Tardieu, F. y Simonneau, T. 1998. Variability among species of stomatal control under fluctuating soil water status and evaporative demand: modelling isohydric and anisohydric behaviours. Journal of Experimental Botany (49):419-432.

Taylor, S.A. y Ashcroft, G.L. 1972. Physical edaphology. En: The physics of irrigated and nonirrigated soils. Freeman, WH. y Company, (ed.). San Francisco: p 431-441. 
Tenhunen, J.D., Lange, O.L. y Jahner, D. 1982. The control by atmospheric factors and water-stress of midday stomatal closure in arbutus-unedo growing in a natural macchia. Oecologia (55):165-169.

Tester, M. y Davenport, R. 2003. $\mathrm{Na}^{+}$tolerance and $\mathrm{Na}^{+}$transport in higher plants. Annals of Botany (91):503-527.

Thompson, R.B., Gallardo, M., Aguera, T., Valdez, L.C. y Fernández, M.D. 2006. Evaluation of the Watermark sensor for use with drip irrigated vegetable crops. Irrigation Science (24):185-202.

Torrecillas, A., Domingo, R., Galego, R. y Ruiz-Sánchez, M.C. 2000. Apricot tree response to withholding irrigation at different phenological periods. Scientia Horticulturae (85):201-215.

Torrecillas, A., Alarcón, J.J., Domingo, R., Planes, J. y Sánchez Blanco, M.J. 1996. Strategies for drought resistance in leaves of two almond cultivars. Plant Science (118):135-143.

Torrecillas, A., Galego, R., Pérez-Pastor, A. y Ruiz-Sánchez, M.C. 1999. Gas exchange and water relations of young apricot plants under drought conditions. Journal of Agricultural Science (132):445-452.

Torrecillas, A., Ruiz-Sánchez, M.C., Del Amor, F. y León, A. 1988a. Seasonal variations on water relations of amygdalus-communis under drip irrigated and non irrigated conditions. Plant and Soil (106):215-220.

Torrecillas, A., Ruiz-Sánchez, M.C., León, A. y Del Amor, F. 1989a. The response of young almond trees to different drip-irrigated conditions development and yield. Journal of Horticultural Science (64):1-7.

Torrecillas, A., Ruiz-Sánchez, M.C., León, A. y García, A.L. 1988b. Stomatal response to leaf water potential in almond trees under drip irrigated and non irrigated conditions. Plant and Soil (112):151-153.

Torrecillas, A., Ruiz-Sánchez, M.C. y Hernansáez, A. 1989b. Response of leaf water potential to estimated transpiration in almond trees. Journal of Horticultural Science (64):667-671.

Turner, N.C. 1981. Techniques and experimental approaches for the measurement of plant water status. Plant and Soil (58):339-366.

Turner, N.C., Schulze, E.D. y Gollan, T. 1984. The responses of stomata and leaf gas exchange to vapour pressure deficits and soil water content. I. 
Species comparisons at high soil water contents. Oecologia (63):338342.

Turner, N.C., Schulze, E.D. y Gollan, T. 1985. The responses of stomata and leaf gas exchange to vapour pressure deficits and soil water content. II. In the mesophytic herbaceous Helianthus annuus. Oecologia (65):348355.

Tyree, M.T. y Jarvis, P.G. 1982. Water in tissues and cells. En: Physiological Plant Ecology II. Lange, OL., Nobel, PS., Osmond, CB., y Ziegler, H., (ed.). Berlin-Heidelberg.New York: p 35-77.

Tyree, M.T. y Sperry, J.S. 1989. Vulnerability of Xylem to Cavitation and Embolism. Annual Review of Plant Physiology and Plant Molecular Biology (40):19-38.

Uriu, K. 1978. Soil and plant analysis and symptomology for diagnosis of mineral deficiences and toxicities. En: Almond orchard management. Micke, WC. y Kester, D., (ed.). University of California: Division of Agricultural Sciences. p 89-96.

Uriu, K., Martin, P.E. y Hagan, R.M. 1970. Radial trunk growth of almonds as affected by soil water and crop density. Journal of the American Society for Horticultural Science (95):166-169.

Valancogne, C. y Nasr, Z. 1989. Measuring sap flow in the stem of small trees by a heat balance method. HortScience (24):383-385.

Vargas, F.J. 1990. Nuts in Spain: almond, hazelnut, walnut and pistachio. FAO "Expert consultation on the promotion of production in Europe and Near East Region". En: Nut Production and Industry in Europe, Near East and North Africa. Turquía: p 255-280.

Vavilov, N.I. 1930. Wild progenitors of the fruit tree of Turkestan and the Caucasus and the problems of the origin of fruit trees. Hortticultural Congress, London.

Vélez, J.E., Intrigliolo, D.S. y Castel, J.R. 2007. Scheduling deficit irrigation of citrus trees with maximum daily trunk shrinkage. Agricultural Water Management (90):197-204.

Villalobos, F.J. 1997. Correction of eddy covariance water vapour flux using additional measurements of temperature. Agricultural and Forest Meteorology (88):77-83. 
Westwood, N.M. y Roberts, A.N. 1970. The relationship between trunk crosssectional area and weigth of apples trees. Journal of the American Society for Horticultural Science (95):28-30.

Williams, L.E. 1987. The effect of cyanamide on budbreak and vine development of Thompson Seedless grapevines in the San-Joaquin Valley of California. Vitis (26):107-113.

Williams, M., Rastette,r E.B., Fernandes, D.N., Goulden, M.L., Wofsy S.C., Shaver G.R., Melillo J.M., Munger J.W., Fan S.M. y Nadelhoffer K.J. 1996. Modelling the soil-plant-atmosphere continuum in a Quercus-Acer stand at Harvard forest: The regulation of stomatal conductance by light, nitrogen and soil/plant hydraulic properties. Plant Cell and Environment (19):911-927.

Winkel, T. y Rambal, S. 1993. Influence of water-stress on grapevines growing in the field - from leaf to whole-plant response. Australian Journal of Plant Physiology (20):143-157.

Wong S.C., Cowan, I.R. y Farquhar, G.D. 1985. Leaf Conductance in Relation to Rate of $\mathrm{CO}_{2}$ Assimilation. 3. Influences of Water-Stress and Photoinhibition. Plant Physiology (78):830-834. 